\title{
WestVirginiaUniversity
}

THE RESEARCH REPOSITORY @ WVU

Graduate Theses, Dissertations, and Problem Reports

2015

\section{Rechargeable Lithium-Sulfur Batteries with High Sulfur-Loading Electrodes}

Jianhua Yan

Follow this and additional works at: https://researchrepository.wvu.edu/etd

\section{Recommended Citation}

Yan, Jianhua, "Rechargeable Lithium-Sulfur Batteries with High Sulfur-Loading Electrodes" (2015).

Graduate Theses, Dissertations, and Problem Reports. 6995.

https://researchrepository.wvu.edu/etd/6995

This Dissertation is protected by copyright and/or related rights. It has been brought to you by the The Research Repository @ WVU with permission from the rights-holder(s). You are free to use this Dissertation in any way that is permitted by the copyright and related rights legislation that applies to your use. For other uses you must obtain permission from the rights-holder(s) directly, unless additional rights are indicated by a Creative Commons license in the record and/ or on the work itself. This Dissertation has been accepted for inclusion in WVU Graduate Theses, Dissertations, and Problem Reports collection by an authorized administrator of The Research Repository @ WVU.

For more information, please contact researchrepository@mail.wvu.edu. 


\title{
Rechargeable Lithium-Sulfur Batteries with High Sulfur-Loading Electrodes
}

\author{
Jianhua Yan \\ Dissertation submitted to the \\ Benjamin M. Statler College of Engineering and Mineral Resources \\ at West Virginia University \\ in partial fulfillment of the requirements for the degree of \\ Doctor of Philosophy in \\ Mechanical and Aerospace Engineering
}

Xingbo Liu, Ph.D., Chair

Bingyun Li, Ph.D.

Ismail Celik, Ph.D.

Xueyan Song, Ph.D.

Xiaodong Shi, Ph.D.

Department of Mechanical and Aerospace Engineering

Morgantown, West Virginia

2015

Keywords: Lithium Sulfur Batteries, High Sulfur-Loading Batteries, Carbon Paper, Carbon Nanotube, Polyaniline

Copyright 2015 Jianhua Yan 


\title{
ABSTRACT \\ Rechargeable Lithium-Sulfur Batteries with High Sulfur- Loading Electrodes
}

\author{
Jianhua Yan
}

Energy is one of the biggest challenges that mankind has been faced for many years. The ever-growing demand for energy is coupled with environmental concerns associated with the excessive use of fossil fuels such as coal, oil and gas. The development of new energy storage device with high energy density has unparalleled advantages in terms of easing the energy crisis and decreasing environmental pollution, and fueling the various energy applications. As one of the prospective energy storage systems, rechargeable lithium-sulfur (Li-S) batteries offer possibilities of low cost and high energy density since sulfur offers a high theoretical capacity of $1672 \mathrm{~mA} \mathrm{~h} \mathrm{~g}^{-1}$ and a high energy density of $2600 \mathrm{Wh} \mathrm{kg}^{-1}$ with relatively low-cost. However, despite 20 years of intensive efforts and advancements achieved in performance improvements, commercialization of the current liquid type Li-S batteries are still challenged by insufficient cycle life with rapid capacity fades and low practical energy/power densities.

In this dissertation, sulfur reaction mechanisms, challenges and recent developments related to Li-S batteries were first summarized. A major challenge of Li-S chemistry is the multi-step sulfur reaction from elemental sulfur $\left(\mathrm{S}_{8}\right)$ to $\mathrm{Li}_{2} \mathrm{~S}\left(\mathrm{~S}_{8} \rightarrow \mathrm{Li}_{2} \mathrm{~S}_{8} \rightarrow \mathrm{Li}_{2} \mathrm{~S}_{6} \rightarrow\right.$ $\left.\mathrm{Li}_{2} \mathrm{~S}_{4} \rightarrow \mathrm{Li}_{2} \mathrm{~S}_{2} \rightarrow \mathrm{Li}_{2} \mathrm{~S}\right)$. During these processes, the long-chain polysulfide species $\left(\mathrm{Li}_{2} \mathrm{~S}_{\mathrm{x}}\right.$, $4 \leq \mathrm{x} \leq 8)$ can easily dissolve into liquid electrolyte and can migrate back and forth between electrodes. This shuttle effect results in a series of problems like self-discharge and low practical capacity. More severely, these species can react with the Li-anode and make the anode unstable. Another challenge is associated with the insoluble and insulating nature of $\mathrm{S}_{8}$ and $\mathrm{Li}_{2} \mathrm{~S} / \mathrm{Li}_{2} \mathrm{~S}_{2}$, which cause high internal resistance and pose major issues for cycle life and power capacity for Li-S batteries. To address these obstacles, low sulfur-loading are always employed in sulfur electrodes, which result in a low practical energy density and inhibit the commercialization of Li-S batteries.

These challenges could be met to a large degree by adopting novel carbon structures with micrometer pores. Sulfurized carbon nanotubes (SCNT) and sulfurized polyanilines (SPANI) with large size pores were successfully synthesized and demonstrated improved performance when used as electrode materials in Li-S batteries. The synthesis method for SCNT involved surface treatment, solvent exchange, and low-temperature treatment. The SCNT composite had a high sulfur content (68 wt.\%). The synthesis method for SPANI involved in situ chlorinated substitution and vulcanization reactions, which resulted in a high sulfur content of $65 \mathrm{wt} . \%$. Both SCNT and SPANI could chemically trap polysulfide species from dissolving into liquid electrolytes by forming strong sulfur chemical bonds on SCNT and SPANI surfaces, thereby extended the cycle lifetime of Li-S batteries. 
A binder-free porous multilayered sulfur cathode structure containing alternately arranged SCNT and SPANI layers demonstrated synergistic effects of both materials. The multilayered structure with multiple micrometer pores served as high efficiency binders, conductive agents, and 3-D mechanical scaffolds for efficient use of sulfur. In addition, the layered structures formed physical and chemical C-S bond barriers that retarded shuttle effects. A significant improvement not only in the active material utilization but also in capacity retention was observed. To move a step closer for commercialization of Li-S batteries, which required a much higher sulfur loadings and low cost, a costeffective carbon nanofiber paper (CNP) electrode structure that could offer high sulfur loading (6-10 $\mathrm{mg} \mathrm{cm}^{-2}$ ), and excellent cycling stabilities and rate capabilities was developed. This electrode had a hierarchical structure with micrometer pores conducive to fast mass transportation, and offered a high degree of interconnectivity of the millimeter length CNF to ensure electron conductivity across the entire film. Such a structure not only provided physical barrier to trap polysulfide anions, but also functioned as a current collector for efficient transportation of electrons and Li-ions. This electrode had presented good mass diffusion and electron transportation properties for high energy density Li-S batteries and is ready to be applied in real applications, and this simple and cost-effective procedure is feasible for mass production.

To elucidate the underlying mechanism of capacity fade, a comprehensive study of a binder-free sulfur-multiwalled CNT composite electrode with a commercialized CNF current collector in different quantity of electrolytes was conducted. By examining electrochemical performance, sulfur reaction kinetics, and EIS, the major reason for the rapid capacity fade was related to the formation of thick layers of solid and nonconductive $\mathrm{Li}_{2} \mathrm{~S}_{2} / \mathrm{Li}_{2} \mathrm{~S}$ films.

Last, a summary was given, and future research recommendations for my research were also discussed. 


\section{Acknowledgements}

First, I would thank my supervisors, Professors Bingyun Li and Xingbo Liu, for their financial support and intelligent guidance without conservation during the last three years. Without the financial support, I wouldn't have had such a good research environment to complete all of the interesting projects. Without their guidance, I could not move my research as far as I would love to. They have been teaching me to extend my scientific horizons in energy storage system and encouraging me to develop critical thinking ability to solve the problems in Li-S battery system.

Second, I would express my gratitude to Professors Ismail Celik, Xiaodong Shi, and Xueyan Song, who have been serving on my committee, and offers their valuable advice on my research.

Third, I would like to thank all of my colleagues for their help and understanding, since it's impossible to handle every task on your own. Meng Yao helped me with battery assemble and materials synthesis in the early stages when I got started on my dissertation. Wenyuan $\mathrm{Li}$ and He Qi assisted my experiments sometimes. I acknowledge Suzanne for proofreading most of my papers.

Last, I would like to thank my parents, brothers and sisters for their supporting on my study abroad. And thank my girlfriend for her accompany with writing the dissertation. 


\section{Table of Contents}

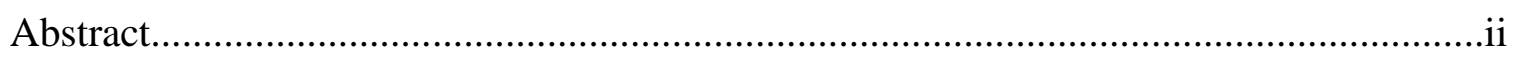

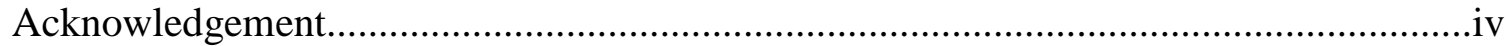

List of Tables.........................................................................

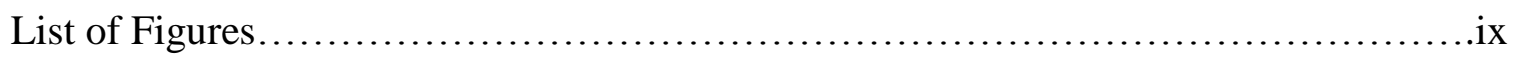

Chapter 1: Introduction.........................................................................................

1.1 Rechargeable Lithium-Ion Batteries....................................

1.2 Rechargeable Lithium Sulfur (Li-S) Batteries.............................5

1.3 Li-S Systems and Principles..........................................6

1.4 Challenges of Li-S Batteries............................................10

1.4.1 Insulating Active Sulfur Materials .............................11

1.4.2 Volume Expansion................................................11

1.4.3 Rapid Capacity Fade.............................................11

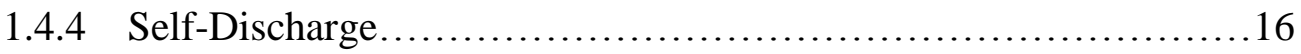

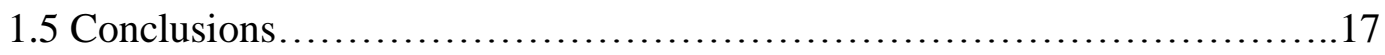

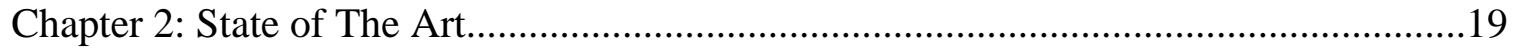

2.1 Properties of Sulfur................................................. 19

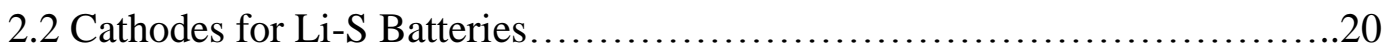

2.2.1 Sulfur-Carbon Composites.....................................21

2.2.1.1 Porous Carbon and Sulfur Composites........................21

2.2.1.2 Carbon Nanotube and Sulfur Composites......................22

2.2.1.3 Graphene and Sulfur Composites............................23

2.2.1.4 Sulfurized Carbon Composites................................23

2.2.2 Sulfur and Polymer Composites....................................25

2.2.3 Sulfur and Metal (Oxide) Composites..............................26

2.2.4 $\mathrm{Li}_{2} \mathrm{~S}$ and Lithium Polysulfide Species as Cathode Materials.........27

2.2.5 Binder-Free Sulfur Cathodes.....................................28

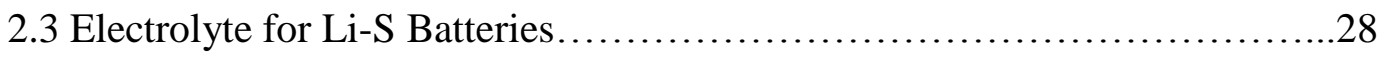

2.3.1 Liquid-Type Electrolytes.......................................28

2.3.2 Non-Liquid Type Electrolytes.................................29 
2.4 Anodes for Li-S Batteries........................................... 30

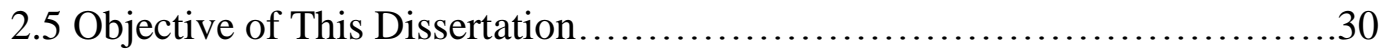

Chapter 3: Sulfur Cathode Materials Development: Sulfurized Carbon Nanotubes.......32

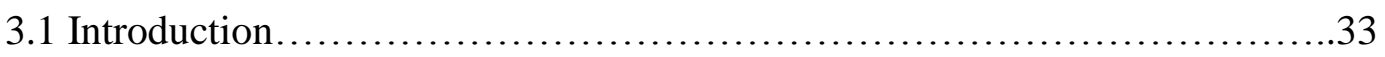

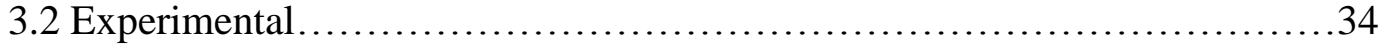

3.2.1 In Situ Sulfur Deposition Synthesis of SCNT Composites................34

3.2.2 Structural and Microstructure Characterizations.............................35

3.2.3 Electrochemical Characterizations.....................................36

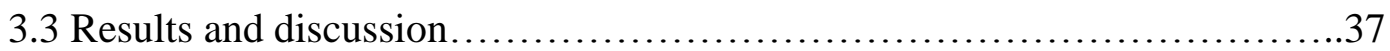

3.3.1 XRD, SEM, TEM and EDS Studies..........................................

3.3.2 Electrochemical Properties.....................................40

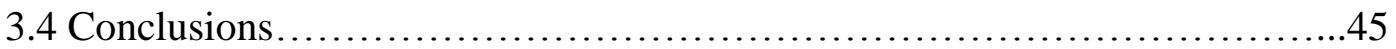

Chapter 4: Sulfur Cathode Materials Development: Sulfurized Polyaniline.......................46

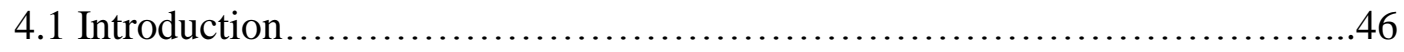

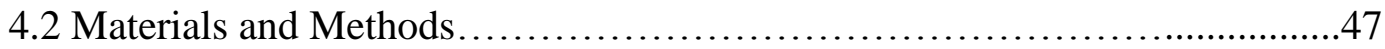

4.2.1 Preparation of SPANI Cathodes......................................4

4.2.2 Physical Characterization.............................................48

4.2.3 Electrochemical Measurements.....................................49

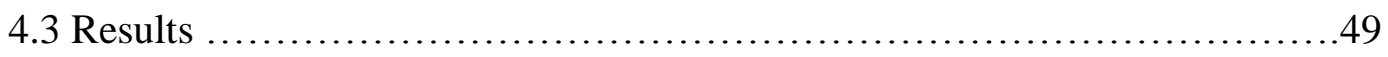

4.3.1 Material Characterizations ......................................49

4.3.2 Electrochemical Performance..........................................54

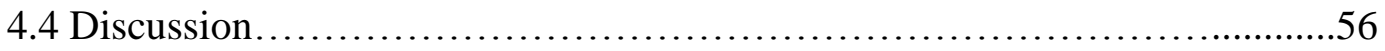

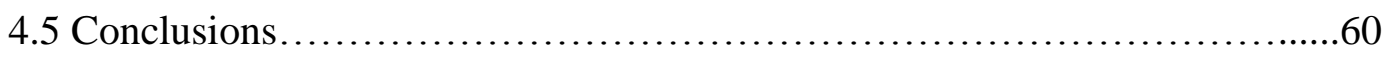

Chapter 5: Sulfur Cathode Structures Development: Multilayered Electrodes ..........61

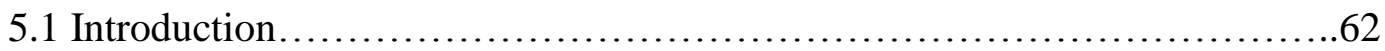

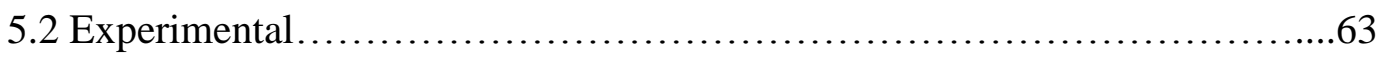

5.2.1 Preparation of S-CNT Composites...............................................63

5.2.2 Preparation of SPANI..........................................................

5.2.3 Fabrication of Multilayered Cathodes Using LbL Nano-Assembly

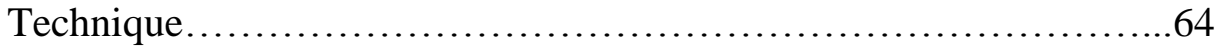

5.2.4 XPS, XRD, and FTIR Measurements..............................65 
5.2.5 Electrochemical Measurements of Multilayered Cathode-Based Cells..65

5.3 Results and discussion. .65

5.3.1 Characterizations of the Multilayered Cathodes and Related Materials.65

5.3.2 Electrochemical Performance of Multilayered Cathodes..................69

5.3.3 Electrochemical Reaction Processes in Multilayered Cathodes............72

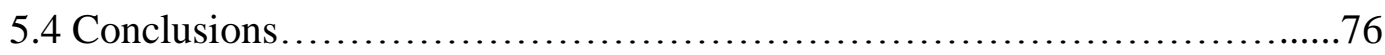

Chapter 6: Sulfur Cathode Structures Development: Carbon Paper Electrode with High

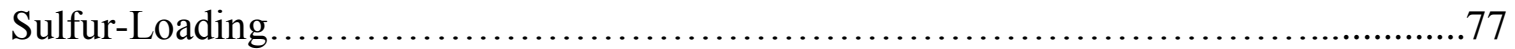

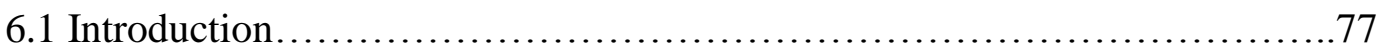

6.2 Experimental Section............................................. 80

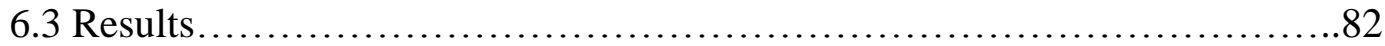

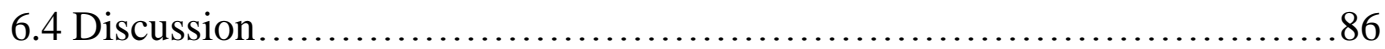

6.5 Conclusions.................................................. 93

Chapter 7: Mechanism and Kinetics of Capacity Fade in Lithium Sulfur Batteries......94

7.1 Experimental Design.............................................94

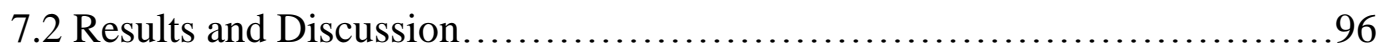

7.2.1 Synthesis and Characterization of SMCNT Electrode.................96

7.2.2 Cycling Performance........................................97

7.2.3 Sulfur Reaction Kinetics....................................99

7.2.4 $\mathrm{Li}_{2} \mathrm{~S}_{2} / \mathrm{Li}_{2} \mathrm{~S}$ Precipitation Analysis............................ 101

7.2.5 Electrochemical Impedance Spectroscopy (EIS) Study..............102

7.3 Conclusions........................................................... 107

Chapter 8: Summary and Recommendations...................................................... 109

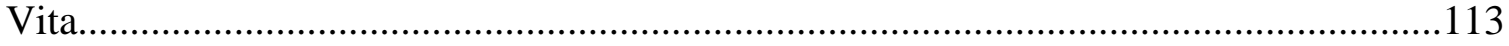

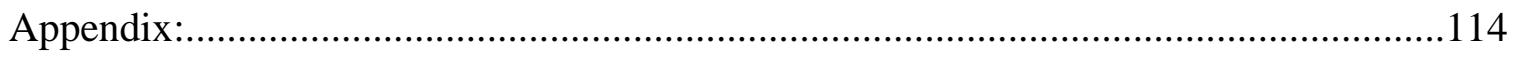

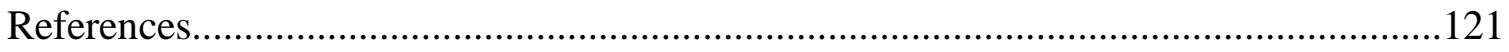




\section{List of Tables}

Table 1-1 Comparison of current commercialized cathode materials.....................4

Table 1-2 EDV demands for power LIBs........................................4

Table 1-3 Comparison of a typical $\mathrm{C} / \mathrm{Li}[\mathrm{CoNiMn}] \mathrm{O}_{2}$ battery and the $\mathrm{Li}-\mathrm{S}$ battery........5

Table 1-4 Discharge capacity vs. DOD in Li-S batteries..........................12

Table 2-1 Dynamic viscosity of liquid phase sulfur at different temperatures............19

Table 2-2 Cycling performance of Li/SPAN batteries with different type of electrolyte. 25

Table 2-3. Preparation condition of carbon and SC and cycling performance...........25

Table 3-1 Surface element contents of CNTs with different treatment methods..........38

Table 3-2 Relationship between oxygen content and -COOH content on CNT surfaces.38

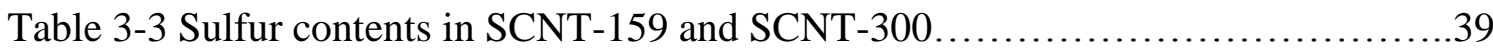




\section{List of Figures}

Figure 1-1 Schematic diagram of rechargeable battery performance and history $\ldots . . . . . .2$ Figure 1-2 A schematic of a commercialized Li-ion battery using $\mathrm{LiCoO}_{2}$ as cathode and

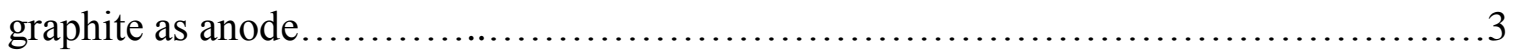

Figure 1-3 Illustration of the charge (red)/discharge (black) process involved in a rechargeable $\mathrm{Li}-\mathrm{S}$ cell consisting of Li-metal anode, organic electrolyte, and sulfur

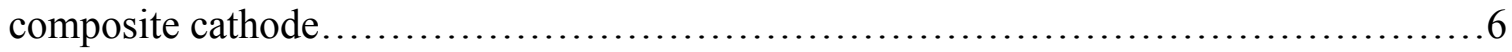

Figure 1-4 (a) A typical charge and discharge curves. (b) A typical discharge curve showing polysulfide anions' solubility under a moderate current ......................

Figure 1-5 Diagrams of poly-shuttle (a) in discharge and (b) charge process in Li-S

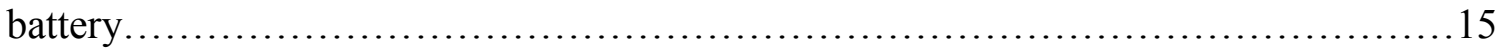

Figure 1-6 Diagrams of charging process in the Li-S batteries.....................15

Figure 2-1 Liquid sulfur compositions at different temperatures.....................20

Figure 2-2 Compositions of sulfur vapor molecular at different temperatures...........20

Figure 2-3 Schematic of the sulfur confined in the interconnected pore structure of

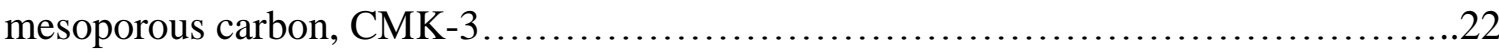

Figure 2-4 Schematic showing the oxidation of initially formed polysulfide by $\mathrm{d}-\mathrm{MnO}_{2}$ to form thiosulfate on the surface, concomitant with the reduction of $\mathrm{Mn}^{4+}$ to $\mathrm{Mn}^{2+}$.... 27

Figure 2-5 (a) Schematic of the synthetic process to sulfur- $\mathrm{TiO}_{2}$ core-shell nanostructures. (b) Internal void space to accommodate the volume expansion of sulfur during lithiation.

Figure 3-1 Schematic illustration of (a) the proposed treatment to integrate oxygencontaining surface groups into CNTs; and (b) the proposed strategy for grafting sulfur onto CNTs .35

Figure 3-2 Typical morphologies of CNTs (a) before and (b) after $\mathrm{H}_{2} \mathrm{O}_{2}$ treatment. Inset TEM figures are with high magnifications. Typical morphologies of SCNT (c) before and (d) after heat treatment. (e, f) TEM images of SCNT materials after heat treatment.....36 Figure 3-3 (a) XRD pattern and (b) XPS analysis of pristine CNTs. (c) TGA profiles of the pristine and prepared CNTs. 
Figure 3-4 Characterizations of CNT and SCNT. (a) TGA tested in a nitrogen environment with a heating rate of $5{ }^{\circ} \mathrm{C} \min ^{-1}$. (b) FTIR spectra. (c) XRD pattern of

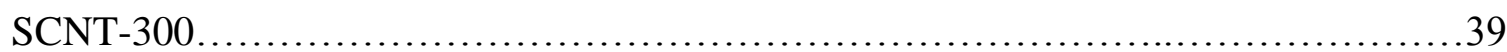

Figure 3-5 XPS analysis. (a) Wide range spectrum of SCNT-300. (b) S 2p regions of SCNT-300. C 1s regions of (c) CNT and (d) SCNT-300. O 1s regions of (e) CNT and (f) SCNT-300.

Figure 3-6 Electrochemical performance of Li-S cells comprised of SCNT cathodes. Voltage profiles of the first two charge/discharge cycles of (a) SCNT-300 cathodes and (b) SCNT-159 cathodes at 0.75 C. CV curves of (c) SCNT-300 cathodes and (d) SCNT159 cathodes at a scan rate of $0.05 \mathrm{mV} \mathrm{s}^{-1}$ at the first two cycles. .41

Figure 3-7 Electrochemical performance of Li-S cells comprised of SCNT-300 cathodes. (a) Rate performance. (b) Cycling performance and Coulombic efficiency at different rates. (c) Voltage profiles at different current rates. (d) Voltage profiles (in the 400th cycle) at 2 C. (e) Cycling properties of Li-S cells comprised of SCNT-159 cathodes (contained $10 \mathrm{wt} \% \%$ of PVDF and $90 \mathrm{wt} . \%$ SCNT-159 material) at 0.75 C. (f) Long-term cycling tests at $1 / 3 \mathrm{C}$ rate.

Figure 3-8 Cycling properties of Li-S cells comprised of S/CNT-159 cathodes (contained

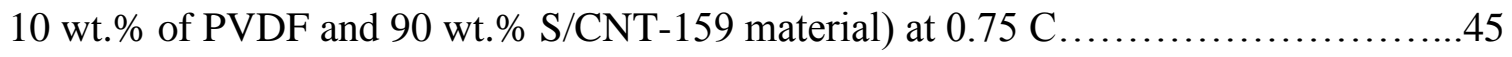

Scheme 4-1 Synthesis routes of SPANI.....................................48

Figure 4-1 SEM characterizations of PANI and SPANI. (a) PANI nanoparticles, (b) synthesized coralloid SPANI composites, and (c) the nano-flakes in the coralloid SPANI

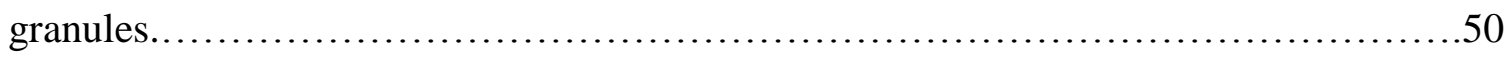

Figure 4-2 EDS spectra and SEM images of (a, d) pristine PANI; (b, e) polychlorinated polyaniline; and (c, f) SPANI............................................... 50

Figure 4-3 ${ }^{1} \mathrm{H}$ NMR spectra of PANI and SPANI. PANI had four characteristic peaks of ${ }^{1} \mathrm{H}$ between 7.1-7.75 ppm. 51

Figure 4-4 Structure characterizations. (a) TGA and DSC analysis of SPANI showing 65 wt.\% of sulfur in SPANI. (b) XRD patterns of S, SPANI, and PANI. (c) FTIR spectra of PANI and SPANI. (d) XPS spectra of PANI and SPANI. (e) S 2p regions of SPANI. C 1s regions of (f) PANI and (g) SPANI. N 1s regions of (h) PANI and (i) SPANI..........53 
Figure 4-5 Electrochemical performance of Li-S batteries employing SPANI cathodes. (a) Continuous CV curves $\left(0.1 \mathrm{mV} \mathrm{s}^{-1}\right)$. (b) Cycling ability at $0.3 \mathrm{C}$. (c) Voltage profiles of initial cycles under different current rates. (d) Long-term cycling stability and (e) Coulombic efficiency at different current rates..................................54 Figure 4-6 Cycling performance of Li-S cell employing (a) S/PANI cathode (50 wt.\% of sulfur, 30 wt.\% of PANI, 10 wt.\% of carbon black, and 10 wt.\% of PVDF) and (b) SPANI cathode (80 wt.\% of S-PANI, $10 \mathrm{wt} . \%$ of carbon black, and $10 \mathrm{wt} \%$ of PVDF) at $0.6 \mathrm{C}$ .57

Scheme 4-2 Proposed electrochemical performance of SPANI composites.............57

Figure 4-7 SEM images of S-PANI and SPANI. (a) S-PANI and (b) SPANI ...........59 Figure 4-8 SEM and EDS mapping data of the cathode after 100 cycles. (a) SEM image of the SPANI cathode. EDS mapping showing the homogenous distribution of (b) carbon, (c) sulfur, and (d) nitrogen in the SPANI composite, respectively. .59

Figure 4-9 (a) EIS tests of Li-S cells employing S/PANI cathode and SPANI cathode. The fabrication of S/PANI cathode was described in Figure S4a. (b) N 1s spectra of SPANI before cycling and after 100 cycles.

Figure 5-1 (a) Schematic diagram of multilayered cathode fabricated by the LbL nanoassembly process and functions of each component. (b) Schematic diagram of the selfcontrol poly-shuttle process in the multilayered cathode.

Figure 5-2 Characterizations of S-CNT materials. Scanning electron microscopy (SEM) images of (a) FCNT and (b) S-CNT. (c) XRD analysis of S-CNT, SPANI and FCNT. (d) FTIR spectra of S-CNT and FCNT. (e) TGA and DSC analysis of S-CNT.............66

Figure 5-3 SEM image of (a) the as-prepared PANI nanotubes and (b) SPANI composites. (c) Wide range XPS spectra of PANI and the obtained SPANI. (d) XPS data of S 2p regions of SPANI. (e) XPS data of C 1s regions of SPANI. (f) XPS data of N 1s regions of SPANI. (g) TGA and DSC analysis of SPANI showing 65.4 wt.\% of sulfur in SPANI composite. .68

Figure 5-4 Characterizations of multilayered cathodes. SEM images of (a) the outermost layer, PANI, (b) SPANI layer, and (c) S-CNT layer. (d) Area mass density $\left(\mathrm{mg} \mathrm{cm}^{-2}\right.$ ) and thickness $(\mu \mathrm{m})$ vs. bilayers of multilayered cathodes on aluminum current collectors. (e) XPS and (f) TGA analysis of the multilayered cathodes. 
Figure 5-5 (a-c) Electrochemical performance of Li-S cells employing multilayered cathodes. (a) Rate performance. Long-term cycling performance and Coulombic efficiency at different current rates (b) with and (c) without lithium nitrate additives in the liquid electrolyte. (d) Cycling performance of Li-S cells employing slurry-coated cathodes (10 wt. \% of PVDF +45 wt. $\%$ S-CNT +45 wt. $\%$ SPANI) .................. 71 Figure 5-6 SEM characterizations of the cathodes at different cycles. (a) Top view and (c) cross-section at the $10^{\text {th }}$ cycle, and (b) top view at the $50^{\text {th }}$ cycle of multilayered cathodes . .72

Figure 5-7 CV scans of Li-S cells employing electrolyte (a) with and (b) without lithium nitrate additives. (c) CV scans of SPANI, SPANI-PSS, and S-CNT-PSS based cathodes. Both scan rates were $0.05 \mathrm{mV} \mathrm{s}^{-1}$. SPANI cathodes contained $10 \mathrm{wt} \%$ of PVDF and 90 wt.\% of SPANI; SPANI-PSS (S-CNT-PSS) cathodes contained 10 wt.\% of PVDF, 30 wt.\% of PSS and $60 \mathrm{wt} . \%$ of SPANI (S-CNT). (d) XRD data of the multilayered cathode after the 50th discharge. (e) Continuous CV scans of multilayered cathodes for the first 3 cycles

Figure 5-8 Electrochemical performance of Li-S cells employing multilayered cathodes and SEM characterizations of the cathodes at different cycles. (a) Voltage profiles at 1st, 50th and 150th cycles. (b) Initial voltage profiles at 0.6 and 1 C. Top surface characterization at the (c) 150th, (d) 250th, and (e) 350th cycles....................74 Figure 5-9 EIS analysis of the Li-S cells containing multilayered cathodes. (a) EIS analysis of Li-S cells. (b) SEM image of cathode surface after 500 cycles..............75 Figure 6-1 (a) Schematic of the CNFPC electrode design, (b) large areal figure of the CNFPC electrode, and (c) carbon black/soluble $\mathrm{Li}_{2} \mathrm{~S}_{6}$ liquid catholyte...............80 Figure 6-2 Electrochemical performance of Li/CNFPC cells. (a) Cycling ability of the battery at a rate of $1670 \mathrm{~mA} \mathrm{~g}^{-1}$. (b) Continuous CV curves of the battery (scanning rate was $0.1 \mathrm{mV} \mathrm{s}^{-1}$ ). (c) Voltage profiles of the battery at different rates. (d, e) Long-term cycling stability and Coulombic efficiency of the battery at different current rates......84 Figure 6-3 SEM images of (a) porous carbon film layer before cycling, (b) native CNF substrate and (c) CNF substrate after infiltration with soluble lithium polysulfides. (d) TEM images of lithium polysulfide wrapped carbon black. (e, f) SEM images of CNF surface after 100th discharge at different magnifications. (g, h) SEM images of CNF 
surface after 100th charge at different magnifications. (i) SEM image of porous carbon film surface after 100th cycles.... .85

Figure 6-4 XRD data collected from the surface of cathode films after the $100^{\text {th }}$ (a) discharge process and (b) charge process...................................... 85 Figure 6-5 EDX data of (a) porous carbon layer surface from the CNFPC cathode and (b) cathode surface from the conventional slurry-coated batteries, respectively .86

Figure 6-6 SEM images of CNFPC cathodes after 1200 cycles. (a, b) CNF current collectors. Both the (a) cross section and (b) top surface images showed the integrity of the CNF conductive framework. (c, d) Porous carbon layer at different magnifications..87 Figure 6-7 SEM images showed that the diameter of CNF was between 6-10 $\mu \mathrm{m} . \ldots . . .87$ Figure 6-8 (a, b) SEM images of CNF current collector after 100 cycles. (c-f) EDS mapping of different elements corresponding to the SEM image of (b) ................88 Figure 6-9 Characterization of the control cells. (a) SEM image of CNF cathodes without a porous carbon layer. (b) Cycling performance of $\mathrm{Li} / \mathrm{CNF}$ batteries at $0.5 \mathrm{C}$. (c) Discharge/charge voltage profiles of $\mathrm{Li} / \mathrm{CNF}$ batteries at $0.5 \mathrm{C}$.

Figure 6-10 Characterizations of surface films on Li-anode. (a, b) SEM images of the Limetal surface from the Li/CNFPC batteries at different magnifications. (c, d) SEM images of the Li-metal surface from the Li/CNF batteries at different magnifications. (e, f) EDS and EDX data of Li-metals surface from (e) Li/CNFPC batteries and (f) Li/CNF batteries, respectively

Figure 6-11 Comparison of the EIS curves of Li/CNFPC battery (red) and Li/CNF battery(black).

Figure 6-12 Electrochemical performance of a thick $(\sim 15 \mu \mathrm{m})$ CNFPC cathode. (a) CV curves. (b) Cycling performance at different currents rates. (c) Discharge/charge curves at $1 \mathrm{C}$

Figure 6-13 High resolution XPS S 2p spectra of the CNF current collector surface (a) before cycling, (b) after the initial discharge and (c) after the initial charge. (d) The initial discharge/charge profiles at $\sim 1 \mathrm{C}$ rate. High resolution XPS c 1s spectra of the CNF current collector surface (e) after the initial discharge and (f) before cycling.... 
Figure 7-1 (a) Typical procedures to SMCNT. (b-d) Surface and (e) cross-sectional SEM images of the porous SMCNT structures. (f) XRD analysis of SMCNT. (g) CNF current collector used in this study

Figure 7-2 Cycling performance, sulfur utilization and capacity fade of Li-S batteries employing different quantities of electrolytes. (a) Cycling performance at 0.1 C. (b) Sulfur utilization vs. cycle numbers. (c) Capacity fade vs. cycle numbers.

Figure 7-3 Output voltage and voltage profiles of Li-S cells with different quantities of electrolytes. (a) Output voltages over 100 cycles as a function of DOD. (b, c, d) The first three cycles' voltage profiles with the three different quantities of electrolytes. 101

Figure 7-4 SEM images of the cathode in Li-S batteries cycled up to 100 times. Fully discharged batteries with electrolyte of (a) $5 \mathrm{ml} / \mathrm{g}$, (b) $8 \mathrm{ml} / \mathrm{g}$, and (c) $12 \mathrm{ml} / \mathrm{g}$. Fully charged batteries with electrolyte of (d) $5 \mathrm{ml} / \mathrm{g}$, (e) $8 \mathrm{ml} / \mathrm{g}$, and (f) $12 \mathrm{ml} / \mathrm{g} \ldots \ldots \ldots \ldots . . .102$ Figure 7-5 EIS plots of batteries cycled up 100 cycles with different quantities of electrolytes at a discharge current rate of $0.1 \mathrm{C}$. The tested batteries had a $8 \mathrm{ml} / \mathrm{g}$ of electrolyte. (a) Fully discharge states (discharge to 1.8 V). (b) Fully charge states (charge to $2.8 \mathrm{~V})$.

Figure 7-6 EIS characterizations of the cells with a $12 \mathrm{ml} / \mathrm{g}$ of electrolyte at the first cycle. (a) The selected points for EIS tests in the voltage profiles. (b) EIS spectra at various points

Figure 7-7 SEM characterizations and sulfur content of SMCNT electrodes at various discharge and charge states in the first cycle. The battery had a $8 \mathrm{ml} / \mathrm{g}$ of electrolyte. (a-e) At discharge points B, C and D, charge points E and F. (f) sulfur content at each tested

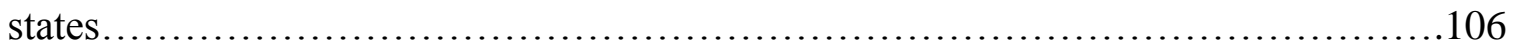

Figure 7-8 (a) Equivalent circuit of the EIS spectra. (b) $\mathrm{R}_{\text {film }}$ resistances of the solid....107 


\section{Chapter 1: Introduction}

Energy is one of the biggest challenges that mankind faces over the last 50 years, and we consume energy 24 hours a day.[1] There are obvious things like our cars, computers, phones, air conditioning and heating in our offices and houses. Most of the time, we're too caught up in modern life to realize the energy makes these all possible. However, the ever-growing demand for energy is always coupled with environmental concerns associated with the excessive use of fossil fuels such as coal, oil and gas. Consequently there are urgent needs to increase electricity generation efficiency and to develop clean and efficient means of energy conversion and storage such as rechargeable batteries. [2]

Take our cars as an example, the heavy carbonaceous emissions from vehicle engines and shortages of fossil fuels have attracted increased research interest in electric vehicles including plug-in hybrid electric vehicles (PHEV), hybrid electric vehicles (HEV) and electric vehicles $(\mathrm{EV})$. Battery-powered electric vehicles use an electric motor for propulsion with batteries for electricity storage. The energy in the batteries provides motive and auxiliary power onboard the vehicle. Electric vehicles offer the prospect of low air pollutants and relatively low cost of the electric motor, as well as very high efficiency. The main drawback is their reliance on batteries that presently have very low energy and power densities compared to oil fuels. [3, 4]

\subsection{Rechargeable Lithium-Ion Batteries}

Since the invention of lead acid batteries in 1859, researchers have developed new chemistries with ever-higher theoretical energy capacity than the last.[5] After the lead acid batteries were nickel cadmium batteries $(\mathrm{NiCd})$, then was the nickel metal hydride batteries $(\mathrm{NiMH})$, and then, in 1991, was the first commercial lithium-ion (Li-ion) batteries, which remains the highest energy secondary (rechargeable) battery chemistry available on the market today (Figure 1-1). [6, 7] 


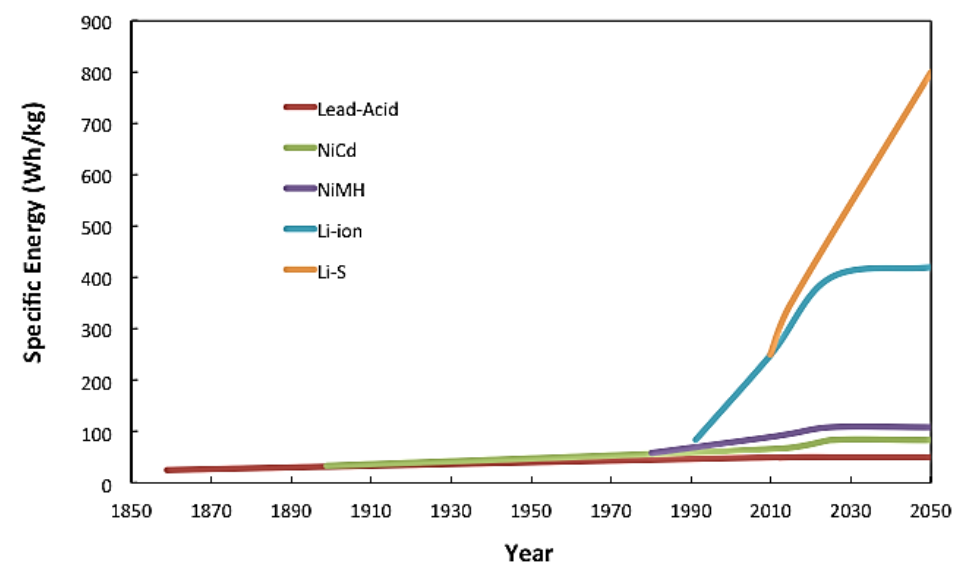

Figure 1-1 Schematic diagram of rechargeable battery performance and history [6].

Li-ion batteries generally contain four components: anode, cathode, electrolyte and separator.[8-10] Anode is the electrode where oxidation reaction takes place, and cathode is the electrode where reduction reaction takes place.[11] Electrolyte is an electron insulating liquid or solid substance that allows Li-ions to move freely.[12, 13] In this dissertation, the positive electrode containing the active material is referred to as the cathode. And the Li-metal is referred as the anode. Between the cathode and anode is a separator, which is a porous film that prevents the anode and cathode from touching, but allows the electrolyte to pass through freely.[14] Figure 1-2 shows how cell operates using the commercialized graphite/ $\mathrm{LiCoO}_{2}$ battery as an example.[15] Usually, the cell is in a discharged state after being assembled. During discharge, lithium ions move from the anode through the separator to the cathode. Simultaneously, electrons move from the anode to the cathode through the external circuit. This process causes the potential of the cathode to decrease and the anode to increase, thus decreasing the voltage of the cell. The direction of electron and ion motion is inversed during charging process in comparison with that in discharging process. [16, 17] 


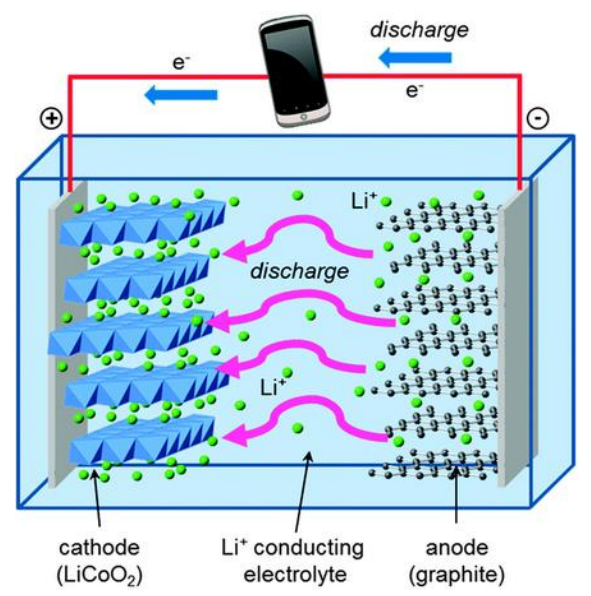

Figure 1-2 A schematic of a commercialized Li-ion battery using $\mathrm{LiCoO}_{2}$ as cathode and graphite as anode.

With Li-ion battery technology poised to move into large scale applications such as PHEV and EV, cost targets and performance requirements are raised especially with regard to energy, power, cycle life, safety and charge/discharge rate; therefore, further advances in Li-ion battery materials and devices are essential. [11] Since the performance of cathode materials is inferior to that of anode materials (i.e. graphite), but the price of cathode materials is much higher than anode materials, most research studies have focused on the development of cathode materials. Among the potential cathode chemistries, spinel lithium transition metal oxides $\left(\mathrm{LiM}_{2} \mathrm{O}_{4}\right)$, olivine lithium transition metal phosphates $\left(\mathrm{LiMPO}_{4}\right)$ and layered ternary compounds $\left(\mathrm{LiMO}_{2}\right.$, in which, $\mathrm{M}$ is a combination of nickel, cobalt and manganese, so-called NCM) have generated significant amount of interest. They have low-cost precursors, their structures are stable and they are environmentally benign. [18-20] These characteristics are in contrast to layered oxide systems such as $\mathrm{LiCoO}_{2}$, which has long been considered state of the art, but is now being reevaluated due to structural instability in recharging process, high cost and potential environmental pollution. [21] Great progress has already been made in new cathode materials for power applications over the past several years and has led to commercial production and increased sales. For example, more cost-competitive NCM is winning a higher share in electric bicycles and motors, while lithium manganese oxide $\left(\mathrm{LiMn}_{2} \mathrm{O}_{4}\right)$ and lithium iron phosphate $\left(\mathrm{LiFePO}_{4}\right)$ are already being used in electric cars. 
However, the current cathode materials have limitations, and their performance is summarized in Table 1-1. The battery system in the 40-mile PHEVs or EVs is expected to be designed with adequate cycle life and safety. Safety is a pre-requirement for power Li-ion batteries and the high energy density must be able to sustain high operating temperatures and poor working conditions. Most of all, the battery systems should have sufficient energy capacity and adequate output peak power, both of which are often considered as two key criteria during material optimization and development. The demands of electric drive vehicles (EDV) for power $\mathrm{Li}$-ion batteries are shown in Table 1-2.

\begin{tabular}{|c|c|c|c|c|}
\hline Performance & LiCoO$_{2}$ & NMC & LiMn$_{2} \mathbf{O}_{4}$ & LiFePO $_{4}$ \\
\hline Cost/kwh & Higher & High & High & High \\
\hline Safety & Poor & Poor & Average & Good \\
\hline Cycle life & Average & Good & Average & Average \\
\hline Power & Good & Good & Good & Average \\
\hline Energy/whkg & Good & Good & Average & Poor \\
\hline
\end{tabular}

Table 1-1 Comparison of current commercialized cathode materials.

\begin{tabular}{|c|c|c|c|c|c|}
\hline $\begin{array}{c}\text { EDV } \\
\text { type }\end{array}$ & $\begin{array}{c}\text { Weight } \\
(\mathrm{max} . \mathrm{kg})\end{array}$ & $\begin{array}{c}\text { Peak Power } \\
(\mathrm{min} . \mathrm{kw})\end{array}$ & $\begin{array}{c}\text { Power } \\
\left(\begin{array}{c}\text { (min. wkg } \\
\text {-1 }\end{array}\right.\end{array}$ & $\begin{array}{c}\text { Capacity } \\
(\text { min. kwh })\end{array}$ & $\begin{array}{c}\text { Energy } \\
\left(\text { min. whkg }^{-1}\right)\end{array}$ \\
\hline HEV & 50 & $40-60$ & $800-1200$ & $1.5-3$ & $30-60$ \\
\hline PHEV & 120 & $50-65$ & $400-540$ & $6-12$ & $50-75$ \\
\hline EV & 250 & $50-100$ & $200-400$ & $25-40$ & $100-160$ \\
\hline
\end{tabular}

Table 1-2 EDV demands for power Li-ion batteries.

While Li-ion batteries have enjoyed a significant degree of success, there is evidence that their rise has begun to plateau due to their high-cost and low capacity/energy density. [22, 23] Consider the emerging electric vehicles (EVs) that use today's state-of-the-art Li-ion cells, yet the batteries are still the weakest link in determining the vehicle's performance, durability, and cost. Even after decades of progress, $\mathrm{Li}$-ion batteries are still too expensive. When the state-of-the-art $\mathrm{Li}$-ion batteries are deployed in quantities of over 7,000 in the Tesla Model S, the result is a highperformance vehicle that accelerates with the best of its internal-combustion engine (ICE) competition. However, despite this promising performance, the Model S is still a heavy car (its batteries weigh over $330 \mathrm{~kg}$ ) and is too expensive for wide use (its batteries cost about $\$ 20,000$ ). The batteries used in the Model S as well as other production EVs are the 
best Li-ion batteries available today, yet they are still the key concern in determining vehicle performance, durability, and cost. The Li-ion battery energy capacity is fundamentally limited by its basic electrochemistry, while its high costs are unavoidable due to the expensive metals used in its construction.

\subsection{Rechargeable Lithium Sulfur (Li-S) Batteries}

In order to further expand the reach of electrochemical energy storage in the market, a substantial improvement will be necessary. Improving the battery chemistry from current lithium intercalation reactions in transition metal oxides or metal phosphates or graphite may boost the energy density of Li-ion batteries. [24] The Li-S chemistry is a potential breakthrough solution to this enduring battery performance problem. [25] Li-S batteries are regarded as one of the next-generation energy storage systems due to their high specific energy and improved energy density compared to Li-ion batteries. [26] The theoretical capacity of sulfur is $1672 \mathrm{~mA} \mathrm{~h} \mathrm{~g}^{-1}$ (two electrons are needed for each sulfur atom, calculated based on $\mathrm{S}^{0} \leftrightarrow \mathrm{S}^{2-}$ ). Coupled with the average operating voltage of a Li-

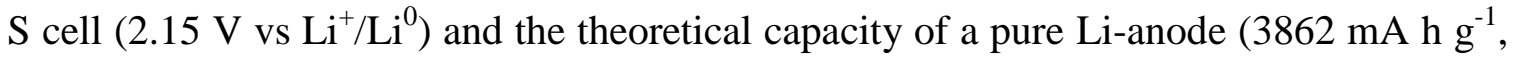
calculated based on $\mathrm{Li}^{+} \leftrightarrow \mathrm{Li}^{0}$ ), the energy density can be estimated to be as high as $\sim 2600 \mathrm{Wh} \mathrm{kg}^{-1}$, which is an order of magnitude higher than that of traditional Li-ion batteries (Table 1-3). [27] In addition to the advantage of significant high energy density, Li-S batteries have been proposed to be an inexpensive alternative of current batteries, owing to the low cost of sulfur. Furthermore, sulfur is benign and far safer than toxic cobalt oxide.

\begin{tabular}{|l|c|c|c|c|c|}
\hline \multicolumn{1}{|c|}{ System } & $\begin{array}{c}\text { Average } \\
\text { discharge } \\
\text { potential } \\
\text { V }\end{array}$ & $\begin{array}{c}\text { Theoretical } \\
\text { capacity of } \\
\text { cathode/ } \mathbf{m A} \mathbf{h} \\
\mathbf{g}^{-1}\end{array}$ & $\begin{array}{c}\text { Practical } \\
\text { capacity of } \\
\text { cathode/mA h } \\
\mathbf{g}^{-1}\end{array}$ & $\begin{array}{c}\text { Energy } \\
\text { density of a } \\
\text { full cell/Wh } \\
\mathbf{K g}^{-1}\end{array}$ & $\begin{array}{c}\text { Practical } \\
\text { specific energy } \\
\text { density of a full } \\
\text { cell/Wh } \mathbf{~ K g}^{-1}\end{array}$ \\
\hline $\mathbf{C - L i ( C o N i M n ) O _ { 2 }}$ & 3.7 & 275 & 160 & 410 & $135-180$ \\
$\mathbf{L i - S}$ & 2.15 & 1672 & $500-1100$ & $950-1700$ & $350-700$ \\
\hline
\end{tabular}

Table 1-3 Comparison of typical C/Li[CoNiMn] $\mathrm{O}_{2}$ and Li-S batteries. [27]

The Li-S battery seems a good fit for many applications due to its low-cost active material, environmental benignity, high gravimetric/volumetric energy density, and low 
operation voltage. Consumer electronics applications, such as power tools and tablet computers, value low-weight batteries, are willing to pay a premium for differentiated performance. By utilizing the Li-S battery technology, the usage time of portable devices could be considerably enhanced by at least three times longer than that of current Li-ion battery systems. The EV market presents a large and growing opportunity for Li-S. The Li-S battery can also be designed as a half-flow-mode cell with a tank of polysulfide catholyte at the cathode side. This concept has recently been proved feasible with a membrane-free, semi-liquid cell configuration. The redox flow Li-S cell is applicable to large-scale stationary energy storage for intermittent renewable energies such as wind, solar, geothermal, and hydropower.

\subsection{Li-S Systems and Principles}

Although a variety of Li-S cells have been considered, a sulfur cathode generally contains elemental sulfur along with supporting components similar to a Li-ion battery, including an electronically conductive additive and a polymer binder. Sulfur is a naturally abundant element that exists as an eight-membered ring $\left(\mathrm{S}_{8}\right)$. In a conventional Li-S cell (Figure 1-3), the cathode is separated from the metallic Li-anode by an organic liquid electrolyte. This configuration has been the platform for subsequent major research activities.

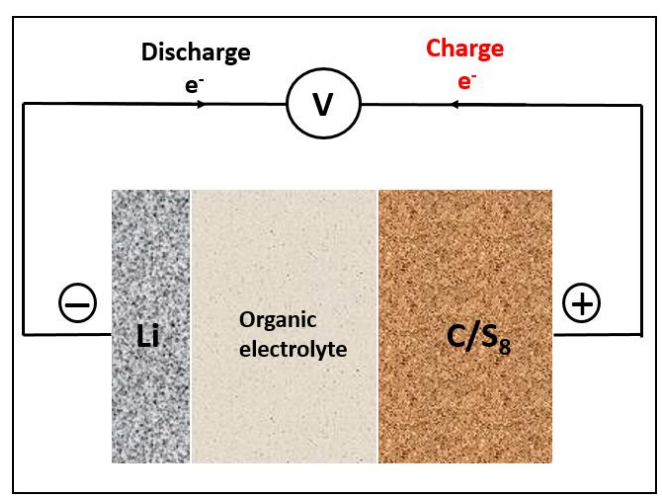

Figure 1-3 Illustration of the charge (red)/discharge (black) process involved in a rechargeable

Li-S battery consisting of Li-metal anode, organic electrolyte, and sulfur composite cathode.

When applied a discharge/charge current to a liquid type Li-S battery, a series of electrochemical reduction/oxidation reactions take place on the sulfur cathode and 
reversed oxidation/reduction reactions take place at the anode. For example, in discharge, the reduction starts from the dissolution of elemental sulfur and end with lithium sulfide, $\mathrm{Li}_{2} \mathrm{~S}$, through an eight-stage process, as shown in equations 1-1 $\rightarrow$ 1-8. [28-31] The overall redox reaction can be written in equation 1-0, in which two electrons are needed for one sulfur atom. On the basis of this 2-electron chemical reaction, in combination with the low weight of lithium and sulfur, Li-S batteries possess a high theoretical specific energy of $2680 \mathrm{Wh} \mathrm{kg}^{-1}$, nearly five times that of the current Li-ion battery technology.

$$
\begin{aligned}
& 2 \mathrm{Li}^{+}+\mathrm{S}+2 \mathrm{e} \Leftrightarrow \mathrm{Li}_{2} \mathrm{~S} \downarrow(1-0) \\
& \mathrm{S}_{8}(\mathrm{~s}) \Leftrightarrow \mathrm{S}_{8}(\mathrm{l}) \\
& \mathrm{S}_{8}(1)+2 e \Leftrightarrow \mathrm{S}_{8}{ }^{2-} \\
& \frac{3}{2} \mathrm{~S}_{8}{ }^{2-}+e \Leftrightarrow 2 \mathrm{~S}_{6}{ }^{2-} \\
& \mathrm{S}_{6}{ }^{2-}+e \Leftrightarrow \frac{3}{2} \mathrm{~S}_{4}{ }^{2-} \\
& \frac{1}{2} \mathrm{~S}_{4}{ }^{2-}+e \Leftrightarrow \mathrm{S}_{2}{ }^{2-} \\
& \frac{1}{2} \mathrm{~S}_{2}{ }^{2-}+e \Leftrightarrow \mathrm{S}_{2}{ }^{-} \\
& \mathrm{S}_{2}^{2-}+2 \mathrm{Li}^{+} \Leftrightarrow \mathrm{Li}_{2} \mathrm{~S}_{2} \downarrow \\
& \mathrm{S}_{2}{ }^{-}+4 \mathrm{Li}^{+} \Leftrightarrow 2 \mathrm{Li}_{2} \mathrm{~S} \downarrow
\end{aligned}
$$
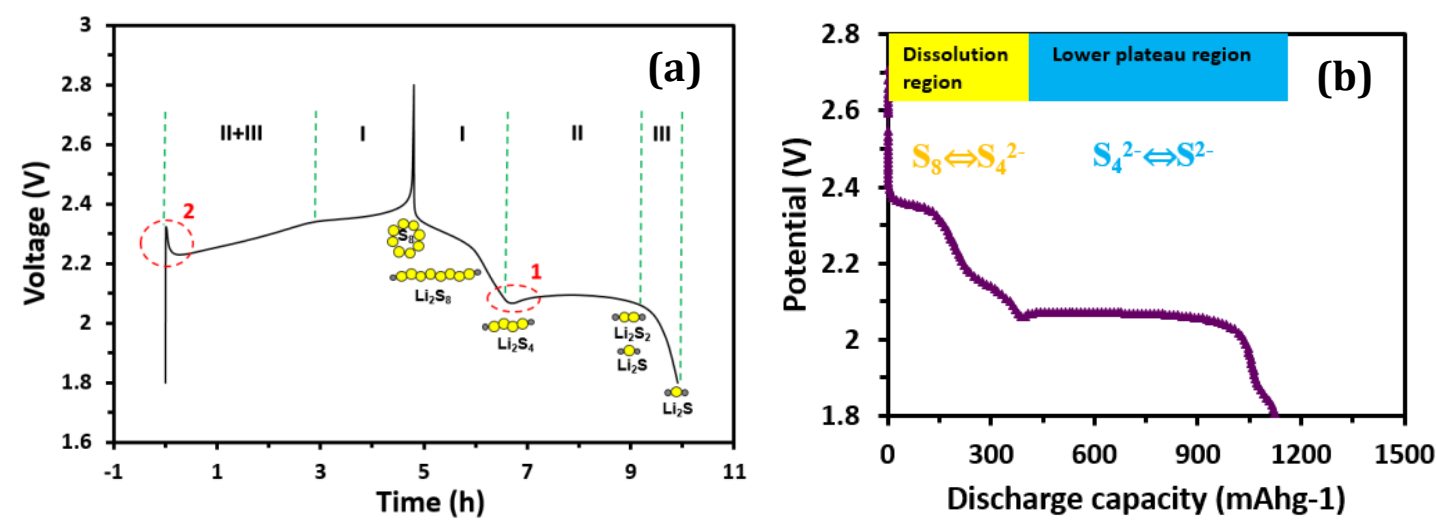

Figure 1-4 (a) A typical charge and discharge curves under a moderate current. (b) A typical discharge curve showing polysulfide anions' solubility under a moderate current.

A typical voltage profile of Li-S battery is plotted in Figure 1-4a. In discharge, solid-phase sulfur rings $\left(\mathrm{S}_{8}\right)$ first dissolve into electrolyte, then the dissolved sulfur is 
reduced step-by-step. It is generally thought that the discharge process can be divided into three reduction regions. [25] The predominant products of these three regions are $\mathrm{Li}_{2} \mathrm{~S}_{4}, \mathrm{Li}_{2} \mathrm{~S}_{2}$ and $\mathrm{Li}_{2} \mathrm{~S}$, respectively. [32] The first region belongs to the dissolution region, and the last two regions are ascribed to the solid-state region, as shown in Figure 1-4b. [33]

Region I: Initially, the solid state sulfur is dissolved into the liquid electrolyte and forms liquid state sulfur, as shown in equation 1-1. Then, the liquid-type sulfur is further reduced to the intermediate long-chain highly soluble polysulfide species $\mathrm{S}_{\mathrm{n}}{ }^{2-}(4 \leq \mathrm{n} \leq 8)$, through a stepwise sequence of soluble polysulfide ions to form $\mathrm{S}_{4}{ }^{2-}$ as shown in equation 1-9, which combined equations 1-1 to 1-4.

$$
\mathrm{S}_{8}(1)+4 e \rightarrow 2 \mathrm{~S}_{4}{ }^{2-}
$$

This is a half-electron charge transfer per sulfur atom, contributing about $25 \%$ of the total sulfur capacity. The controlled Nernst equation is shown in equation 1-10 [34]:

$$
E_{U}=E_{U}^{\Theta}+\frac{R T}{n_{H} F} \ln \frac{\left[S_{8(l)}^{0}\right]}{\left[S_{4}^{2-}\right]^{2}}
$$

Increased with the depth of discharge, the concentration of soluble $\mathrm{S}_{4}{ }^{2-}$ anions gradually increases, while the concentration of $S_{8}$ is maintained at or a little lower than its saturated concentration in the electrolyte all the time because of the low solubility of elemental sulfur in liquid electrolyte. Therefore, the voltage in the upper plateau, which decreases all the time, is mainly affected by the concentration of $\mathrm{S}_{4}{ }^{2-}$. When the electrolyte viscosity rises to a certain level, the Li-ion transport will encounter some difficulties, as verified by the small reverse peak that is circled as point 1 (Figure 1-4a). Thus, the fast voltage drop in the sloping region reflects the concentration polarization.

Region II: Next, the liquid long-chain polysulfide $\mathrm{S}_{4}{ }^{2-}$ is further reduced to shortchain $\mathrm{Li}_{2} \mathrm{~S}_{2}$ or $\mathrm{Li}_{2} \mathrm{~S}$, as seen in equations 1-11 and 1-12.

$$
\begin{aligned}
& \mathrm{S}_{4}{ }^{2-}+6 e \rightarrow 4 \mathrm{~S}^{2-} \\
& \mathrm{S}_{4}{ }^{2-}+2 e \rightarrow 2 \mathrm{~S}_{2}{ }^{2-}
\end{aligned}
$$

Some literatures suggested that the transition from the high to the low discharge voltage plateau took place concurrently with the start of the formation of solid lithium sulfide. 
This stage contributes to the major portion of the capacity with a fixed voltage. The controlled Nernst equation is shown in equation 1-13 [35]:

$$
E_{L}=E_{L}^{\Theta}+\frac{R T}{n_{L} F} \ln \frac{\left[S_{4}^{2-}\right]}{\left[S_{2}^{2-} / S^{2-}\right]^{4}}
$$

Since both $\mathrm{Li}_{2} \mathrm{~S}$ and $\mathrm{Li}_{2} \mathrm{~S}_{2}$ have a very low solubility in electrolyte, the concentration of $\mathrm{S}_{2}{ }^{2-} / \mathrm{S}^{2-}$ is almost maintained at its saturated concentration. On the other hand, although the concentration of $\mathrm{S}_{4}{ }^{2-}$ gradually decreases along with the discharge time, the kinetic reactions of equations 1-11/1-12 are very slow, thus the discharge curve keeps between 2.1 and $2 \mathrm{~V}$ for a long time. Until the concentration of $\mathrm{S}_{4}{ }^{2-}$ is reduced to a certain extent, the voltage shows a quick decrease, and the reaction is terminated.

Region III: The last sloping tail corresponds to a solid-to-solid reduction from $\mathrm{Li}_{2} \mathrm{~S}_{2}$ to $\mathrm{Li}_{2} \mathrm{~S}$, as seen in equation 1-14:

$$
\mathrm{Li}_{2} \mathrm{~S}_{2}+2 \mathrm{Li}^{+}+2 e \rightarrow 2 \mathrm{Li}_{2} \mathrm{~S}
$$

The inter-conversion of $\mathrm{Li}_{2} \mathrm{~S}_{2}$ to $\mathrm{Li}_{2} \mathrm{~S}$ is kinetically slow and difficult. This conversion is impeded due to the sluggishness of solid state diffusion in the bulk. [35]

Region II together with region III accounted for a one and half electron charge transfer per sulfur, contributing the remaining $75 \%$ of the sulfur capacity. $\mathrm{Li}_{2} \mathrm{~S}$ was found to form in the beginning of the low plateau, which contributes to the major portion of the capacity with a fixed voltage. [36]

In the charge process, the electrons transfer from the cathode active materials to the electrode until the charging cut off voltage. A long flat low plateau is seen first, representing the oxidation of insoluble $\mathrm{Li}_{2} \mathrm{~S}$ and $\mathrm{Li}_{2} \mathrm{~S}_{2}$ to long-chain soluble polysulfide species.[37] A reduced polarization caused by the oxidation from solid $\mathrm{Li}_{2} \mathrm{~S}$ and $\mathrm{Li}_{2} \mathrm{~S}_{2}$ to liquid long-chain polysulfide species is verified by the small peak that is circled as point 2 (Figure 1-4a). The upper charge plateau, which is hard to define, indicates the oxidation reactions from the soluble long-chain polysulfide species to elemental sulfur. It is suggested that all the polysulfide species transform into the intermediate with the most facile oxidation kinetics (via charge transfer), which is believed to be $\mathrm{S}_{8}{ }^{2-}$. [38] 


\subsection{Challenges of Li-S Batteries}

Sulfur's high theoretical capacity of $1675 \mathrm{~mA} \mathrm{~h} \mathrm{~g}^{-1}$, a ten-fold greater capacity versus today's Li-ion and Na-ion batteries, make Li-S batteries an attractive candidate for meeting increasing demand for high energy density high energy storage devices. In addition, the cheap sulfur materials may contribute to alleviating the cost-efficient nature of renewable energy. However, the commercialization of Li-S batteries is hindered by their short calendar life caused by the rapid capacity fade. [24, 39-41]

A prominent issue is associated to the multi-step process from $\mathrm{S}_{8}$ to $\mathrm{Li}_{2} \mathrm{~S}\left(\mathrm{~S}_{8} \leftrightarrow \mathrm{S}_{8}{ }^{2-}\right.$ $\left.\leftrightarrow \mathrm{S}_{6}{ }^{2-} \leftrightarrow \mathrm{S}_{4}{ }^{2-} \leftrightarrow \mathrm{Li}_{2} \mathrm{~S}_{2} \leftrightarrow \mathrm{Li}_{2} \mathrm{~S}\right)$. First, $\mathrm{S}_{8}$ and $\mathrm{Li}_{2} \mathrm{~S}_{2} / \mathrm{Li}_{2} \mathrm{~S}$ are insoluble species and have extremely low electronic conductivity, which greatly decrease the utilization of the active sulfur materials and pose major issues for power capability. The soluble long-chain polysulfide species $\left(\mathrm{Li}_{2} \mathrm{~S}_{\mathrm{n}}, \mathrm{n} \geq 3\right)$ can be directly reduced to $\mathrm{Li}_{2} \mathrm{~S}_{2} / \mathrm{Li}_{2} \mathrm{~S}$, and deposit or accumulate on the cathode surface, which decreases the electrochemical reaction sites in the cathode structure and thus results in capacity fade. Although adding a large amount of conduct carbon agents can alleviate this problem, the overall capacity content of sulfur cathode is correspondingly decreased, which neutralizes the advantage of high energydensity. [42]

A second significantly complicated issue is related to the formation of intermediate long-chain lithium polysulfide species during cycling. For one thing, these intermediate polysulfide species exist only in the electrolyte, and can diffuse from the cathode to the electrolyte, reducing the overall quantity of sulfur in the cathode, and thus leading to a decreased battery capacity. For another, they can further diffuse to the Li-anode, where they are reduced to nonconductive $\mathrm{Li}_{2} \mathrm{~S}$, which is deposited on the anode or in the electrolyte. [34, 43-45] Some of these $\mathrm{Li}_{2} \mathrm{~S}$ may continue to react with long-chain polysulfide species and form short-chain polysulfide species, which can diffuse back to the cathode. The uncontrollable deposition layers consume active sulfur materials and increase cell's resistance, resulting in rapid capacity fade of cells, while the shuttle circulating between the two electrodes leads to self-discharge, making the charging time 
of the battery towards infinity, and greatly decreasing the Coulombic efficiency and cycle life of cells. [46-48]

\subsubsection{Insulating Active Sulfur Materials}

The first problem in a Li-S cell is the nonconductive property of $\mathrm{Li}_{2} \mathrm{~S}_{2} / \mathrm{Li}_{2} \mathrm{~S}$ and sulfur (with a high resistance of $5 \times 10^{-30} \mathrm{~S} \mathrm{~cm}^{-1}$ ), which is required to contact with conductors since the reduction or oxidation of sulfur can only take place on the conductive surface.[49] The high resistance of sulfur leads to low active utilization in Li$\mathrm{S}$ cells. Although this problem could be addressed by introducing a large amount of conductive agents, the low sulfur content in sulfur electrodes may neutralize the advantages of high-energy density Li-S batteries.

\subsubsection{Volume Expansion}

Sulfur has a high mass density of $2.03 \mathrm{~g} \mathrm{~cm}^{-3}$, which expands during discharge owing to the lower density of the final discharge products $\left(\mathrm{Li}_{2} \mathrm{~S}\right)$ with a mass density of

$1.67 \mathrm{~g} \mathrm{~cm}^{-3}$, and contracts again on charge. The volume change is an important factor to consider when designing sulfur electrodes, since it induces strain inside the electrode, and causes huge crack, resulting in the detachment of lithium polysulfide species from the carbon surface, and leading to low efficiency and fast capacity decay of cycling.[50] Utilizing conductive polymer materials or fabricating binder-free sulfur electrode could mitigate this problem.

\subsubsection{Rapid Capacity Fade}

Li-S battery is a liquid electrochemical system, in which the sulfur-to-electrolyte ratio plays an essential role in the cell's performance.[51, 52] More electrolyte causes larger amounts of materials loss, and leads to a rapid capacity fade. However, the dissolution of long-chain lithium polysulfide species exposes the inner nonconductive sulfur $/ \mathrm{Li}_{2} \mathrm{~S}_{2} / \mathrm{Li}_{2} \mathrm{~S}$ to the conductive carbon framework, making it easy for electrontransfer, and thus promotes a complete reaction and produces a high capacity. [35] In addition, the dissolution enhances ion diffusion, which promotes a high charge and 
discharge rate. Therefore, these two opposite factors should be properly balanced to get a good performance with a reasonable capacity and cycle life.

To understand the capacity decay mechanism in Li-S battery, where the discharge capacity from and the effects of transformations between the various polysulfide species on the discharge capacity should be clearly understood. The discharge capacity at different depth of discharge (DOD) is summarized in Table 1-4.

\begin{tabular}{|c|c|c|c|}
\hline $\begin{array}{c}\text { Discharge } \\
\text { Products }\end{array}$ & $\begin{array}{c}\text { Electrons transferred } \\
\text { (mol (mol.S) }\end{array}$ & DOD & $\begin{array}{c}\text { Specific capacity } \\
\text { (mA h } \mathbf{g}^{-1} \text { ) }\end{array}$ \\
\hline $\mathbf{S}_{\mathbf{8} \leftrightarrow \mathbf{S}_{\mathbf{8}} \mathbf{2 -}^{2-}}$ & 0.25 & $12.5 \%$ & 209 \\
\hline $\mathbf{S}_{\mathbf{8} \leftrightarrow \mathbf{S}_{\mathbf{4}}{ }^{2-}}$ & 0.5 & $25 \%$ & 418 \\
\hline $\mathbf{S}_{\mathbf{8} \leftrightarrow \mathbf{L i}} \mathbf{S}_{\mathbf{2}}$ & 1 & $50 \%$ & 836 \\
\hline $\mathbf{S}_{\mathbf{8}} \leftrightarrow \mathbf{L i} \mathbf{2} \mathbf{S}$ & 2 & $100 \%$ & 1672 \\
\hline
\end{tabular}

Table 1-4 Discharge capacity vs. DOD in Li-S batteries.

The theoretical capacity $\left(\mathrm{mA} \mathrm{h} \mathrm{g}^{-1}\right)$ of initial discharge is expressed as:

$$
\mathrm{q}=\frac{n F}{M}
$$

Where, $\mathrm{M}$ is molar of quality of sulfur, $\mathrm{F}$ is Faraday constant, and $\mathrm{n}$ is transferred electrons per sulfur atoms.

The initial discharge capacity ( $\mathrm{mA} \mathrm{h} \mathrm{g}^{-1}$ ) can be calculated by equation 1-16:

$$
\begin{aligned}
q_{r 1}= & \sum \omega_{n} q_{S_{8} \rightarrow L i_{2} S_{n}}=\omega_{8} q_{S_{8} \rightarrow S_{8}^{2-}+} \omega_{4} q_{S_{8} \rightarrow S_{4}^{2-}+} \omega_{2} q_{S_{8} \rightarrow L i_{2} S_{2}}+\omega_{1} q_{S_{8} \rightarrow L i_{2} S} \\
& =210 \omega_{8}+420 \omega_{4}+840 \omega_{2}+1680 \omega_{1}
\end{aligned}
$$

Where, $\omega_{\mathrm{n}}$ is the weight percent of $\mathrm{S}_{8}$ being converted to $\mathrm{S}_{\mathrm{n}}{ }^{2-}$,

$$
\sum \omega_{n}=1, \mathrm{n}=1,2,4,8
$$

Since the thermodynamic reaction from solid $\mathrm{Li}_{2} \mathrm{~S}_{2}$ to solid $\mathrm{Li}_{2} \mathrm{~S}$ is very difficult, $\omega_{1}$ is far below than 1, this is the major reason for a low initial capacity in Li-S cells. On the other hand, since the intermediate polysulfide species can easily be dissolved into the liquid electrolyte, and the thermodynamic reaction from polysulfide species to the elemental sulfur is very slow, only a small amount of active materials can be oxidized to elemental sulfur at the end of the initial charge.[53] Therefore, after the initial cycle, most 
of active materials in the cathode are soluble high-order polysulfide species in high valence states.

From the second cycle, the discharge capacity can be calculated by equation 1-18:

$$
\begin{gathered}
q_{r x(x>1)}=\sum \omega_{m}^{s_{8}} q_{S_{8} \rightarrow \square i_{2} S_{n}}+\sum \omega_{m}^{S_{8}^{2-}} q_{S_{8}^{2-} \rightarrow L i_{2} S_{n}}+ \\
\sum \omega_{m}^{S_{4}^{2-}} q_{S_{4}^{2-} \rightarrow L i_{2} S_{n}}
\end{gathered}
$$

This discharge capacity comprises three parts: from elemental sulfur to $\mathrm{Li}_{2} \mathrm{~S}_{\mathrm{n}}$, from $\mathrm{Li}_{2} \mathrm{~S}_{8}$ to $\mathrm{Li}_{2} \mathrm{~S}_{\mathrm{n}}$, and from $\mathrm{Li}_{2} \mathrm{~S}_{4}$ to $\mathrm{Li}_{2} \mathrm{~S}_{\mathrm{n}}$. These three parts indicate three kinds of active materials at the very beginning of the second discharge process. Since there are still some insoluble $\mathrm{Li}_{2} \mathrm{~S}_{2} / \mathrm{Li}_{2} \mathrm{~S}$ at the end of charging process, the total weight percent of these three active materials are described in equation 1-19:

$$
\sum \omega_{m}^{S_{8}}+\sum \omega_{m}^{S_{8}^{2-}}+\sum \omega_{m}^{S_{4}^{2-}}=1-\frac{\sum \Delta S_{\left(L i_{2} S+L i_{2} S_{2}\right)}}{S}
$$

Each of the three summarizations also contains three parts, take $\sum \omega_{m}^{S_{8}^{2-}}$ as an example:

$$
\begin{gathered}
\sum \omega_{m}^{S_{8}^{2-}} q_{S_{8}^{2-} \rightarrow L i_{2} S_{n}}=\omega_{4}^{S_{8}^{2-}} q_{S_{8}^{2-} \rightarrow S_{4}^{2-}}+\omega_{2}^{S_{8}^{2-}} q_{S_{8}^{2-} \rightarrow L i_{2} S_{2}}+\omega_{1}^{S_{8}^{2-}} q_{S_{8}^{2-} \rightarrow L i_{2} S} \\
=210 \omega_{4}^{S_{8}^{2-}}+630 \omega_{2}^{S_{8}^{2-}}+1270 \omega_{1}^{S_{8}^{2-}}
\end{gathered}
$$

In the charge process, as mentioned previously, most of the active sulfur materials exist as long-chain polysulfide species at the end of charge process.

In addition to the basic reactions in a Li-S battery that has been discussed in section 1.3, there are some other complicated reactions during cycling. For example, the longchain polysulfide species react with lithium ions in the electrolyte and form insoluble $\mathrm{Li}_{2} \mathrm{~S}$, as seen in equation 1-21:

$$
\mathrm{Li}_{2} \mathrm{~S}_{\mathrm{n}}+2 \mathrm{e}+2 \mathrm{Li}^{+} \rightarrow \mathrm{Li}_{2} \mathrm{~S}+\mathrm{Li}_{2} \mathrm{~S}_{\mathrm{n}-1}
$$

This reaction consumes electrolyte, and causes capacity fade with cycling. [25]

On the other hand, due to the free movement of long-chain polysulfide species in the electrolyte through the separator to the Li-anode where they are reduced to insoluble $\mathrm{Li}_{2} \mathrm{~S}_{2}$ or $\mathrm{Li}_{2} \mathrm{~S}$, as seen in equations 1-22 and 1-23 [26, 54]: 


$$
\begin{aligned}
& 2 \mathrm{Li}+\mathrm{Li}_{2} \mathrm{~S}_{\mathrm{n}} \rightarrow \mathrm{Li}_{2} \mathrm{~S} \downarrow+\mathrm{Li}_{2} \mathrm{~S}_{\mathrm{n}-1} \\
& 2 \mathrm{Li}+\mathrm{Li}_{2} \mathrm{~S}_{\mathrm{n}} \rightarrow \mathrm{Li}_{2} \mathrm{~S}_{2} \downarrow+\mathrm{Li}_{2} \mathrm{~S}_{\mathrm{n}-2}
\end{aligned}
$$

These nonconductive solid products easily precipitate onto the Li-anode surface, and the Li-anode may be fully coated by $\mathrm{Li}_{2} \mathrm{~S} / \mathrm{Li}_{2} \mathrm{~S}_{2}$, part of which may continue to react with the following arrived long-chain polysulfide species to form short-chain polysulfide species, as seen in equations 1-24 and 1-25:

$$
\begin{aligned}
& \mathrm{Li}_{2} \mathrm{~S}+\mathrm{Li}_{2} \mathrm{~S}_{\mathrm{n}} \rightarrow \mathrm{Li}_{2} \mathrm{~S}_{\mathrm{m}}+\mathrm{Li}_{2} \mathrm{~S}_{\mathrm{n}-\mathrm{m}+1} \\
& \mathrm{Li}_{2} \mathrm{~S}_{2}+\mathrm{Li}_{2} \mathrm{~S}_{\mathrm{n}} \rightarrow \mathrm{Li}_{2} \mathrm{~S}_{\mathrm{m}}+\mathrm{Li}_{2} \mathrm{~S}_{\mathrm{n}-\mathrm{m}+2}
\end{aligned}
$$

When these short polysulfide species become concentrated at the anode side, they will diffuse back to the positive electrode and are then re-oxidized into long-chain polysulfide species. This repeated migration behavior is called "polysulfide shuttle effect", which causes self-discharge and produces current in the cell. [34] The polysulfide species reduced at the anode cause a continuous evolution of porous Li metal structure, and lead to unstable solid-state electrolyte interface layers, damaging long-term cell performance and presenting safety issues. Polysulfide shuttle takes place in both charge and discharge processes (Figure 1-5) in the Li-S cell systems. But it is severe especially at the upper plateau region of the charge curve, even until the cell is reaching over its theoretical capacity.[48] In charge, the insoluble $\mathrm{Li}_{2} \mathrm{~S}$ can be easily transformed into soluble high-order polysulfide species, but the conversion from the soluble polysulfide species to elemental sulfur is very difficult, and the process is slow (Figure 1-6a), and some reports demonstrated that polysulfide species do not transform back to elemental sulfur even at $100 \%$ depth of charge in the initial several cycles, and only a little active materials are oxidized into elemental sulfur, say $20 \%$ sulfur plus $80 \%$ polysulfide species. Along with the depth of charging, the concentration of the long-chain polysulfide species at the cathode is much larger than that in the anode, and thus the diffusion dynamics of these polysulfide species for transporting from the cathode to the $\mathrm{Li}$-anode become larger. At the same time, the reduced reactions of these migrated polysulfide species on the Li-anode surface are also accelerated. Therefore, the second voltage plateau in the charging curve might be the result of a competition between electrochemical oxidation and reduction (Figure 1-6b). 


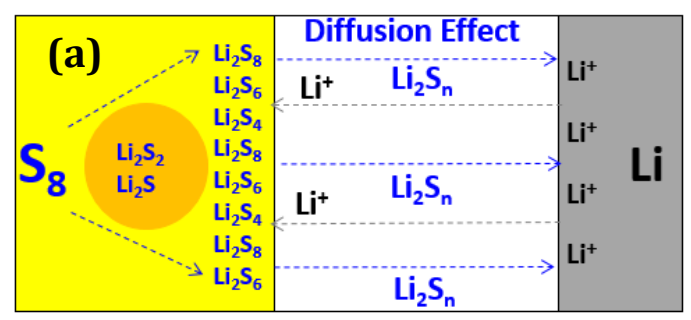

Discharge

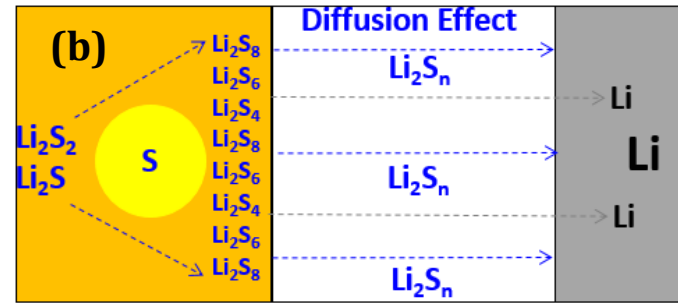

Charge

Figure 1-5 Diagrams of poly-shuttle in (a) discharge and (b) charge process in Li-S battery.

(a)

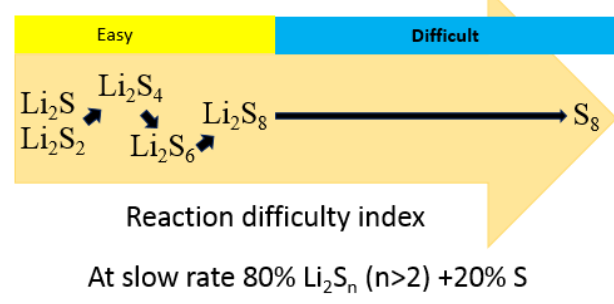

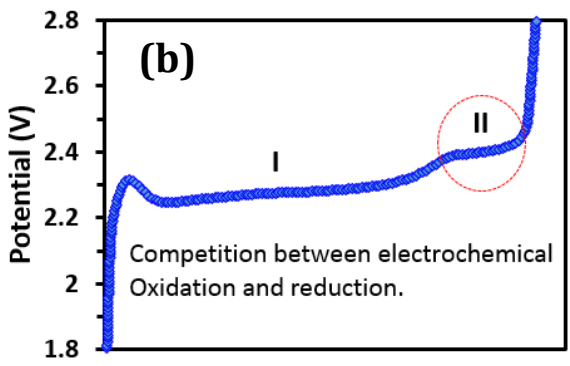

Figure 1-6 Diagrams of charging process in the Li-S batteries.

However, the current associated with these reactions does not contribute to charging the battery, resulting in a low Coulombic efficiency. These highly active polysulfide species can further react with the electrolyte, depleting both active materials and solvent molecules. Of note, poly-shuttle effect can prevent overcharge of Li-S batteries.

The diffusion and migration of the soluble long-chain polysulfide species can be described by Nernst-Planck equation 1-26 [55]:

$$
J_{j}(x)=-D_{j} \frac{\partial C_{j}(x)}{\partial x}-\mu_{j} C_{j} \frac{\partial V(x)}{\partial x}
$$

In which, $\mathrm{j}$ is the polysulfide anion; $\mathrm{C}$ is the concentration of the polysulfide anions; $\mathrm{V}$ is electrostatic potential; D is the diffusion constant, which indicates the ease with which the anions pass through the liquid electrolyte under a concentration gradient; and $\mu$ is the mobility of polysulfide anions, representing the ease with which the anions pass through the liquid electrolyte when an external electrical field is applied. Equation 1-26 comprises two parts: the first one is diffusion, and the second one is migration. Since for a particular cell, the applied voltage is fixed, thus the migration is controlled by open circuit voltage $(\mathrm{OCV})$. From equation 1-26, the concentration of polysulfide anions in the cell is an 
important factor for polysulfide shuttle, which can be adjusted by controlling the quantity of electrolytes. Similarly calculations can be applied to the other three formulas.

Another reason for the capacity fade is due to the formation of thick and insulating $\mathrm{Li}_{2} \mathrm{~S}$ and $\mathrm{Li}_{2} \mathrm{~S}_{2}$ layers covering sulfur electrodes after cycling.[54] This deposition behavior may lead to the formation of some "inactive regions" in the cell. The chemistry results in uncontrollable deposition of $\mathrm{Li}_{2} \mathrm{~S} / \mathrm{Li}_{2} \mathrm{~S}_{2}$ species on both electrode surfaces, significantly inhibiting further lithiation from $\mathrm{Li}_{2} \mathrm{~S}_{2}$ to $\mathrm{Li}_{2} \mathrm{~S}$, leading to low sulfur utilization and deteriorating the cyclability. In addition, the deposited $\mathrm{Li}_{2} \mathrm{~S}_{2}$ can destroy the conductive structure in the cathode. This part of sulfur will cause irreversible capacity loss. More seriously, it might cause cell failure if the agglomeration of $\mathrm{Li}_{2} \mathrm{~S} / \mathrm{Li}_{2} \mathrm{~S}_{2}$ blocks the electron and ion pathways in the electrode. Appropriate pore distribution in the cathode matrix should be designed in order to trap the soluble polysulfide intermediates in the pores, which can avoid active material agglomeration plating on the surface of electrodes.

Based on the above analysis, the total capacity fade, Q, of the liquid type Li-S battery can be divided into three parts:

$$
\mathrm{Q}=\mathrm{Q}_{1}+\mathrm{Q}_{2}+\mathrm{Q}_{3}
$$

Where $\mathrm{Q}_{1}$ is capacity fade due to the loss of active sulfur materials into the liquid electrolyte; $\mathrm{Q}_{2}$ is capacity fade due to the precipitation of nonconductive $\mathrm{Li}_{2} \mathrm{~S}_{2} / \mathrm{Li}_{2} \mathrm{~S}$ films onto the surfaces of both electrodes and formation of passivation layers, which inhibit further lithiation/delithiation; $\mathrm{Q}_{3}$ is capacity fade due to the incomplete conversions from $\mathrm{Li}_{2} \mathrm{~S}_{2}$ to $\mathrm{Li}_{2} \mathrm{~S}$ in discharge and from long-chain polysulfide species to elemental sulfur in charge.

\subsubsection{Self-Discharge}

The formation of soluble long-chain polysulfide species through the reduction of $\mathrm{S}_{8}$ or oxidation of $\mathrm{Li}_{2} \mathrm{~S}_{2} / \mathrm{Li}_{2} \mathrm{~S}$ is common to most current Li-S batteries. The solubility of the long-chain polysulfide species can assist the utilization of active sulfur materials because

the dissolved polysulfide species can migrate freely to ensure intimate contact with 
conductive carbon or polymers. However, the dissolution behavior brings numerous drawbacks, mainly including rapid capacity fade. Accompanied with the rapid capacity fade is the fourth problem: self-discharge in current liquid type Li-S battery, which is also resulted from the polysulfide dissolution. [56] With the increasing storage time of Li-S battery, the long-chain soluble polysulfide species may react with Li-ions in the electrolyte and, therefore, produces short-chain soluble polysulfide species that gradually diffuse out of the cathode, and insoluble $\mathrm{Li}_{2} \mathrm{~S}$ that precipitate in electrolyte, as shown in equations 1-22 and 1-28:

$$
\begin{gathered}
\mathrm{Li}_{2} \mathrm{~S}_{\mathrm{n}}+2 e+2 \mathrm{Li}^{+} \Leftrightarrow \mathrm{Li}_{2} \mathrm{~S} \downarrow+\mathrm{Li}_{2} \mathrm{~S}_{\mathrm{n}-1} \\
\mathrm{xLi}_{2} \mathrm{~S}_{\mathrm{n}-1} \Leftrightarrow \mathrm{Li}_{2} \mathrm{~S} \downarrow+\mathrm{yLi}_{2} \mathrm{~S}_{\mathrm{n}}
\end{gathered}
$$

These reactions are helpful for generating the final discharge products of $\mathrm{Li}_{2} \mathrm{~S}$. While self-discharge occurs, the open circuit voltage (OCV) of the cell declines and the upper discharge plateau shortens, implying the change in the oxidation state of the active material. The self-discharge rate may also depend on properties of current collectors.

\subsection{Conclusions}

In this chapter, we first introduced lithium battery systems, and then focused on the Li-S chemistries upon which this work is primarily based. A detailed discussion of Li-S fundamentals, challenges and potential applications is presented to provide a general context for the research that is covered in this dissertation. The successful operation of a Li-S battery relies on the progress of the multiple reactions in the cell. Based on the analysis, we concluded some reasons for rapid capacity fade, which is a main problem for the current Li-S batteries. The chemical properties of the polysulfide species differ greatly. Specifically, $\mathrm{S}_{8}$ and $\mathrm{Li}_{2} \mathrm{~S}$ are solid and insoluble in nearly all common electrolyte solvents, while the soluble long-chain polysulfide species are easily dissolved by most of solutions including organic solvents, ionic liquids and polymers. During the cell operations, these polysulfide species are continuously produced and consumed, and at the same time, some of them can diffuse from the cathode structure to the electrolyte, reducing the overall quantity of active sulfur materials and resulting in decreased battery capacity. In addition, these polysulfide species can further migrate to and react with the Li-anode. These parasitic reactions consume useful energy and are regarded as one of the 
biggest challenges associated with Li-S batteries. Furthermore, the species insolubility is another issue that related to these parasitic reactions. The solid $\mathrm{Li}_{2} \mathrm{~S}_{2} / \mathrm{Li}_{2} \mathrm{~S}$ may precipitate everywhere including cathode, anode and electrolyte once they are produced, and most of them are potentially impossible to be reused. Interrelated with the challenges for cathodes is the issue of anode stability. As with all Li-metal anode battery designs, there is a significant concern related to dendrite growth during cycling.

In spite of the barriers researchers have faced to date, the potential of a viable $\mathrm{Li}-\mathrm{S}$ battery is too great to ignore. The emergence of new nanomaterials science and its supporting research tools is enabling progress on the open challenge. When designing a battery, there must be a careful consideration of the trade-offs to meet the needs of the given applications. These criteria can vary significantly, and some of the most common crucial metrics for batteries include: (1) Energy content with respect to weight (specific energy, $\mathrm{Wh} / \mathrm{kg}$ ) and volume (energy density, $\mathrm{Wh} / \mathrm{L}$ ). (2) Power content with respect to weight (specific power, W/kg) and volume (power density, W/L). (3) Rechargeable lifetime (number of cycles). (4) Cost $(\$ / \mathrm{kWh})$. (5) Safety (environmental toxicity and response to mechanical and electrical shock). The recent improvements in Li-S batteries are summarized in Chapter 2. 


\section{Chapter 2: State of The Art}

In this chapter, a detailed literature review on sulfur properties, and recent developments in various sulfur cathodes, electrolytes and Li-S cell configurations are summarized.

\subsection{Properties of Sulfur}

\begin{tabular}{|cc|}
\hline \multicolumn{2}{|c|}{ Dynamic viscosity of liquid phase sulfur } \\
\hline $120.0^{\circ} \mathrm{C}$ & 0.017 \\
\hline $140.0^{\circ} \mathrm{C}$ & 0.008 \\
\hline $158.0^{\circ} \mathrm{C}$ & 0.0064 \\
\hline $160.0^{\circ} \mathrm{C}$ & 5.952 \\
\hline $180.0^{\circ} \mathrm{C}$ & 86.304 \\
\hline $187.8^{\circ} \mathrm{C}$ & 93.0 \\
\hline $200.0^{\circ} \mathrm{C}$ & 78.864 \\
\hline $300.0^{\circ} \mathrm{C}$ & 3.72 \\
\hline
\end{tabular}

Table 2-1 Dynamic viscosity of liquid phase sulfur at different temperatures.[49]

The amount of sulfur in the Earth is about 0.05 wt.\%, which is higher than carbon. It ranks about number 16 among the elements in terms of their abundance in the earth. Elemental sulfur could be achieved from mined deposits by the Frasch process or from oil and gas production. Sulfur is in the form of polyatomic molecules with different structures, and rhombic sulfur $(\alpha-\mathrm{S})$ with eight-membered ring $\left(\mathrm{S}_{8}\right)$ is the most stable allotrope at room temperature. Sulfur melts at $115.21^{\circ} \mathrm{C}$, boils at $444.6{ }^{\circ} \mathrm{C}$ and sublimes easily. At $95.2{ }^{\circ} \mathrm{C}$, below its melting temperature, $S_{8}$ changes from $\alpha$-S to $\beta$ polymorph. The structure of the $S_{8}$ ring is virtually unchanged by this phase change, which affects the intermolecular interactions. Between its melting and boiling temperatures, $S_{8}$ changes its allotrope again, turning from $\beta$-S to $\gamma$-S, again accompanied by a lower density but increased viscosity due to the formation of polymers. The dynamic viscosity of liquid sulfur under different temperatures is shown in Table 2-1. It is found that sulfur has the lowest viscosity at $158{ }^{\circ} \mathrm{C}$, above which sulfur has a quick increased viscosity due to the formation of polysulfide species $(\mathrm{S} \mu)$ with large molecular weight $(60,000-150,000)$. Generally, sulfur exists in the form of $S_{8}, S_{7}$, and $S_{6}$ below $400{ }^{\circ} \mathrm{C}$ 
(Figure 2-1). However, in the temperature between $500-800{ }^{\circ} \mathrm{C}$, sulfur mainly existed in the form of $\mathrm{S}_{4}$ and $\mathrm{S}_{2}$ (Figure 2-2).

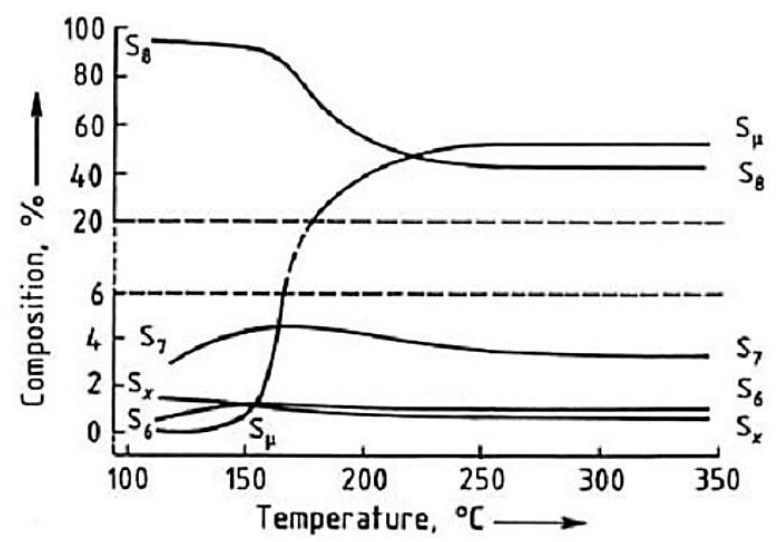

Figure 2-1 Liquid sulfur compositions at different temperatures. [49]

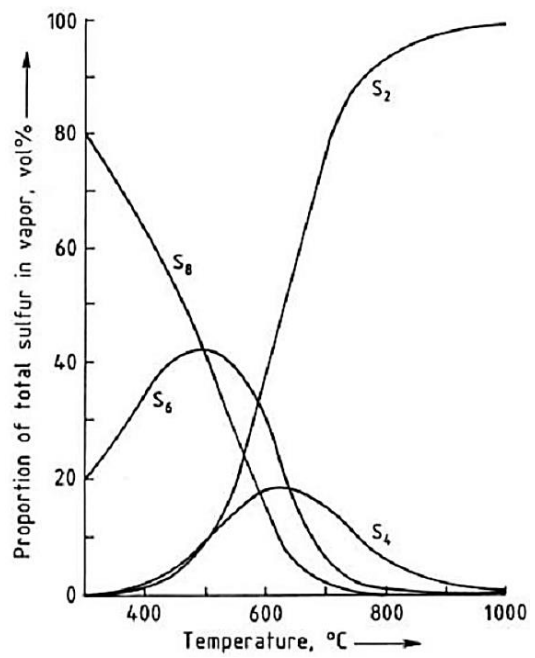

Figure 2-2 Compositions of sulfur vapor molecular at different temperatures. [49]

\subsection{Cathodes for Li-S Batteries}

Since sulfur has a lot of challenges when used as cathode materials, most current studies have focused on the development of sulfur materials or sulfur cathode structures to improve cell performance. [41] Generally, an ideal sulfur electrode should contain four characteristics: (1) sufficient space to accommodate sulfur volumetric expansion; (2) short transport channels for both electrons and Li-ions to achieve high capacity and high power capability; (3) a large conductive surface area for deposition of insulating 
$\mathrm{Li}_{2} \mathrm{~S}_{2} / \mathrm{Li}_{2} \mathrm{~S}$ in order to preserve the morphology of the electrode; (4) effective trapping of polysulfide species through physical and chemical means. In the following sections, we summarize different sulfur cathodes.

\subsubsection{Sulfur-Carbon Composites}

Carbon is widely used as electronic conductor in battery industry, and plays a particularly important role in sulfur electrodes. [57-60] The commonly developed carbon materials include porous carbon, graphene, carbon nanotubes, and carbon nanofibers. Since the role of hollow carbon including spheres and tubes is similar to that of porous carbon, we will not summarize it individually. In addition, carbon black is always used as additional conductive additive because of its superior conductivity, thus we will not introduce it as an individual section. The conventional synthesis procedures for sulfur and carbon composites contain physical mixing, melting route at $159{ }^{\circ} \mathrm{C}$, sulfur chemical bonding at a high temperature $\left(>300{ }^{\circ} \mathrm{C}\right)$, and solution-based deposition. Currently, employing sulfur/carbon composites is the most common and effective way to improve Li-S cell performance. [61] High carbon content improves electrode conductivity but at

the expense of reduced energy density. Some studies showed that the initial state and distribution of sulfur may only influence the first a few cycles since sulfur is converted into long-chain polysulfide species, and then they freely diffuse to their preferred electrochemical locations, where they are thermodynamically stable in the carbon structure. [51] Therefore, the carbon properties are the main factors to impact the cathode performance in Li-S batteries. In the following subsections we will group different carbon sulfur composites and sulfurized carbon composites.

\subsubsection{Porous Carbon and Sulfur Composites}

Porous carbon is frequently used as sulfur matrix owing to their absorbability of soluble polysulfide species. [56, 62-75] Peled et al. first described the concept of loading sulfur into the porous structure of carbon materials to establish more efficient electronic contact and to improve volumetric energy density of Li-S battery. [75] Generally, micropores $(\mathrm{d}<2 \mathrm{~nm})$ were demonstrated as the ideal container for accommodating soluble polysulfide species due to the small size. While the meso-pores $(2 \mathrm{~nm}<\mathrm{d}<50 \mathrm{~nm})$ could 
promote Li-ion transport by providing abundant channels for the electrolyte at the cathode structure. However, they are less efficient than micro-pores to trap soluble polysulfide species since the size of polysulfide ions is closer to that of micro-pores. The electronic contact of sulfur encapsulated in the macro-pores $(\mathrm{d}>50 \mathrm{~nm})$ is quite limited, which results in considerable polarization. When sulfur mass is large, incomplete discharge occurs with sulfur remaining within the core of the particles, particularly at high power output. The size of meso-pores in the carbon does not have a great effect on the cyclability of Li-S cells when the meso-pores are fully-filled.[76] However, partiallyfilled sulfur-mesoporous carbon composites are better than fully-filled composite cathodes due to the intimate contact between sulfur and the partially-filled carbon, which enhances electronic and ionic transport. Nazar et al. reported a mesoporous CMK3/sulfur composite that comprised high pore volume carbons with $3 \mathrm{D}$-accessible channel nanostructures.[64] Sulfur is readily incorporated from the melt by capillary forces. The residual pore volume in the composite is designed to retain pathways for electrolyte/ $\mathrm{Li}^{+}$ ingress and to accommodate the active mass volume expansion during cycling. The semiamorphous and microporous morphology of the wall structure of CMK-3 carbon is also conductive to Li-ion transport. The conductive carbon framework constrains the sulfur within its channels and generates essential electrical contact as shown schematically in Figure 2-3.

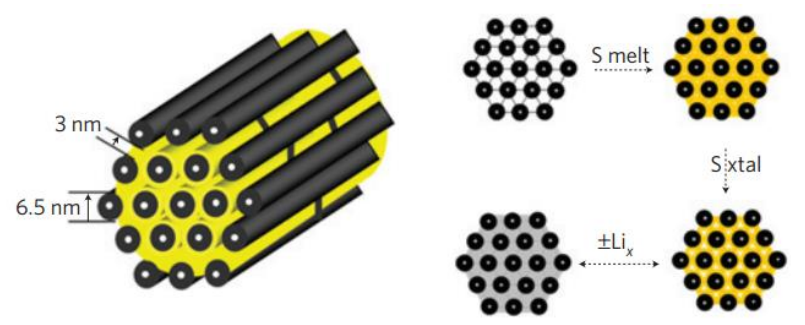

Figure 2-3 Schematic of the sulfur confined in the interconnected pore structure of mesoporous carbon, CMK-3 [64].

\subsubsection{Carbon Nanotube and Sulfur Composites}

Carbon nanotube (CNT) materials are widely used as sulfur carriers because of their superior mechanical strength and electrical conductivity. [77-80] In addition, CNTs have tunable chemical characters including formation of oxygen-containing groups on surfaces 
and changes in nanotube structures and thermal stability; these chemical characters may enhance reactivity of aromatic carbon rings for sulfur immobilization. [81-83] Some network structures built from CNTs are able to suppress the polysulfide shuttle due to their high absorbability. [84, 85] Pore structures can also be introduced in CNTs via various synthesis methods to obtain improved cycle performance. [86, 87]

However, multi-walled CNT sulfur networks have obvious limitations. [88] First, the surface area and pore volume of CNTs are typically less than $350 \mathrm{~m}^{2} \mathrm{~g}^{-1}$ and $0.5 \mathrm{~cm}^{3}$ $\mathrm{g}^{-1}$, respectively, which limit their capacity to accommodate the sulfur active materials. [27] Moreover, the tubes are unfavorable for Li ion transport since ion mobility can only take place along the long CNT axis, and not perpendicular to it.

\subsubsection{Graphene and Sulfur Composites}

Graphene, a two-dimensional (2D) carbon monolayer that can be extracted from graphite, is regarded as an ultra-light, thin, and hard material with high conductivity. [58, $89,90]$ The flexible characteristic of graphene renders it suitable to be the sulfur carrier in Li-S batteries. Graphene in composite coatings or wrap in sulfur can suppress the loss of active sulfur species due to dissolution during cycling. [86, 91-96] The high electrical conductivity of graphene can improve the active material utilization as well. Ji et al. applied graphene oxide as the carbon source, and both epoxy and hydroxyl groups could assist in immobilizing the active material during discharge/charge.

\subsubsection{Sulfurized Carbon Composites}

Besides sulfur and carbon composites, sulfurized carbon materials are often seen in the literature to be used for sulfur cathodes. As mentioned in Chapter 1, all of the problems of Li-S batteries are related to the dissolution of lithium polysulfide species, a series of sulfur reduction intermediates, in the liquid electrolyte, and resulting parasitic reactions with the $\mathrm{Li}$ anode. In order to prevent the dissolution of polysulfide species, sulfurized carbons (SCs) have been intensively investigated due to their ability to chemically trap polysulfide species thereby potentially reducing the dissolution of 
polysulfide species as well as the parasitic reactions with Li-anodes. Zhang summarized the recent development of SC cathode materials. [40]

Commonly, SCs are synthesized at high temperatures $\left(>500{ }^{\circ} \mathrm{C}\right)$ by reacting carbon with sulfur. During the reaction, $S_{8}$ may decompose into small sulfur allotropes (i.e., $S_{2}$, $\mathrm{S}_{4}$, and $\mathrm{S}_{6}$ ) which can bond with carbon atoms via reacting with surface functional groups on carbon surfaces. To enhance the binding of sulfur to C-C bond, surface functionalization is a facile route to be conducted for polymer substrates. The functional groups work as a medium for the intimate connection between the soluble polysulfide intermediates and carbon surface. It was reported that carboxyl, hydroxyl, and epoxy are favorable functional groups to enhance the cyclability of Li-S cells. Researchers have studied various carbon or polymer materials that containing surface functional groups such as $-\mathrm{OH},>\mathrm{C}=\mathrm{O},-\mathrm{C}(=\mathrm{O}) \mathrm{OH}$, and $>\mathrm{C}=\mathrm{C}<$, which have shown some progress in binding sulfur on the surfaces of carbon during heat treatments. [76, 97-99] Indeed, SCs have been shown to reduce the adverse effects of polysulfide dissolution, but at the same time, have caused several concerns including: (i) the low sulfur content (e.g. $<50$ wt.\%) due to high-temperature treatments (e.g. $>500{ }^{\circ} \mathrm{C}$ ), which reduces the energy density of Li-S batteries. The significant use of conductive agents may also neutralize the high energy density of Li-S batteries. (ii) Long sulfur chains $\left(-\mathrm{S}_{\mathrm{x}^{-}}, \mathrm{x}>4\right)$ bonded on carbon have led to high capacities but inferior cycling stability, since they can rearrange to release elemental sulfur and form soluble polysulfide species during cell operations, whereas short sulfur chains $\left(-S_{x^{-}}, x \leq 4\right)$ may result in low capacity but good capacity retention. [40] Therefore, it is important to develop proper sulfurization technology of SC cathodes to enhance sulfur immobilization and utilization in Li-S batteries. Tables 2-2 and 2-3 summarize recent developments in SC cathodes used in Li-S batteries. [40] 


\begin{tabular}{|c|c|c|}
\hline Electrolyte & SPAN composition & Main results \\
\hline $\begin{array}{l}\text { Liquid, } 1 \mathrm{MLiPF}_{6} \\
\text { 1:1:1 EC-DMC-EMC }\end{array}$ & $\begin{array}{l}\text { SPAN made at } 350^{\circ} \mathrm{C} \text { with sulfur } \\
\mathrm{S}=42 \%\end{array}$ & $\begin{array}{l}795 \mathrm{mAhg}^{-1} \text { at } 50^{\text {th }} \text { cycle, } 1.0-3.0 \\
\text { V at } 100 \mathrm{~mA} / \mathrm{g}\end{array}$ \\
\hline $\begin{array}{l}\text { Liquid, } 1 \mathrm{MLiPF}_{6} \\
\text { 2:1:1 EC-DMC-EMC }\end{array}$ & $\begin{array}{l}\text { SPAN made at } 550^{\circ} \mathrm{C} \text { with sulfur } \\
\mathrm{S}=44 \%\end{array}$ & $\begin{array}{l}440 \mathrm{mAhg}^{-1} \text { at } 40^{\text {th }} \text { cycle, } 1.0-3.0 \\
\text { V at } 0.1 \mathrm{C}^{-1}\end{array}$ \\
\hline $\begin{array}{l}\text { Gel polymer, } \mathrm{SiO}_{2}- \\
\mathrm{P} \text { (VDF-HFP) }\end{array}$ & $\begin{array}{l}\text { SPAN made at } 280-300^{\circ} \mathrm{C} \text { with } \\
\text { sulfur } \mathrm{S}=53.4 \%\end{array}$ & $\begin{array}{l}\text { Above } 600 \mathrm{mAhg}^{-1} \text { after } 50^{\text {th }} \\
\text { cycles, } 1.0-3.0 \mathrm{~V} \text { at } 0.3 \mathrm{~mA} / \mathrm{cm}^{2}\end{array}$ \\
\hline $\begin{array}{l}\text { Gel polymer, } \mathrm{SiO}_{2}- \\
\text { P(VDF-HFP) }\end{array}$ & $\begin{array}{l}\text { SPAN made at } 280-300^{\circ} \mathrm{C} \text { with } \\
\text { sulfur } \mathrm{S}=53.4 \%\end{array}$ & $\begin{array}{l}\sim 620 \mathrm{mAhg}^{-1} \text { at } 70^{\text {th }} \text { cycle, } 1.0-3.0 \\
\mathrm{~V} \text { at } 0.25 \mathrm{~mA} / \mathrm{cm}^{2}\end{array}$ \\
\hline $\begin{array}{l}\text { Quasi solid, TEGDME- } \\
\text { LiTFSI-SiO }_{2}\end{array}$ & SPAN made at $450^{\circ} \mathrm{C}$ & $\begin{array}{l}390 \mathrm{mAhg}^{-1} \text { at } 50^{\text {th }} \text { cycle, } 1.3-3.0 \\
\text { V at } 0.1 \mathrm{C}\end{array}$ \\
\hline
\end{tabular}

Table 2-2 Cycling performance of Li/SPAN batteries with different type of electrolyte. [40]

\begin{tabular}{|c|c|c|}
\hline Carbontype & Sulfurize condition & Main results \\
\hline $\begin{array}{l}\text { Carbon spheres made by } \mathrm{H}_{2} \mathrm{SO}_{4} \text { - assisted } \\
\text { dehydration of sucrose at } 120^{\circ} \mathrm{C} \text { for } 10 \mathrm{~h} \text {, } \\
\text { followed by heating at } 1000^{\circ} \mathrm{C} \text { for } 2 \mathrm{~h}\end{array}$ & $\begin{array}{l}149^{\circ} \mathrm{C} \text { for } 6 \mathrm{~h} \text {, plus } 300^{\circ} \mathrm{C} \\
\text { for } 2 \mathrm{~h} . \mathrm{S}=42 \%\end{array}$ & $\begin{array}{l}\sim 800 \mathrm{mAhg}^{-1}-\mathrm{S} \text { or } 336 \\
\mathrm{mAhg}^{-1}-\mathrm{SC} \text { without } \\
\text { fading up to } 100 \text { cycles, } \\
1.0-3.0 \mathrm{~V} \text { at } 400 \mathrm{~mA} / \mathrm{g}\end{array}$ \\
\hline $\begin{array}{l}\text { Carbon fiber coated with microporous } \\
\text { carbon spheres made by } \mathrm{H}_{2} \mathrm{SO}_{4} \text {-assisted } \\
\text { dehydration of sucrose at } 120^{\circ} \mathrm{C} \text { for } 12 \mathrm{~h} \\
\text { and then heating at } 1000^{\circ} \mathrm{C} \text { for } 2 \mathrm{~h}\end{array}$ & $400^{\circ} \mathrm{C}$ for $6 \mathrm{~h}, \mathrm{~S}=44 \%$ & $\begin{array}{l}720 \mathrm{mAhg}^{-1}-\mathrm{S} \text { or } 288 \\
\mathrm{mAhg}-1-\mathrm{SC} \text { at } 100 \text { th } \\
\text { cycle, } 1.0-3.0 \mathrm{~V} \text { at } 100 \\
\mathrm{~mA} / \mathrm{g} .\end{array}$ \\
\hline $\begin{array}{l}\text { Carbon made by } \mathrm{Ni}(\mathrm{OH})_{2} \text {-assisted } \\
\text { pyrolysis of phenolic resin at } 600^{\circ} \mathrm{C} \text { for } 4 \\
\mathrm{~h}\end{array}$ & $\begin{array}{l}155^{\circ} \mathrm{C} \text { for } 12 \mathrm{~h}, \mathrm{~S}=43 \% \text { and } \\
16 \% \text {, respectively, before } \\
\text { and after } \mathrm{CS}_{2} \text { extraction }\end{array}$ & $\begin{array}{l}\sim 900 \mathrm{mAhg}^{-1}-\mathrm{S} \text { or } 387 \\
\mathrm{mAhg}-1-\mathrm{SC}^{2} 50 \text { th cycle, } \\
1.5-2.8 \mathrm{~V} \text { at } 150 \mathrm{~mA} / \mathrm{g}\end{array}$ \\
\hline $\begin{array}{l}\text { Multiwalled carbon nanotubes coated } \\
\text { with microporous carbon by pyrolysis of } \\
\text { glucose at } 190^{\circ} \mathrm{C} \text { for } 15 \mathrm{~h} \text { and then } 800^{\circ} \mathrm{C} \\
\text { for } 2 \mathrm{~h}\end{array}$ & $\begin{array}{l}155^{\circ} \mathrm{C} \text { to impregnate sulfur } \\
\text { and then } 115^{\circ} \mathrm{C} \text { for } 20 \mathrm{~h}, \\
\mathrm{~S}=40 \%\end{array}$ & $\begin{array}{l}1142 \mathrm{mAhg}^{-1}-\mathrm{S} \text { or } 457 \\
\text { mAhg }{ }^{-1}-\mathrm{SC} \text { at } 200 \text { th } \\
\text { cycle, } 1.0-3.0 \mathrm{~V} \text { at } 0.1 \mathrm{C}\end{array}$ \\
\hline $\begin{array}{l}\text { Polyyne made by KOH-assisted } \\
\text { dehydrochlorination of PVC in THF } \\
\text { solution for } 2 \mathrm{~h}\end{array}$ & $350^{\circ} \mathrm{C}$ for $3 \mathrm{~h}, \mathrm{~S}=54.1 \%$ & $\begin{array}{l}960 \mathrm{mAhg}^{-1}-\mathrm{S} \text { or } 519 \\
\mathrm{mAhg}^{-1}-\mathrm{SC} \text { at } 200^{\text {th }} \\
\text { cycle, } 1.0-3.0 \mathrm{~V} \text { at } 1 \mathrm{C}\end{array}$ \\
\hline
\end{tabular}

Table 2-3 Preparation condition of carbon and SC and cycling performance. [40]

\subsubsection{Sulfur and Polymer Composites}


Besides carbons, polymers including conductive polymers and non-conductive polymers are often used in sulfur electrodes. [100] Conductive polymers such as polyaniline, and polythiophene, may facilitate electron transport and improve sulfur utilization. [101-106] In addition, coating a layer of polymer is also adopted, which may act as a barrier to retard the polysulfide dissolution in electrolyte. [107, 108] Nonconductive polymers, such as polyacrylonitrile and polyethylene glycol, were employed to offer a chemical binding to suppress the migration and diffusion of long-chain polysulfide species. [92, 109-112] In our group, we used polyaniline and multi-walled CNT to fabricate a multilayered sulfur electrode with a layer-by-layer technique. [113] In general, polymers in Li-S cells play a protective role to reduce the capacity fade by retaining the soluble polysulfide species at the cathode region, whereas a certain amount of carbon additives is still critical to enhance the sulfur utilization and cyclability.

\subsubsection{Sulfur and Metal (Oxide) Composites}

Serving as absorbing agents, various nanosized metal oxides have been used as additives in sulfur electrode, such as nickel, alumina, silica, and titanium oxides. [67, 96, 114-119] The redox potential of the material must not overlap that of sulfur (1.5-2.8 V vs. $\left.\mathrm{Li}^{+} / \mathrm{Li}^{0}\right)$ to prevent unwanted electrochemical reactions and structural change from the additives. Nazar et al. reported a strategy to trap polysulfides in the cathode that relied on a chemical process, whereby a host-manganese dioxide nanosheets served as the prototype-reacts with initially formed lithium polysulfides to form surface-bound intermediates (Figure 2-4). [117] These function as a redox shuttle to catenate and bind higher polysulfides and convert them on reduction to insoluble lithium sulfide via disproportionation. The sulfur/manganese dioxide nanosheet composite with 75 wt.\% sulfur exhibited a reversible capacity of $1300 \mathrm{~mA} \mathrm{~h} \mathrm{~g}^{-1}$ at moderate rates and a fade rate over 2,000 cycles of $0.036 \%$ per cycle.

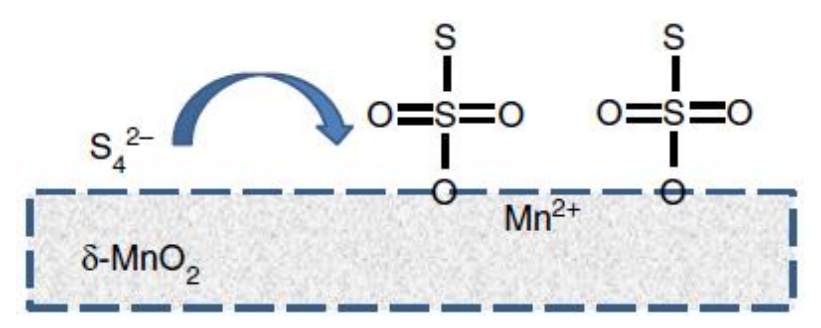


Figure 2-4 Schematic showing the oxidation of initially formed polysulfide by $\mathrm{d}-\mathrm{MnO}_{2}$ to form thiosulfate on the surface, concomitant with the reduction of $\mathrm{Mn}^{4+}$ to $\mathrm{Mn}^{2+}$ [117].

Cui et al. designed a $\mathrm{TiO}_{2}$-sulfur yolk-shell composite that exhibited prolonged cyclability over 1000 cycles, showing that metal oxides might replace a portion of carbon to trap polysulfides, although the sulfur loading needs to be further increased for practical use. [116] The schematic of the synthetic process that involves coating of sulfur nanoparticles with $\mathrm{TiO}_{2}$ to form sulfur- $\mathrm{TiO}_{2}$ core-shell nanostructures, followed by partial dissolution of sulfur in toluene to achieve the yolk-shell morphology is shown in Figure 2-5a. The idea of the yolk-shell structure is to avoid the fracture of the $\mathrm{TiO}_{2}$ spheres during volume expansion of the active material, which could lead to serious leakage of polysulfides. Extra void or pore space remained in the cathode structure is desirable not only to retain the dissolved polysulfides but also cushion the volume change during discharge/charge.

(a)

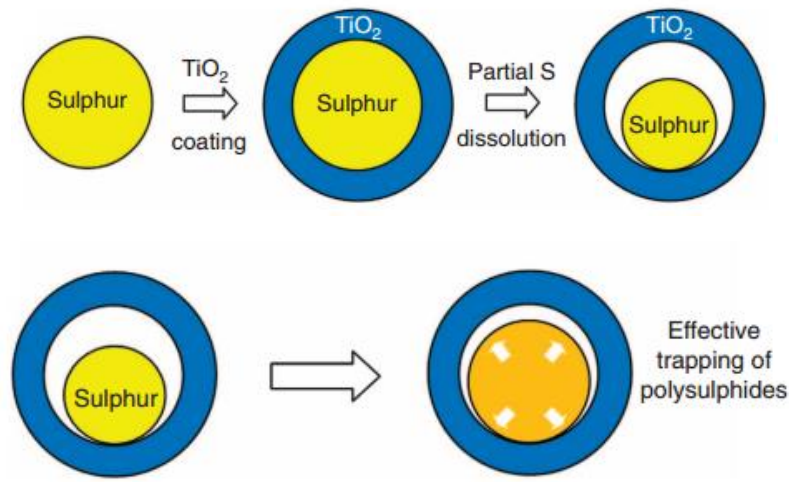

Figure 2-5 (a) Schematic of the synthetic process to sulfur- $\mathrm{TiO}_{2}$ core-shell nanostructures. (b) Internal void space to accommodate the volume expansion of sulfur during lithiation [116].

\subsection{4 $\mathrm{Li}_{2} \mathrm{~S}$ and Lithium Polysulfide Species as Cathode Materials}

Although there are several advantages to use Li-S system as energy storage devices, employing highly active lithium metal as anode still brings safety concerns. [120, 121] In this regard, one way is to use $\mathrm{Li}_{2} \mathrm{~S}$ as the starting cathode material which has a theoretical capacity of $1166 \mathrm{~mA} \mathrm{~h} \mathrm{~g}^{-1}$. When the cathode is lithiated, other lithium-free high energy anodes (e.g., silicon) could be used to substitute lithium metal anode.[122] Recent studies show that $\mathrm{Li}_{2} \mathrm{~S}$ can be reversible in electrochemical reactions. [123-129] Wu et al. 
discovered that large energy barrier and over-potential were found when charging the $\mathrm{Li}_{2} \mathrm{~S}$ cathode because of the sluggish oxidation of solid-state bulk $\mathrm{Li}_{2} \mathrm{~S}$. [123] The charge transfer between $\mathrm{Li}_{2} \mathrm{~S}$ and the electrolyte and lithium-ion diffusion in $\mathrm{Li}_{2} \mathrm{~S}$ are kinetically slow. Uniform $\mathrm{Li}_{2} \mathrm{~S}$ distribution can be obtained by bonding lithium and nitrile groups in PAN. $\mathrm{Si} / \mathrm{Li}_{2} \mathrm{~S}$ and $\mathrm{Sn} / \mathrm{Li}_{2} \mathrm{~S}$ systems were demonstrated as full cells without any lithium metal anodes. Moreover, high active material utilization was achieved with a design of $\mathrm{Li}_{2} \mathrm{~S} / \mathrm{CNTs}$ sandwiched structure, showing the potential of $\mathrm{Li}_{2} \mathrm{~S}$ for practical applications.

\subsubsection{Binder-Free Sulfur Cathodes}

The traditional sulfur cathode preparation method is a slurry-casting procedure, in which polymer binders like polyvinylidene fluoride (PVDF) are added to stick sulfur and carbon network onto aluminum substrate. The addition of binders increases the cell weight and reduces the electrode conductivity. In addition, binder-free composites can eliminate the use of toxic N-Methyl-Pyrrolidone (NMP) solvent during regular electrode fabrication in Li-ion battery industry. Two major means are carried out to synthesize binder-free cathodes. One is employing a rigid carbon substrate that comprises pore structure. [124] The carbon substrate is then co-heated with sulfur to make the sulfur melt infiltrate into the pores to form the composite. In addition, polysulfide catholytes can be pre-deposited into the film before vacuum filtration. Another way is to fabricate the cathode with a new method, like layer-by-layer, electrophoretic deposition (EPD) techniques. [50]

\subsection{Electrolyte for Li-S Batteries}

Electrolyte plays a critical role to influence the battery performance. [130] In this part, we discuss the commonly used liquid electrolytes and non-liquid electrolytes like gel polymers and solid-state electrolytes.

\subsubsection{Liquid-Type Electrolytes}

Liquid electrolyte plays a key role in commercial lithium batteries to allow conduction of lithium-ion between cathode and anode.[16] For Li-S systems, in addition 
to the polysulfide dissolution problem at the cathode, other research suggested that the side reactions between the migrated polysulfide species and the Li-metal on the Li-anode also damaged long-term cell performance due to the formation of lithium dendrites, which were caused by uneven current distributions at the metal-electrolyte interface during cycling. [131] The uncontrolled inevitable dendrite formation and the continuous evolution of a porous Li metal structure might cause serious safety issues and lower cell efficiency. These side reactions may repeatedly expose new lithium surface area that further react with the electrolyte to form unstable solid-state electrolyte interface (SEI) layers, thus increasing internal cell resistance and accelerating capacity fade. [120]

The mainstream Li-S battery research mostly adopts low viscosity ethers such as 1 , 3-dioxolane (DOL) and 1, 2-dimethoxy ethane (DME) as the electrolyte solvents. [132] DME possesses higher polysulfide solubility than DOL, but DME is reactive with lithium metal anode. DOL can help the anode surface to form a SEI. Employing only one of the solvents alone results poor cycle performance. By mixing two solvents together, synergistic benefit may be obtained on active material utilization and cyclability of Li-S batteries. $\mathrm{LiCF}_{3} \mathrm{SO}_{3}, \mathrm{LiN}\left(\mathrm{CF}_{3} \mathrm{SO}_{2}\right)_{2}$, and LITFSI are common lithium salts added into the organic solvent to prepare electrolytes for Li-S cells. These three salts only have slight impact on the battery performance. [132] Other conventional salts like $\mathrm{LiPF}_{6}$ and $\mathrm{LiBF}_{4}$ are inappropriate because they react with lithium polysulfide species and induce ringopening polymerization of DOL solvent. Sion Power found that $\mathrm{LiNO}_{3}$, used as an electrolyte additive, helped to minimize complicated deleterious reactions between polysulfide species and Li metal, resulting in improved cell life. However, gradual consumption of additives on the electrodes led to a decrease in the protection efficiency. [133]

\subsubsection{None-Liquid Type Electrolytes}

Solid state electrolytes or ionic liquid electrolytes are also used in rechargeable batteries. Replacing flammable liquid electrolytes with solid polymers or inorganic electrolytes could bring some interesting perspective to address the Li-anode unstable

problem in Li-ion battery or polysulfide dissolution related issues in Li-S batteries. [72, 
134-137] Soluble polysulfide species are difficult to migrate in high-viscosity gel electrolytes and solid-state electrolytes, which decreases loss of sulfur and shuttle effect.[131] Various glass ceramics are used as the solid-state electrolytes, such as $\mathrm{Li}_{2} \mathrm{~S}$ $\mathrm{P}_{2} \mathrm{~S}_{5}$ and $\mathrm{Li}_{2} \mathrm{~S}-\mathrm{GeS}_{2}-\mathrm{P}_{2} \mathrm{~S}_{5}$ glass compounds.[138-140] These electrolytes make all-soldstate Li-S battery possible, but the kinetic properties are limited, due to both low conductivity at room temperature and high interfacial resistance. Recently, Suo et. al designed a new class of 'Solvent-in-Salt' electrolyte with ultrahigh salt concentration and high lithium-ion transference number (0.73), in which salt holds a dominant position in the lithium-ion transport system. [131] It remarkably enhanced the cyclic and safety performance of next-generation high-energy rechargeable lithium batteries via an effective suppression of lithium dendrite growth and shape change in the metallic Lianode. However, this electrolyte with such high salt concentration had an inferior rate capability, which led to a decrease in power density of Li-S batteries.

\subsection{Anodes for Li-S Batteries}

With the significant progress that has been made toward the development of cathode materials and electrolytes in $\mathrm{Li}-\mathrm{S}$ batteries in recent years, the stability of $\mathrm{Li}$-anode in $\mathrm{Li}$ $\mathrm{S}$ batteries has become one of the more urgent challenges in order to reach long-term stability of Li-S batteries. Compared to cathodes and electrolytes, less attention has been paid to the modification of Li-metal anodes. In Li-S batteries, a passivation layer may be easily formed on the metallic $\mathrm{Li}$ anode surface because of the presence of polysulfide species and electrolyte additives. Recently, Zhang et. al. summarized the improvements on Li-anodes for Li-S batteries.[141] Most reported literature have focused on the mitigation of side reactions between polysulfide species and the Li-anode by adopting protection layers.[120, 142, 143] For Li-S battery, where Li metal is coupled with sulfur cathode, the deposition and reduction of insoluble $\mathrm{Li}_{2} \mathrm{~S}_{2} / \mathrm{Li}_{2} \mathrm{~S}$ species on $\mathrm{Li}$-anode surface partially mitigate the dendrite growth problem. However, the problem of continuous $\mathrm{Li}$ erosion still exists and is compounded with the presence of dissolved polysulfide species that also get involved in the continuous SEI formation.[144]

\subsection{Objectives of This Dissertation}


As aforementioned in the first two chapters, the battery industry is both vast and diverse, with countless battery chemistries being employed across myriad applications. Among these batteries, Li-S battery has received growing interest in recent decades due to its high energy density and low cost of raw sulfur materials. However, Li-S battery suffers great problems because of the intrinsic limitations of sulfur chemistry. To mitigate these limitations, the traditional strategy for sulfur composite synthesis was a complex, expensive and time-intensive process. More importantly, most research focused on developing low sulfur-loading cathodes $\left(<2 \mathrm{mg} \mathrm{cm}^{-2}\right)$, and less attention was paid on commercialization requirements $\left(>3 \mathrm{mg} \mathrm{cm}^{-2}\right.$ ) of Li-S batteries. In response to the recent renewed interest in Li-S batteries and the challenges involved in achieving a successful product, we started on several innovative designs for Li-S batteries. The primary objective of this dissertation is to solve the issues persistently remaining with $\mathrm{Li}-\mathrm{S}$ batteries and then focus on high sulfur loading battery designs. The most critical challenge is the polysulfide dissolution/migration during cycling, and low conductivities of sulfur and sulfides. Here we demonstrate the enhanced electrochemical performance of Li-S batteries via (1) developing new sulfur composite cathodes (i.e. sulfurized carbon nanotube and sulfurized polyaniline) based on in situ chemical synthesis method; (2) creating innovative nano-structured sulfur composite cathode using layer-by-layer nanoassembly technology. Then considering the commercialization requirements of $\mathrm{Li}-\mathrm{S}$ batteries, we design high sulfur-loading batteries based on carbon paper electrodes with open structures. 


\section{Chapter 3: Sulfur Cathode Materials Development: Sulfurized Carbon Nanotubes}

Li-S battery chemistry is very complicated. In response to the challenges involved in achieving a successful Li-S battery product, we started on synthesizing innovative materials to solve the issues persistently remaining with Li-S batteries. As mentioned in Chapters 1 and 2, the most critical challenge is the polysulfide dissolution/migration during cycling, and low conductivities of sulfur and the final discharge products $\left(\mathrm{Li}_{2} \mathrm{~S}_{2} / \mathrm{Li}_{2} \mathrm{~S}\right)$. Sulfur and carbon composites have been used to enhance the conductivity and stability of sulfur cathodes. However, the physical barriers provided by adsorption in carbon materials can only slow down sulfur loss in a short term owing to the weak interactions between nonpolar carbon and highly polar polysulfide species. Theoretically, the sulfur and carbon composites cannot prevent the dissolution of long-chain polysulfide species. Instead, they can trap to some degree the dissolved polysulfide species within the carbon pores before the polysulfides being reduced to insoluble products $\left(\mathrm{Li}_{2} \mathrm{~S}_{2} / \mathrm{Li}_{2} \mathrm{~S}\right)$. Indeed, migration of ionic polysulfide species is hard to be completely prevented by physical adsorption in carbon since it is driven by electrical field in the electrolyte. In this case, the parasitic reactions between the dissolved polysulfide species and solvents still remain and more importantly, large amounts of carbon must be incorporated into the battery, which significantly reduces energy density of the battery.

A complete solution to the dissolution of polysulfide species is to chemically bind sulfur species onto a polymer backbone or carbon surface. This can be achieved by using sulfurized carbon (SC) as the cathode material of Li-S batteries. Due to the substantial insolubility of $\mathrm{SC}$ and $\mathrm{Li}_{2} \mathrm{~S}$ in organic electrolytes, the $\mathrm{SC}$ is discharged and charged entirely through a solid-to-solid phase transition from the $\mathrm{SC}$ to $\mathrm{Li}_{2} \mathrm{~S}$ phase. In discharge, the $\mathrm{SC}$ is directly reduced to $\mathrm{Li}_{2} \mathrm{~S}$ on the surface of conducting carbon. In charge, the

carbanion linking to a conjugated $\mathrm{sp}^{2}$ carbon and the C-S anion linking to a nonconjugated $\mathrm{sp}^{3}$ carbon preferentially lose an electron to form an anionic radical, onto which sulfur is grafted and grown. Indeed, SCs have been shown to reduce the adverse effects of polysulfide dissolution, but at the same time, have caused several concerns 
including: (i) the low sulfur content (e.g. $<50$ wt.\%) due to by high-temperature treatments (e.g. $>500{ }^{\circ} \mathrm{C}$ ), has reduced the energy density of Li-S batteries; (ii) $\mathrm{Li}_{2} \mathrm{~S}$ has the possibility to form long-chain polysulfide species on the surface of the conductive carbon, which is affected by the nature of electrolyte solvents and the charge rate. Therefore, it is important to develop proper sulfurization technology of SC cathodes to enhance sulfur immobilization and utilization in Li-S batteries.

To develop novel SC materials with high sulfur contents and proper sulfur chains, we tried two methods via: (1) at a low temperature (i.e. $300{ }^{\circ} \mathrm{C}$ ) and (2) in situ chemical vulcanization. Based on this idea, sulfurized carbon nanotubes (SCNT) and sulfurized polyaniline (SPANI) were synthesized as cathode materials in this dissertation. The value of these two materials are that they have led to long cycle lifetime in comparison with most of other reports, and at the same time, maintained a high capacity retention. In this chapter, we will focus on SCNT and its application in Li-S battery. In next chapter, we will discuss SPANI as a cathode material in Li-S batteries.

\subsection{Introduction}

As a promising cathode material, SC has been intensively investigated due to their ability to chemically trap polysulfide species thereby may potentially reduce the dissolution of polysulfides as well as the parasitic reactions with Li-anode.[40] Commonly, SCs are synthesized at high temperatures $\left(>500{ }^{\circ} \mathrm{C}\right)$ by reacting carbon with sulfur. During the reaction, $\mathrm{S}_{8}$ may decompose into small sulfur allotropes (i.e., $\mathrm{S}_{2}, \mathrm{~S}_{4}$, and $\mathrm{S}_{6}$ ), which can bond with carbon atoms via reacting with surface functional groups on carbon surfaces. Researchers have studied various carbon or polymer materials that containing surface functional groups such as $-\mathrm{OH},>\mathrm{C}=\mathrm{O},-\mathrm{C}(=\mathrm{O}) \mathrm{OH}$, and $>\mathrm{C}=\mathrm{C}<$, which have shown some progress in binding sulfur on carbon surface during the heat treatments. Indeed, SCs have been shown to reduce the adverse effects of polysulfide dissolution, but at the same time, have caused several concerns talked previously. Therefore, it is important to develop proper sulfurization technology of SC cathodes to enhance sulfur immobilization and utilization in Li-S batteries. 
Here, we report long-life and high-efficiency Li-S cell comprised of SCNT cathode. We developed a new strategy to fabricate SCNT materials with a high sulfur content (68 wt.\%) under a relatively low temperature of $300^{\circ} \mathrm{C}$, by functionalizing CNTs and using a solvent exchange method to graft sulfur chains onto CNTs. CNT was chosen as a sulfur carrier, because it is composed of hybridized $\mathrm{sp}^{2}$ carbon that could form electrochemically active C-S bonds. [88] CNT also has superior mechanical strength and electrical conductivity. [80] In addition, CNT has tunable chemical characters including formation of oxygen-containing groups on surfaces and changes in nanotube structures and thermal stability; these chemical characters may enhance reactivity of aromatic carbon rings for sulfur immobilization via forming covalent bonds (e.g., O-S bonds) or holding sulfur in nanopores of CNTs. [87] As a result, Li-S battery comprised of SCNT cathode exhibited an ultralong cycle life (exceeding 1300 cycles at $1 / 3 \mathrm{C}$ ) with an ultrahigh capacity retention (67.8\% from 809 to $549 \mathrm{~mA} \mathrm{~h} \mathrm{~g} \mathrm{~g}^{-1}$ over 1300 cycles). Moreover, these Li-S cells had an excellent high-rate response up to $2 \mathrm{C}$, and their Coulombic efficiency was higher than $95.5 \%$.

\subsection{Experimental}

\subsubsection{In Situ Sulfur Deposition Synthesis of SCNT Composites}

Our strategy for the preparation of SCNT materials with a high sulfur content involved CNT surface treatment and solvent exchange methods. The typical fabrication process of the SCNT materials is shown in Figures 3-1a and 3-1b. First, Multi-walled carbon nanotubes (CNTs, 10 50 $\mathrm{nm}$ in diameter and 5 9 $\mu \mathrm{m}$ in length, Sigma-Aldrich, St. Louis, MO) were soaked in nitric acid (70 wt.\%) and sulfuric acid (98 wt.\%) (v 1:3) in an ultrasonic container for $1 \mathrm{~h}$, kept in an oven of $70{ }^{\circ} \mathrm{C}$ for $2 \mathrm{~h}$, and then rinsed with distilled water to obtain the treated CNTs. In this step, the amorphous carbon was removed from CNTs and oxygen-containing groups were formed on CNT surfaces. Second, elemental sulfur was dissolved into carbon disulfide solution $\left(\mathrm{CS}_{2}\right.$, SigmaAldrich) for $1 \mathrm{~h}$ to reach saturation. Meanwhile, the treated CNTs in the first step were immersed in hydrogen peroxide $\left(\mathrm{H}_{2} \mathrm{O}_{2}\right.$, Sigma-Aldrich) solution for $1 \mathrm{~h}$ to obtain the functionalized CNTs. Third, the prepared sulfur in $\mathrm{CS}_{2}$ suspension were added dropwise to the CNTs in $\mathrm{H}_{2} \mathrm{O}_{2}$ solution (with $\mathrm{pH}=7$, adjusted by $\mathrm{LiOH}$ ) at a slow rate of $2 \mathrm{ml}$ per 
minute. Next, the mixture was stirred under magnetic at $50{ }^{\circ} \mathrm{C}$ in a sealed glass box for 2 h. During such a process, $\mathrm{CS}_{2}$ quickly reacted with $\mathrm{H}_{2} \mathrm{O}_{2}$ and formed colloidal sulfur. ${ }^{28}$ Then, the solution was evaporated at $50{ }^{\circ} \mathrm{C}$ in a fume hood for $1.5 \mathrm{~h}$ to obtain the pristine SCNTs. Last, the samples were treated at $300{ }^{\circ} \mathrm{C}$ in a vacuum oven for $5 \mathrm{~h}$, and designated as SCNT-300. Two types of control samples were prepared: (i) SCNT-159, obtained by heating the pristine SCNTs in a vacuum oven at $159{ }^{\circ} \mathrm{C}$ for $10 \mathrm{~h}$; (ii) S/CNT159, fabricated by mixing sulfur and functionalized CNTs together and heating the mixture in a vacuum oven at $159^{\circ} \mathrm{C}$ for $10 \mathrm{~h}$.

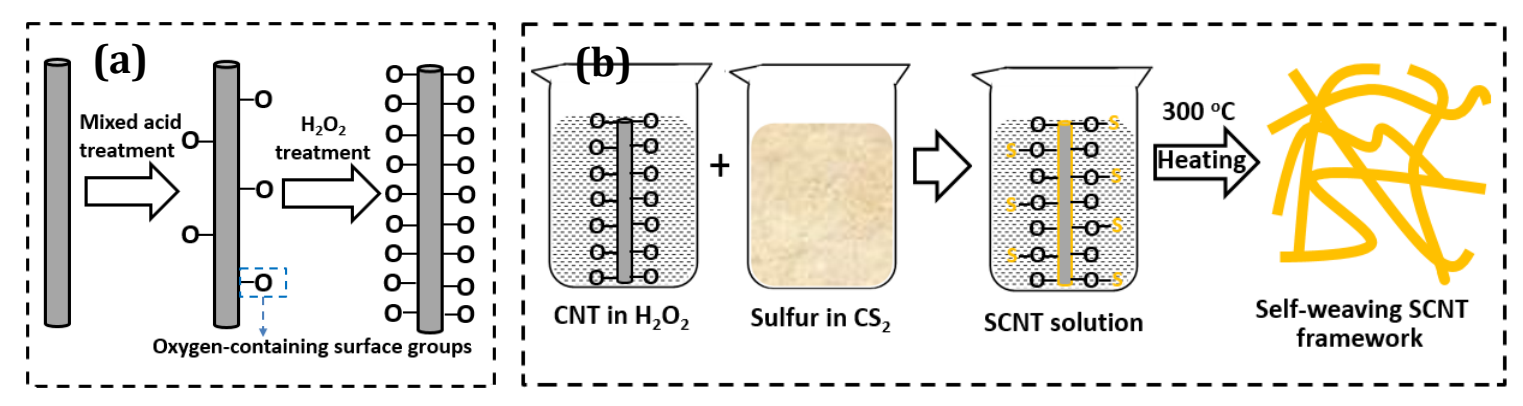

Figure 3-1 Schematic illustration of (a) the proposed treatment to integrate oxygen-containing surface groups into CNTs; and (b) the proposed strategy for grafting sulfur onto CNTs.

\subsubsection{Structural and Microstructure Characterizations}

The morphologies of the CNTs before (Figure 3-2a) and after (Figure 3-2b) $\mathrm{H}_{2} \mathrm{O}_{2}$ treatment were similar. However, the CNTs intended to be more agglomerated after $\mathrm{H}_{2} \mathrm{O}_{2}$ treatment. Sulfur was well dispersed on CNT surfaces after the solvent-exchange process (Figure 3-2c), probably because the reactive groups on CNT surfaces might act as growth points for sulfur precipitation. After being treated at $300{ }^{\circ} \mathrm{C}$ for $5 \mathrm{~h}$, most of the bulk sulfur was evaporated and a dense thin layer of sulfur was formed on CNT surfaces (Figure 3-2d). The synthesized SCNTs tended to agglomerate due to van der Waals interactions and formed 3D interconnected ionic- and electric-conductive channels. Meanwhile, sulfur particles were observed mainly at the ends of CNTs (Figures 3-2e and 3-2f), which were probably owing to the strong capillary force at the ends of CNTs. 

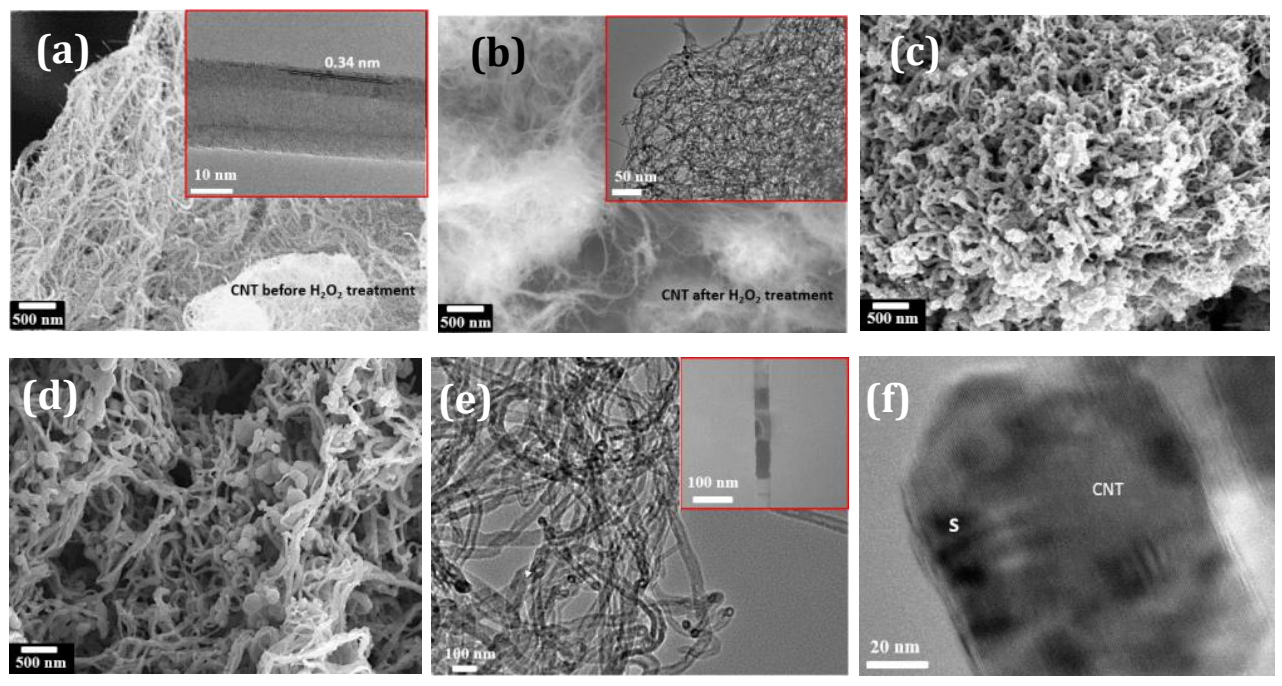

Figure 3-2 Typical morphologies of CNTs (a) before and (b) after $\mathrm{H}_{2} \mathrm{O}_{2}$ treatment. Inset TEM figures are with high magnifications. Typical morphologies of SCNT (c) before and (d) after heat treatment. (e, f) TEM images of SCNT materials after heat treatment.

\subsubsection{Electrochemical Characterizations}

Cathode slurries were prepared by mixing $90 \mathrm{wt} . \%$ of SCNTs and $10 \mathrm{wt} . \%$ of polyvinylidene fluoride (PVDF), and then coated onto aluminum foils that had been precoated with a thin layer of carbon. The electrodes were dried at $60{ }^{\circ} \mathrm{C}$ in a vacuum oven for $5 \mathrm{~h}$. The electrochemical performance of the SCNT electrodes was evaluated by measuring coin-type half-cells with lithium foil as the counter electrodes. CR2016-type cells were assembled in an argon glove box. $1.0 \mathrm{~mol} \mathrm{~L}^{-1}$ lithium bis(trifluoromethane sulfonyl) imide (LiTFSI) and $0.15 \mathrm{molL}^{-1} \mathrm{LiNO}_{3}$ dissolved in dioxolane (DOL) and dimethoxyethane (DME) (1:1, v/v) were used as electrolytes and Cellgard 2400 microporous membranes were used as separators. The cathode material was on a $0.8 \mathrm{~cm}$ $\times 0.8 \mathrm{~cm}$ square aluminum substrate, and the amount of electrolyte for each cell was about $0.02 \mathrm{ml}$. The cells were charged and discharged at different current rates between 1 (or 1.5) and $3 \mathrm{~V}\left(\mathrm{vs} \mathrm{Li} / \mathrm{Li}^{+}\right)$using an Arbin battery test station. The cyclic voltammetry (CV) measurements were carried out with a scan rate of $0.05 \mathrm{mV} \mathrm{s}^{-1}$ on a NOVA potentiostat analyzer. The specific capacity was calculated based on active sulfur materials. All experiments were conducted at room temperature unless specified. 


\subsection{Results and Discussion}

\subsubsection{XRD, SEM, TEM and EDS Studies}

After being treated in concentrated nitric acid and sulfuric acid followed with $\mathrm{H}_{2} \mathrm{O}_{2}$, CNTs were found to have much more surface active groups (19.7 wt.\%) (Figures 3-3a and 3-3b) and much lower thermal stability (Figure 3-3c) compared to the pristine CNTs. The intensities of both carbon peaks and oxygen peaks in Figure 3-3b increased with the mixed acids and $\mathrm{H}_{2} \mathrm{O}_{2}$ treatments. Compared to the non-treated CNTs, the $\mathrm{C} 1 \mathrm{~s}$ peak exhibited both a shift and an asymmetric broadening to higher binding energies (Figure 3-3b inset). The tip-shift of this peak, due to the polar character of the carbon oxygen bonds, was an evidence of the incorporation of oxygen into the nanotube structure. A contribution at about $288.4 \mathrm{eV}$ described surface oxygen groups with multiple carbon oxygen bonds. The oxygen and corresponding - $\mathrm{COOH}$ contents in the CNTs were calculated in Tables 3-1 and 3-2, respectively. The oxygen content in the CNTs significantly increased from $1.1 \mathrm{wt} . \%$ of pristine CNT to $10.4 \mathrm{wt} . \%$ and $19.7 \mathrm{wt} . \%$ respectively, after being treated with the mixed concentrated nitric and sulfuric acids or treated with the two mixed concentrated acids followed with $\mathrm{H}_{2} \mathrm{O}_{2}$ treatment.
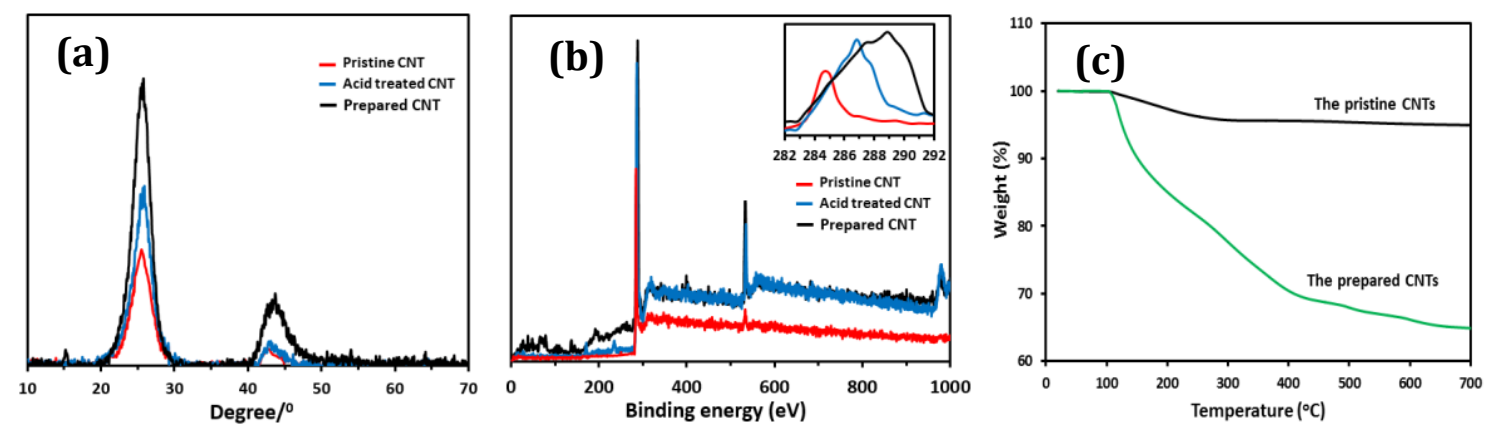

Figure 3-3 (a) XRD pattern and (b) XPS analysis of pristine CNTs. (c) TGA profiles of the pristine and prepared CNTs.

\begin{tabular}{|c|c|c|c|c|}
\hline Sample & Peak & Center & Wt.\% & Stoichiometric amount \\
\hline Pristine CNT & $\mathrm{C} 1 \mathrm{~s}$ & 284.5 & 98.5 & 1.00 \\
& $\mathrm{O} 1 \mathrm{~s}$ & 531.4 & 1.5 & 0.01 \\
\hline CNT treated with mixed acids & $\mathrm{C} 1 \mathrm{~s}$ & 286.4 & 89.6 & 1.00 \\
& $\mathrm{O} 1 \mathrm{~s}$ & 530.9 & 10.4 & 0.09 \\
\hline CNT treated with mixed acids and $\mathrm{H}_{2} \mathrm{O}_{2}$ & $\mathrm{C} 1 \mathrm{~s}$ & 288.4 & 80.3 & 1.00 \\
& $\mathrm{O} 1 \mathrm{~s}$ & 530.4 & 19.7 & 0.18 \\
\hline
\end{tabular}


Table 3-1 Surface element contents of CNTs with different treatment methods.

\begin{tabular}{|c|c|c|c|}
\hline Sample & $\begin{array}{c}\text { O stoichiometric } \\
\text { amount (\%) }\end{array}$ & $\begin{array}{c}\text {-COOH stoichiometric } \\
\text { amount (\%) }\end{array}$ & $\begin{array}{c}\text {-COOH weight } \\
\text { (wt.\%) }\end{array}$ \\
\hline Pristine CNT & 1.1 & 0.55 & 4.2 \\
\hline $\begin{array}{r}\text { CNT treated with mixed } \\
\text { acids }\end{array}$ & 8.7 & 4.35 & 12.2 \\
\hline $\begin{array}{c}\text { CNT treated with mixed } \\
\text { acids and } \mathrm{H}_{2} \mathrm{O}_{2}\end{array}$ & 18.4 & 9.2 & 25.9 \\
\hline
\end{tabular}

Table 3-2 Relationship between oxygen content and -COOH content on CNT surfaces.

Sulfur content and the mechanism of sulfur incorporation in SCNTs were examined using thermo-gravimetric analysis (TGA). The weight contents of sulfur in SCNT-159 and SCNT-300 were found to be $84.8 \%$ (or $3.07 \mathrm{mg} \mathrm{cm}^{-2}$ ) and $68.0 \%$ (or $2.94 \mathrm{mg} \mathrm{cm}^{-2}$ ), respectively (Figure 3-4a and Table 3-3). The weight loss of SCNT-300 could be distinctly divided into two regions according to the rates of weight loss: The fast weight loss region from 300 to $400{ }^{\circ} \mathrm{C}$ was probably belonged to the decomposition of S-S bonds, and the slow weight loss region from 400 to $700{ }^{\circ} \mathrm{C}$ could be assigned to the breakdown of $\mathrm{C}-\mathrm{S}$ bonds. It is known that $\mathrm{C}-\mathrm{S}$ bond has a much higher bond energy than S-S bond (i.e., $740 \mathrm{~kJ} \mathrm{~mol}^{-1}$ for C-S and $418 \mathrm{~kJ} \mathrm{~mol}^{-1}$ for S-S bond at $298 \mathrm{~K}$ ). [110]

The structure characteristics of the prepared CNTs and SCNTs were examined using Fourier transform infrared spectroscopy (FTIR), as shown in Figure 3-4b. Both of the pristine CNTs and the prepared CNTs had typical characteristic peaks at 1290, 1430, and $1680 \mathrm{~cm}^{-1}$ corresponding to $\mathrm{C}-\mathrm{O}, \mathrm{C}=\mathrm{O}$, and $\mathrm{C}=\mathrm{C}$ stretches, respectively. [145] The spectra of SCNTs were much different from those of CNTs. For both SCNT-159 and SCNT-300, the C-O stretching vibration at $1290 \mathrm{~cm}^{-1}$ was shifted to lower wave lengths and the intensity of both $\mathrm{C}=\mathrm{C}$ and $\mathrm{C}=\mathrm{O}$ vibrational bands at 1680 and $1439 \mathrm{~cm}^{-1}$ were significantly weak, indicating the replacement of $\mathrm{H}$ and $\mathrm{O}$ atoms by $\mathrm{S}$ atoms. In addition, a new band, appeared at $1050 \mathrm{~cm}^{-1}$ for SCNT-159 and SCNT-300, could be ascribed to the vibrations of O-S. A second new band, centered at $925 \mathrm{~cm}^{-1}$ for SCNT-300, could be assigned to the vibrations of C-S. [49, 146] Both the TGA and FTIR results indicated that a large portion of elemental sulfur reacted with CNTs and formed a cross-linked porous SCNT framework with short sulfur chains $\left(-S_{\mathrm{x}^{-}}\right)$. As a result, the majority of sulfur in 
SCNTs had the uncommon monoclinic phase rather than the typical orthorhombic phase, and the monoclinic sulfur was very stable even after stored for 30 days at room temperature (Figure 3-4c).
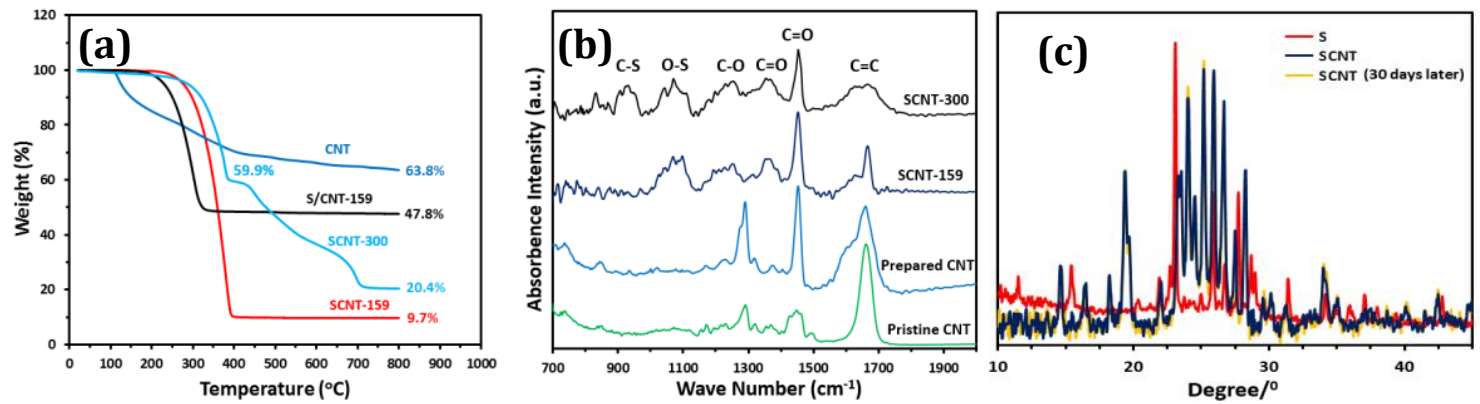

Figure 3-4 Characterizations of CNT and SCNT. (a) TGA tested in a nitrogen environment with a heating rate of $5{ }^{\circ} \mathrm{C} \mathrm{min}^{-1}$. (b) FTIR spectra. (c) XRD pattern of SCNT-300.

\begin{tabular}{|c|c|c|c|c|}
\hline Sample & $\begin{array}{l}\text { Weight loss } \\
\text { (wt.\%) }\end{array}$ & $\begin{array}{l}\text { CNT content } \\
\text { (wt.\%) }\end{array}$ & $\begin{array}{l}\text {-COOH content } \\
\text { (wt.\%) }\end{array}$ & $\begin{array}{l}\text { Sulfur content } \\
\text { (wt.\%) }\end{array}$ \\
\hline FCNT & 36.2 & 63.8 & 36.2 & 0 \\
\hline SCNT-159 & 90.3 & 9.7 & 5.5 & 84.8 \\
\hline SCNT-300 & 79.6 & 20.4 & 11.6 & 68 \\
\hline
\end{tabular}

Table 3-3 Sulfur contents in SCNT-159 and SCNT-300.

The presence of $\mathrm{C}-\mathrm{S}$ and $\mathrm{O}-\mathrm{S}$ bonds was further examined using X-ray photoelectron spectroscopy (XPS) (Figure 3-5a). The S 2p spectra of SCNT-300 were composed of three sub-peaks (Figure 3-5b). The peak at $164.2 \mathrm{eV}$ in the $\mathrm{S} 2 \mathrm{p} 3 / 2$ spectrum corresponded to elemental sulfur. An additional peak at $163.8 \mathrm{eV}$ in the $\mathrm{S} 2 \mathrm{p} 3 / 2$ spectrum was slightly lower than that of elemental sulfur, revealing the possible presence of S-C species. [147] The peak at $165.4 \mathrm{eV}$ in the $\mathrm{S} 2 \mathrm{p} 1 / 2$ spectrum suggested that $\mathrm{S}$ atoms were linked to a carbon ring or oxygen atoms. Figures 3-5c and 3-5d show the XPS spectra of the C 1s for the prepared CNTs and SCNT-300, respectively. Compared to $\mathrm{CNT}$, the $\mathrm{C}-\mathrm{O}$ and $\mathrm{C}=\mathrm{O}$ peaks of SCNT-300 shifted to higher binding energies. The tip-shift of these two peaks, due to the polar characters of the carbon sulfur and oxygen sulfur bonds, was an evidence of incorporation of sulfur into the CNT framework. Figures 3-5e and 3-5f show the XPS spectra of the O 1s core level of the prepared CNTs 
and SCNT-300, respectively. Both of the two spectra could be separated and fitted into two peaks. The lower binding energy feature $(532.2 \mathrm{eV})$ was due to $\mathrm{C}=\mathrm{O}$ groups in the aromatic ring. The second peak was due to $\mathrm{C}-\mathrm{O}$ bonds.
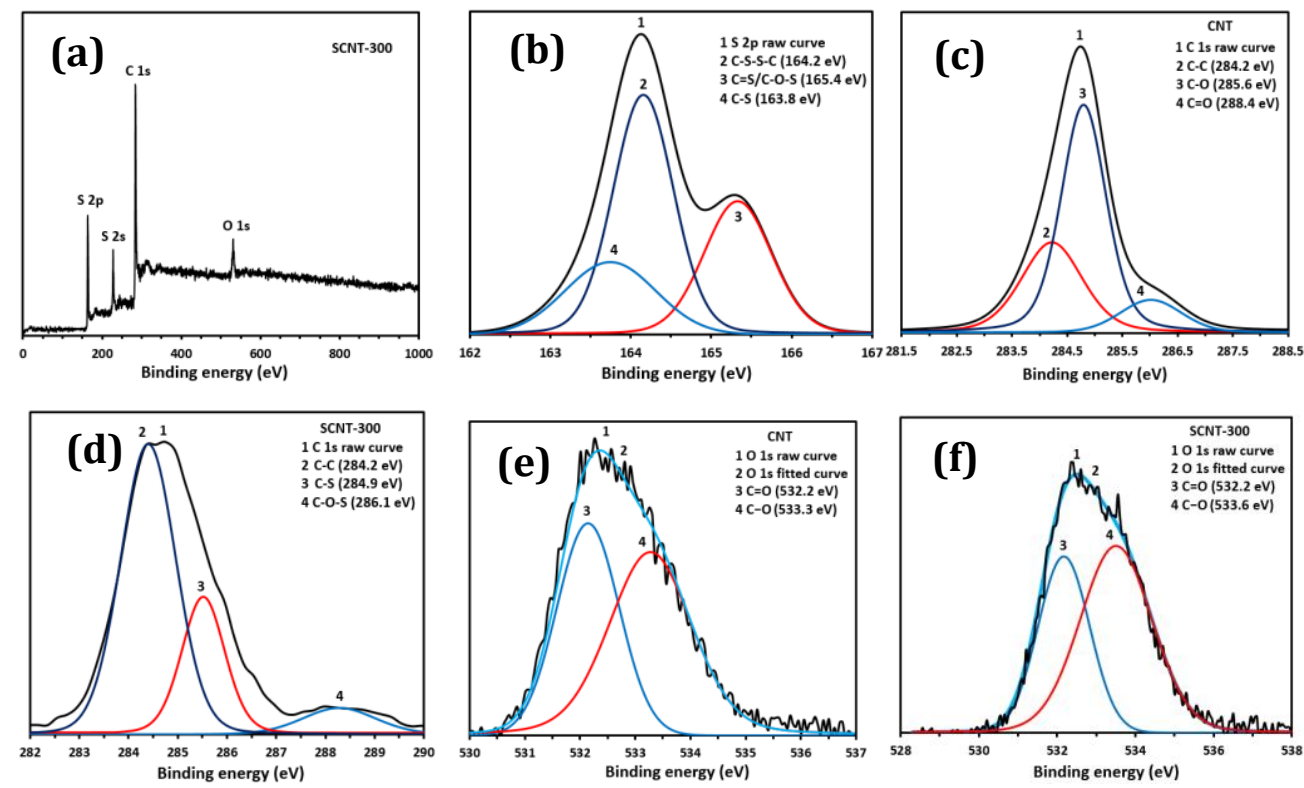

Figure 3-5 XPS analysis. (a) Wide range spectrum of SCNT-300. (b) S 2p regions of SCNT-300. C 1s regions of (c) CNT and (d) SCNT-300. O 1s regions of (e) CNT and (f) SCNT-300.

\subsubsection{Electrochemical Properties}

Figure 3-6a shows the first two charge/discharge curves of SCNT-300 cathodes at $0.75 \mathrm{C}$. Three discharge plateaus were clearly observed at 2.3, 2.1, and $1.9 \mathrm{~V}$. The plateau I was believed to be related to the reduction of $S_{8}$ to high-order soluble lithium polysulfide species (i.e., $\mathrm{Li}_{2} \mathrm{~S}_{4}$ ), and plateau II was due to further reduction of $\mathrm{Li}_{2} \mathrm{~S}_{4}$ into $\mathrm{Li}_{2} \mathrm{~S}$. While plateau III at $1.9 \mathrm{~V}$ was lower than the potential of $\mathrm{S}_{4}{ }^{2-}$ to $\mathrm{Li}_{2} \mathrm{~S}_{2}$ reaction at around 2.1 V. This third discharge plateau was probably related to the reduction of short sulphur chains that covalently bonded on CNTs. Generally, the Li-S cells comprised of sulfurized carbon cathodes featured a single discharge plateau between 2-1.6 V. The reverse reactions of SCNT-300 cathodes in the oxidation process also had three potential plateaus in the charge curve. It seems that the SCNT-300 presented both behaviors of elemental sulfur and sulfur bonded on CNT surfaces. As a comparison, we examined the voltage profiles of SCNT-159 cathodes (Figure 3-6b), which had typical sulfur cathode 
charge and discharge behaviors with two discharge potential plateaus at 2.35 and $2.1 \mathrm{~V}$, and two charge potential plateaus at 2.38 and $2.40 \mathrm{~V}$.
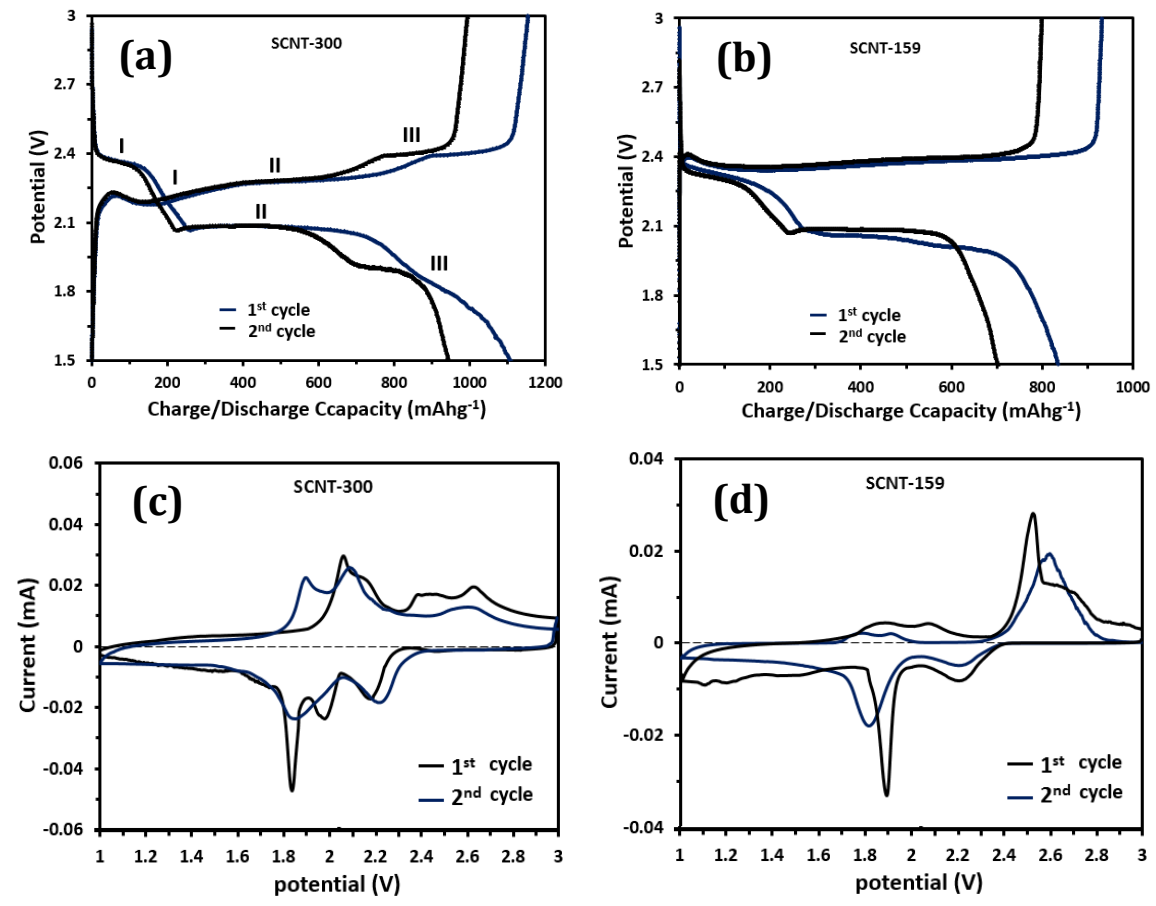

Figure 3-6 Electrochemical performance of Li-S cells comprised of SCNT cathodes. Voltage profiles of the first two charge/discharge cycles of (a) SCNT-300 cathodes and (b) SCNT-159 cathodes at 0.75 C. CV curves of (c) SCNT-300 cathodes and (d) SCNT-159 cathodes at a scan rate of $0.05 \mathrm{mV} \mathrm{s}^{-1}$ at the first two cycles.

The CV tests of SCNT-300 and SCNT-159 cathodes were performed between 3.0$1.0 \mathrm{~V}$ using a $0.05 \mathrm{mV} \mathrm{s}^{-1}$ scan rate. For SCNT-300, three reduction and three oxidation peaks were observed (Figure 3-6c), indicating that the electrochemical reactions in SCNT-300 were dominated by a new reaction, represented by the oxidation peak at $2.1 \mathrm{~V}$ and the third reduction peak at $1.9 \mathrm{~V}$. It seems that the intermediate reactions of sulfur and polysulfide species in conventional cathodes were suppressed in the SCNT-300 cathodes. In comparison, in the CV curves (Figure 3-6d) of SCNT-159 cathodes, two partially overlapped oxidation peaks centered at $2.05 \mathrm{~V}$ were observed, in addition to the two typical sulfur oxidation peaks at 2.5 and $2.6 \mathrm{~V}$. The new oxidation peaks of SCNT159 , which was not treated at $300{ }^{\circ} \mathrm{C}$, could be caused by $\mathrm{O}-\mathrm{S}$ bonds, since multiple studies showed that chemical reactions between sulfur or polysulfide species and oxygen 
functional groups on CNTs could occur and lead to improved stability of Li-S cells. [74, $76,148]$ In addition, the wide cathodic base line from 1.5-1 V might be due to the reduction of oxygen-containing surface groups or the reduction of lithium nitrite in the electrolyte. [79]

SCNT-300 cathodes were found to present a great rate capability (Figure 3-7a). With the current density varying from 0.25 to $2 \mathrm{C}$, the SCNT-300 cathodes exhibited a high participation of sulfur and preserved decent capacity retentions over long cycling. For instance, at $0.25 \mathrm{C}$, the initial discharge capacity reached $1002 \mathrm{~mA} \mathrm{~h} \mathrm{~g}^{-1}$, which was $59.8 \%$ of the theoretical value of sulfur. A quick increase in discharge capacities was observed in the first 5 cycles followed with a gradual decrease in the following 35 cycles. After that, the cathode reached a steady state and exhibited a stable lithiation degree with a reversible capacity of $1180 \mathrm{~mA} \mathrm{~h} \mathrm{~g}^{-1}$ with almost $100 \%$ capacity retention even after 300 cycles.

The cycling behavior and Coulombic efficiency of Li-S cells comprised of SCNT300 cathodes at different current densities are shown in Figure 3-7b. Excellent cycling stabilities were observed at relatively lower rates $(0.25 \mathrm{C}, 0.75 \mathrm{C}$ and $1 \mathrm{C})$. For instance, at $0.75 \mathrm{C}$, the cell exhibited an initial discharge capacity of $1291 \mathrm{~mA} \mathrm{~h} \mathrm{~g}^{-1}$, corresponding to $77.1 \%$ of sulfur participating in reactions. The cell showed great stability of $67.5 \%$ retention with a discharge capacity of $799 \mathrm{~mA} \mathrm{~h} \mathrm{~g}^{-1}$ over 600 cycles except the 1 st cycle. In addition, the Coulombic efficiency of the cells was always higher than $95.5 \%$, indicating the effectiveness of SCNT-300 cathodes in trapping intermediate lithium polysulfide species during discharge processes. However, at a relatively higher rate of 2 C, the SCNT-300 cathodes had a fast capacity fading of 39\% retention after 500 cycles. At such a high current rate, sulfur might not react completely and the cathode might have a severe polarization, which could inhibit regular lithium intercalation/de-intercalation processes. The discharge curve at $2 \mathrm{C}$ demonstrated a severe voltage hysteresis with a shortened capacity in comparison with those in lower current rates (Figure 3-7c), and only the first discharge plateau was observed in the later cycles (Figure 3-7d). 
SCNT-300 cathodes were also cycled up to 1300 cycles at a rate of $1 / 3 \mathrm{C}$ and were found to present an extremely low capacity decay rate $(0.025 \%$ per cycle) (Figure 3-7e). After 1300 cycles, the discharge capacity was $549 \mathrm{~mA} \mathrm{~h} \mathrm{~g}^{-1}$ of sulfur. When calculated the capacity with the whole cathode weight, the retained discharge capacity of the Li-S cells over 1300 cycles was $336 \mathrm{~mA} \mathrm{~h} \mathrm{~g}^{-1}$, which was still much higher than currently commercialized Li-ion batteries. By contrast, the Li-S cells containing SCNT-159 cathodes had a fast capacity fading of only 30.7\% retention from 1095 (in the 6th cycle) to $336 \mathrm{~mA} \mathrm{~h} \mathrm{~g}^{-1}$ over 600 cycles with a relatively low average Coulombic efficiency of $87.1 \%$ (Figure 3-7f). The capacity at $1 / 3 \mathrm{C}$ was smaller than that at $1 \mathrm{C}$ and the underlying reason is still unknown and will be investigated in the future.

Compared to the performance of recently reported S-doped CNT cathodes, the SCNT-300 cathodes had much higher capacity retention and much higher capacity utilization at 1 C. $[84,85,149]$ The capacity utilization of SCNT-300 cathodes was also higher than that of composite electrodes at $\mathrm{C} / 10$ and $\mathrm{C} / 20$ rates. Such enhanced performance likely originated from the good dispersion of S within the CNT matrixes, good mechanical stability of cathodes, and suppressed polysulfide species dissolution. Specifically, the SCNT-300 cathodes enhanced the electrochemical performance of Li-S cells in the following three aspects: (i) the prepared CNTs tended to agglomerate to form a strong skeleton with a porous 3D structure that could provide interconnected channels for the transport of electrons and ions. Being treated with the concentrated acids and $\mathrm{H}_{2} \mathrm{O}_{2}$, these CNTs had many nanopores and multiple surface reactive groups, which could react with sulfur in the subsequent synthesis process. To verify the strong affinity between sulfur and CNTs, we tested the performance of Li-S cells employing S/CNT-159 cathodes, in which CNTs were not treated with the concentrated acid mixture of nitric acid and sulfuric acid or treated with $\mathrm{H}_{2} \mathrm{O}_{2}$ solution. The results were shown in Figure 38. Clearly, both capacity and Coloumbic efficiency of S/CNT-159 cathodes were worse than those of SCNT-159 and SCNT-300, indicating the advantages of combining solvent exchange and surface treatment with low-temperature treatment. (ii) The proposed synthesis method for SCNT-300 materials had great advantages such as high sulfur immobilization and low temperature treatment. The surface treatment and solvent 
exchange processes were crucial for high sulfur immobilization and improved the interactions between sulfur and CNTs. The heat-treatment process was also important since it allowed molten sulfur to be immobilized onto CNTs through nanopores and to form C-S bonds. (iii) The C-S bonds resulted in enhanced utilization of sulfur, and suppressed the dissolution of polysulfide species into liquid electrolytes. In addition, the oxygen-containing surface groups improved the interactions of CNT with sulfur and enhanced the physical and chemical adsorptions of sulfur particles and polysulfide anions during cell operation.
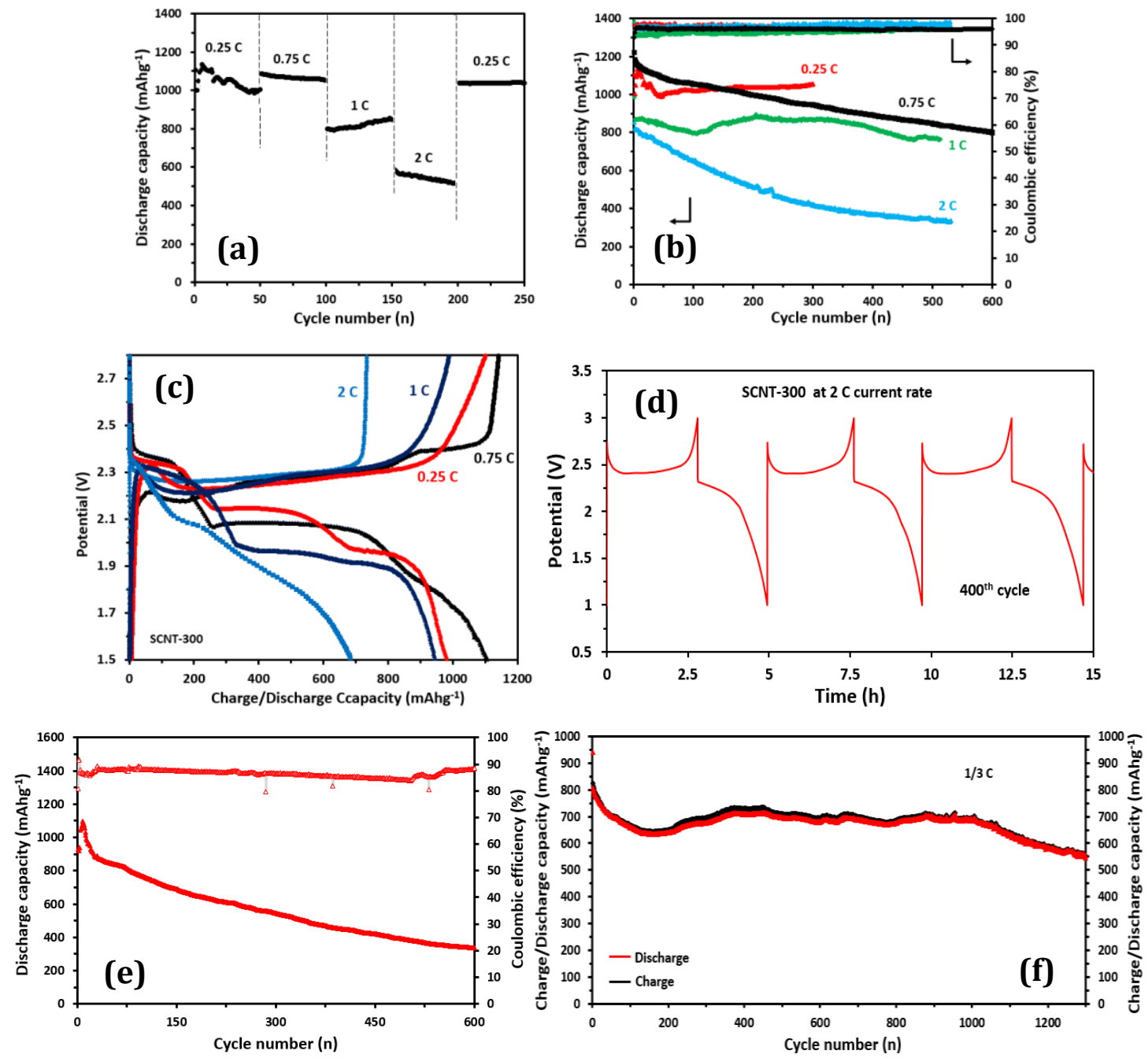

Figure 3-7 Electrochemical performance of Li-S cells comprised of SCNT-300 cathodes. (a) Rate performance. (b) Cycling performance and Coulombic efficiency at different rates. (c) Voltage profiles at different current rates. (d) Voltage profiles (in the 400th cycle) at 2 C. (e) 
Cycling properties of Li-S cells comprised of SCNT-159 cathodes (contained $10 \mathrm{wt} . \%$ of PVDF and 90 wt. $\%$ SCNT-159 material) at 0.75 C. (f) Long-term cycling tests at $1 / 3 \mathrm{C}$ rate.

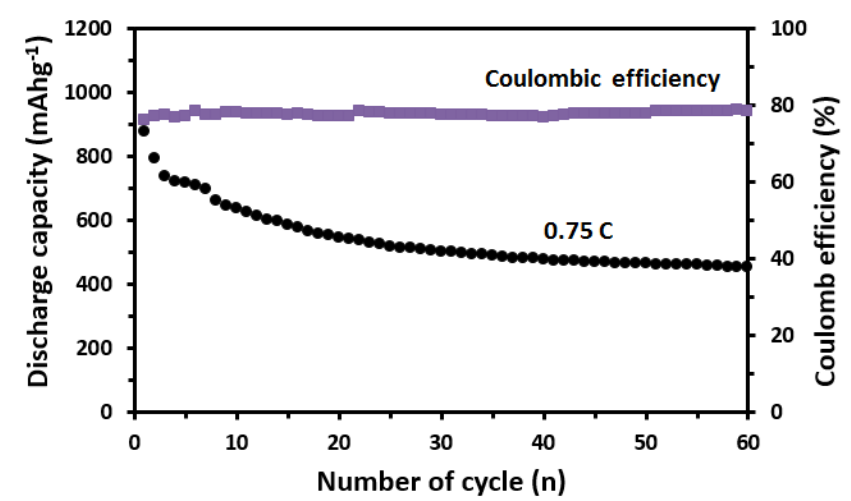

Figure 3-8 Cycling properties of Li-S cells comprised of S/CNT-159 cathodes (contained 10 wt.\% of PVDF and $90 \mathrm{wt} . \%$ S/CNT-159 material) at $0.75 \mathrm{C}$.

\subsection{Conclusions}

In summary, SCNT-300 cathodes with a high sulfur content of 68 wt. $\%$ was fabricated by combining surface treatment and solvent exchange methods. SEM and TEM images indicated that dense sulfur layers were formed onto CNT surfaces with the help of $\mathrm{H}_{2} \mathrm{O}_{2}$ and $\mathrm{CS}_{2}$ as two reaction solutions for sulfur precipitation. The interconnected 3D CNT framework served as electrical conductive network and could accommodate high amounts of sulfur. As a result, the SCNT-300 cathodes demonstrated high performance and cyclic stability with high Coulombic efficiency for Li-S batteries. 


\section{Chapter 4: Sulfur Cathode Materials Development: Sulfurized Polyaniline}

In this chapter, we will focus on the fabrication of SPANI and discussion for its application in Li-S batteries. Polyaniline (PANI) was chosen as a sulfur carrier due to its superior mechanical strength and electrical conductivity. [93, 102, 103, 150] In addition, it has unsaturated bonds that could form electrochemically active C-S bonds. [104] In this dissertation, an in situ sulfurized process has been developed for synthesizing SPANI composite as cathode material. The value of this novel material is that it has the ability to chemically trap polysulfide species by forming strong chemical binding of sulfur to PANI host. Therefore, the dissolution of polysulfide species into the liquid electrolyte is greatly reduced, thereby enhanced the cyclic capabilities of $\mathrm{Li}-\mathrm{S}$ cells. In addition, $\mathrm{LiNO}_{3}$-free electrolyte could be used for this cathode and excellent battery stabilities could be obtained. A primary novelty of this synthesis method is that the final products of SPANI had a coralloid nanostructure, which enhanced electrical conductivity, and enabled a high sulfur loading (65 wt.\% of sulfur in SPANI). In addition, SPANI could accommodate volume change of sulfur during cycling, and thus led to an improved electrochemical performance.

\subsection{Introduction}

As we have talked in the previous chapter, in recent years some researchers transferred their research focus from sulfur carbon composites to SC composites because the chemical bonds between sulfur and carbon might effectively inhibit dissolution of polysulfide species. PAN and CNT have been found suitable in the fabrication of SC materials due to their special surface functional groups (i.e. $\mathrm{C} \equiv \mathrm{N}$ in $\mathrm{PAN}$ and $\mathrm{C}=\mathrm{C}$ in CNT). However, most of these SC materials fabricated with the traditional strategy had low sulfur content and insufficient cycle life. Reaction of carbon with sulfur at a high temperature was the most common method to fabricate SC materials, which resulted in low sulfur contents due to the evaporation of sulfur. In addition, the chemical bonded sulfur greatly decreased the conductivity of host carbon. 
Here, we report a facile chemical approach to fabricate nanoporous SPANI that offers high sulfur content (65 wt.\%) and electric/ionic conductivity. The SPANI contains three parts: a main backbone chain providing electron conductivity; a high degree of interconnected nanoporous structures conducive to large elemental sulfur loading and fast ionic conduction and mass transportation; and a disulfide side chain functioning as the second electrochemical redox component. PANI is well known as a conductive and electroactive polymer, which also provides strong affinity and high loading of sulfur and polysulfide species. In addition, the multiple positively charged amino-containing surface groups on its backbones also favor catenating and stabilizing polysulfide anions during cycling. Therefore the electrical contact between sulfur and PANI during cycling can be guaranteed by the strong chemical and physical confinement in this nanoporous SPANI structures. As a result, the Li-S batteries employing SPANI cathodes showed high efficiency of sulfur encapsulation, excellent cycling stabilities and rate capabilities. Stable reversible capacities over $700 \mathrm{~mA} \mathrm{~h} \mathrm{~g}^{-1}$ at $0.3 \mathrm{C}, 600 \mathrm{~mA} \mathrm{~h} \mathrm{~g}^{-1}$ at $0.6 \mathrm{C}$, and 500 $\mathrm{mA} \mathrm{h} \mathrm{g}^{-1}$ at $1 \mathrm{C}$ over 200 cycles were obtained; the capacity is calculated based on sulfur weight.

\subsection{Materials and Methods}

\subsubsection{Preparation of SPANI Cathodes}

In this study, SPANI was fabricated with a wet chemical method, which involved insitu chlorinated substitution and vulcanization reactions, as shown in Scheme 4-1. The detailed synthesis method of SPANI is described below: First, Polyaniline (emeraldine salt, 3-100 $\mu \mathrm{m}$ particle size), sulfur monochloride (98\%), and aluminum chloride (99.999\%), purchased from Sigma-Aldrich, were dissolved in acetonitrile (99.8\%) in a sealed flask for $10 \mathrm{~h}$, washed using ether, and dried in a vacuum oven at $80^{\circ} \mathrm{C}$ for $24 \mathrm{~h}$ to obtain polychlorinated polyaniline. Next, sulfur and sodium sulfide (molar ratio of 8:1) were soaked in N,N-dimethylformamide (DMF) in a vacuum oven for $6 \mathrm{~h}$ to obtain $\mathrm{Na}_{2} \mathrm{~S}_{5}$ and sulfur composites. Then, the polychlorinated polyaniline was added into the prepared $\mathrm{Na}_{2} \mathrm{~S}_{5}$ solution for $24 \mathrm{~h}$ in a vacuum oven, washed with deionized water, and dried in a vacuum oven at $80{ }^{\circ} \mathrm{C}$ for $24 \mathrm{~h}$ to achieve the as-prepared SPANI. Finally, the asprepared SPANI was heated in a vacuum oven at $159{ }^{\circ} \mathrm{C}$ for $6 \mathrm{~h}$ to obtain SPANI. In 
summary, the polychloride groups were first created in situ by chlorination of the pristine PANI nanoparticles. These polychloride groups were then substituted by polysulfide groups through in situ vulcanization reaction. After the two-step reaction, the SPANI composites were extracted from acetone solution. Last, the SPANI was annealed at 159 ${ }^{\circ} \mathrm{C}$ in a vacuum oven for $6 \mathrm{~h}$ to further anchor sulfur onto the SPANI surfaces. Sulfur content in SPANI was $65 \mathrm{wt} \%$, which contained elemental sulfur and disulfide bonds on SPANI chains. Cathode slurries contained 80 wt.\% of SPANI, 10 wt.\% of carbon black, and $10 \mathrm{wt} . \%$ of polyvinylidene fluoride (PVDF). Sulfur loading in the cathode was $\sim 3.01$ $\mathrm{mg} \mathrm{cm}{ }^{-2}$.

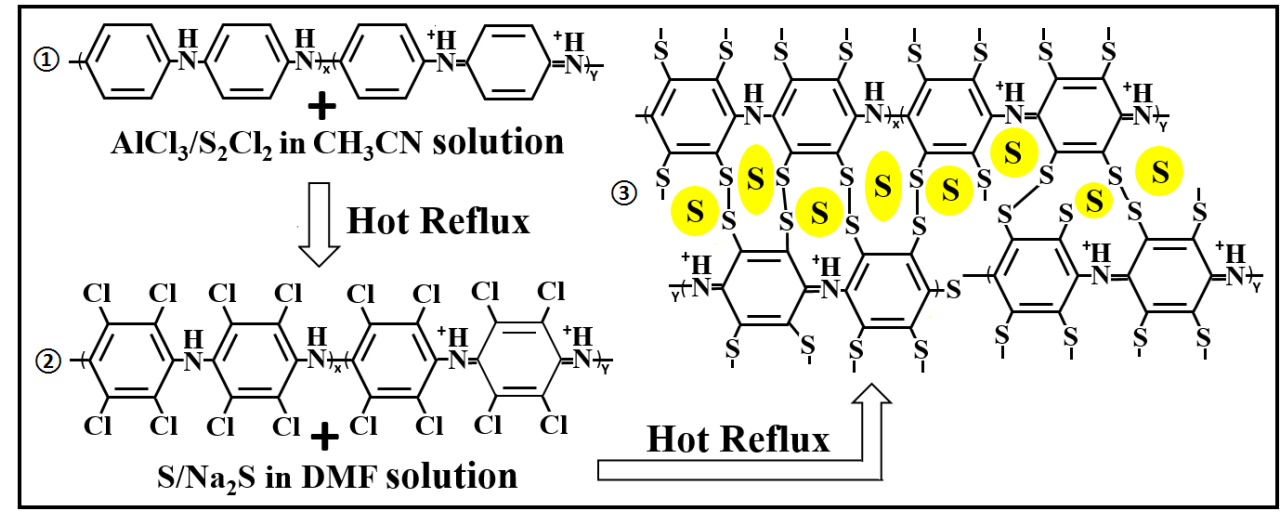

Scheme 4-1 Synthesis routes of SPANI.

\subsubsection{Physical Characterization}

Scanning electron microscopy (SEM) characterizations were performed with a working distance of $12 \mathrm{~cm}$. All the samples were attached to conductive copper tape directly for imaging. Energy dispersive X-ray spectrometry (EDS) was performed with the connection of SEM device. Crystal structure characterization was conducted with a PANalytical X-ray diffraction (XRD) with $\mathrm{Cu} \mathrm{K} \alpha$ radiation between 10 and $60^{\circ}$ at a scan rate of $0.1^{\circ} \mathrm{s}^{-1}$. FTS 7000 Fourier transform-infrared spectroscopy (FTIR) and Kratos Axis Ultra X-ray photoelectron spectroscopy (XPS, Kratos Analytical) with a monochromatized $\mathrm{Al} \mathrm{Ka}$ X-ray source were used to analyze the surface chemistry of SPANI cathodes. Deconvolution of the XPS spectra was performed with a Casa XPS program with Gaussian-Lorentzian functions. 


\subsubsection{Electrochemical Measurements}

CR2032-type coin cells were used for battery assembling. Lithium foils were used as the anodes, Cellgard 2400 microporous membranes as separators, $1.0 \mathrm{molL}^{-1}$ bis(trifluoromethane sulfonyl) imide (LiTFSI) dissolved in dioxolane (DOL) and 1,2dimethoxyethane (DME) $(1: 1, \mathrm{v} / \mathrm{v})$ as electrolytes. The cathode material was on a $0.8 \times$ $0.8 \mathrm{~cm}^{2}$ square aluminium substrate, and the amount of electrolyte for each cell was $\sim 20$ $\mu 1$. The cells were assembled in an argon-filled glove box. Electrochemical measurements were performed galvanostatically between 1.0 and $3.0 \mathrm{~V}$ at various current densities. Capacity was calculated based on the weight of sulfur on the cathodes. The cyclic voltammograms $(\mathrm{CV})$ experiments were conducted using a NOVA potentiostat at a scan rate of $0.1 \mathrm{mV} \mathrm{s}^{-1}$. EIS measurements were carried out using a NOVA electrochemical workstation in a frequency range between $100 \mathrm{kHz}$ and $100 \mathrm{mHz}$ at a potentiostatic signal amplitude of $5 \mathrm{mV}$. All experiments were conducted at room temperature.

\subsection{Results}

\subsubsection{Material Characterizations}

The pristine PANI had a nanoparticle morphology with an average particle size of 1 $\mu \mathrm{m}$, as shown in Figure 4-1a. Interestingly, the obtained SPANI had a hierarchical coralloid-like structure with sulfur uniformly coverage on the external surface (Figure 41b). A high magnification image (Figure 4-1c) clearly showed that the coralloid-like structure was constructed by multiple nano-flakes, which had a high degree of interconnectivity and formed a three dimensional porous framework with increased surface areas and macro-pore volumes. As can be seen, the pore size was $\sim 500 \mathrm{~nm}$. These multiple pores enhanced mass transportation because of the decreased diffusion length for the intercalating electrolyte anions, and thus facilitated more rapid battery operation. In addition, these pores could greatly alleviate the volume changes of active sulfur materials during the repeated discharging and charging processes. The formation of the hierarchical coralloid nano-flaked SPANI structure was probably due to the variation of surface energy of PANI polymers caused by the unsaturated surface functional groups in the PANI backbones during the synthesis process. The EDS and nuclear magnetic 
resonance (NMR) characterizations of SPANI are shown in Figures 4-2 and 4-3, which demonstrated a structural change of PANI after being reacted with sulfur, probably was caused by the substitution of hydrogen atoms with sulfur atoms in PANI backbones. In addition, the EDS analysis revealed that the sulfur content was 63 wt.\%.
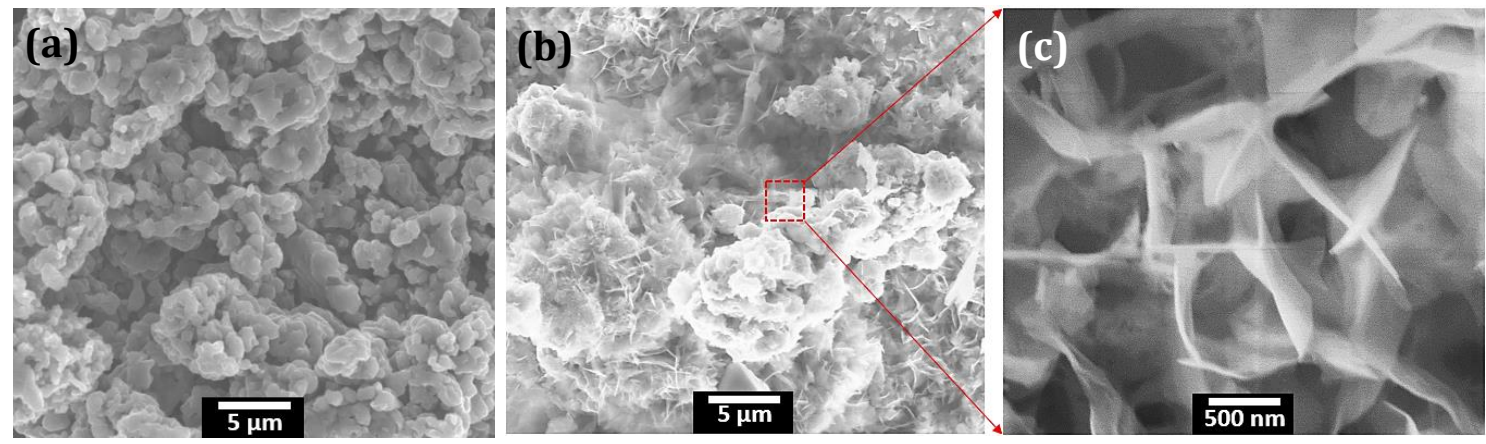

Figure 4-1 SEM characterizations of PANI and SPANI. (a) PANI nanoparticles, (b) synthesized coralloid SPANI composites, and (c) the nano-flakes in the coralloid SPANI granules.
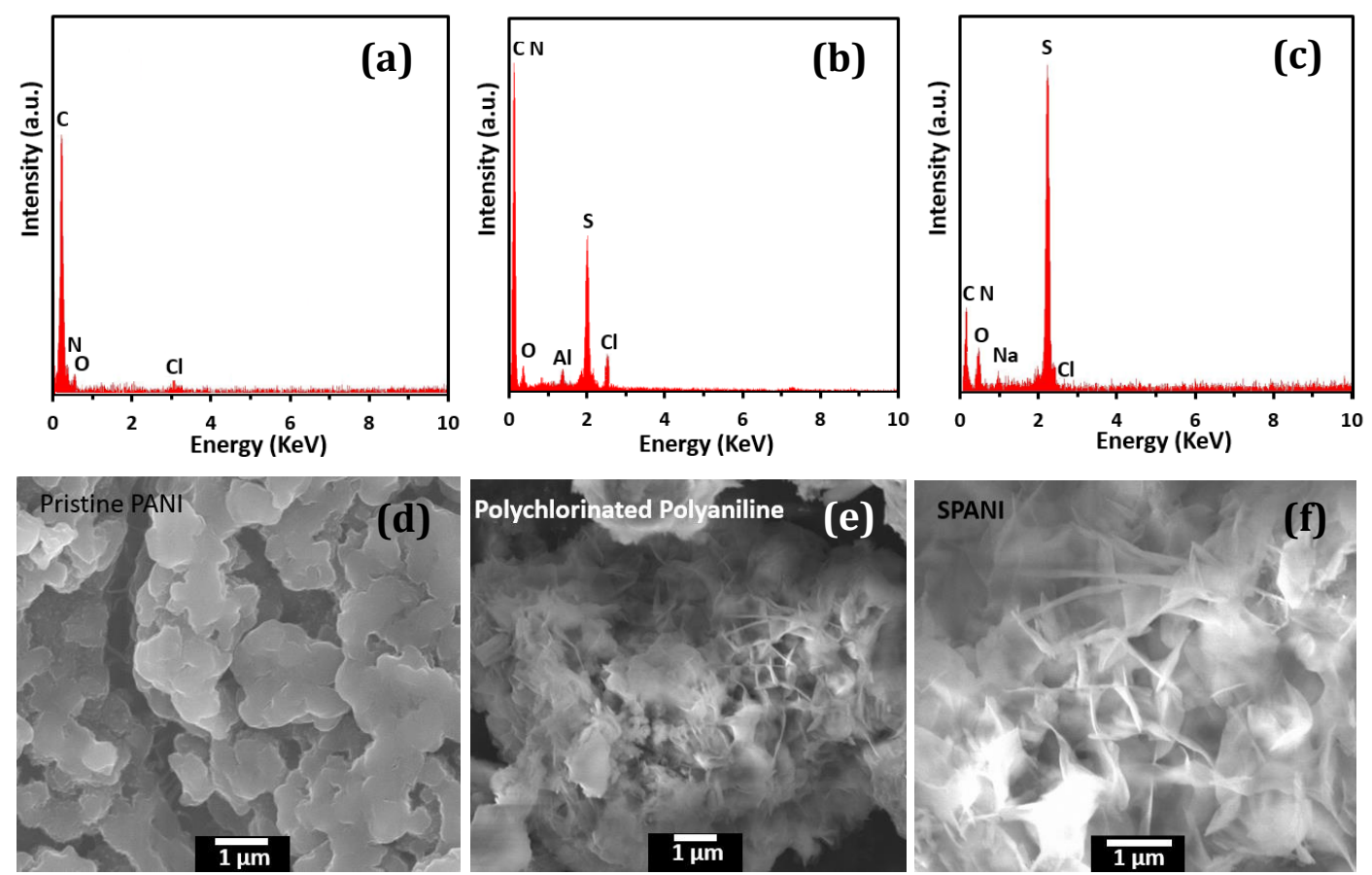

Figure 4-2 EDS spectra and SEM images of (a, d) pristine PANI; (b, e) polychlorinated polyaniline; and (c, f) SPANI. 

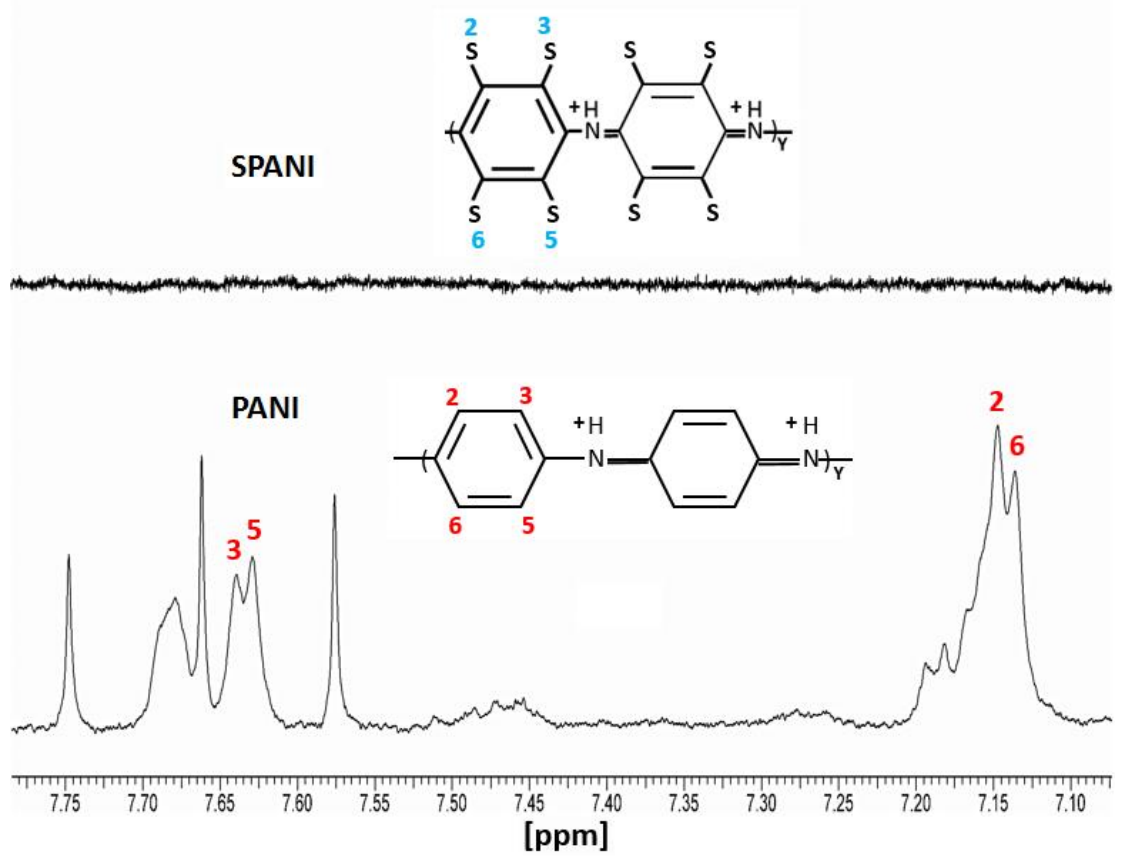

Figure 4-3 ${ }^{1} \mathrm{H}$ NMR spectra of PANI and SPANI. PANI had four characteristic peaks of ${ }^{1} \mathrm{H}$ between 7.1-7.75 ppm.

The sulfur/disulfide bonds and sulfur content in SPANI were determined by differential scanning calorimetry (DSC) and thermogravimetric analysis (TGA), as shown in Figure 4-4a. Two obvious peaks were observed at 220 and $400{ }^{\circ} \mathrm{C}$ in the DSC curve of SPANI, indicating the existence of two different kinds of sulfur bonds. The one at 220 ${ }^{\circ} \mathrm{C}$ corresponded to the decomposition of S-S bonds, and the other one belonged to the breakdown of C-S bonds on the SPANI backbones. Generally, the S-S bond has a much lower bond energy than the C-S bond (i.e., $418 \mathrm{~kJ} \mathrm{~mol}^{-1}$ for the S-S bond and $740 \mathrm{~kJ} \mathrm{~mol}^{-}$ ${ }^{1}$ for the C-S bond at room temperature). [110] Since there was an obvious weight loss begin from $420{ }^{\circ} \mathrm{C}$ in PANI curve, which may be due to the carbonization of PANI, we measured the weight loss of SPANI by reducing the weight loss of PANI at $420{ }^{\circ} \mathrm{C}$. From the weight loss analysis of TGA tests, sulfur content in SPANI was 65 wt.\%.

The SPANI was further characterized using XRD (Figure 4-4b). For PANI, the crystalline peaks appeared at $2 \theta=15.3^{\circ}, 20.7^{\circ}$, and $25.2^{\circ}$, corresponding to the (011), (020), and (200) crystal planes of PANI in its emeraldine salt form, respectively. For 
sulfur, all the strong diffraction peaks can be attributed to orthorhombic sulfur with high crystallinity. Clearly, the SPANI showed the characteristic peaks of sulfur and PANI.

The structure of SPANI was determined by FTIR, as shown in Figure 4-4c. PANI showed characteristic bands at 3419, 1565, 1492, 1325, and 1139 (808) $\mathrm{cm}^{-1}$, corresponding to the $\mathrm{N}-\mathrm{H}, \mathrm{C}=\mathrm{N}, \mathrm{C}=\mathrm{C}, \mathrm{C}-\mathrm{N}$, and in-plane $\mathrm{C}-\mathrm{H}$ (out-of-plane $\mathrm{C}-\mathrm{H}$ ) stretching vibrations, respectively. [151] These results further confirmed that PANI existed in the form of emeraldine salt. In the SPANI spectra, the $\mathrm{C}-\mathrm{H}$ stretching vibration at $1109 \mathrm{~cm}^{-1}$ could be assigned to benzenoid rings that shifted to lower wave numbers and the intensity of both $\mathrm{C}-\mathrm{H}$ vibrational bands at 1109 and $808 \mathrm{~cm}^{-1}$ significantly weakened, indicating the replacement of $\mathrm{H}$ atoms on aromatic rings by $\mathrm{S}$ atoms. In addition, according to $\mathrm{Yu}$ et. al, the two peaks at 915 and $816 \mathrm{~cm}^{-1}$ could be assigned to the vibrations of S-S bonds, the two peaks at 720 and $529 \mathrm{~cm}^{-1}$ could be assigned to the vibrations of C-S bonds. [146]

The sulfur bonds in SPANI were further investigated using XPS, and the wide range spectra is shown in Figure 4-4d. Figure 4-4e shows the S2p spectra of the SPANI. The binding energy of the $\mathrm{S} 2 \mathrm{p} 3 / 2$ peak was $163.7 \mathrm{eV}$, which is slightly lower than that of elemental sulfur at $164.0 \mathrm{eV}$, revealing the possible presence of $\mathrm{C}-\mathrm{S}$ bonds. While the peak at $165.4 \mathrm{eV}$ in the $\mathrm{S} 2 \mathrm{p} 1 / 2$ spectra suggested that $\mathrm{S}$ atoms were linked to a benzenoid ring and a quinoid ring. The reason for the large peak distance of $1.4 \mathrm{eV}$ could be attributed to the presence of C-S bonds and disulfide bondes in SPANI structure. Figures 4-4f and 4-4g show the XPS spectra of the N 1s core level of PANI and SPANI, respectively. Both of them were composed of three subpeaks, corresponding to $-\mathrm{N}=$, $\mathrm{NH}-$, and $-\mathrm{N}^{+}$-. [152] Compared with PANI, all the three peaks of SPANI had lower binding energies, indicating substitution of the $\mathrm{H}$ atom by sulfur. In addition, the ratio of $[-\mathrm{N}=] /[-\mathrm{NH}-]$ for SPANI was obviously higher than that of pure PANI, further confirming the existence of chemically bonded sulfur on the SPANI backbones. Figures 4-4h and 4-4i show the C 1s spectra of PANI and SPANI, respectively. Both of them could be separated into four fitted peaks, corresponding to $\mathrm{C}-\mathrm{C}, \mathrm{C}-\mathrm{N}, \mathrm{C}=\mathrm{N}$, and $\pi-\pi^{*}$. $[152,153]$ Compared to PANI, the C-C and C-N peaks of SPANI shifted to higher 
binding energies. The tip-shift of these two peaks, due to the polar character of the C-S bonds, was evidence of the incorporation of sulfur into the PANI backbone structure. A contribution at about $288.4 \mathrm{eV}\left(\pi-\pi^{*}\right)$, which was smaller than that in PANI, indicated that SPANI was more stable than PANI.
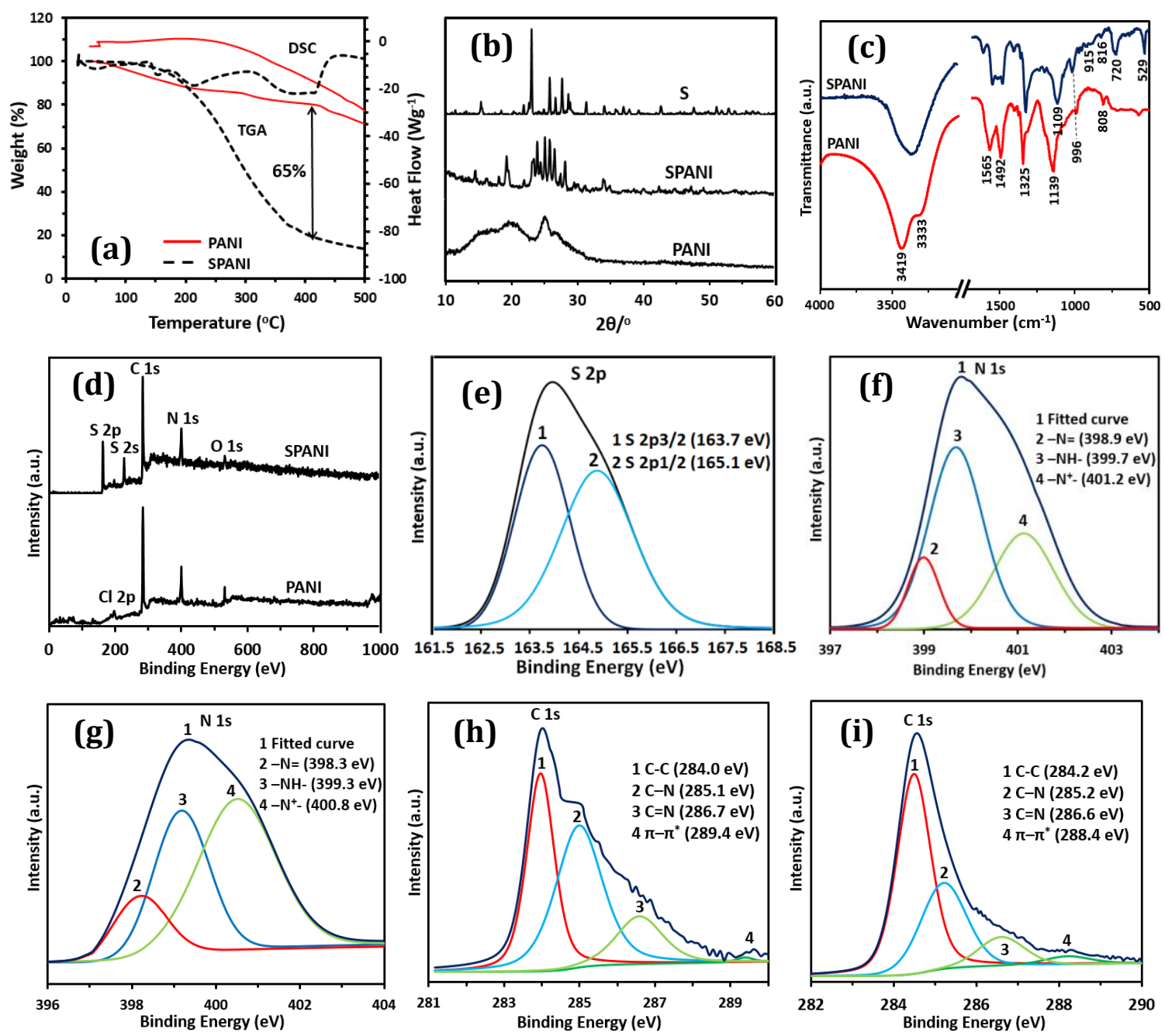

Figure 4-4 Structure characterizations. (a) TGA and DSC analysis showing $65 \mathrm{wt} . \%$ of sulfur in SPANI. (b) XRD patterns of S, SPANI, and PANI. (c) FTIR spectra of PANI and SPANI. (d) XPS spectra of PANI and SPANI. (e) S 2p regions of SPANI C 1s regions of (f) PANI and (g) SPANI. N 1s regions of (h) PANI and (i) SPANI.

Based on the data from TGA, XRD, FTIR, and XPS, we believed during the wet chemical synthesis process, part of sulfur reacted with PANI to form a cross-linked porous framework with both intra- and inter-chain disulfide bonds. The rest of sulfur covered onto the surfaces or infused into the voids and nanopores of SPANI polymers. 
Therefore, sulfur was both physically and chemically confined in the coralloid SPANI structure. The porous SPANI framework could work not only as an additional host for Liion insertion/extraction, but also as a container for electrolyte to penetrate into the aggregated bulk sulfur.

\subsubsection{Electrochemical Performance}
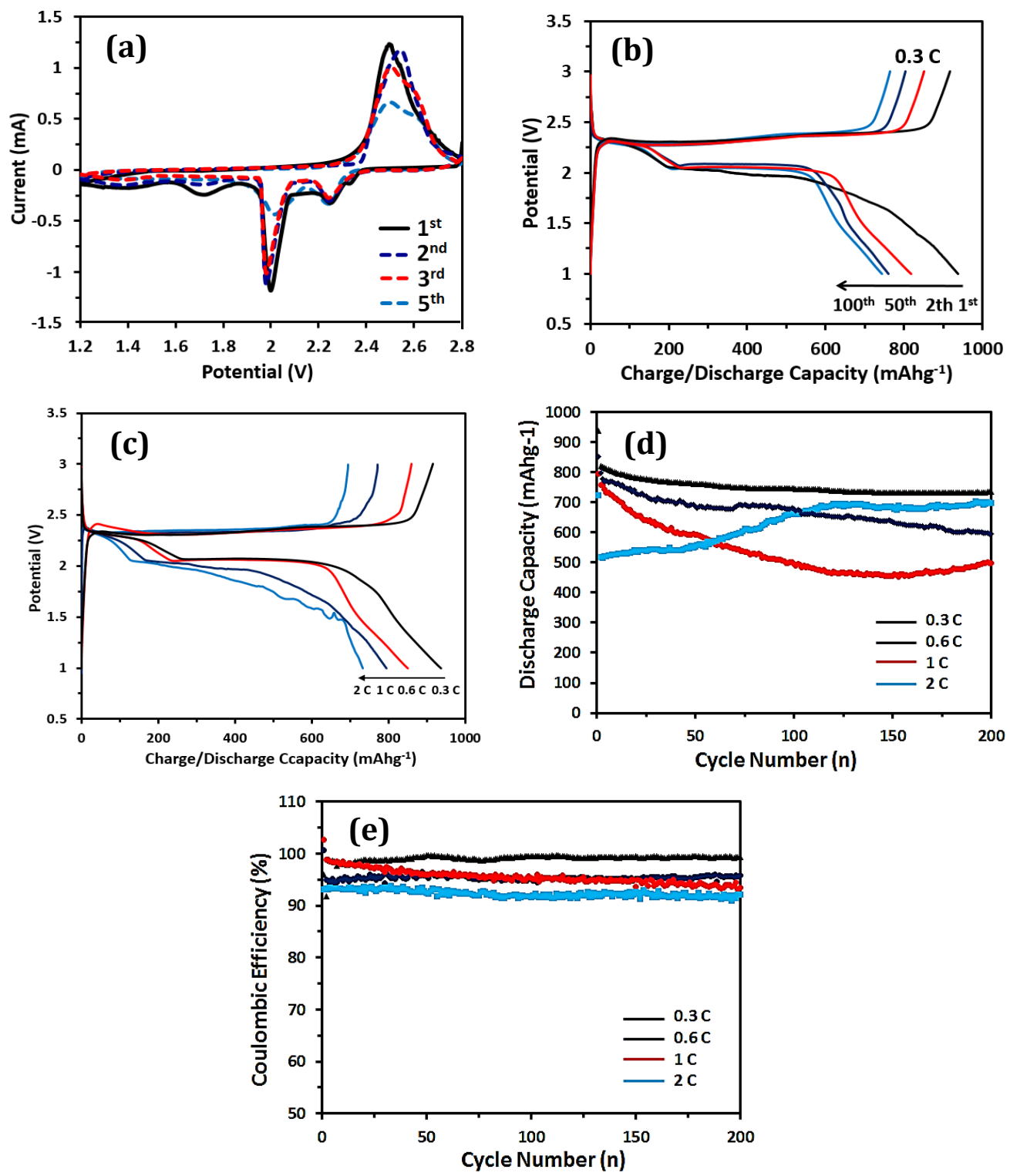

Figure 4-5 Electrochemical performance of Li-S batteries employing SPANI cathodes. (a) Continuous CV curves $\left(0.1 \mathrm{mV} \mathrm{s}^{-1}\right)$. (b) Cycling ability at $0.3 \mathrm{C}$. (c) Voltage profiles of initial cycles under different current rates. (d) Long-term cycling stability and (e) Coulombic efficiency at different current rates. 
The first five cycles' CV curve of the Li-SPANI battery at a scan rate of $0.1 \mathrm{mV} \mathrm{s}^{-1}$ is shown in Figure 4-5a. We observed two cathodic peaks at $\sim 2.25$ and $\sim 1.95 \mathrm{~V}$, and two almost overlapped anodic peaks at $\sim 2.45$ and $\sim 2.50 \mathrm{~V}$. The sulfur chemical bonds in SPANI changed the equilibrium potential of S-Li reactions, which led to a discharge potential shifting to a lower plateau. The cathodic peak at $1.70 \mathrm{~V}$ disappeared after the initial cycle, probably due to the rearrangement of the active sulfur materials to electrochemically favorable positions after their dissolution into the liquid electrolyte during the first cycles. The $\mathrm{CV}$ curves in the subsequent cycles showed good reproducibility, indicating a high degree of reversibility of the multi-step reaction. The charge/discharge voltage profiles of these Li-S cells at a current rate of $0.3 \mathrm{C}$ are shown in Figure 4-5b. The cells had typical sulfur cathode behavior with two discharge potential plateaus at 2.3 and $2.1 \mathrm{~V}$, and two charge potential plateaus at 2.3 and $2.4 \mathrm{~V}$. The length ratios between the upper and lower plateaus were nearly identical for all of the cycles, indicating a high efficiency of sulfur utilization in the SPANI cathode. The discharge capacity value of the cell at the first cycle was $\sim 937 \mathrm{~mA} \mathrm{~h} \mathrm{~g}^{-1}$, corresponding to a high sulfur utilization of $\sim 58.2 \%$. However, a large capacity drop between the 1 st and the 2 nd cycles was observed, which was attributed to the catalytic reduction of electrolyte solvents on the fresh surfaces of SPANI, and the formation of solid electrolyte interface films on the Li-anode in the first cycle (Figure 4-5c).

Figures 4-5d and 4-5e compared the long-term cycling behavior and Coloumbic efficiency of Li-S cells at different discharge/charge current rates. High cycling stabilities were observed at all rates. For example, at $0.3 \mathrm{C}$, the cell delivered a stable reversible capacity of $734 \mathrm{~mA} \mathrm{~h} \mathrm{~g}^{-1}$ over 200 cycles with a low decay rate $(0.051 \%$ per cycle). Meanwhile, the cell always had a high Coulombic efficiency of $99.3 \%$, indicating that the poly-shuttle effects were significantly reduced in the cells. Similar cycling performance enhancements were observed at 0.6 and $1 \mathrm{C}$, over 200 cycles, strongly suggesting that the developed SPANI cathode played a key role in extending the cycling life of Li-S batteries. Even at a high current of $2 \mathrm{C}$, the cell retained a capacity of above $700 \mathrm{~mA} \mathrm{~h} \mathrm{~g}^{-1}$ after 100 cycles, demonstrating exceptional rate performance. At $2 \mathrm{C}$, it appeared that the active material took about 100 cycles to reach a steady state in the cathode region to offer 
stable electrochemical performance because of the solubility of the intermediate lithium polysulfide species in the electrolyte, indicating strong affinity of the discharged lithium polysulfide species in the SPANI framework. Surprisingly, the Coulombic efficiency of SPANI was consistently decreased with increasing current rates from $0.3 \mathrm{C}$ to $2 \mathrm{C}$, which was different with the traditional Li-S batteries.

\subsection{Discussion}

When sulfur covalently bonded on PANI chains, it is not soluble in organic electrolytes during the cell operations, and thus can improve the long-cycle stability of Li-S batteries. However, the capacities of these active sulfur materials decrease. To verify the contribution of disulfide on SPANI, we designed two control experiments based on S and PANI composites. The first one (S/PANI) was fabricated by simply mixing sulfur and PANI together, and the second one (S-PANI) was fabricated with a traditional heating strategy at $159{ }^{\circ} \mathrm{C}$ for $8 \mathrm{~h}$, and then at $280{ }^{\circ} \mathrm{C}$ for $2 \mathrm{~h}$ in vacuum oven. Both cathodes employing these composites have the same sulfur content with SPANI cathode. The electrochemical performances for both cathodes are shown in Figure 4-6. As can be seen, at $0.6 \mathrm{C}$, both electrodes showed inferior cycling stability with a much lower capacity in comparison with SPANI electrode. Of note, the battery had a higher capacity at $2 \mathrm{C}$ than that at $0.6 \mathrm{C}$ and $1 \mathrm{C}$. The exact mechanisms controlling this unusual phenomenon are still under investigation. One possible explanation is that carbon sulfur bonds (C-S) and disulfide bonds (S-S) on PANI chains have different electrochemical performance with elemental sulfur. The proposed mechanism of the SPANI composite is shown in Scheme 4-2. The disulfide bonds have electrochemical activity due to the intramolecular electrocatalytic effect of the aniline moiety, as well as the improved recombination efficiency from the confined polymer structure that was interconnected with the S-S bonds. During the discharge process, the side chains of S-S functional groups de-polymerized and combined lithium ions to form lithium polysulfides, while the main chain of PANI was stable. During the charge process, a reversed reaction takes place. Generally, the cleavage of S-S bonds and the recombination efficiency are low, since they need a high energy, which was affected by the steric resistant effect of S-S bonds. However, at a larger discharge and charge current, an improved recombination 
efficiency can be achieved, because the S-S bonds could be separated easier. It was confirmed by the larger capacity retention of $700 \mathrm{~mA} \mathrm{~h} \mathrm{~g}^{-1}$ at $2 \mathrm{C}$ than $600 \mathrm{~mA} \mathrm{~h} \mathrm{~g}^{-1}$ at 0.6 $\mathrm{C}$ after 200 cycles. This means that the S-S electrochemical cleavage and recombination process was enhanced at large current rate. Surprisingly, the Coulombic efficiency of $\mathrm{Li} / \mathrm{SPANI}$ battery was lower at $2 \mathrm{C}$ than that at $0.3,0.6$ and $1 \mathrm{C}$. The formation and breaking of the S-S bonds may be the key reason for the different Coulombic efficiency change trend, and further work should be performed to research the fundamental reason.
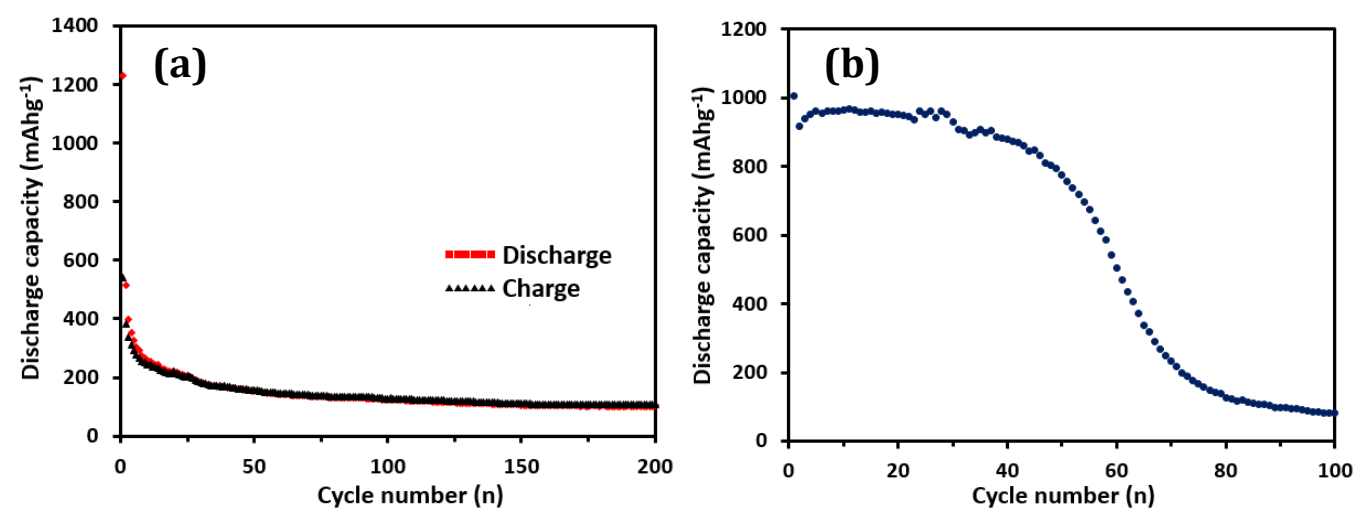

Figure 4-6 Cycling performance of Li-S cell employing (a) S/PANI cathode (50 wt.\% of sulfur, 30 wt.\% of PANI, 10 wt.\% of carbon black, and 10 wt.\% of PVDF); and (b) S-PANI cathode (80 wt.\% of S-PANI, $10 \mathrm{wt} . \%$ of carbon black, and $10 \mathrm{wt} . \%$ of PVDF) at $0.6 \mathrm{C}$.
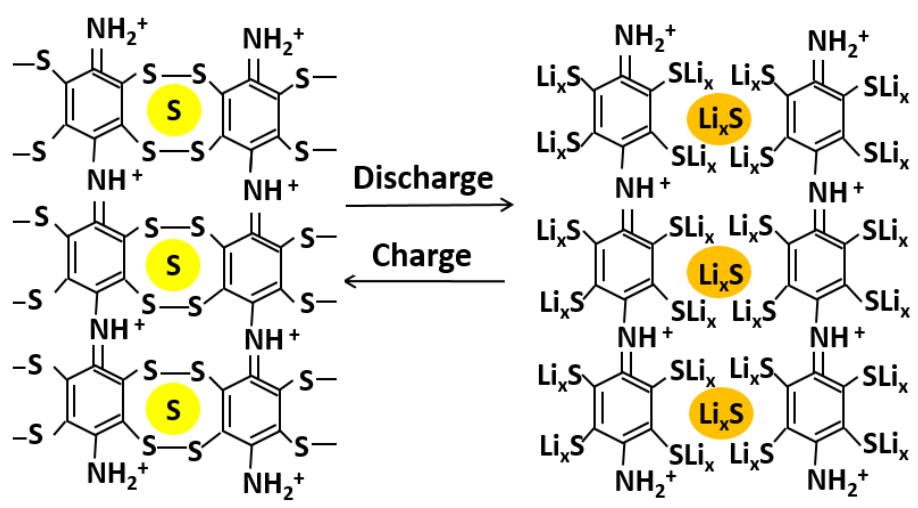

Scheme 4-2 Proposed electrochemical performance of SPANI composites.

Based on the above analysis, the SPANI cathodes enhanced cycling stability of Li-S batteries. We attributed the improved performance to the unique structure of SPANI, which not only provided multiple nanopores and strong affinity to trap polysulfide anions during the repeated cycles, but also contained multiple disulfide bonds with 
electrochemical activity. When comparing the surface morphologies of SPANI with the S-PANI that was fabricated by heating, we observed there were multiple interconnected nanopores on SPANI surface, while the S-PANI had a nanoparticle morphology with a relatively smooth surface without pores (Figure 4-7). The nanoporous coralloid structure in SPANI was conducive to fast mass transportation within the macrometer size pores, and offered a high degree of interconnectivity of PANI chains to ensure high electron conductivity across the entire structure. In addition, the multiple nano-flakes in the coralloid SPANI structure also accommodated volume change of sulfur and provided large specific surface areas, which not only offered more electroactive sites for sulfur, but also immobilized polysulfide species and reduced the aggregation of sulfur. The SEM image of the SPANI cathodes after 100 cycles is shown in Figure 4-8a. As can be seen, the active sulfur materials were uniformly distributed on the porous coralloid SPANI structure and formed a thick layer, indicating the strong interaction between sulfur and PANI. The corresponding Energy-dispersive X-ray spectroscopy (EDS) mapping was shown in Figures 4-8b-8d. The density of sulfur materials was much higher than carbon and nitrogen, confirming the existence of both elemental sulfur and disulfide bonds in SPANI materials.

When sulfur was reduced upon fully discharge, the sulfur chemical bonding and a strong interaction between intermediate polysulfide species and the SPANI framework was important to hold the active sulfur materials in the cathode and retain effectively electrical contact with PANI. This assumption was verified by electrochemical impedance spectroscopy spectra (EIS), as shown in Figure 4-9a. When compared with S/PANI composite cathode, the SPANI cathode presented a smaller semicircle at the high-frequency region, since the chemical bonding and strong interactions significantly reduced the charge-transfer resistance in SPANI structure. The improved electronic conductivity together with the enhanced fast mass transportation property might increase the electrocatalytic activity of sulfur toward complete transformation to lithium sulfide $\left(\mathrm{Li}_{2} \mathrm{~S}\right)$. In addition, the electrostatic interaction between the alkyl ammonium cations and polysulfide anions might also be vital for the effectively entrapment of polysulfide species during cycling. As shown in the XPS spectra (Figure 4-9b), the binding energy 
of $\mathrm{N}$ 1s peak was reduced from 399.2 (before cycling) to $398.3 \mathrm{eV}$ (after cycling), indicating the strong interactions of the alkyl ammonium cations with polysulfide species.

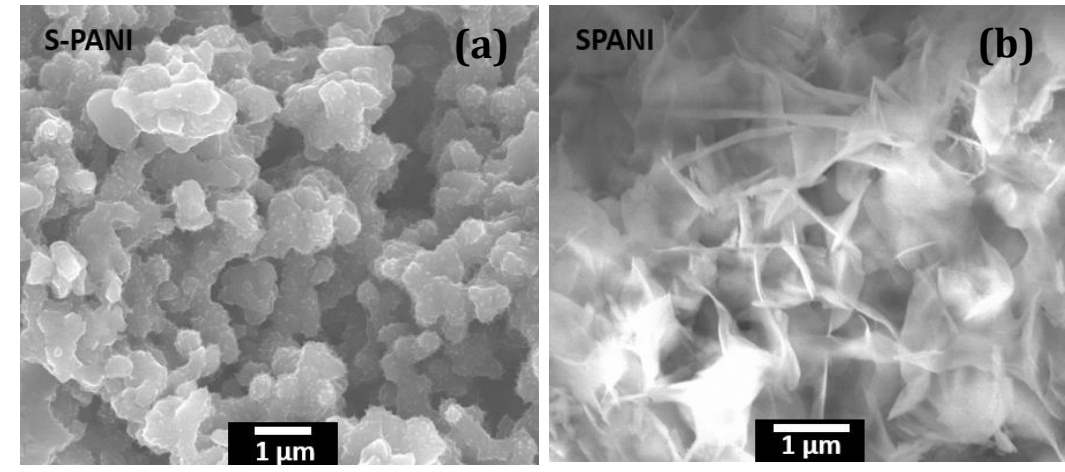

Figure 4-7 SEM images of S-PANI and SPANI. (a) S-PANI and (b) SPANI.
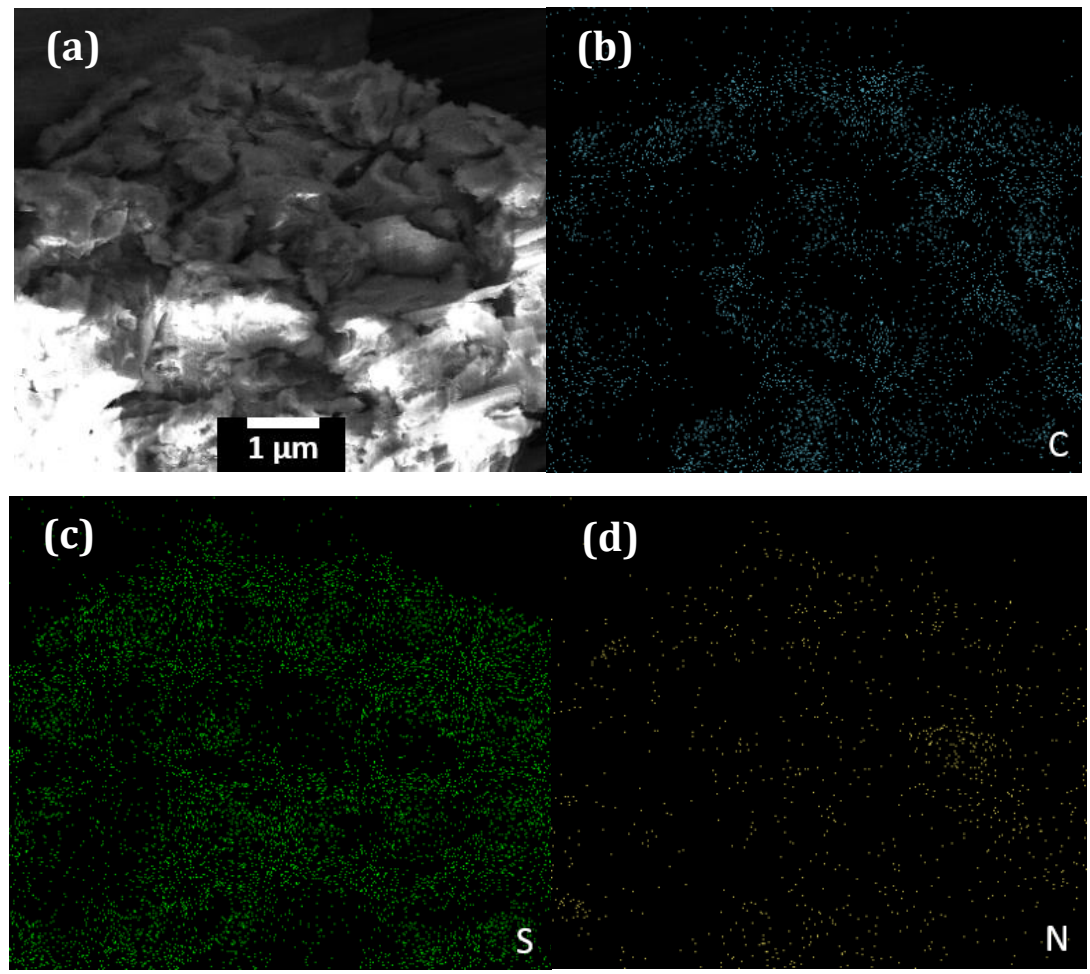

Figure 4-8 SEM and EDS mapping data of the cathode after 100 cycles. (a) SEM image of the SPANI cathode. EDS mapping showing the homogenous distribution of (b) carbon, (c) sulfur, and (d) nitrogen in the SPANI composite, respectively. 

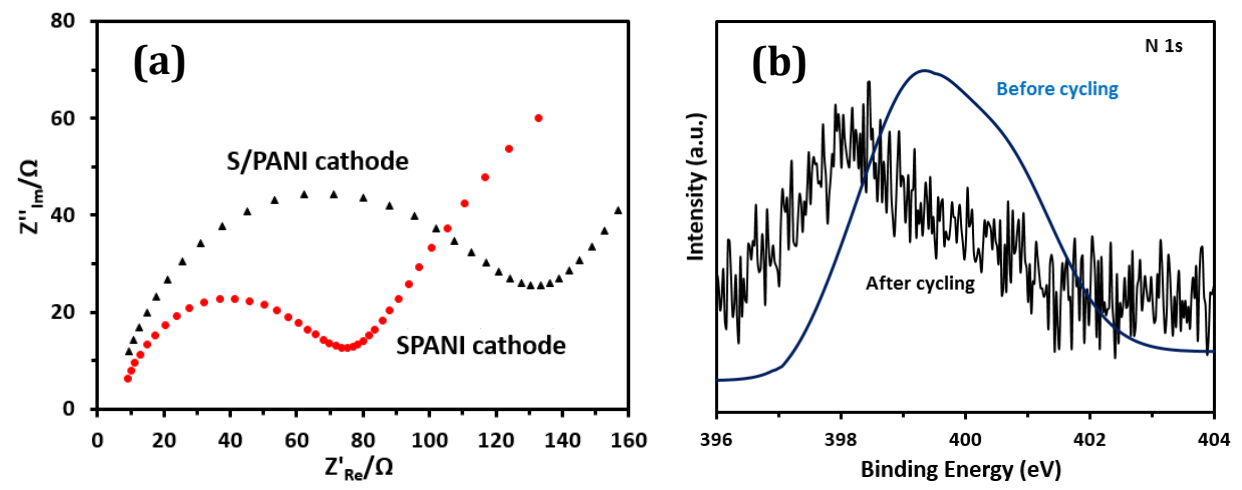

Figure 4-9 (a) EIS tests of Li-S cells employing S/PANI cathode and SPANI cathode. The fabrication of S/PANI cathode was described in Figure S4a. (b) N 1s spectra of SPANI before cycling and after 100 cycles.

\subsection{Conclusions}

In summary, for the first time, we have fabricated nanoporous coralloid SPANI polymers with a two-step chemical process, and showed a bonding stabilization of polysulfide species on its long-chain backbones. These covalently bonded polysulfide species contributed to high performance of Li-S batteries including high rate capability, long lifespan and high reversible capacity. The coralloid SPANI structure had tripe role in improving electrochemical performance of the SPANI cathodes: (i) it crosslinked to enhance strong interaction between the nonpolar carbon surface and various polar discharge polysulfide species; (ii) it fixed sulfur on SPANI by chemical interaction, and thus reduced the diffusion of polysulfides during cycling; and (iii) it enhanced the electron and ion conductivities in the composite cathode by increasing the meso-pore volumes and surface areas. In addition, the SPANI framework provided a high mechanical stability. Based on this structure, the SPANI demonstrated a superior rate response up to $2 \mathrm{C}$, and delivered a high performance over 200 cycles with $89.4 \%$ capacity retention. The SPANI cathodes may offer a new way to solve the long-term cycling difficulty for sulfur-carbon cathodes and can serve as the basis for significant future work. Further investigations will be conducted to understand the disulfide bond reaction mechanism and enhance the high-rate capability of Li-S cells employing SPANI cathodes. 


\section{Chapter 5: Sulfur Cathode Structures Development: Multilayered Electrodes}

As demonstrated in Chapters 3 and 4, SC materials are effective in trapping polysulfide anions within the cathode structure. The capacity of such materials could be improved. As aforementioned (Chapter 1), two electrons are needed for each sulfur atom, based on this calculation, sulfur has a high theoretical capacity of $1675 \mathrm{~mA} \mathrm{~h} \mathrm{~g}$. When sulfur combined with carbon, the sulfur atom that directly bonded with carbon atom will lose one electron, which lead to half of its theoretical capacity. In order to maximize the value of Li-S batteries, novel cathode structure design is a strategy. The objective in this chapter is to develop advanced cathode materials by building the right nano-structures using the right material combinations. Battery electrodes (anode and cathode) must conduct electrons and ions to the active redox sites within the electrode matrix, and as a result most electrodes generally consist of multiple materials and the interface among these materials are important. In this chapter, we developed a novel nano-structured sulfur composite cathode using layer-by-layer nano-assembly technology, from which the interface among the composite materials can be finely tuned to minimize interface barrier.

Due to the film growth behavior of multilayered electrodes, extra cell components such as binders are rendered unnecessary, thereby decreasing the cell weight. In addition, the binder-free composite could eliminate the use of toxic NMP solvent during regular electrode fabrication in Li-ion battery industry. The value of this design was that it is able to achieve a high degree of sulfur loading by using multilayered structure as a scaffold for sulfur deposition, and to obtain rapid charge and discharge without sacrificing capacity. Currently, electrodes (particularly cathodes) are usually solvent cast from slurry, and optimized interfaces among component materials have not been achieved. Moreover, it is suggested that the ideal electrode architecture that can provide efficient ion and electron transport should consist of an interpenetrating network of electron and ion pathways. In addition, layer-by-layer nano-assembly could be scaled up, and has been widely studied to prepare multiple nano-layers on a variety of surfaces. Electrostatic 
attraction is believed to be the main driving force while other forces (e.g. hydrophobic, and van der Waals) may also play a role in the multiple nano-layer formation.

\subsection{Introduction}

In the current Li-S systems, polysulfide dissolution represents a common but not the sole reason for the capacity decay of sulfur cathodes. [24, 32] Investigations by in operando transmission X-ray microscopy and inductively coupled plasma-optical emission spectroscopy have revealed that dissolution of sulfur in electrolytes is not so severe and takes limited responsibility for capacity fade. [32] Recently, the detachment and separation of lithium sulfides $\left(\mathrm{Li}_{2} \mathrm{~S}\right.$ and $\left.\mathrm{Li}_{2} \mathrm{~S}_{2}\right)$, the full-discharge products, from the carbon matrix were identified as another important, but rarely noticed, contributing factor to cause irreversible active mass loss and electrical contact isolation. [154, 155] To mitigate this problem, amphiphilic polymers have been introduced to modify the interfacial properties of sulfur-carbon composites, achieving a long lifespan of 300 cycles at 0.5 C. [154] Nevertheless, the rate capability of cells is still limited by non-covalent adsorption of the poorly conductive polymer shell on carbon surfaces. Well-designed electrode structures and manipulation of sulfur distributions and attachments on the nanometer scale may be effective in enhancing the stability and performance of sulfur cathodes.

Here, we report the layer-by-layer (LbL) nano-assembly fabrication of efficient, multilayered sulfur cathodes. [93, 156-160] The multilayered cathodes were fabricated on aluminum current collectors by alternate adsorption of negatively charged S-carbon nanotubes polystyrene sulfonate (S-CNT-PSS ${ }^{-}$) and positively charged S-polyaniline nanotubes (SPANI)-NH ${ }^{+}$as shown in Figure 5-1a. Polyaniline (PANI) was deposited as the outermost layer to prevent direct contact between sulfur and the electrolyte. The formed sandwich-like porous structures acted as self-control poly-shuttle frameworks by forming physical and chemical barriers that reduced the migration of polysulfides from the cathode toward the Li-anode as shown in Figure 5-1b. 

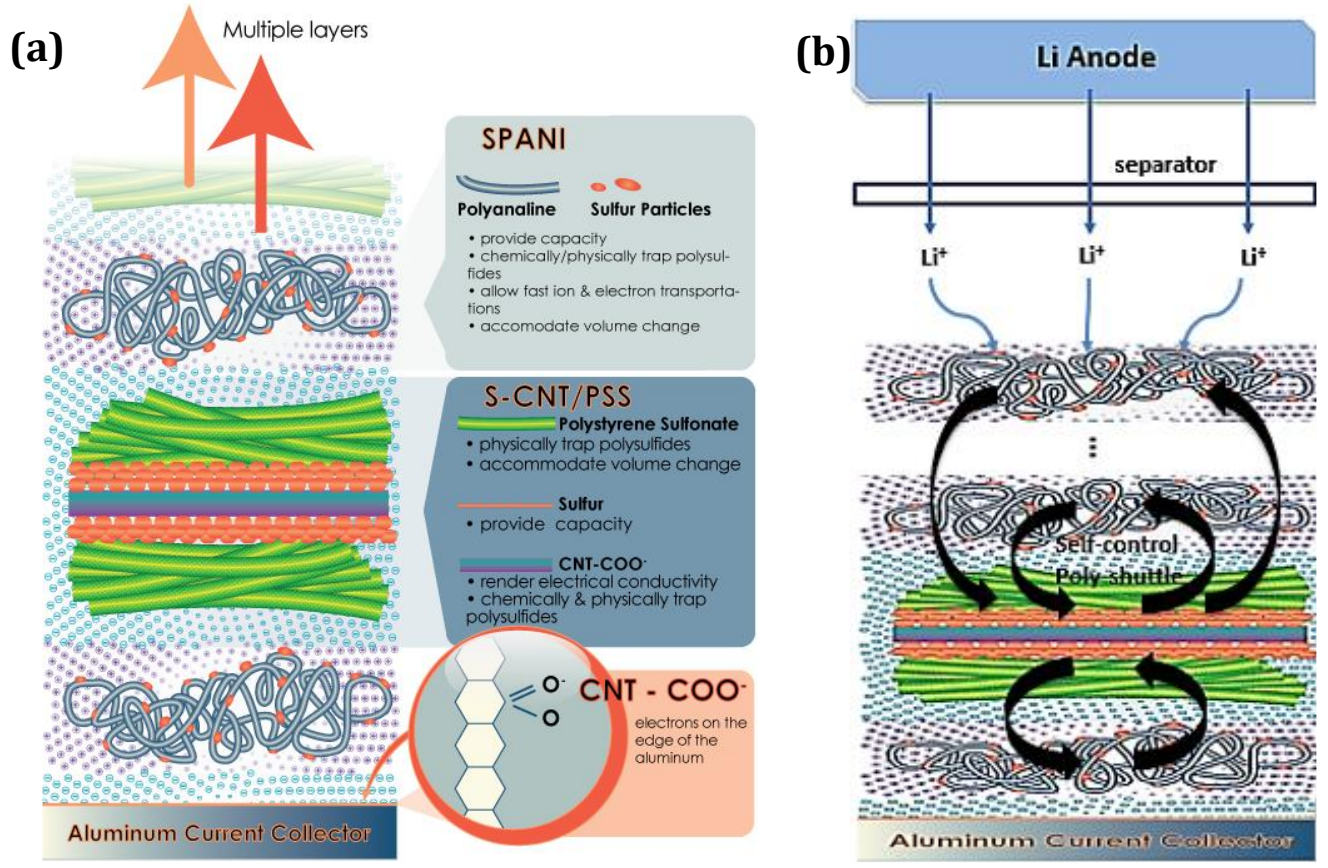

Figure 5-1 (a) Schematic diagram of multilayered cathode fabricated by the LbL nano-assembly process and functions of each component. (b) Schematic diagram of the self-control poly-shuttle process in the multilayered cathode.

\subsection{Experimental}

\subsubsection{Preparation of S-CNT Composites}

Multi-walled carbon nanotubes (CNTs, 110 170 nm in diameter and 5 9 $\mu \mathrm{m}$ in length, Sigma-Aldrich, St. Louis, MO) were soaked in nitric acid (70 wt.\%) and sulfuric acid (98 wt.\%) (v 1:3) in an ultrasonic container for $1 \mathrm{~h}$, kept in an oven of $70{ }^{0} \mathrm{C}$ for $2 \mathrm{~h}$, and then rinsed with distilled water to get FCNTs. The FCNTs were dispersed into sodium dodecyl sulfate (SDS) aqueous solution (Sigma-Aldrich). Meanwhile, sulfur powder $(99.98 \%$, Sigma-Aldrich) was dissolved in tetrahydrofuran (THF, SigmaAldrich) to form a saturated solution. Next, the sulfur-saturated THF and FCNTs in SDS were mixed for $12 \mathrm{~h}$ under magnetic stirring, then centrifuged. The supernatant was decanted and the remaining materials were washed using deionized water to remove SDS. Finally, the as-prepared S-CNTs were mixed with sulfur (1:1 wt.\%) and treated in a vacuum oven at $159{ }^{\circ} \mathrm{C}$ for $8 \mathrm{~h}$ then at $300{ }^{\circ} \mathrm{C}$ for $1.5 \mathrm{~h}$. 


\subsubsection{Preparation of SPANI}

Aniline, sodium dodecylbenzenesulfonate (SDBS), and ammonium persulfate, purchased from Sigma-Aldrich, were dissolved in hydrochloride aqueous solution for 40 $\mathrm{h}$, washed using distilled water and dried in a vacuum oven at room temperature for $24 \mathrm{~h}$ to obtain PANI nanotubes. PANI, sulfur monochloride (Sigma-Aldrich), and aluminum chloride (Sigma-Aldrich), were soaked in acetonitrile in a sealed flask for $10 \mathrm{~h}$, washed using ether, and dried in a vacuum oven at $80{ }^{\circ} \mathrm{C}$ for $24 \mathrm{~h}$ to obtain chloride PANI. Sulfur and sodium sulfide were then mixed in N,N-dimethylformamide (DMF) in a vacuum oven for $6 \mathrm{~h}$ to obtain disodium pentasulfide $\left(\mathrm{Na}_{2} \mathrm{~S}_{5}\right)$. Next, the chloride PANI was soaked in a $\mathrm{Na}_{2} \mathrm{~S}_{5}$ solution for $24 \mathrm{~h}$ in a vacuum oven, washed with deionized water, and dried in a vacuum oven at $80{ }^{\circ} \mathrm{C}$ for $24 \mathrm{~h}$ to achieve initial sulfurized PANI. Finally, the initial sulfurized PANI was mixed with sulfur (1:1 wt.\%) in carbon disulfide solution $\left(\mathrm{CS}_{2}\right.$, Sigma-Aldrich) for $2 \mathrm{~h}$ under magnetic stirring and heated in a vacuum oven at 280 ${ }^{\circ} \mathrm{C}$ for $2 \mathrm{~h}$ to obtain SPANI.

\subsubsection{Fabrication of Multilayered Cathodes Using LbL Nano-Assembly Technique}

A. Aluminum substrate treatment. Aluminum current collector was used as the

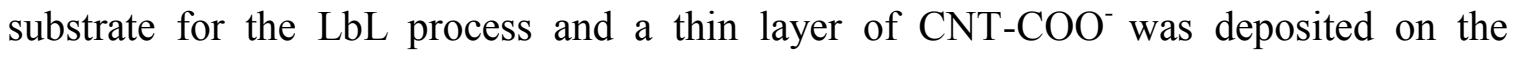
substrate by electrophoretic deposition (EPD) technique.

B. LbL process. First, SPANI was treated with $\mathrm{NH}_{2} \mathrm{OH}$ solution at $70{ }^{\circ} \mathrm{C}$ for $2 \mathrm{~h}$ and SCNT was mixed with poly(styrenesulfonate) (PSS, MW 70,000, Sigma-Aldrich) solution for $2 \mathrm{~h}$. These treated powders were then sonicated for $6 \mathrm{~h}$ in deionized water separately. The $\mathrm{pH}$ values of both solutions were adjusted to 3.5 and the solutions were sonicated for $3 \mathrm{~h}$ before LbL assembly. The purpose of introducing PSS here was to facilitate the growth of the multilayer films via electrostatic interactions; PSS is a strong polyelectrolyte. Details of LbL assembly of cathodes can be found elsewhere. In brief, the process involves immersing the treated substrate into the SPANI suspension for $3 \mathrm{~min}$ and then washing the substrate in deionized water for $30 \mathrm{sec}$; next, placing the SPANIcoated substrate into S-CNT suspension for 3 min and then washing in deionized water for $30 \mathrm{sec}$. These steps are repeated until the desired number of layers is achieved. In the 
present study, the multilayered cathode has 90 bi-layers with sulfur loading of 1.76 $\mathrm{mg} \cdot \mathrm{cm}^{-2}$. Finally, the assembled multilayered cathodes are dried in air and treated at 100 ${ }^{\circ} \mathrm{C}$ in a vacuum oven for $5 \mathrm{~h}$. The cathode is now ready to be assembled into a cell. Note that the LbL method can produce a large number of samples by robot machines and has the potential for large-scale industrial applications.

\subsubsection{XPS, XRD, and FTIR Measurements}

Kratos Axis Ultra XPS (Kratos Analytical) with a monochromatized Al Ka X-ray source, PANalytical XRD, and FTS 7000 FTIR were used to analyze the surface chemistry of S-CNT, SPANI, and multilayered cathodes. Curve fittings of the XPS spectra were performed following a Shirley-type background subtraction.

\subsubsection{Electrochemical Measurements of Multilayered Cathode-Based Cells}

CR2016-type coin cells were used as the testing cells. Lithium foils were used as the anodes, Cellgard 2400 microporous membranes as separators, $1.0 \mathrm{molL}^{-1}$ bis(trifluoromethane sulfonyl) imide (LiTFSI) and $0.15 \mathrm{molL}^{-1} \mathrm{LiNO}_{3}$ dissolved in dioxolane (DOL) and dimethoxyethane (DME) $(1: 1, \mathrm{v} / \mathrm{v})$ as electrolytes, and SCNT/SPANI multilayered composite as cathodes. The cells were assembled in an Argonfilled glove box. Electrochemical measurements were performed galvanostatically between 1.0 and $3.0 \mathrm{~V}$ at current densities of 550, 1300, 1950, and $6400 \mathrm{mAg}^{-1}$. Capacity was calculated based on the weight of all materials on the cathodes. CV experiments were conducted using a NOVA potentiostat at scan rates of 5, 0.5, and $0.1 \mathrm{mVs}^{-1}$. EIS measurements were carried out using a NOVA electrochemical workstation in a frequency range between $100 \mathrm{kHz}$ and $100 \mathrm{mHz}$ at a potentiostatic signal amplitude of 5 $\mathrm{mV}$. All experiments were conducted at room temperature.

\subsection{Results and Discussion}

\subsubsection{Characterizations of the Multilayered Cathodes and Related Materials}

S-CNT Materials. S-CNT was synthesized using functionalized CNT (FCNT). The pristine FCNT tended to agglomerate due to strong van der Waals interactions (Figure 5-2a). However, these interactions appeared to weaken after a thin layer of sulfur 
was coated on the surface of the FCNT (Figure 5-2b). The sulfur on the FCNT surface was evaluated by X-ray diffraction (XRD), in which obvious characteristic peaks of sulfur were observed for S-CNT (Figure 5-2c). The S-CNT had typical sulfur peaks, indicating its uniform deposition on CNT surfaces. By comparison, SPANI showed both sulfur and PANI peaks, indicating that sulfur layers did not completely coat the PANI surfaces. A monoclinic sulfur phase was detected by XRD in S-CNT after heating at 159 ${ }^{\circ} \mathrm{C}$ for $8 \mathrm{~h}$ and then $300{ }^{\circ} \mathrm{C}$ for $1.5 \mathrm{~h}$. At $300{ }^{\circ} \mathrm{C}$, elemental sulfur may react with FCNTs and form covalently bonded sulfur. C-S bonds formed were verified by the two additional peaks at $740 \mathrm{~cm}^{-1}$ and $933 \mathrm{~cm}^{-1}$ in the Fourier transform infrared spectroscopy (FTIR) analysis (Figure 5-2d), since it is known that $S_{8}$ shows no vibrational activity in the 900 to $2000 \mathrm{~cm}^{-1}$ range.[146] FCNT showed characteristic bands at 1290, 1430, and $1680 \mathrm{~cm}^{-}$ ${ }^{1}$ corresponding to the $\mathrm{C}-\mathrm{O}, \mathrm{C}=\mathrm{O}$, and $\mathrm{C}=\mathrm{C}$ stretch, respectively. All the $\mathrm{C}-\mathrm{O}$ and $\mathrm{C}=\mathrm{O}$ peaks of S-CNT were smaller than that of FCNT, indicating the decrease of functional groups after reacting with sulfur. The sulfur content in the S-CNT was found to be 76.9 wt.\% by thermo gravimetric analysis (TGA) (Figure 5-2e). TGA results indicated that the weight-loss and weight-loss temperature of S-CNT were higher than those of S/CNT composites, suggesting a promoted affinity and interaction between sulfur and FCNT.
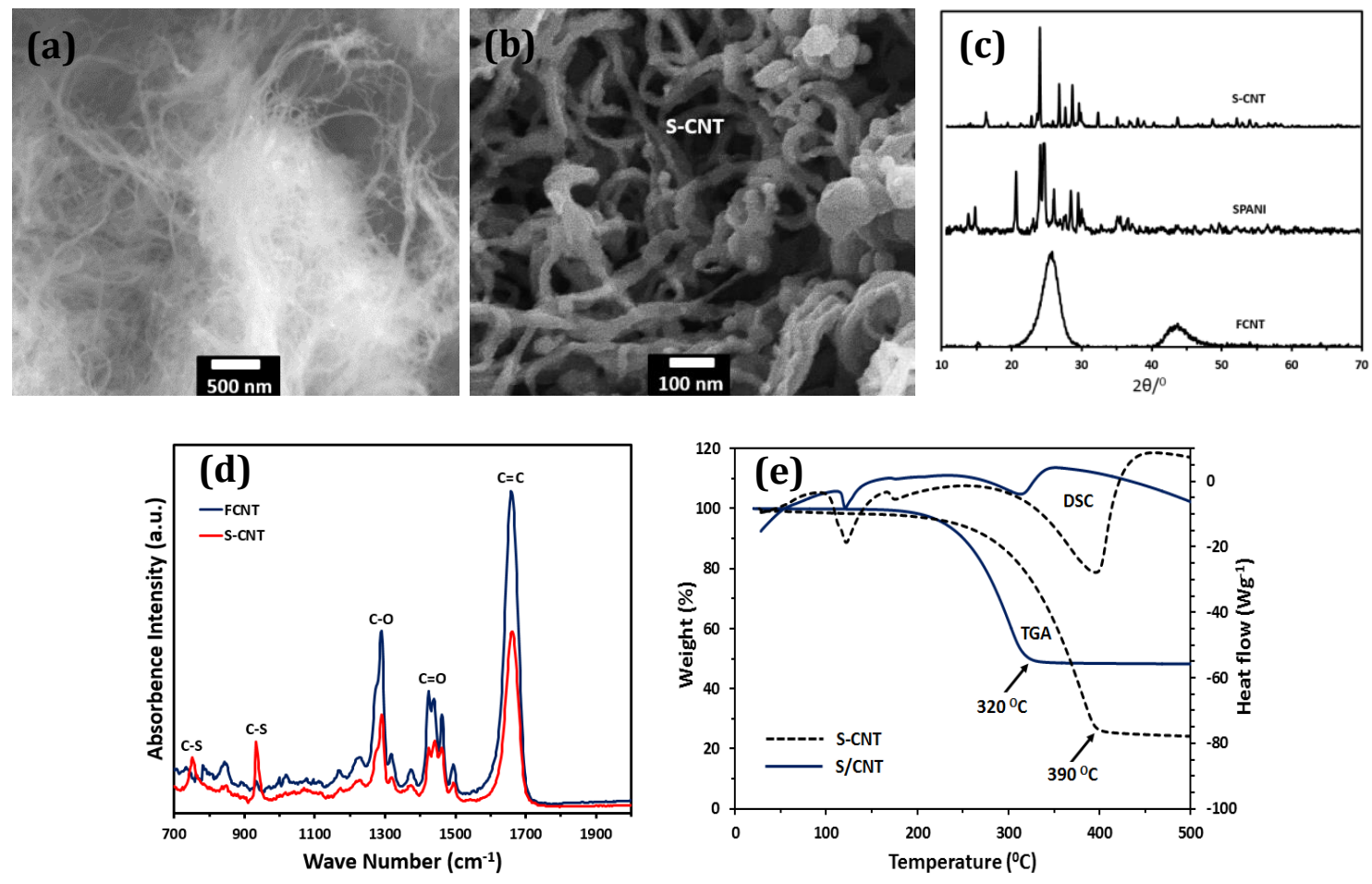
Figure 5-2 Characterizations of S-CNT materials. Scanning electron microscopy (SEM) images of (a) FCNT and (b) S-CNT. (c) XRD analysis of S-CNT, SPANI and FCNT. (d) FTIR spectra of S-CNT and FCNT. (e) TGA and DSC analysis of S-CNT.

SPANI Materials. SPANI was synthesized using PANI precursors. The as prepared PANI nanotubes were shown in Figure 5-3a. The typical morphology of the SPANI was shown in Figure 5-3b where bulk sulfur particles were also found on SPANI surfaces which may be attributed to strong capillary force during the post-heat treatment. X-ray photoelectron spectroscopy (XPS) was conducted on the SPANI polymer and the fitted curves indicated that the back-chains of PANI were chemically modified and physically coated with sulfur (Figures 5-3c-f). The lower binding energy feature (163.7 $\mathrm{eV}$ ) was due to $\mathrm{S}_{8}$. The second peak at $165 \mathrm{eV}$ could be attributed to C-S bonds. The ratio of $[\mathrm{S}] /[\mathrm{C}-\mathrm{S}]$ provided a direct evaluation of the covalent bonds between sulfur and the $\mathrm{C}$ atoms of PANI. These C 1s spectra could be separated into four peaks. The first three peaks were due to the $\mathrm{C}-\mathrm{C}$ group $(284.2 \mathrm{eV})$ in the aromatic ring, $\mathrm{C}-\mathrm{N}$ bonds $(285.2 \mathrm{eV})$, and $\mathrm{C}=\mathrm{N}$ bonds $(286.6 \mathrm{eV})$. The fourth peaks centered at $288.4 \mathrm{eV}$ was attributed to the $\pi-\pi^{*}$ shake-up satellite. [152, 153] The $\mathrm{N}^{+}$peak at $400.8 \mathrm{eV}$ was due to the protonated amine after being heated with sulfur at $300{ }^{\circ} \mathrm{C}$. TGA results indicated that the sulfur content in SPANI was 65.4\% (Figure 5-3g).
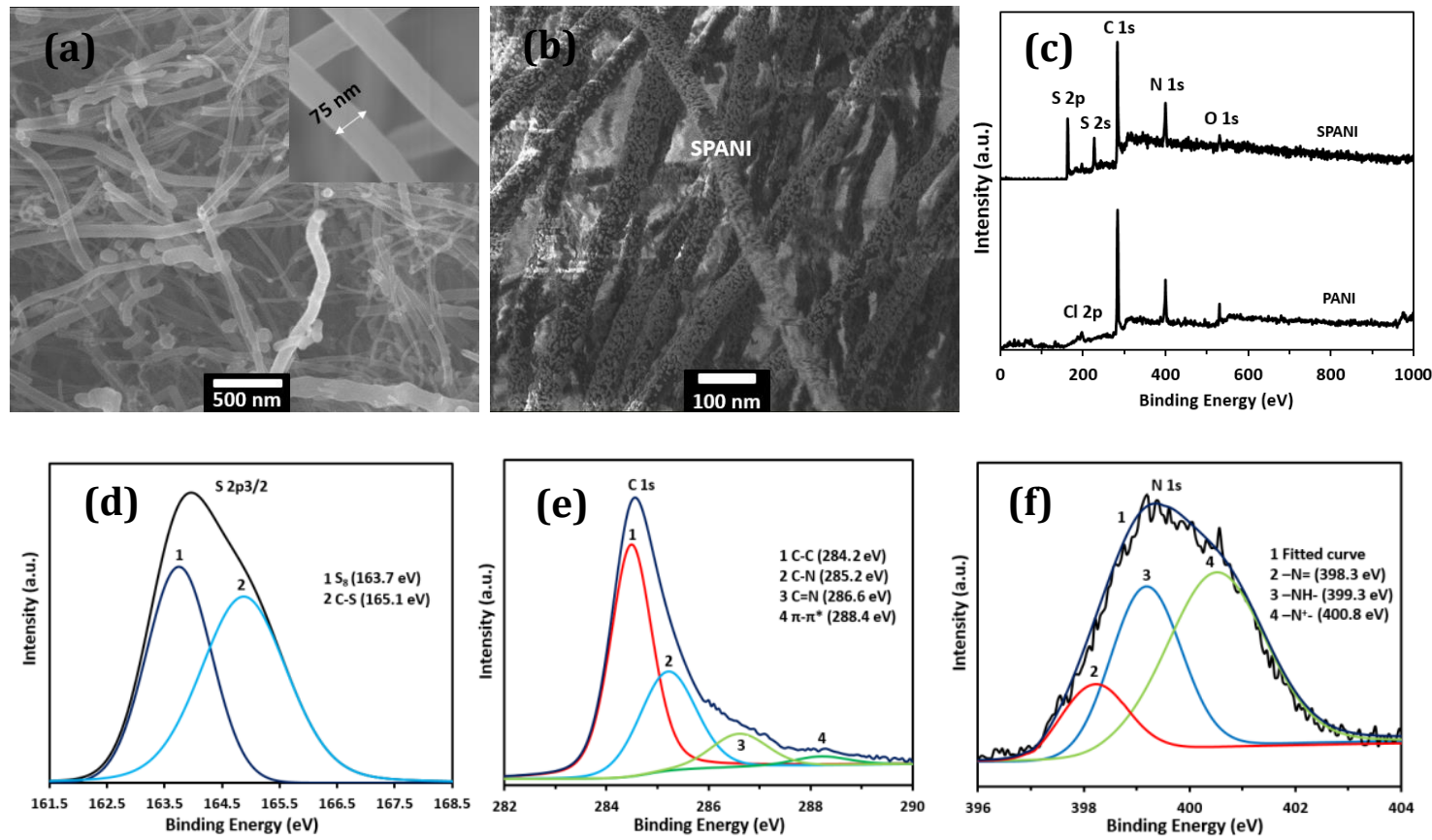


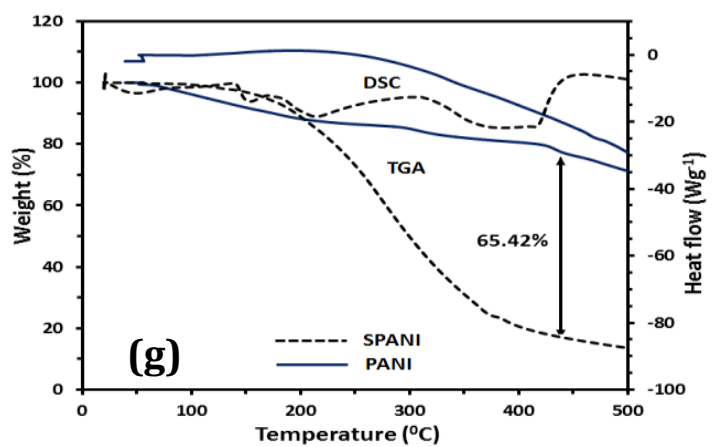

Figure 5-3 SEM image of (a) the as-prepared PANI nanotubes and (b) SPANI composites. (c) Wide range XPS spectra of PANI and the obtained SPANI. (d) XPS data of S 2p regions of SPANI. (e) XPS data of C 1 s regions of SPANI. (f) XPS data of N 1s regions of SPANI. (g) TGA and DSC analysis of SPANI showing $65.4 \mathrm{wt} \%$ of sulfur in SPANI composite.

Multilayered Cathodes. The ultrahigh aspect ratio and good mechanical strength of FCNT and PANI led to a multilayered cathode with a robust structure that possessed abundant interconnected channels through which Li-ions might pass (Figures 5-4a-c). These channels formed 3-D porous frameworks that favored the penetration of electrolytes. Since sulfur is involved in multi-step reactions during discharge and charge, Li-ion and electron transports are important factors. The empty pores in the multilayered cathode acted as reservoirs for liquid electrolytes capable of fast Li-ion conduction. Meanwhile, the highly intertwined PANI and FCNT facilitated electrical conductivity and, to a lesser extent, Li-ion transport. The multilayered structure formed a 3-D integrated skeleton and the discrete layers ensured a homogeneous sulfur distribution. The skeleton provided large reactive interfacial areas that allowed easy incorporation and manipulation of sulfur. The structure facilitated electronic and ionic conduction across the multilayered interfaces between the discrete layers and the electrolyte, maximizing the efficiency of sulfur in combining with lithium. The thickness of the multilayered cathode increased approximately linearly with the increasing number of bilayers; the cathode with 90 bilayers had a thickness of $35.3 \mu \mathrm{m}$ with a material density of $2.75 \mathrm{mg}$ $\mathrm{cm}^{-2}$ after heat treatment (Figure 5-4d). XPS analysis of the multilayered cathodes after heat treatment revealed significant amounts of $\mathrm{S}_{8}$ and C-S bonds within the cathodes (Figure 5-4e). The peak at $164.4 \mathrm{eV}$ in the $\mathrm{S} \mathrm{2p3/2} \mathrm{spectrum} \mathrm{indicated} \mathrm{elemental} \mathrm{sulfur,}$ while the peak at $165.4 \mathrm{eV}$ in the $\mathrm{S} 2 \mathrm{p} 1 / 2$ spectrum suggested that $\mathrm{S}$ atoms were linked to 
a benzenoid ring (SPANI) and a quinoid ring (sulfurized CNT). The small peak at 168.5 corresponded to PSS. The atomic composition of the multilayered cathode was found to be 29.2 wt.\% carbon, 64.1 wt.\% sulfur, 4.6 wt.\% oxygen, and 2.1 wt.\% nitrogen. TGA results indicated that the sulfur content in the whole cathode was $67.5 \%$ (Figure 5-4f).
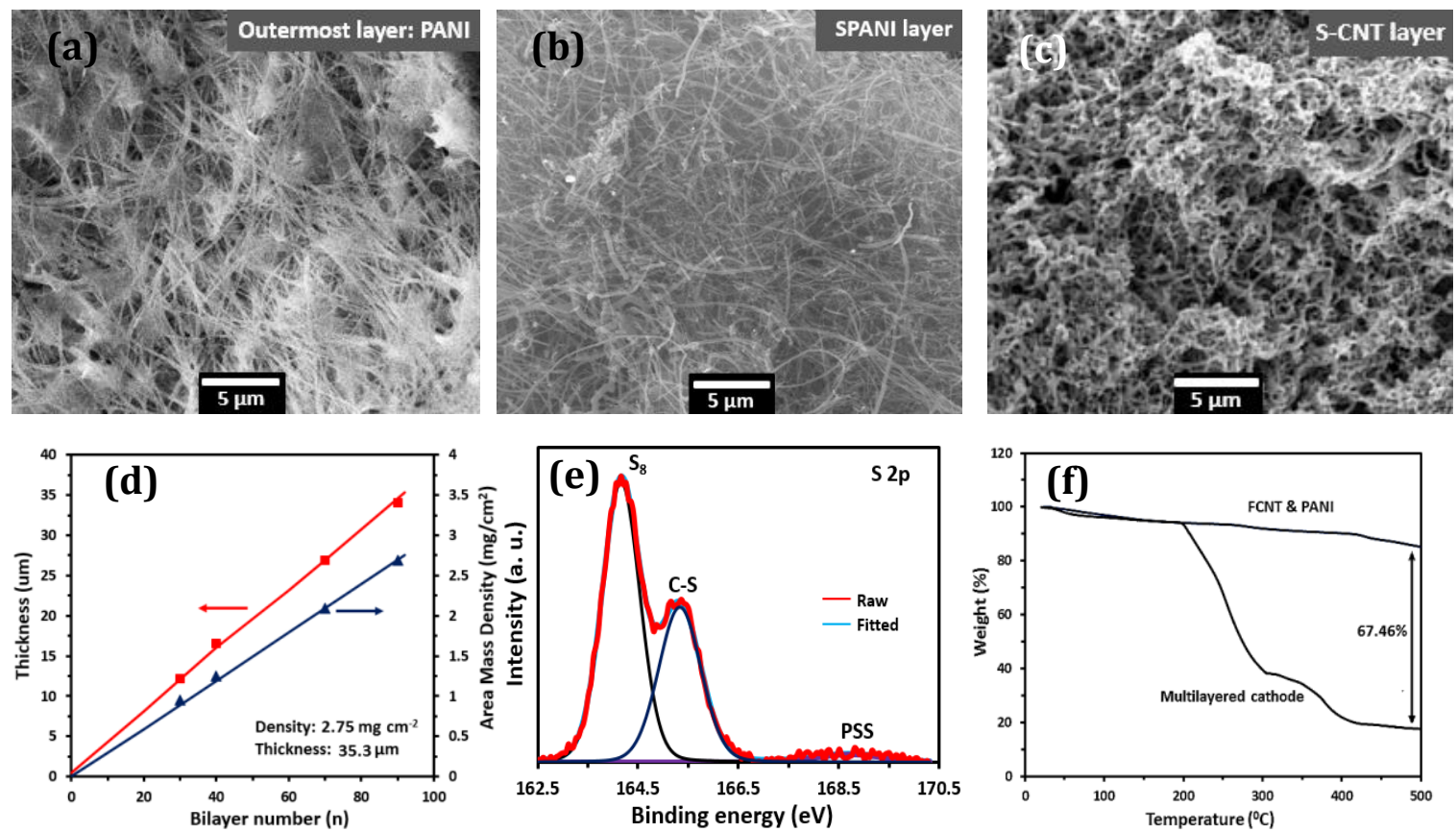

Figure 5-4 Characterizations of multilayered cathodes. SEM images of (a) the outermost layer, PANI, (b) SPANI layer, and (c) S-CNT layer. (d) Area mass density $\left(\mathrm{mg} \mathrm{cm}^{-2}\right)$ and thickness $(\mu \mathrm{m})$ vs. bilayers of multilayered cathodes on aluminum current collectors. (e) XPS and (f) TGA analysis of the multilayered cathodes.

\subsubsection{Electrochemical Performance of Multilayered Cathodes}

The rate capability of multilayered cathodes is shown in Figure 5-5a. The $\mathrm{C}$ rates specified in this study are based on the theoretical capacity of sulfur, with $1 \mathrm{C}=1675 \mathrm{~mA}$ $\mathrm{g}^{-1}$. The initial discharge capacity reached $1346 \mathrm{~mA} \mathrm{~h} \mathrm{~g}^{-1}$ of sulfur at $0.1 \mathrm{C}$, which is $80.4 \%$ of the theoretical value for sulfur. A reversible capacity of $1014 \mathrm{~mA} \mathrm{~h} \mathrm{~g}^{-1}$ was observed at the 300th cycle, corresponding to $75.3 \%$ capacity retention. The results demonstrated the superiority of the multilayered structure in enhancing the active material utilization. As current density varied from 0.1 to $2.5 \mathrm{C}$, the multilayered cathodes still displayed reasonable capacity although capacity decreased gradually, which 
may be due to the polarization effect. Even at a rate of $2.5 \mathrm{C}$, the cell capacity exceeded $580 \mathrm{~mA} \mathrm{~h} \mathrm{~g}^{-1}$ after 150 cycles, demonstrating high rate performance and robust structure.

The long-term cycling behavior and Coulombic efficiency of multilayered cathodes at different current densities are shown in Figure 5-5b. Significantly improved cycling stability was observed at the current densities studied. For instance, at $0.3 \mathrm{C}$, the cell had a high reversible capacity of $1100 \mathrm{~mA} \mathrm{~h} \mathrm{~g}^{-1}$. A reversible capacity of $818 \mathrm{~mA} \mathrm{~h} \mathrm{~g}^{-1}$ was obtained even after 600 cycles, corresponding to $74.4 \%$ of capacity retention with an average Coulombic efficiency of $97.5 \%$. It is noteworthy to mention that Li-S cells using the same multilayered cathode but having no lithium nitrate additive in electrolyte also had a high Coulombic efficiency of $96.3 \%$ (Figure 5-5c), while the traditional Li-S cells using slurry-coating sulfur cathodes had a much lower Coulombic efficiency of $\sim 80 \%$ (Figure 5-5d). These results indicated that the polysulfide shuttling effects were significantly mitigated in the multilayered sulfur cathode based cells. Unlike traditional sulfur cathodes with poor contact between sulfur and carbon during discharge/charge, the multilayered sulfur structure provided strong affinity of polysulfides/sulfur and reduced their dissociation from the interconnected network of CNTs and PANIs during cycling (Figures 5-6a and 6b). The intimate contact layers within the multilayered structure further attracted polysulfide anions and prevented the anions from "leaking" out (Figure 5-6c). In addition, the porous frameworks in the multilayered cathodes accommodated the volume change of the sulfur and the corresponding strains accumulated in the cathodes, thus leading to improved cycling stability.

The current density also had a great influence on the discharge reactions (Figure 5$5 \mathbf{b})$. At a high current density of $2.5 \mathrm{C}$, the discharge capacity of multilayered cathodes reached a steady state after 130 cycles, probably because sulfur could not be reacted until it was exposed to the electrolyte after the initial cycles at high $\mathrm{C}$ rates. However, at a low current density of $0.1 \mathrm{C}$, we estimated that $\sim 80 \%$ of sulfur reacted with lithium from the beginning of the test. While at moderate current densities of $0.3,0.6$, and $1 \mathrm{C}$, a decrease in the first few cycles followed by an increase in discharge capacity was observed. The decrease was probably caused by the catalytic reduction of electrolyte solvents on the 
fresh surfaces of the multilayers, and the formation of solid electrolyte interface films on Li-anodes. The increase was probably related to the high solubility of polysulfides in electrolytes. Initially, the cathodes contained bulk sulfur, which could not completely react at the end of discharge. After a few cycles, the electrolyte infiltrated into the internal layers and the bulk sulfur reacted and pulverized. Subsequently, the cells reached a steady state and showed stable cyclic properties.
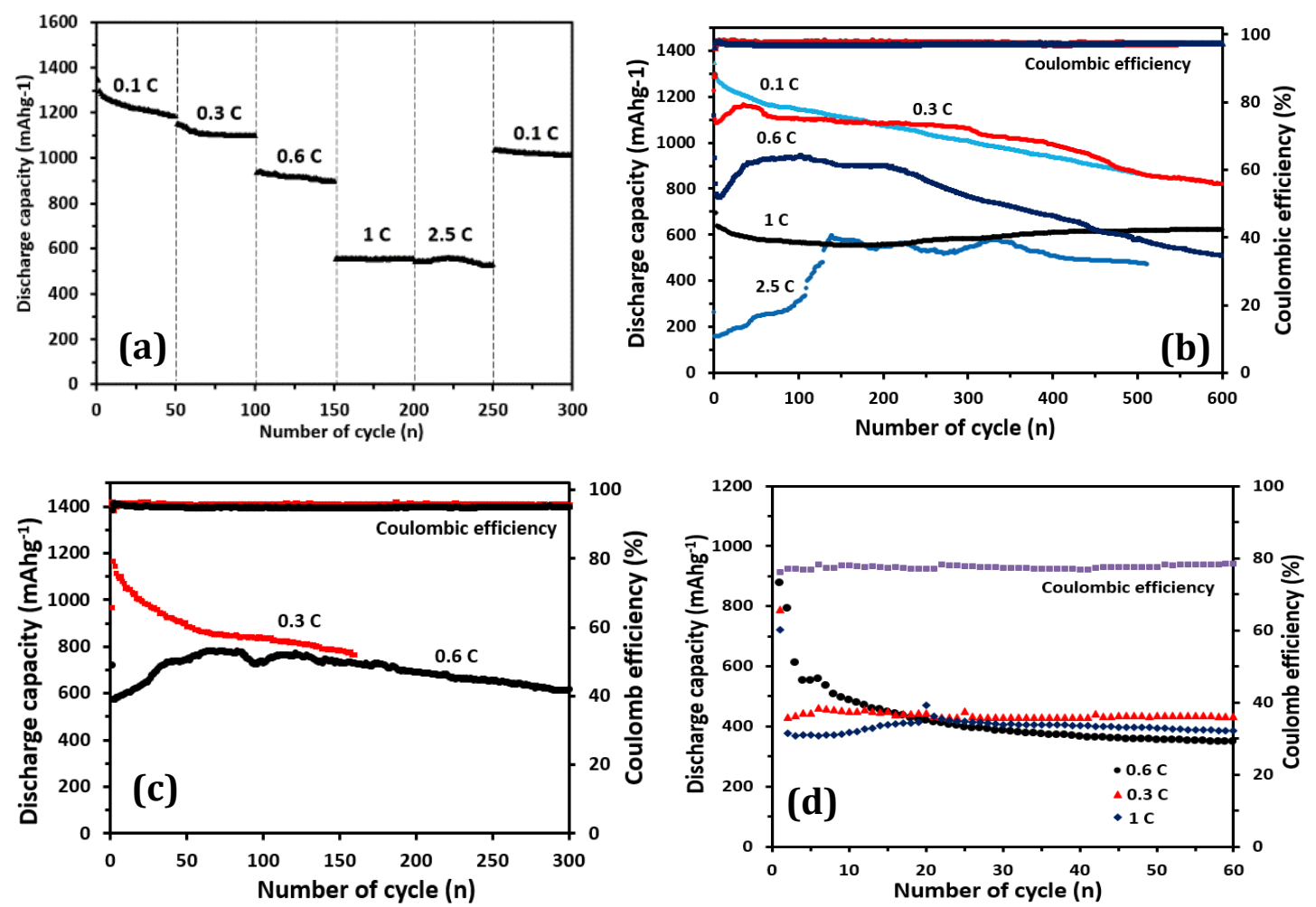

Figure 5-5 (a-c) Electrochemical performance of Li-S cells employing multilayered cathodes. (a) Rate performance. Long-term cycling performance and Coulombic efficiency at different current rates (b) with and (c) without lithium nitrate additives in the liquid electrolyte. (d) Cycling performance of Li-S cells employing slurry-coated cathodes (10 wt.\% of PVDF +45 wt.\% SCNT + 45 wt.\% SPANI).
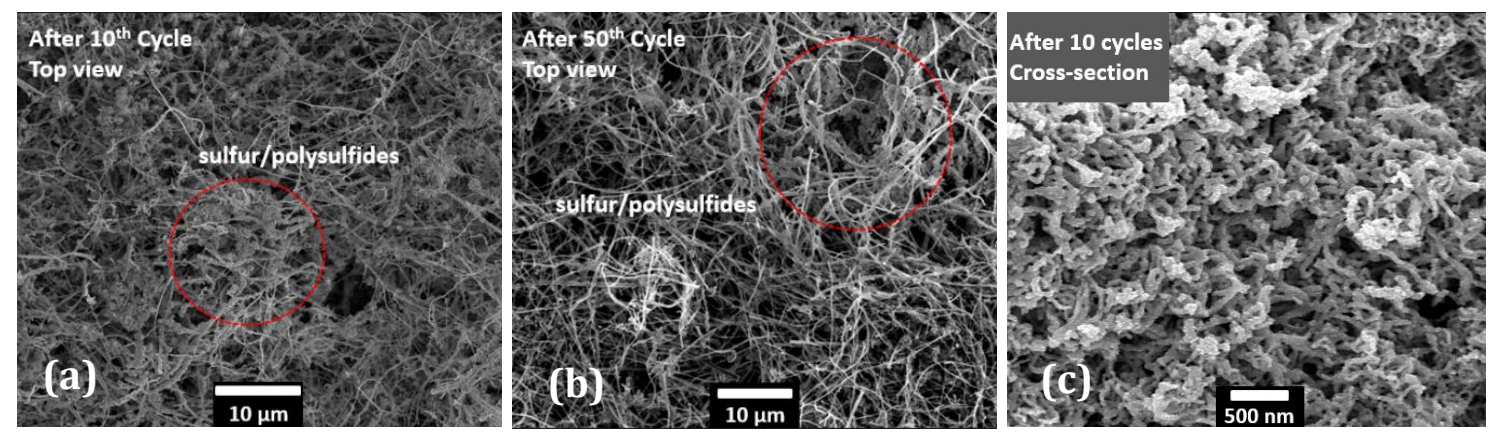
Figure 5-6 SEM characterizations of the cathodes at different cycles. (a) Top view and (c) crosssection at the $10^{\text {th }}$ cycle, and (b) top view at the $50^{\text {th }}$ cycle of multilayered cathodes.

\subsubsection{Electrochemical Reaction Processes in Multilayered Cathodes}

The electrochemical reaction mechanism of sulfur in multilayered cathodes was revealed using cyclic voltammetry $(\mathrm{CV})$ at a scan rate of $0.05 \mathrm{mV} \mathrm{s}^{-1}$. As shown in Figure 5-7a, the fresh multilayered cathode featured three reduction current peaks at around $2.38,2.1$, and $1.8 \mathrm{~V}$. The first two narrow peaks showed typical characteristics of two-step reduction of sulfur from solid-liquid $\left(\mathrm{S}_{8}-\mathrm{S}_{6}{ }^{2-}\right)$ and liquid-solid $\left(\mathrm{S}_{6}{ }^{2-}-\mathrm{Li}_{2} \mathrm{~S}_{2}\right)$ phase transitions. The third broad reduction current peak at $1.8 \mathrm{~V}$ was lower than the potential of $\mathrm{S}_{4}{ }^{2-}$ to $\mathrm{Li}_{2} \mathrm{~S}_{2}$ reaction at around $2.1 \mathrm{~V}$. [87] Similarly, multilayered cathodes without lithium nitrate additives had three reduction peaks (Figure 5-7b). However, SPANI, SPANI-PSS, and S-CNT-PSS based cathodes presented typical sulfur characteristics with two reduction peaks at 2.30 and 1.97, 2.31 and 2.01, and 2.44 and $2.04 \mathrm{~V}$, respectively (Figure 6-7c). These observations indicated that the multilayered cathodes experienced a new reaction represented by the reduction peak at $1.8 \mathrm{~V}$, which was possibly attributed to the reaction from $\mathrm{Li}_{2} \mathrm{~S}_{2}$ to $\mathrm{Li}_{2} \mathrm{~S}$. As shown in Figure 5-7d, the four characteristic peaks at $23^{\circ}, 31^{\circ}, 45^{\circ}$, and $50^{\circ}$ in the XRD pattern indicated the existence of $\mathrm{Li}_{2} \mathrm{~S}$. However, the $\mathrm{CV}$ curves at the 50th cycle showed significantly different behavior. The first two reduction peaks showed in the initial cycle were substituted by a new broad peak centered at $2.2 \mathrm{~V}$ in the 50th cycle. Most likely, the high potential polarization between soluble, high-order polysulfides (HPS, i.e. $\mathrm{Li}_{2} \mathrm{~S}_{\mathrm{n}}, \mathrm{n} \geq 3$ ) and insoluble, low-order polysulfide species $\left(\mathrm{Li}_{2} \mathrm{~S}_{\mathrm{n}}, \mathrm{n} \leq 2\right)$ caused an overlap of the two possible reduction peaks. The continuous CV scans of the multilayered cathodes shown in Figure 5-7e demonstrated gradual changes during the electrochemical reaction processes.
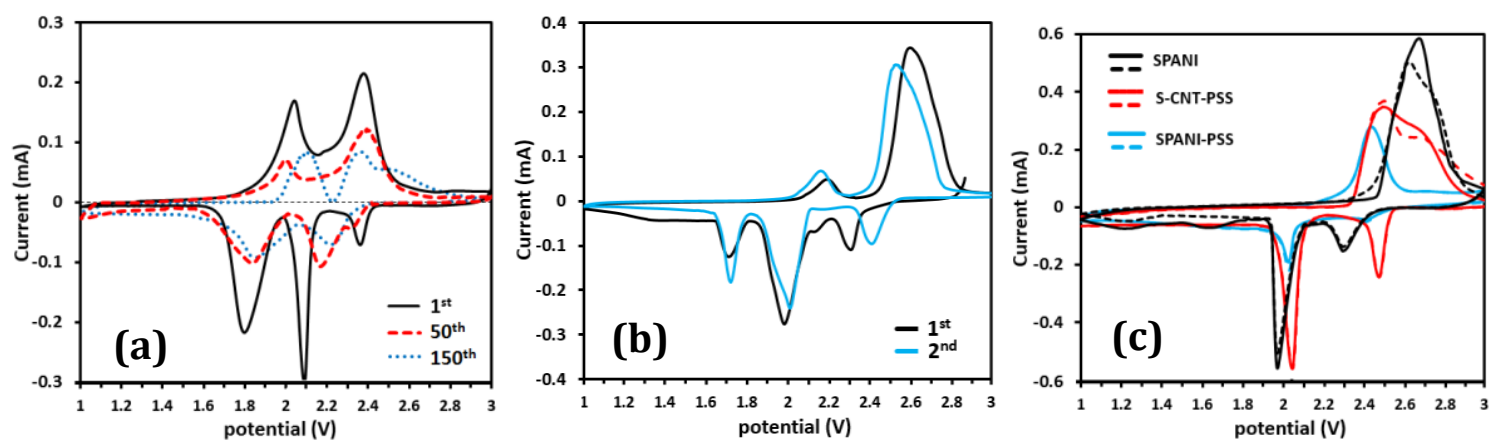

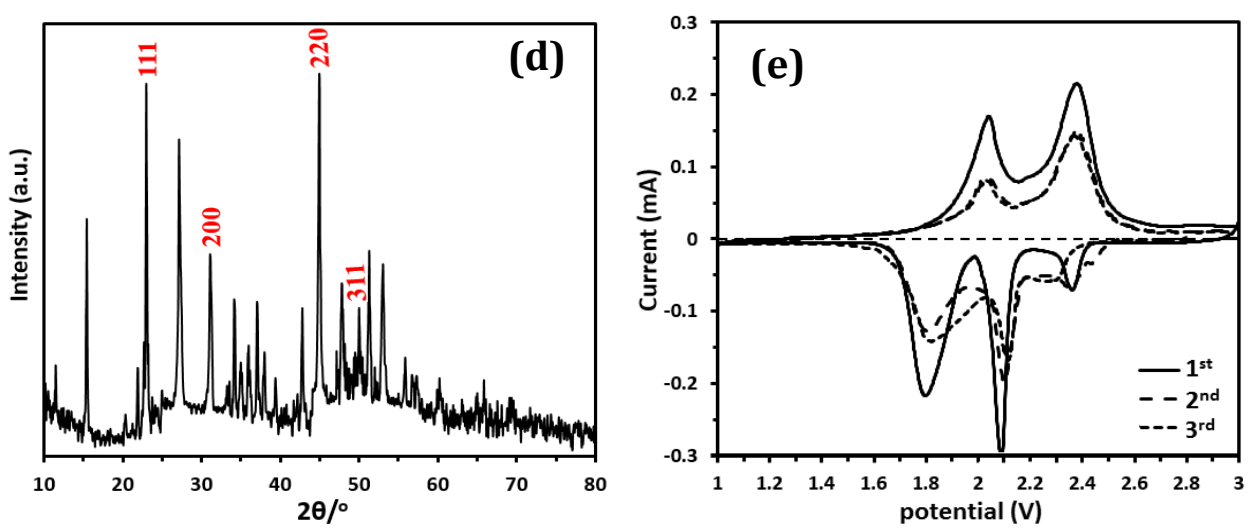

Figure 5-7 CV scans of Li-S cells employing electrolyte (a) with and (b) without lithium nitrate additives. (c) CV scans of SPANI, SPANI-PSS, and S-CNT-PSS based cathodes. Both scan rates were $0.05 \mathrm{mV} \mathrm{s}^{-1}$. The SPANI cathodes contained $10 \mathrm{wt} . \%$ of PVDF and $90 \mathrm{wt}$. $\%$ of SPANI; the SPANI-PSS (S-CNT-PSS) cathodes contained $10 \mathrm{wt} . \%$ of PVDF, $30 \mathrm{wt} . \%$ of PSS and $60 \mathrm{wt} . \%$ of SPANI (S-CNT). (d) XRD data of the multilayered cathode after the 50th discharge. (e) Continuous CV scans of multilayered cathodes for the first 3 cycles.

At $0.3 \mathrm{C}$, the discharge/charge profiles of multilayered cathodes in Figure 5-8a exhibited three discharge plateaus at $2.3,2.1$, and $1.9 \mathrm{~V}$ and two discrete charge plateaus at 2.3 and $2.4 \mathrm{~V}$, which were consistent with the $\mathrm{CV}$ analyses. Similar results were observed at 0.6 and $1.0 \mathrm{C}$ (Figure 5-8b). The upper discharge plateau at $2.3 \mathrm{~V}$ corresponded to the reduction of sulfur into soluble lithium polysulfide species. The discharge capacity values of the cell corresponding to this plateau at the $1^{\text {st }}, 50^{\text {th }}$, and $150^{\text {th }}$ cycles were identical, demonstrating the effectiveness of the multilayered cathode in trapping soluble polysulfide species and enhancing the utilization of sulfur. When sulfur in each layer is reduced upon full discharge, the strong affinity of polysulfide species for the sandwich-like porous frameworks is vital for retaining the active mass and electrical contact of sulfur/ polysulfide species within the conductive framework. SEM images (Figures 5-8c-e) of the multilayered cathodes in the discharged state revealed that the discharge products were kept within the cathode structure to form thick layers instead of discrete particles, implying the strong interaction between polysulfides and the multilayered structure. The thick sulfur layer observed on the surface of the cathode could be attributed to the insoluble $\mathrm{Li}_{2} \mathrm{~S}$ or $\mathrm{Li}_{2} \mathrm{~S}_{2}$ layers formed at the end of discharge. 

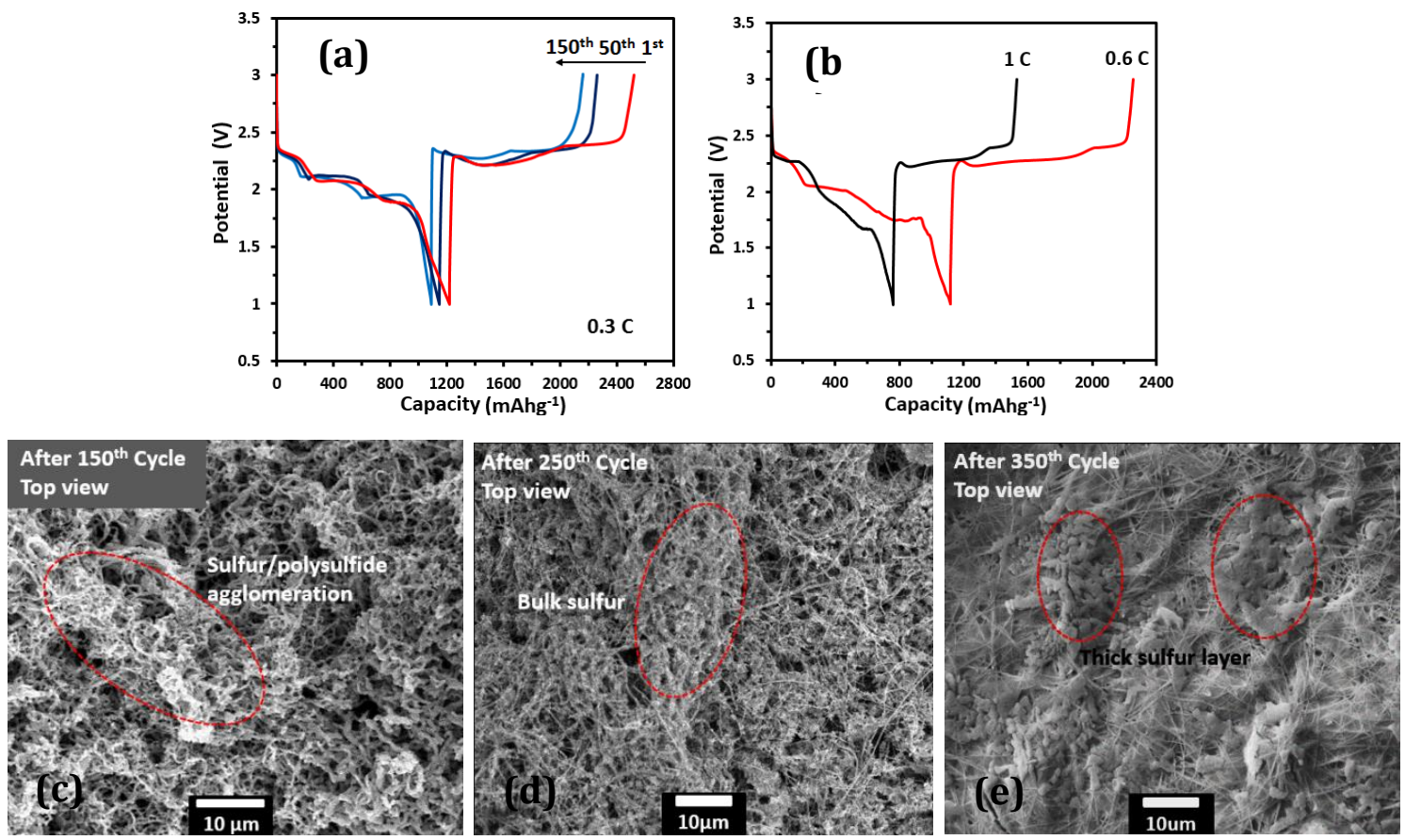

Figure 5-8 Electrochemical performance of Li-S cells employing multilayered cathodes and SEM characterizations of the cathodes at different cycles. (a) Voltage profiles at 1st, 50th and 150th cycles. (b) Initial voltage profiles at 0.6 and 1 C. Top surface characterization at the (c) 150 th, (d) 250th, and (e) 350th cycles.

The multilayered sulfur cathodes reduced the dissolution of polysulfide species probably because, in the multilayered structure design, the alternately arranged SPANI layers and S-CNT-PSS layers not only provided capacity, but also served as chemical and physical barriers that reduced unwanted polysulfide migration from the cathode to the electrolyte. The electrostatic interaction between the alkylammonium cations and polysulfide anions might also trap polysulfide species during the repeated cycles, leading to high cycling stability. In addition, multiple studies have shown that chemical interactions between sulfur or polysulfide with an oxygen functional group or unsaturated carbon bonds on CNT and PANI in the multilayered cathodes could reduce the dissolution of polysulfide species. The porous 3-D framework in the multilayered structure provided efficient electron and Li-ion conduction, which contributed to a high utilization of sulfur and fast kinetics. 

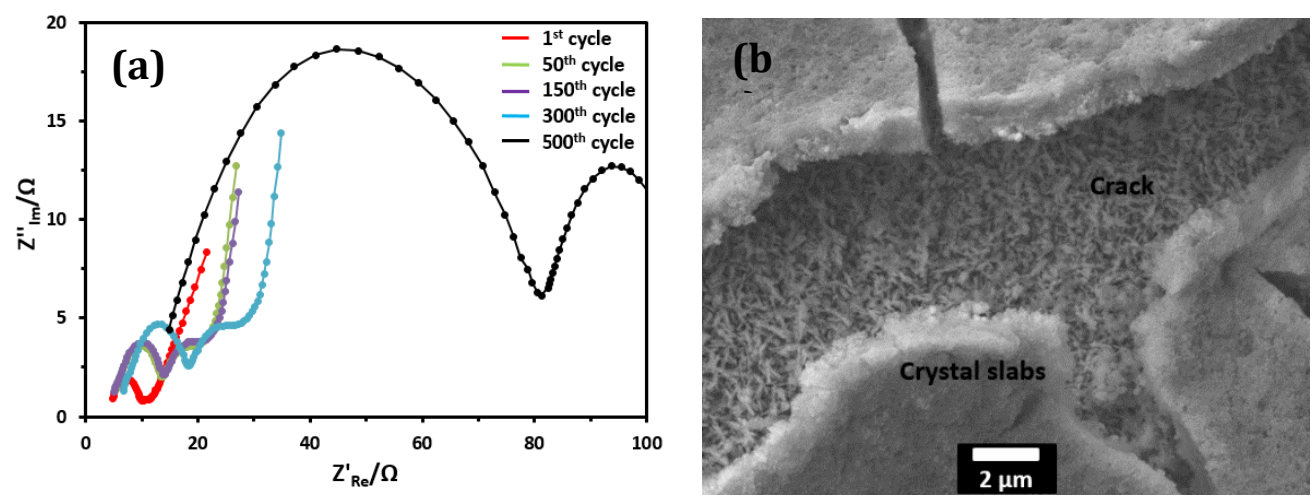

Figure 5-9 EIS analysis of the Li-S cells containing multilayered cathodes. (a) EIS analysis of LiS cells. (b) SEM image of cathode surface after 500 cycles.

Electrochemical impedance spectra (EIS) analysis was performed to further evaluate the multilayered cathodes. As shown in Figure 5-9a, the EIS spectra were comprised of two semicircles at the high frequency region and an inclined tail in the low frequency region.[33, 46, 54, 109] The real axis intercepting at the high frequency represented the electrolyte resistance. The semicircle from high to medium frequency corresponded to the SEI layer resistance, and the second semicircle at medium frequency was related to the charge transfer resistance. The short inclined line in the low frequency regions was due to ionic diffusion within the cathode. The interfacial charge-transfer resistance was recognizable from the second semicircle owing to the redox formation of soluble polysulfide species and insoluble short-chain polysulfide species. The resistances at the $50^{\text {th }}$ and $150^{\text {th }}$ cycles were identical, indicating a stable SEI layer on the lithium surface and a smooth charge transfer of lithium ions in the cell. These findings might indicate that there was limited polysulfide shuttling in the first 150 cycles since otherwise, the dissolved polysulfide species would migrate toward the Li-anode at which point they would be reduced to LPS and irreversibly precipitate onto the Li-anode surface. This would inhibit charge transfer of lithium ions thereby leading to an increase in cell impedance. Cathode kinetics and charge-transfer polarization accounted for the majority of the voltage loss in the cells. The multilayered cathodes had low resistance, which presented an ideal opportunity to create intimate organic-inorganic interfaces for efficient electrochemical reactions in Li-S batteries. At the 500th cycle, by contrast, both the interfacial resistance and charge transfer resistance increased. The reactions of sulfur 
resulted in great morphological changes at the 500th cycle, leading to (i) obvious cracks and (ii) formation of crystal slabs on the surfaces of the multilayered cathodes (Figure 59b). Both the nonconductive crystal slabs and the cracks caused high resistance within the cell.

\subsection{Conclusions}

In summary, we demonstrated a unique multilayered sulfur electrode fabricated with LbL nano-assembly method. With this method, extra cell components such as PVDF binders were not necessary. Within the multilayered structure, the PANI and FCNT layers served as an electrical conductive network and the abundance of pores served as ionic conductive pathways. The structure separated sulfur layers and maintained a high surface area, and led to enhanced sulfur utilization. The discharge/charge voltage profiles and the CV scans, combined with the EIS, XPS, and FTIR analyses, revealed that the multilayered cathodes resulted in reduced polysulfide shuffling effects and more complete sulfur transformation, leading to excellent cell operation with high efficiency, good reversibility, and fast kinetics. SEM images showed no significant structural damage to the multilayered cathode before 350 cycles, indicating high structural stability of the multilayered cathode. As a result, the multilayered cathodes provided a long lifetime of more than 600 cycles with an average Coulombic efficiency of $97.5 \%$ under a variety of discharge/charge current densities. The tunable nature of the $\mathrm{LbL}$ technique allows for the incorporation and manipulation of non-conductive sulfur and highly conductive CNTs/PANIs. These multilayered cathodes may contribute to potential development and applications of long-lived, high energy density and high power Li-S batteries for electric vehicle systems and flexible and thin-film devices. 


\section{Chapter 6: Sulfur Cathode Structures Development: Carbon Paper Electrode with High Sulfur-Loading}

In this chapter, we will develop a cost-effective approach to obtain electrodes with high energy density and long-cycling properties. Carbon nanofiber (CNF) substrates with a high electrical conductivity $\left(420 \mathrm{~S} \mathrm{~cm}^{-1}\right)$ and an extremely low density $\left(\sim 0.2 \mathrm{~g} \mathrm{~cm}^{-3}\right)$ were used as current collectors and also as hosts for high sulfur loading $\left(\sim 6.7 \mathrm{mg} \mathrm{cm}^{-2}\right)$, while the carbon black nanoparticles which were well-distributed within the CNF substrates, functioned as electrical bridges for nonconductive sulfur and highly conductive CNF framework. In addition, a densely packed $\left(\sim 6.6 \mathrm{~g} \mathrm{~cm}^{-3}\right)$ porous carbon layer $(\sim 5 \mu \mathrm{m})$ on the top of $\mathrm{CNF}$ acted as a protective layer to inhibit polysulfide shuttle between cathode and anode. As a result, this unique design enabled the fabrication of Li$\mathrm{S}$ batteries with a remarkably high reversible capacity exceeding $900 \mathrm{~mA} \mathrm{~h} \mathrm{~g}^{-1}$ at $0.2 \mathrm{C}$, $800 \mathrm{~mA} \mathrm{~h} \mathrm{~g}^{-1}$ at $0.5 \mathrm{C}$, and $700 \mathrm{~mA} \mathrm{~h} \mathrm{~g}^{-1}$ at $1 \mathrm{C}$, while the average Coulombic efficiency was greater than $99.5 \%$. Moreover, at a high current rate of $1.5 \mathrm{C}$, capacity retention from 709 to $302 \mathrm{~mA} \mathrm{~h} \mathrm{~g}^{-1}$, corresponding to an areal capacity of $>2 \mathrm{~mA} \mathrm{~h} \mathrm{~cm}{ }^{-2}$, was obtained over 1000 cycles.

\subsection{Introduction}

Owing to the low cost and a high capacity of sulfur, rechargeable lithium sulfur (Li-S) battery offers the possibilities of low cost and high energy density. [26, 168] Despite 20 years of intensive efforts and advancements achieved in fundamental electrochemistry and performance improvements, the real applications of current liquid type Li-S battery are still challenged by insufficient cycle life with a rapid capacity fade and low practical energy/power density. [24, 26, 39, 42] It is well accepted that the major degradation mechanisms of S-cathode are (1) low electric conductivity of S and sulfides, (2) insoluble discharge products such as $\mathrm{Li}_{2} \mathrm{~S}$, and (3) poly-shuttle related issues. [25] Although the long-term cycling stability of Li-S batteries could be obtained by using hybrid carbon structures, such as carbon nanotubes and carbon fibers, to enhance the conductivity of the active sulfur materials, to gain a much lower polarizations and to retard the polysulfide migrations in the cathode compared with the use of single 
conductive carbon agents. $[53,63,76,92,103,161,162]$ However, most research have focused on developing novel sulfur porous carbon/polymer composites with low sulfurloadings (i.e. $<2 \mathrm{mg} \mathrm{cm} \mathrm{cm}^{-2}$ ), and less attention was paid on commercialization requirements of a Li-S battery. [73, 92, 159]

Indeed, a high sulfur-loading cathode commonly results in low sulfur utilization due to the non-ideal mass transportation, and thus deteriorates battery performance. [91, 149, 169] In the reported Li-S batteries with high sulfur-loading, the researchers found that increasing the amount of sulfur-loading resulted in decreased transport efficiency for electrons and ions and thus inferior performance of Li-S batteries. Recently, $\mathrm{Zu}$ et al. fabricated a sulfur cathode with a high sulfur-loading of $5.5 \mathrm{mg} \mathrm{cm}{ }^{-2}$ using soluble polysulfide species as the active material in the cathode and a carbon nanofiber (CNF) film as the current collector.[38] In their cells, high capacities, larger than $1000 \mathrm{~mA} \mathrm{~h} \mathrm{~g}{ }^{-1}$, were obtained. However, these exceptional capacities were achieved only at very low current densities (i.e., $0.2 \mathrm{C}$ and $0.1 \mathrm{C}$ ). Further, their cells had inferior cycling performance ( 50 cycles) due to the anode corrosion caused by side reactions between the lithium metal and soluble polysulfide species. Their configuration is also conducive to the formation of dendrites upon repeated charges and discharges, resulting in an unstable Li-anode. This situation urges the investigation of high sulfur-loading cathode together with a cost-effective process from a system point of view, while simultaneously considering the performance of $\mathrm{Li}-\mathrm{S}$ batteries.

The traditional strategy for sulfur composite synthesis is somewhat complex and requires high temperature or other high-cost procedures like CVD and chemical reactions to disperse sulfur into/onto porous carbon or other designed porous structures. [27, 37, 167, 170] Albeit this, such cathodes always resulted in inferior cycle life and poor sulfur utilization due to the lacking of porosity for nonconductive sulfur $/ \mathrm{Li}_{2} \mathrm{~S}_{2} / \mathrm{Li}_{2} \mathrm{~S}$ deposition, and the instability of cathode structure that impaired electron and Li-ion transportation. $[38,50]$ This situation is severe in a high sulfur-loading Li-S cathode. [149] Since longchain polysulfide species $\left(\mathrm{Li}_{2} \mathrm{~S}_{\mathrm{x}}, 3 \leq \mathrm{x} \leq 8\right)$ are easily dissolved into the electrolyte, sulfur will rearrange their positions during the repeated cycles and tend to agglomerate to form 
large particles, which may destroy cathode structure and cause electrical contact problems and thus result in capacity fade. [84] In our previous study, introducing micrometer size pores in the cathode was found beneficial for fast mass transportation and sulfur kinetics performance. [124] Therefore, in a high sulfur-loading cathode, the initial state of sulfur may not be so important, in contrast, an ideal mass transportation and an ideal electron conduction path in a stable conductive carbon network is essential.

In this chapter, a commercial CNF-porous carbon paper (CNFPC, $\sim 165 \mu \mathrm{m})$ coupled with carbon black nanoparticles and soluble lithium polysulfide species was used as a sulfur electrode and a current collector (Figures 6-1a and 1b). In this structure, the threedimensional (3D) CNF substrate provided multiple 3D interlinked electron pathways and sufficient space to accommodate a large amount of active sulfur materials. On the top of the CNF substrate was a compact porous carbon film $(\sim 5 \mu \mathrm{m})$ with a high tap density of $6.6 \mathrm{~g} \mathrm{~cm}^{-3}$, which was designed to keep the soluble high-order polysulfides within the cathode. A liquid polysulfide $\left(\mathrm{Li}_{2} \mathrm{~S}_{6}\right)$ catholyte (Figure 6-1c) was used as the active material, simplifying the fabrication process and ensuring efficient contact with the conductive CNF matrix. The CNF acted as the long-range conductive framework, while the carbon black nanoparticles served as the short-range conductive agents, which bridged the gaps between sulfur materials and the CNF framework. As a result, reversible capacities over $900 \mathrm{~mA} \mathrm{~h} \mathrm{~g}_{\text {sulfur }}{ }^{-1}$ at $0.2 \mathrm{C}, 800 \mathrm{~mA} \mathrm{~h} \mathrm{~g}_{\text {sulfur }}{ }^{-1}$ at $0.5 \mathrm{C}$, and $700 \mathrm{~mA} \mathrm{~h}$ $\mathrm{g}_{\text {sulfur }}{ }^{-1}$ at $1 \mathrm{C}$ over 200 cycles were obtained with a high sulfur loading of $6.7 \mathrm{mg} \mathrm{cm}^{-2}$. Therefore, our simple and cost-effective sulfur cathode structure led to Li-S batteries with high performance. 


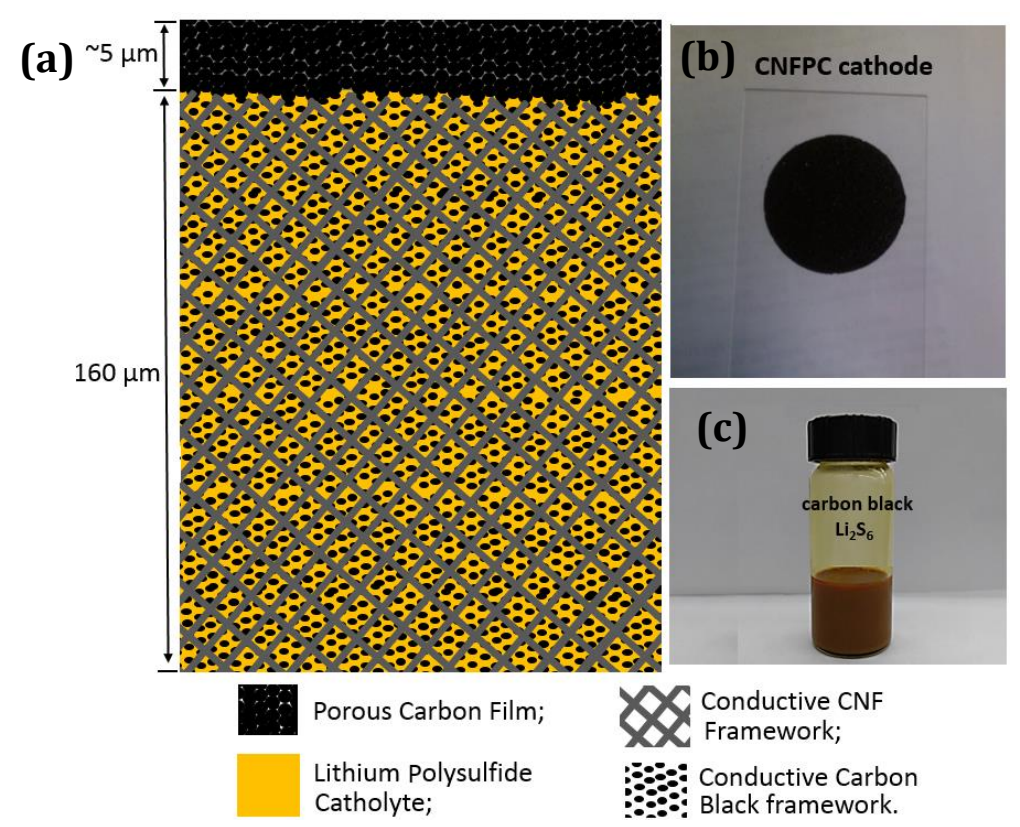

Figure 6-1 (a) Schematic of the CNFPC electrode design, (b) large areal figure of the CNFPC electrode, and (c) carbon black/soluble $\mathrm{Li}_{2} \mathrm{~S}_{6}$ liquid catholyte.

\subsection{Experimental Section}

Preparation of CNFPC Electrodes. The CNF substrate used in this experiment had a thickness of $\sim 160 \mu \mathrm{m}$, an electrical conductivity of $420 \mathrm{~S} \mathrm{~cm}^{-1}$ and a density of $\sim 0.2 \mathrm{~g} \mathrm{~cm}^{-}$ 3. The porous carbon layer had a thickness of $\sim 5 \mu \mathrm{m}$, and a density of $\sim 6.6 \mathrm{~g} \mathrm{~cm}^{-3}$. According to these data, the areal loading of CNF was $3.2 \mathrm{mg} \mathrm{cm}^{-2}$, and the areal loading of porous carbon was $3.3 \mathrm{mg} \mathrm{cm}^{-2}$. The controlled CNF paper electrode that without the porous carbon layer had the same parameters of CNF, carbon black and active sulfur materials. The soluble polysulfide catholyte was formed by chemically reacting 0.025 mol sublimed sulfur (99.5\%, Sigma-Aldrich) and $0.005 \mathrm{~mol} \mathrm{Li}_{2} \mathrm{~S}$ (99.98\%, SigmaAldrich) in $10 \mathrm{ml}$ dioxolane (DOL) and 1, 2-dimethoxyethane (DME) (1:1, v/v). The chemical reaction was: $5 \mathrm{~S}+\mathrm{Li}_{2} \mathrm{~S}=\mathrm{Li}_{2} \mathrm{~S}_{6}$. Next, $28 \mathrm{mg}$ of carbon black $(\sim 150 \mathrm{~nm}$, US Research Nanomaterials, Inc.) was added into the above solution and stirred for $2 \mathrm{~h}$. Then $300 \mu \mathrm{L}$ of polysulfide catholyte was added into a $2 \mathrm{~cm} \times 2 \mathrm{~cm} \mathrm{CNFPC/CNF}$ paper current collector (SGL group, the carbon company), corresponding to a carbon blackloading of $0.23 \mathrm{mg} \mathrm{cm}^{-2}$, and a high sulfur-loading of $6.7 \mathrm{mg} \mathrm{cm}^{-2}$. Lastly, after the evaporation of DME and DOL, the prepared electrode was used for battery assembly. 
Based on the above calculation, the sulfur ratio in the whole electrode (including current collector) was $50 \mathrm{wt} . \%$. All of the experiments were conducted in a glove box.

Material characterization. Morphology of the CNFPC current collectors was examined by SEM, TEM, and EDX (EDS). Crystal structure characterization was conducted with a PANalytical XRD with $\mathrm{Cu} \mathrm{K} \alpha$ radiation between 10 and $80^{\circ}$ at a scan rate of $0.1^{\circ} \mathrm{s}^{-1}$. Kratos Axis Ultra XPS (Kratos Analytical) with a monochromatized Al Ka X-ray source was used to analyze the surface chemistry of CNFPC electrodes. Deconvolution of the XPS spectra was performed with a Casa XPS program with Gaussian-Lorentzian functions after subtraction of a Shirley background. The pretreatments for the samples after cycling included the following several steps. First, the disassembled cathode and anode were washed with DOL solution 5 times to remove the soluble polysulfides on the surfaces and bottoms of the cathode and anode. Next, the cathode and anode were left in the glove box for 1 day to evaporate the solution remained. Then, the cathode and anode samples were anchored onto the SEM specimen mount holders, and placed into two separated vacuum jars for test. Last, the samples were quickly transferred to the SEM chamber. For XPS test, the electron gun was used to remove several nanometers of the oxidized surfaces of the samples.

Electrochemical Measurements. CR2032-type coin cells were used as the testing cells. Lithium foils were used as the anodes, Cellgard 2400 microporous membranes as separators, $1.0 \mathrm{~mol} \mathrm{~L}^{-1}$ bis(trifluoromethane sulfonyl) imide (LiTFSI) and $0.1 \mathrm{~mol} \mathrm{~L}^{-1}$ $\mathrm{LiNO}_{3}$ dissolved in dioxolane (DOL) and 1,2-dimethoxyethane (DME) $(1: 1, \mathrm{v} / \mathrm{v})$ as electrolytes. The ring lithium foil with a thickness of $20 \mu \mathrm{m}$ and diameter of $2.8 \mathrm{~cm}$ was used as the anode. $\mathrm{LiNO}_{3}$ was used to form a protective film on the surface of $\mathrm{Li}$-anode. The cells were assembled in an argon-filled glove box. The size of the electrode material was $0.9 \mathrm{~cm} \times 0.9 \mathrm{~cm}$, and the amount of electrolyte for each cell was about $0.04 \mathrm{ml}$. Electrochemical measurements were performed galvanostatically between 1.8 and $3.0 \mathrm{~V}$ at various current densities. Capacity was calculated based on the weight of sulfur on the electrodes. CV experiments were conducted using a NOVA potentiostat at a scan rate of $0.1 \mathrm{mV} \mathrm{s}^{-1}$. EIS measurements were carried out using a NOVA electrochemical 
workstation in a frequency range between $100 \mathrm{kHz}$ and $100 \mathrm{mHz}$ at a potentiostatic signal amplitude of $5 \mathrm{mV}$. All of the CV, EIS, cycling and rate performance were collected on Li-S batteries with an areal sulfur loading of $6.7 \mathrm{mg} \mathrm{cm}^{-2}$. All experiments were conducted at room temperature.

\subsection{Results}

Battery Performance. Using our developed CNFPC sulfur electrode, the Li-S battery delivered a reversible capacity of $>700 \mathrm{~mA} \mathrm{~h} \mathrm{~g}^{-1}$ over 200 cycles at $1670 \mathrm{~mA} \mathrm{~g}^{-1}$ $(\sim 1 \mathrm{C})$ as shown in Figure 6-2a; this improvement in capacity retention in such a high sulfur-loading electrode is remarkable. However, the initial discharge capacity was lower than $600 \mathrm{~mA} \mathrm{~h} \mathrm{~g}^{-1}$ due to the loss of the high voltage plateau near $2.35 \mathrm{~V}$, which was ascribed to the transition from $\mathrm{S} / \mathrm{Li}_{2} \mathrm{~S}_{8}$ to $\mathrm{Li}_{2} \mathrm{~S}_{6}$. As the soluble lithium polysulfides $\left(\mathrm{Li}_{2} \mathrm{~S}_{6}\right)$ were directly used as the active materials, the discharge process started at the transition from $\mathrm{Li}_{2} \mathrm{~S}_{6}$ to $\mathrm{Li}_{2} \mathrm{~S}_{4}$. In addition, a severe voltage hysteresis was observed in the initial discharge curve, which was possibly caused by severe battery polarization because of large amounts of active sulfur materials. These soluble active materials rearranged themselves to electrochemically favorable positions in the electrode after the first cycle, and then the discharge profiles came back to normal, as shown in Figure 6-2a. This phenomenon was also verified by cyclic voltammogram $(\mathrm{CV})$ testing (Figure 6-2b): the over-potential of the first cathodic peak disappeared after the first cycle, then the CV curves presented a high reversibility of the electrode. Figure 6-2c presents the discharge/charge voltage profiles (the 2 nd cycle) of the Li/CNFPC batteries at different current densities. Even at a current rate of $2500 \mathrm{~mA} \mathrm{~g}^{-1}(\sim 1.5 \mathrm{C})$, the battery capacity exceeded $650 \mathrm{~mA} \mathrm{~h} \mathrm{~g}^{-1}$, demonstrating exceptional rate performance. Of note, the voltage gap between discharge and charge was obviously reduced using CNFPC electrodes compared to using traditional sulfur electrodes we previously reported. For example, the charging voltage plateau decreased to $2.2 \mathrm{~V}$ at $167 \mathrm{~mA} \mathrm{~g}^{-1}(\sim 0.1 \mathrm{C})$. The smaller voltage plateau difference was probably attributed to the fast kinetics in the surface oxidation reaction, and thus a high redox electrochemical reversibility within this electrode. The porous and thick structure of CNFPC cathode drove the soluble polysulfide species to 
electrochemically favorable sites and stabilized them, which could be further reduced or oxidized with the help of long-range CNF conductive agents.

Figure 6-2d compares the cycling performance and Coulombic efficiency of the $\mathrm{Li} / \mathrm{CNFPC}$ batteries at $335 \mathrm{~mA} \mathrm{~g}^{-1}(\sim 0.2 \mathrm{C}), 840 \mathrm{~mA} \mathrm{~g}^{-1}(\sim 0.5 \mathrm{C})$, and $1670 \mathrm{~mA} \mathrm{~g}^{-1}(\sim 1$ C). Reversible capacities of $\sim 900 \mathrm{~mA} \mathrm{~h} \mathrm{~g}^{-1}$ (at $335 \mathrm{~mA} \mathrm{~g}^{-1}$ ), $\sim 830 \mathrm{~mA} \mathrm{~h} \mathrm{~g}^{-1}$ (at $840 \mathrm{~mA}$ $\mathrm{g}^{-1}$ ), and $710 \mathrm{~mA} \mathrm{~h} \mathrm{~g}^{-1}$ (at $1670 \mathrm{~mA} \mathrm{~g}^{-1}$ ) over 200 cycles were obtained. The Coulombic efficiency approached $100 \%$ for most cycles, indicating that polysulfide migration from cathode to anode was significantly reduced in this novel sulfur electrode structure. It is worth mentioning that long-term cycle stability of the high-sulfur-loading batteries at $2500 \mathrm{~mA} \mathrm{~g}^{-1}$ was also observed (Figure 6-2e). The battery retained a capacity of $302 \mathrm{~mA}$ $\mathrm{h} \mathrm{g}^{-1}$ after 1000 cycles, corresponding to only $0.057 \%$ capacity fade per cycle. Particularly, the Coulombic efficiency of the Li-S battery decreased from $104.3 \%$ to 99.6\% over 1000 cycles. In addition, a rapid capacity fading in the initial 100 cycles was noted, which was probably caused by a severe polarization in the electrode at such a high current rate. After some cycles, the resistance of polarization and reaction dynamics in the cell reached equilibrium, and thus the battery had a stable capacity with cycle numbers.
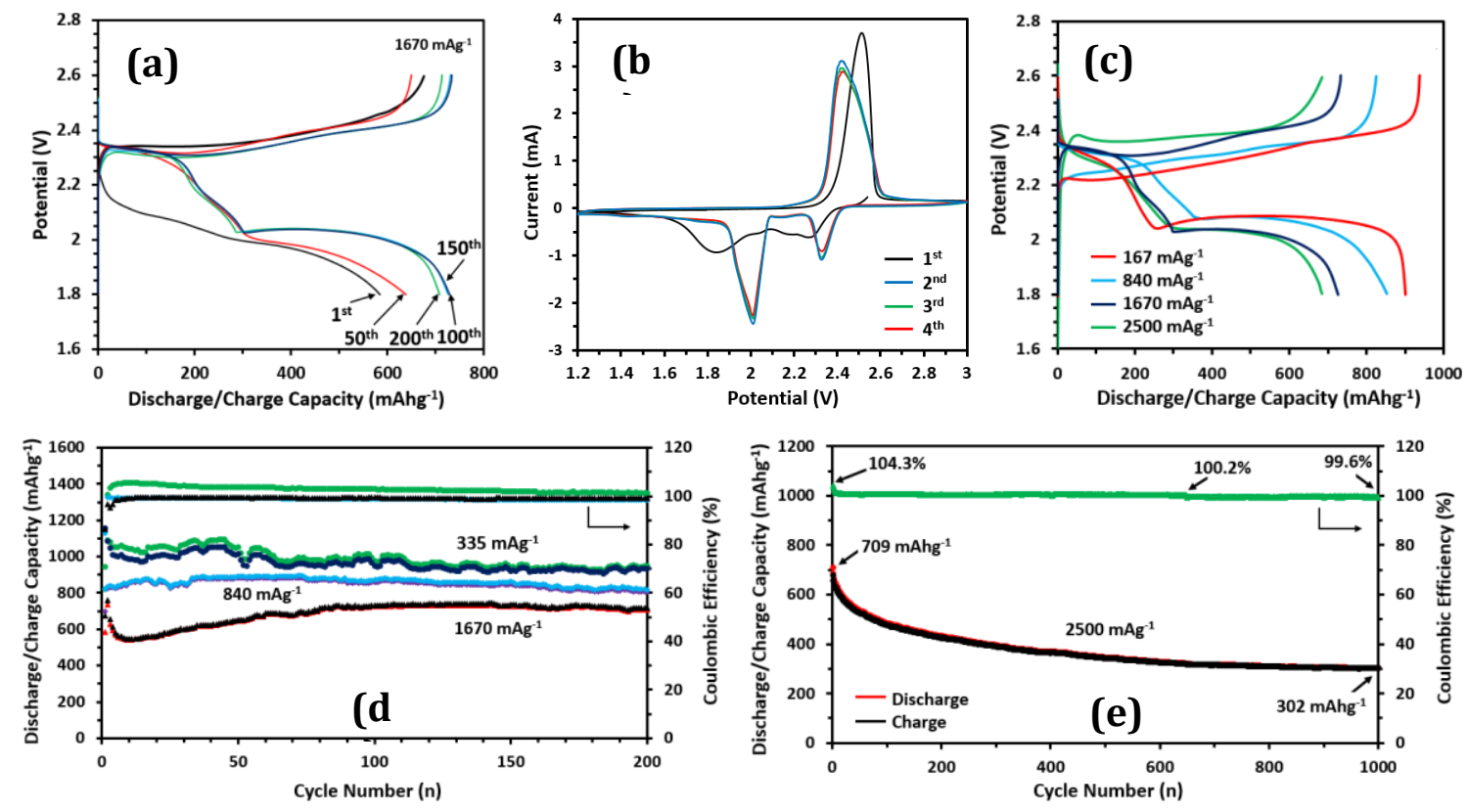
Figure 6-2 Electrochemical performance of Li/CNFPC cells. (a) Cycling ability of the battery at a rate of $1670 \mathrm{~mA} \mathrm{~g}^{-1}$. (b) Continuous $\mathrm{CV}$ curves of the battery (scanning rate was $0.1 \mathrm{mV} \mathrm{s}^{-1}$ ). (c) Voltage profiles of the battery at different rates. (d, e) Long-term cycling stability and Coulombic efficiency of the battery at different current rates.

Material Characterization. Structural variations of the cycled CNFPC paper electrodes were characterized by scanning electron microscopy (SEM) and transmission electron microscopy (TEM). The porous carbon nanoparticles with an average size of $\sim 100 \mathrm{~nm}$ constructed a densely compact film layer $\left(\sim 6.6 \mathrm{~g} \mathrm{~cm}^{-3}\right)$ (Figure 6-3a). The native CNF current collector had a robust structure with large spaces between individual fibers (Figure 6-3b), which could hold large amounts of carbon black/soluble lithium polysulfides (Figure 6-3c). TEM images showed that these soluble lithium polysulfides were uniformly coated onto the surfaces of carbon nanoparticles, which connected together and formed a well-distributed framework across the 3D CNF skeleton (Figure 63d). However, after the 100th discharge, these active sulfur nanoparticles changed into thin films and covered the surfaces of the CNF skeleton (Figures 6-3e and 3f). The chemical compositions of these thin films were identified as crystalline $\mathrm{Li}_{2} \mathrm{~S}$ and other polysulfides by X-ray diffraction (XRD), as shown in Figure 6-4a. The cycled sulfur electrodes were further investigated after the 100th charge (Figure 6-3g). A magnified image of these films indicated that there were numerous nanoparticles after charging (Figure 6-3h). Most of these nanoparticles were amorphous sulfur, as verified by XRD in Figure 6-4b. The end discharge product of lithium sulfide formed at the end of discharge was converted to amorphous sulfur at the end of the following charge. The original morphology of the porous carbon layer was well preserved even after 100 cycles (Figure 6-3i), indicating its robust mechanical structure. Energy dispersive spectroscopy (EDS) studies found that the chemical composition on the surface of the cycled porous carbon layer had a very small amount of sulfur or polysulfide species (Figure 6-5a). Unlike the traditional sulfur electrode, the chemical composition of surface film on the electrode was more sophisticated, as polysulfide species are always involved (Figure 6-5b).[120, 141] The results indicated high effectiveness of the porous carbon layer on trapping polysulfide species within CNFPC electrodes. 

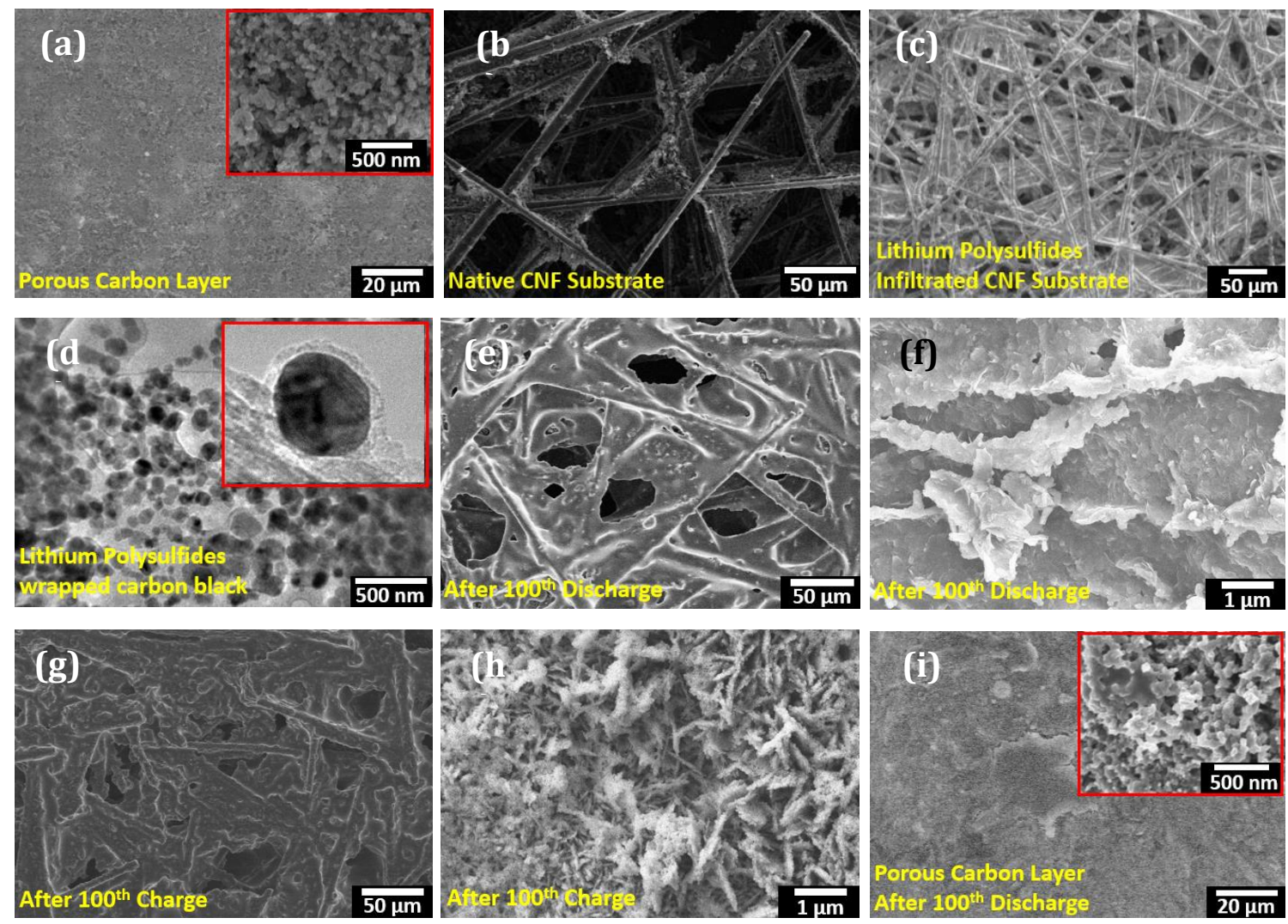

Figure 6-3 SEM images of (a) porous carbon film layer before cycling, (b) native CNF substrate and (c) CNF substrate after infiltration with soluble lithium polysulfides. (d) TEM images of lithium polysulfide wrapped carbon black. (e, f) SEM images of CNF surface after 100th discharge at different magnifications. (g, h) SEM images of CNF surface after 100th charge at different magnifications. (i) SEM image of porous carbon film surface after 100th cycles.
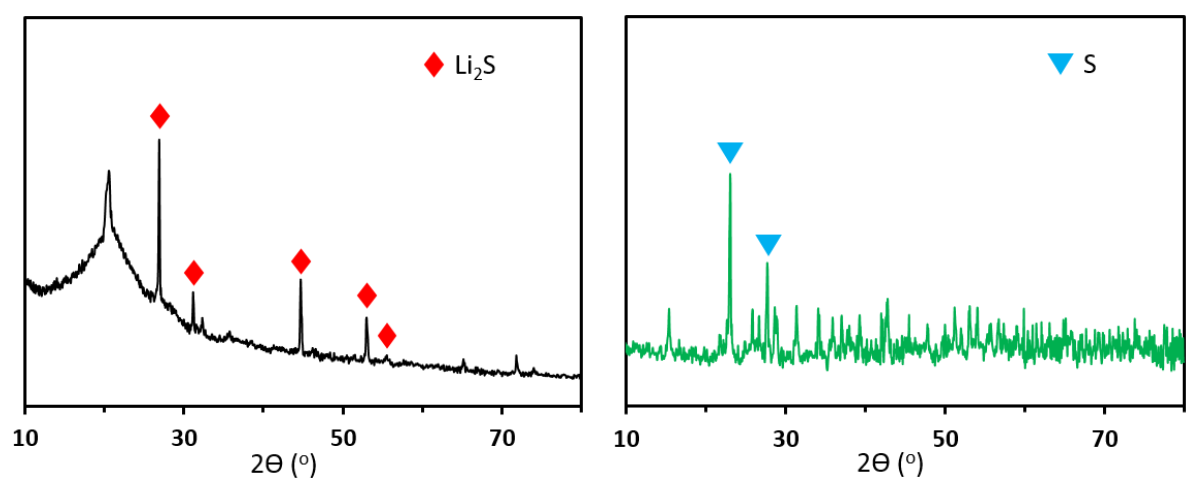

Figure 6-4 XRD data collected from the surface of cathode films after the $100^{\text {th }}$ (a) discharge process and (b) charge process. 

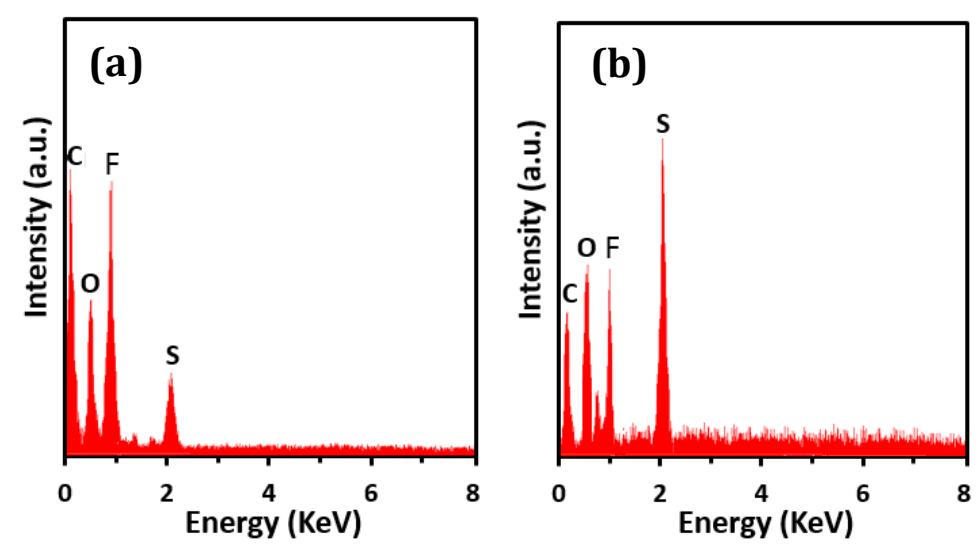

Figure 6-5 EDX data of (a) porous carbon layer surface from the CNFPC cathode and (b) cathode surface from the conventional slurry-coated batteries, respectively.

\subsection{Discussion}

The charge/discharge rates and sulfur-loading used in this study were found to be substantially higher than those used in conventional Li-S batteries. More importantly, decent battery capacity retention over 1000 cycles was obtained at a large current rate of 1.5 C. A systematic investigation on the exact mechanisms controlling the CNFPC paper electrode for high rate capability and long-term stability were conducted. The function of a CNFPC paper as a sulfur host was quite different from a carbon or metal framework to conduct electrons and constrain polysulfide diffusion. Unlike the traditional slurry-coated electrodes with a compact conductive carbon framework that tended to fail after a few cycles if the sulfur-loading was high, the CNFPC paper electrode had a robust and effective conductive framework even after 1200 cycles (Figure 6-6). In this electrode structure, the current collector had multiple micro-scale spaces, which were built by interconnected CNFs with large diameters of 6 10 $\mu \mathrm{m}$ (Figure 6-7). These spaces not only enabled a very high sulfur-loading of $6.7 \mathrm{mg} \mathrm{cm}^{-2}$, but also favored the penetration of the electrolyte through the electrodes, and thus enhanced Li-ion conductivity in the electrode. In addition, the large CNFs served as the long-range conductive pathways, while the well-distributed carbon black nanoparticles (particle size of $\sim 150 \mathrm{~nm}$ ) in the interspaces acted as the short-range conductive bridges. These two conductive systems facilitated effective electron conduction. As a result, the electrical conductivity, tested by van der Pauw method, of the CNFPC paper electrode with high sulfur-loading reached 
$230 \mathrm{~S} \mathrm{~cm}^{-1}$, which was much larger than those formerly reported.[91, 149] For example, Yuan et al. reported a carbon-nanotube paper electrode with a conductivity of $17.1 \mathrm{~S} \mathrm{~cm}^{-}$ ${ }^{1}$, which was larger than the electrical conductivity of electrodes prepared by the slurrycoated method.[149]
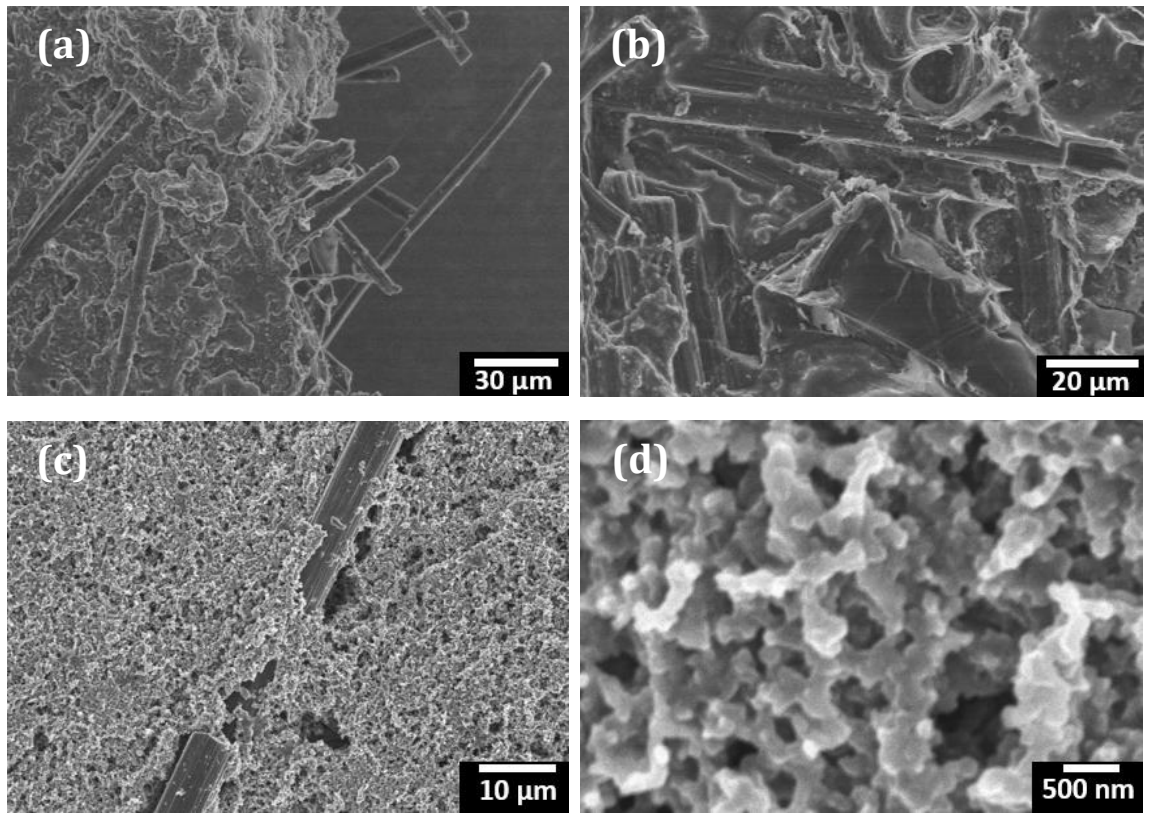

Figure 6-6 SEM images of CNFPC cathodes after 1200 cycles. (a, b) CNF current collectors. Both the (a) cross section and (b) top surface images showed the integrity of the CNF conductive framework. (c, d) Porous carbon layer at different magnifications.
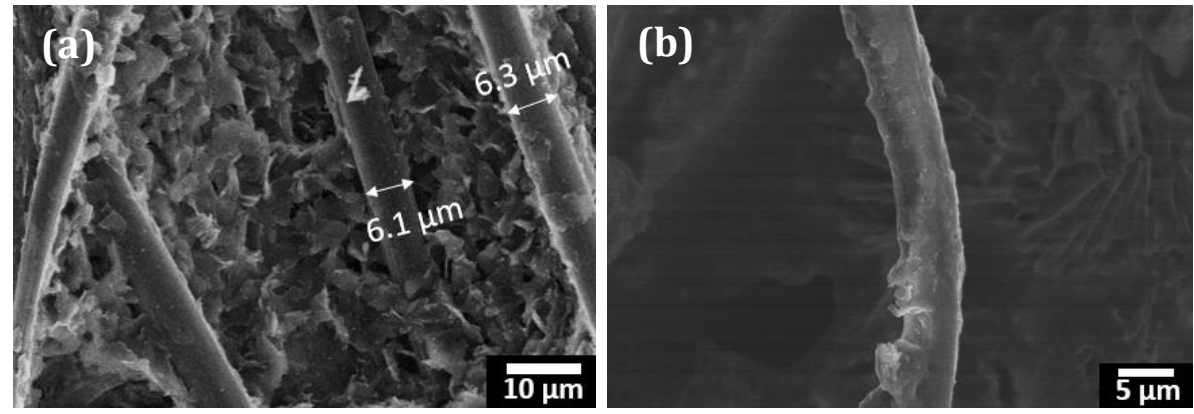

Figure 6-7 SEM images showed that the diameter of CNF was between 6-10 $\mu \mathrm{m}$.

In addition, the directly use of soluble polysulfide species resulted in good dispersion of active sulfur materials in the CNFPC electrodes. Both SEM images and EDS mapping showed that the active sulfur materials were uniformly integrated throughout the cathode without individual sulfur particles after 100 cycles (Figure 6-8), 
revealing the efficient electrical contact between active sulfur materials and the CNF conductive framework. Furthermore, the CNF paper current collector was still intact without damage, indicating the effectiveness of the electrode to accommodate volume changes of sulfur during the repeated cycles. The robust CNF structure with a large thickness $(\sim 160 \mu \mathrm{m})$ favored the utilization of the active sulfur materials. Consequently, highly efficient electron/ion pathways and high sulfur-loading capability were obtained.
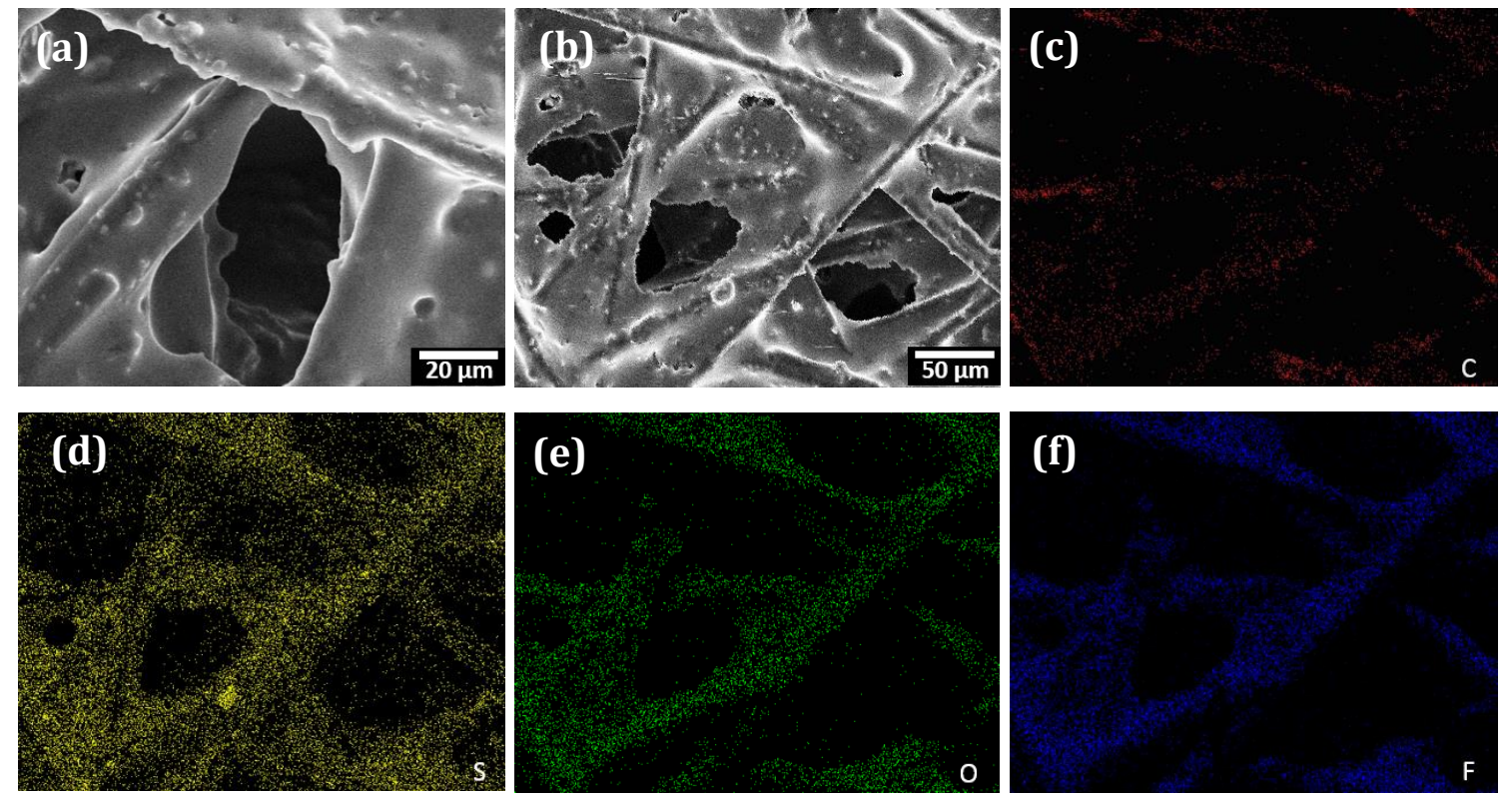

Figure 6-8 (a, b) SEM images of CNF current collector after 100 cycles. (c-f) EDS mapping of different elements corresponding to the SEM image of (b).

Now that the roles of the CNF current collector and carbon black have been investigated, the factors influencing long-term cycling stability need to be discussed. One possible explanation for the excellent cycling stability was that the compact porous carbon layer with a high tap density on the surface of the CNF current collector may have functioned as a physical barrier that decreased the transport of polysulfide species from cathode to anode. This layer was reasonably vital to retain the active mass and electrical contact of CNFPC paper electrode, and thus enhanced the Coulombic efficiency of Li-S batteries. Control cells adopting the CNF electrode without a porous carbon layer were assembled (Figure 6-9a). Capacities of these control cells decreased all the time at all rates studied (Figure 6-9b), and capacities of these batteries were low (Figure 6-9c), indicating that the porous carbon layer probably acted as a physical barrier that reduced 
polysulfide shuttle and thus protected capacity retention. On the other hand, the Li-anode dissembled from the Li/CNFPC battery after 100 cycles had a much more dense structure (Figures 6-10a and 6-10b). In contrast, there were obviously cracks and numerous lithium dendrites on the surface of the Li-anode in the control cells (Figures 6-10c and 610d). In addition, the chemical composition of surface film on the Li-anode in the control cells was more sophisticated and contained much more sulfur substance (Figures 6-10e and 6-10f). The results indicated that the side reactions between soluble polysulfides and Li-anode might be an important reason for the growth of lithium dendrites in $\mathrm{Li}-\mathrm{S}$ batteries. These side reactions were largely alleviated in the Li/CNFPC batteries, further supporting the effectiveness of a porous carbon film layer on trapping polysulfides within CNFPC electrodes.
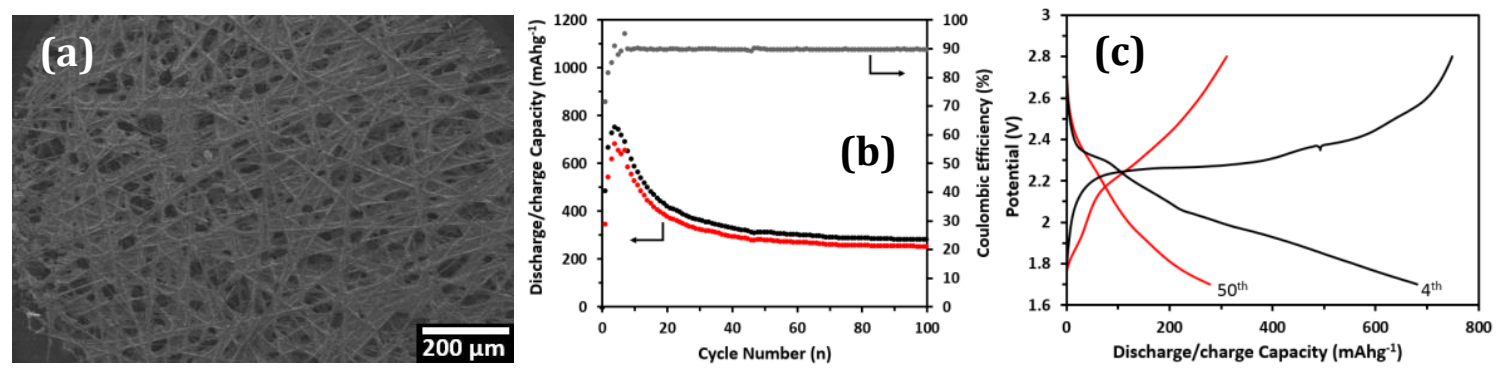

Figure 6-9 Characterization of the control cells. (a) SEM image of CNF cathodes without a porous carbon layer. (b) Cycling performance of Li/CNF batteries at $0.5 \mathrm{C}$. (c) Discharge/charge voltage profiles of $\mathrm{Li} / \mathrm{CNF}$ batteries at $0.5 \mathrm{C}$.
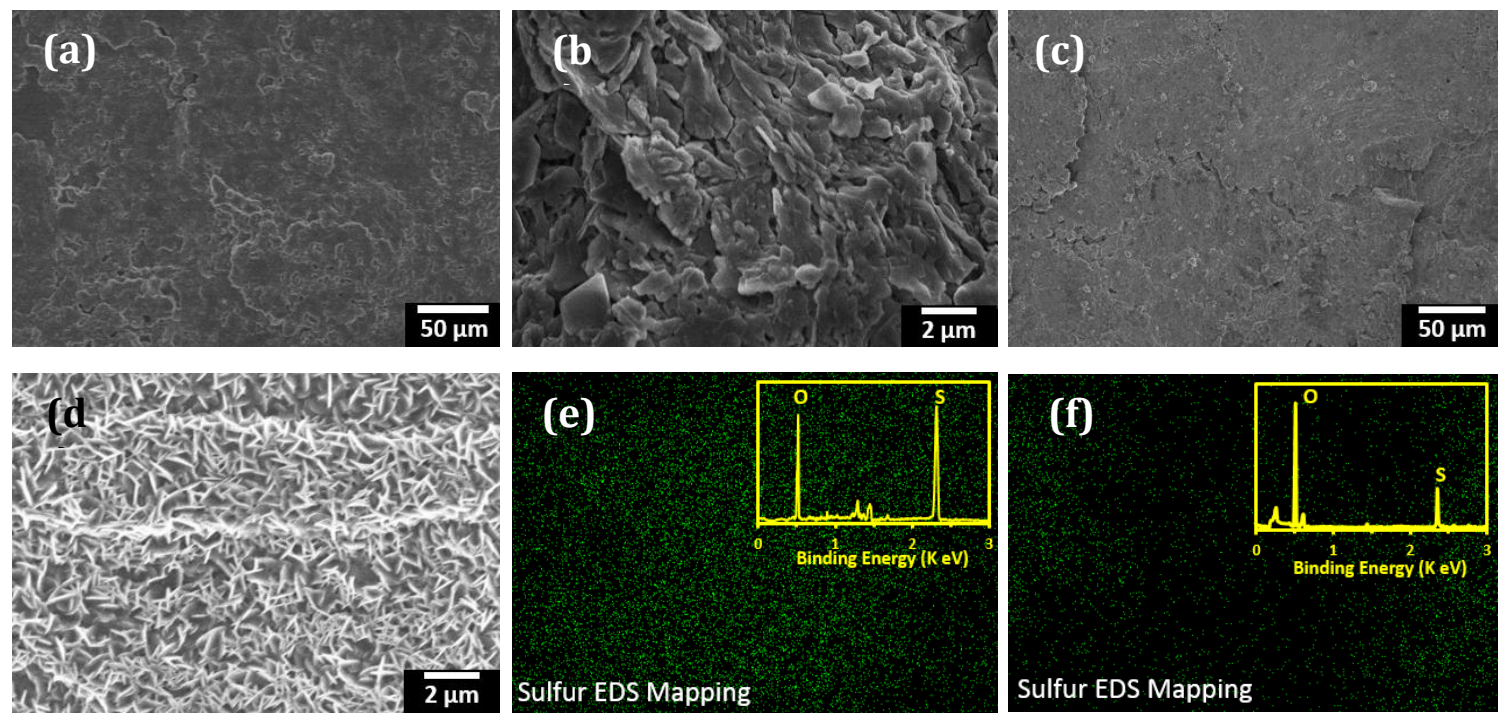
Figure 6-10 Characterizations of surface films on Li-anode. (a, b) SEM images of the Li-metal surface from the Li/CNFPC batteries at different magnifications. (c, d) SEM images of the Limetal surface from the Li/CNF batteries at different magnifications. (e, f) EDS and EDX data of Li-metals surface from (e) Li/CNFPC batteries and (f) Li/CNF batteries, respectively.

Furthermore, it is worth noting that the porous carbon layer in CNFPC electrodes reduced the charge-transfer resistance (activation polarizations), as characterized by the smaller semicircle at the high-frequency region in the electrochemical impedance spectroscopy spectra (Figure 6-11) compared to the control batteries. However, the thickness of the porous carbon layer had a great influence on the performance of Li-S batteries. When increasing the thickness from 5 to $15 \mu \mathrm{m}$, negative effects on electrochemical performance were observed (Figure 6-12). A high over-potential in the CV curves (Figure 6-12a) and a relatively fast capacity fading were noted (Figures 612b and 6-12c). One possible explanation is that the thick and densely tapped porous carbon film decreased the efficiency of Li-ion diffusion, which was governed by random jumps of Li-ions, leading to position exchange with their neighbors. As shown in Figure 6-12b, the Coulombic efficiency of the two batteries at different current rates was always larger than 100\%, and the higher the current rate, the lower the Coulombic efficiency. This result infers that it is more difficult for lithium ions to diffuse out of the cathode than to insert into the cathode.

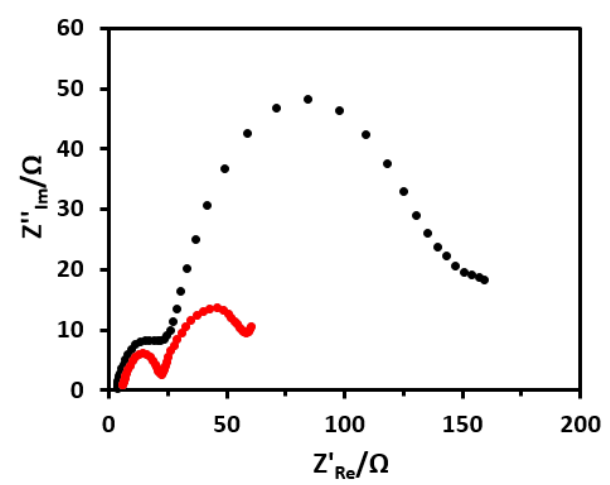

Figure 6-11 Comparison of the EIS curves of Li/CNFPC battery (red) and Li/CNF battery (black). 

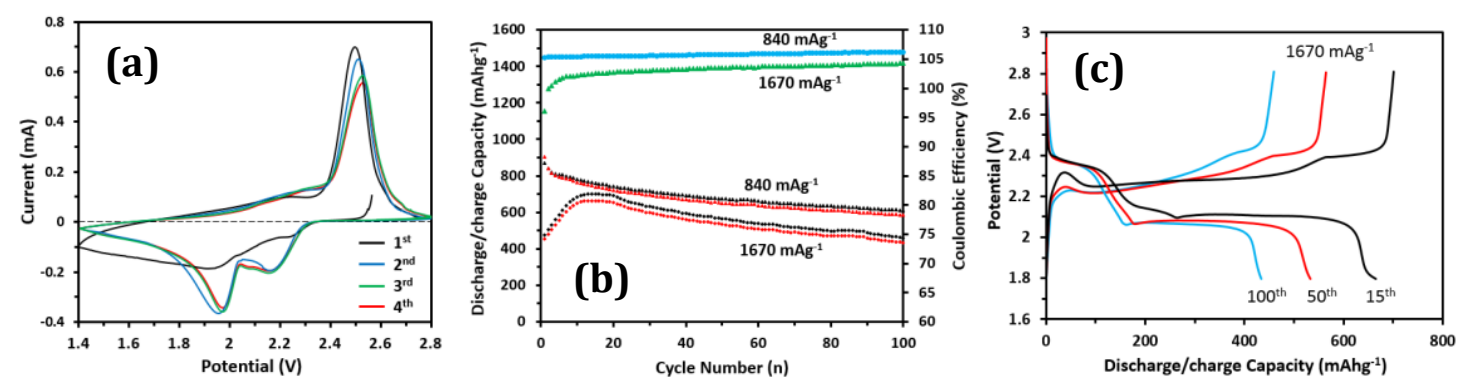

Figure 6-12 Electrochemical performance of a thick $(\sim 15 \mu \mathrm{m})$ CNFPC cathode. (a) CV curves. (b) Cycling performance at different current rates. (c) Discharge/charge curves at $1 \mathrm{C}$.

From the above discussion, the combination of highly conductive CNFPC paper and carbon black nanoparticles with soluble lithium polysulfide species resulted in a high sulfur-loading composite electrode that can take advantage of each part. However, the specific capacities at all of the rates studied were not high. To get insight into the chemistry of the Li/CNFPC battery, X-ray photoelectron spectroscopy (XPS) (Figure 613) was performed to confirm the surface compositions of the cathode after initial charge/discharge. The high-resolution $\mathrm{S} 2 \mathrm{p}$ region spectra of $\mathrm{CNF}$ current collector are shown in Figures 6-13a-c, corresponding to the three points $A-C$ in Figure 6-13d, respectively. Initially, before cycling, the electrode contained high-order polysulfides (mainly as $\mathrm{Li}_{2} \mathrm{~S}_{6}$ ), as verified by the characteristic $\mathrm{S} 2 \mathrm{p} 3 / 2$ peak at $161.9 \mathrm{eV}$ (Figure 613a). After being fully discharged to $1.8 \mathrm{~V}$, the electrode contained $\mathrm{Li}_{2} \mathrm{~S}(158.1 \mathrm{eV})$, $\mathrm{Li}_{2} \mathrm{~S}_{2}(159.4 \mathrm{eV})$, and high-order lithium polysulfide species (centered at $160.9 \mathrm{eV}$ ) (Figure 6-13b). After being fully charged to $2.5 \mathrm{~V}$, the electrode contained $\mathrm{Li}_{2} \mathrm{~S}_{1} \mathrm{Li}_{2} \mathrm{~S}_{2}$, high-order lithium polysulfide species, and elemental sulfur (163.2 eV) (Figure 6-13c). The results showed an incomplete conversion in both discharge/charge processes, resulting in a relatively low capacity. In this study, the electrolyte-to-sulfur ratio was around $7.4 \mathrm{ml} / \mathrm{g}$, which was a little smaller than the ratio reported, and thus generate a relatively lower capacity. Since the reduction of sulfur and oxidation of $\mathrm{Li}_{2} \mathrm{~S}_{2} / \mathrm{Li}_{2} \mathrm{~S}$ can only take place on the surface of carbon, some of the active sulfur materials in the dead corner of CNFPC structure that lost the direct contact with the conductive matrix did not contribute capacity. It was suggested that most of the polysulfide species were transformed into intermediates with the most facile reduction and oxidation kinetics (via charge transfer), as the kinetic dynamics from high order polysulfide species to 
$\mathrm{Li}_{2} \mathrm{~S}_{2} / \mathrm{Li}_{2} \mathrm{~S}$ or elemental sulfur were very slow. For example, after the initial cycle, most of the active materials in the electrode were soluble high-order polysulfide species in the higher valence state (i.e. $\mathrm{S}_{8}{ }^{2-}$ ). Unlike the nonconductive sulfur or $\mathrm{Li}_{2} \mathrm{~S}_{2} / \mathrm{Li}_{2} \mathrm{~S}$, these incompletely transformed high-order polysulfide species dissolved into the electrolyte might have enhanced the transports of Li-ions and electrons, which is why, at a large current rate of $1.5 \mathrm{C}$, a decent cell capacity was retained over 1000 cycles. In addition, the $\mathrm{C}$ 1s region spectra of the CNFPC electrodes was also performed. Compared to the electrode before cycling, which presented a main peak at $284.1 \mathrm{eV}$ corresponding to $\mathrm{sp}^{2}$ carbon (C-H) (Figure 6-13f), the one after the $100^{\text {th }}$ discharge showed a new peak at $287.3 \mathrm{eV}$ (Figure 6-13e), which was assigned to a combination of $\mathrm{C}-\mathrm{O}$ and $\mathrm{C}=\mathrm{O}$ bonds, implying the chemical stability of the electrodes.
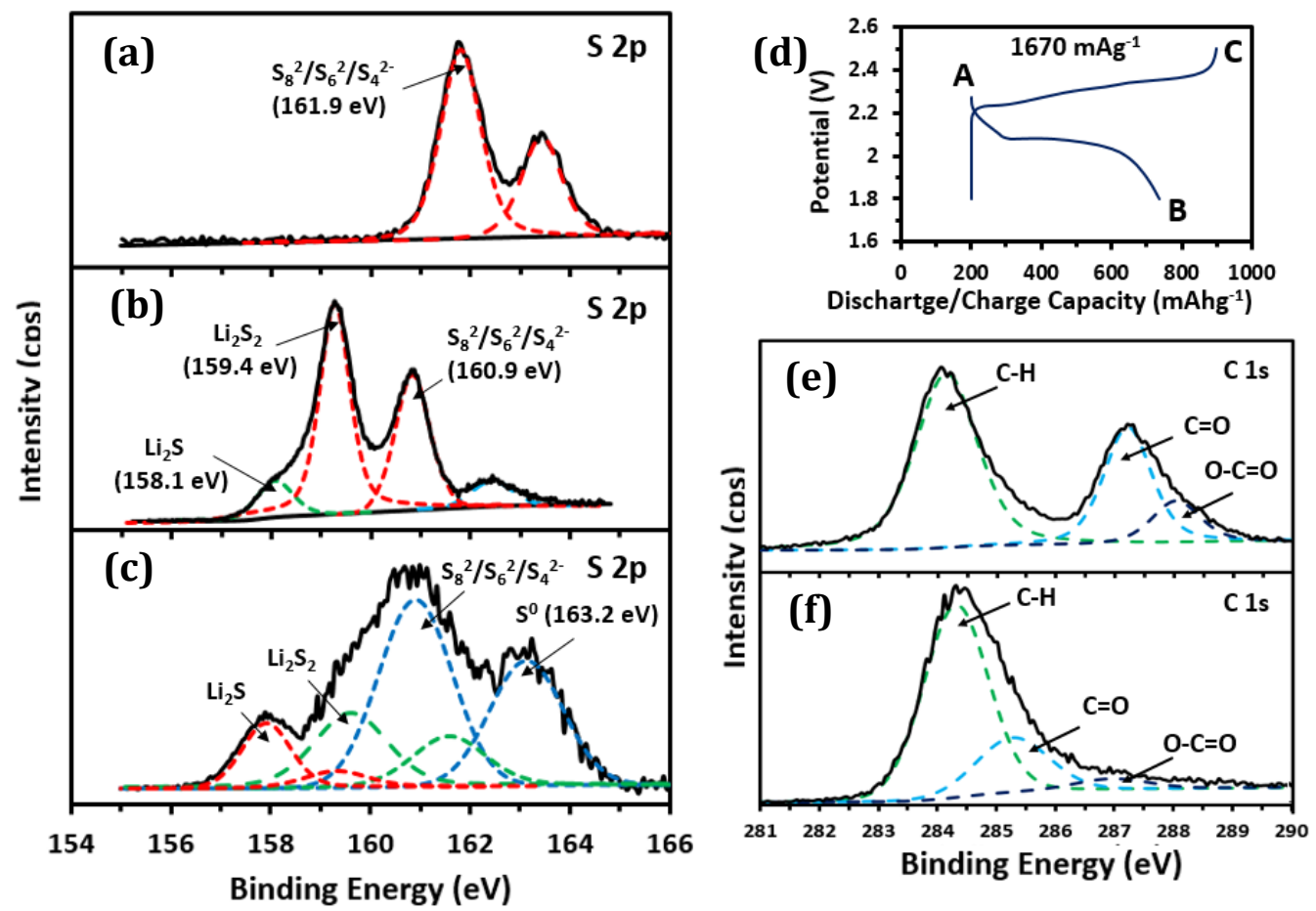

Figure 6-13 High resolution XPS S 2p spectra of the CNF current collector surface (a) before cycling, (b) after the initial discharge and (c) after the initial charge. (d) The initial discharge/charge profiles at $\sim 1 \mathrm{C}$ rate. High resolution XPS c 1s spectra of the CNF current collector surface (e) after the initial discharge and (f) before cycling.

On the basis of these discussions, the integrated CNF and carbon black system provided an effective conductive framework, which facilitated fast discharging/charging; 
while the porous carbon layer greatly reduced polysulfide migration, leading to excellent capacity retention. The primary results indicated that polysulfide dissolution was the reason for a low capacity, and polysulfide migration was responsible for fast capacity decay. The areal capacity of Li/CNFPC battery was high. For example, at $0.5 \mathrm{C}$, the areal

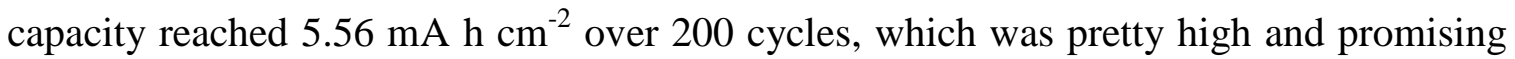
for commercial applications.

\subsection{Conclusions}

In summary, we demonstrated herein an effective, low cost method to achieve high sulfur-loading Li-S batteries with a great rate capability and an excellent long-cycle stability. The CNFPC electrode with an ultrahigh sulfur-loading of $6.7 \mathrm{mg} \mathrm{cm}^{-2}$ and a high electrical conductivity was obtained using a simple method. The functions of each part in this unique CNFPC design were verified. The CNF current collector served as the long-range conductive framework and as a host for the soluble polysulfides while the incorporation of carbon black nanoparticles, which acted as the short-range conductive framework, further enhanced electron transport. In addition, the CNF framework had superior integrity and an improved ability to accommodate the volume changes of the active sulfur materials due to the large interspaces in this framework, which also facilitated electrolyte infiltration and thus enhanced Li-ion transport. We also found that the top layer of porous carbon film on the CNF current collector not only reduced polysulfide migration from cathode to anode, but also enhanced the integrity of the whole cathode structure. As a result, at a high current rate of $1.5 \mathrm{C}$, reversible capacities of 302 $\mathrm{mAh} \mathrm{g}^{-1}$ over 1000 cycles were achieved in such high sulfur-loading Li-S batteries. At the same time, the Coulombic efficiency was always larger than $99.5 \%$, indicating the highly reversible capability of $\mathrm{Li}-\mathrm{S}$ batteries employing CNFPC electrodes. We believe that these CNFPC electrodes fabricated using a simple method at low cost, producing Li$\mathrm{S}$ batteries with high rate capability and long-cycling performance, move a step closer to Li-S battery commercialization. 


\section{Chapter 7: Mechanism and Kinetics of Capacity Fade in Lithium Sulfur Batteries}

Rechargeable Li-S batteries are receiving ever-increasing attention due to their high theoretical energy density and inexpensive raw sulfur materials. However, rapid capacity fade has been one of the main barriers to further improvements in $\mathrm{Li}-\mathrm{S}$ batteries and is expected to remain so for the near future. As we have talked in Chapter 1, it is generally thought that polysulfide species dissolution and shuttle, nonconductive $\mathrm{Li}_{2} \mathrm{~S}_{2} / \mathrm{Li}_{2} \mathrm{~S}$ precipitation, and irreversible transformations of sulfur cause various degrees of capacity fade. Li-S battery is a liquid electrochemical system, in which the sulfur-to-electrolyte ratio plays an essential role in the cell's performance. More electrolyte causes larger amounts of materials loss, and leads to a more rapid capacity fade as mentioned previously. However, the dissolution of long-chain lithium polysulfide species exposes the inner nonconductive sulfur $/ \mathrm{Li}_{2} \mathrm{~S}_{2} / \mathrm{Li}_{2} \mathrm{~S}$ to the conductive carbon framework, making it easy for electron-transfer, and thus promotes a complete reaction and produces a high capacity. In addition, the dissolution enhances ion diffusion, which promotes a high charge and discharge rate. [25] Therefore, these two opposite factors should be properly balanced to get a good performance with a reasonable capacity and cycle life.

Most literatures did not mention the amount of electrolytes used in batteries, although the sulfur-to-electrolyte ratio strongly affects battery performance. [154] With this in mind, in an effort to quantify these degradation processes and elucidate the underlying mechanism of capacity fade, we conducted a comprehensive study of a binder-free sulfur-multiwall carbon nanotube (SMCNT) composite electrode with a commercialized carbon nanofiber $(\mathrm{CNF})$ current collector with different amounts of electrolytes. The capacity loss was discussed and separated into three parameters. By discussing the electrochemical performance, sulfur reaction kinetics, and EIS, the major reason for the rapid capacity fade was ascribed to the formation of thick layers of solid and nonconductive $\mathrm{Li}_{2} \mathrm{~S}_{2} / \mathrm{Li}_{2} \mathrm{~S}$ films.

\subsection{Experimental Design}


Based on the capacity fade analysis in Chapter 1, the total capacity fade, Q, of the liquid type Li-S battery can be divided into three parts: sulfur loss $\left(\mathrm{Q}_{1}\right)$, the precipitation of nonconductive $\mathrm{Li}_{2} \mathrm{~S}_{2} / \mathrm{Li}_{2} \mathrm{~S}$ films $\left(\mathrm{Q}_{2}\right)$ and sulfur reaction kinetics $\left(\mathrm{Q}_{3}\right)$. All of them are related to the quantity of electrolytes. To quantify $\mathrm{Q}_{1}, \mathrm{Q}_{2}$, and $\mathrm{Q}_{3}$, three different amounts of electrolytes were adopted: $5 \mathrm{ml} / \mathrm{g}, 8 \mathrm{ml} / \mathrm{g}$, and $12 \mathrm{ml} / \mathrm{g}$, based on sulfur, representing insufficient, proper, and sufficient quantity of electrolytes, respectively. There are a lot of parameters should be considered when designing a sulfur cathode, in which the conductivity, porosity, and thickness are the most important factors. [39-41, 44] In order to reliably track the influence of electrolyte, all other parameters should be fixed. In this study, we designed a binder-free SMCNT electrode with a 3D carbon nanofiber (CNF)based current collector. Our former studies demonstrated that using PVDF leads to a blockage of pores in the sulfur electrode, which strongly limits the access to active materials and dramatically reduces specific capacity of Li-S cell. [50] Whereas, binderfree electrodes may lead to high specific capacities. $[155,156]$ In addition, the 3D CNF current collector provided an improved conductive network and made it easy for electrolyte access to the porous structure, and confined the polysulfide species during cycling, to limit the loss of the active sulfur materials. [124]

The sulfur loading in the SMCNT electrode was $1.9 \mathrm{mg} \mathrm{cm}^{-2}$, and sulfur content was $71 \mathrm{wt} . \%$. We found the sulfur cathode could be infiltrated even with a small amount of electrolyte $\left(5 \mathrm{ml} \mathrm{g}^{-1}\right)$, indicating the effectiveness of binder-free sulfur electrode on absorbing electrolyte. CR2032-type coin cells were used as the testing cells. Lithium foils were used as the anodes, Cellgard 2400 microporous membranes as separators, $1.0 \mathrm{~mol} \mathrm{~L}^{-}$ ${ }^{1}$ bis(trifluoromethane sulfonyl) imide (LiTFSI)/bis(fluorosulfonyl) imide (LiFSI) (mass ratio 1:1) and $0.1 \mathrm{~mol} \mathrm{~L}^{-1} \mathrm{LiNO}_{3}$ dissolved in dioxolane (DOL) and 1,2-dimethoxyethane (DME) $(1: 1, \mathrm{v} / \mathrm{v})$ as electrolytes. The ring lithium foil with a thickness of $20 \mu \mathrm{m}$ and diameter of $1.65 \mathrm{~cm}$ was used as $\mathrm{Li}$-anode. $\mathrm{LiNO}_{3}$ was used to form a protective film on the surface of Li-anode. [133] The cells were assembled in an argon-filled glove box. The size of the electrode material was $1 \mathrm{~cm} \times 1 \mathrm{~cm}$. Electrochemistry measurements were performed galvanostatically between 1.8 and $3.0 \mathrm{~V}$ at various current densities. Capacity was calculated based on the weight of sulfur on the electrodes. CV experiments were 
conducted using a NOVA potentiostat at a scan rate of $0.1 \mathrm{mV} \mathrm{s}^{-1}$. EIS measurements were carried out using a NOVA electrochemical workstation in a frequency range between $100 \mathrm{kHz}$ and $100 \mathrm{mHz}$ at a potentiostatic signal amplitude of $5 \mathrm{mV}$. All experiments were conducted at room temperature.

\subsection{Results and Discussion}

\subsubsection{Synthesis and Characterization of SMCNT Electrode}

The porous SMCNT structure was synthesized by the facile two-step approach illustrated in Figure 7-1a. This strategy involved solvent exchange and freeze-drying methods. The detailed information about the solvent exchange procedure to SMCNT in the water was described in our former work. [37] With this method, CNTs presented oxygen-containing groups and sulfur was well dispersed on CNT surfaces. Then, freezedrying strategy was applied to the SMCNT samples to achieve fine control of porous SMCNT framework structures. The freeze-drying method involves freezing the material at low temperatures (typically $-170{ }^{\circ} \mathrm{C}$ in liquid nitrogen) and then directly evaporate ice crystals. [157] Scanning electron microscopy (SEM) images of the composite, which has an irregular spherical morphology with CNTs protruding to the surface, are shown in Figures 7-1b and 7-1c. It was found that the infiltration of sulfur into MCNTs leads to electrodes with minimized particle agglomeration. The average particle size was about 30um (Figure 7-1d). The cross-section image showed that the CNTs were dispersed throughout the particle interior (Figure 7-1e). XRD was performed to characterize the composite, as shown in Figure 7-1f. Sulfur in the SMCNT composite had both monoclinic phase and orthorhombic phase. The monoclinic phase might attribute to the chemical bonds between sulfur and oxygen-containing groups on the CNT surfaces. The 3D CNF current collector (Figure 7-1g) might be of interest for enlarging the reaction area. In our former study, we identified the 3D current collector enabled good conductivity, and the flexible, porous architecture accommodated the volume changes during cycling and retained the polysulfide species in the electrode region. [124] It was confirmed by SEM that the active sulfur materials were well distributed in the electrodes 
even after long-term cycling. In addition, the mechanical stability of the CNF electrode was sufficient to achieve long cycle life without binder.
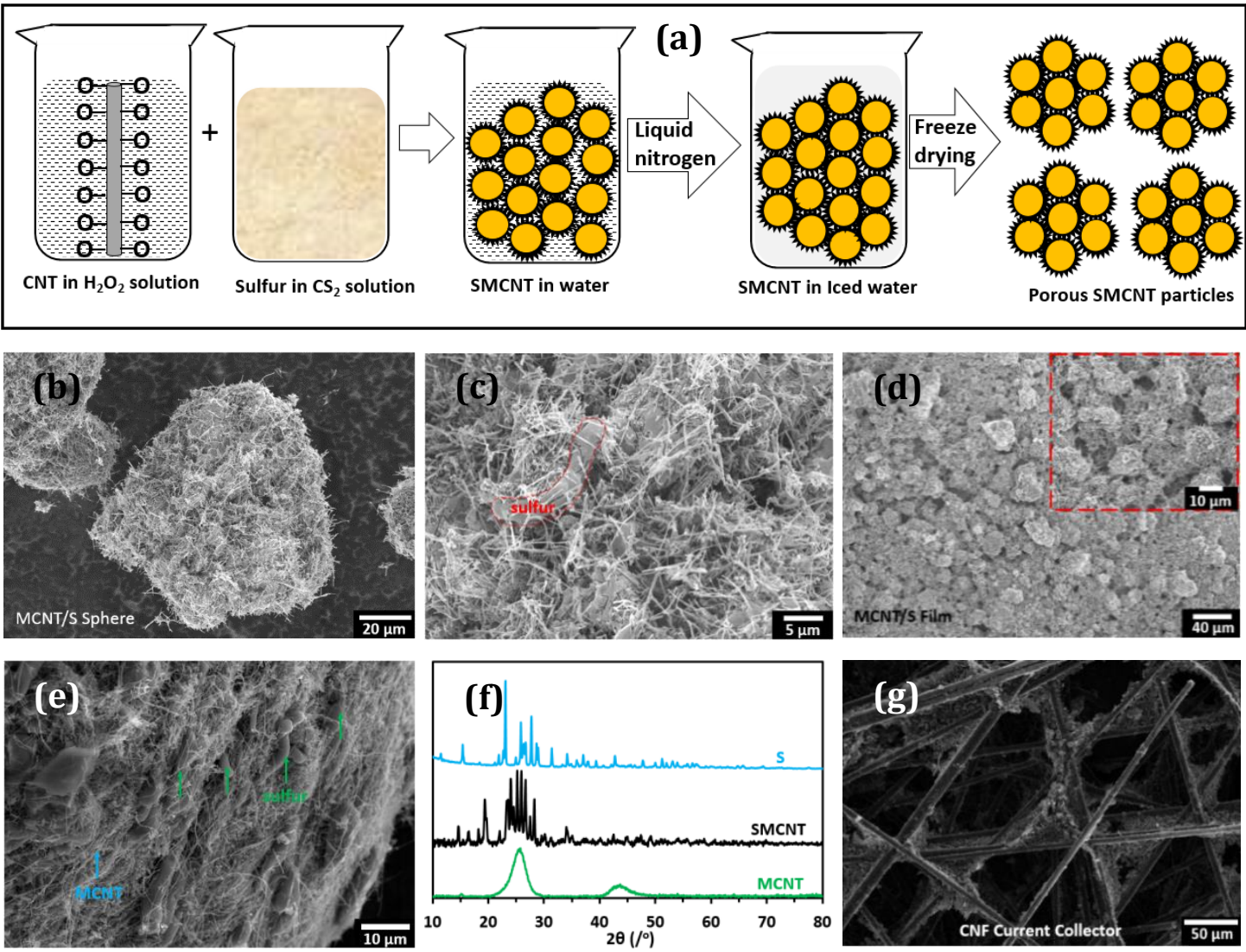

Figure 7-1 (a) Typical procedures to SMCNT. (b-d) Surface and (e) cross-sectional SEM images of the porous SMCNT structures. (f) XRD analysis of SMCNT. (g) CNF current collector used in this study.

\subsubsection{Cycling Performance}

To analyze the capacity fade in Li-S batteries with various amounts of electrolytes, long-cycling performance and the relatively capacity fade were examined, as shown in Figure 7-2. The discharge current rate was $0.1 \mathrm{C}\left(167 \mathrm{~mA} \mathrm{~g}^{-1}\right)$. The cycling stability is shown in Figure 7-2a. The cell with $5 \mathrm{ml} / \mathrm{g}$ of electrolyte presented a low initial capacity but a very stable capacity throughout cycling. By contrast, the cell with $12 \mathrm{ml} / \mathrm{g}$ of electrolyte resulted in a high initial capacity. However, the discharge capacity dropped quickly in the first 30 cycles, and then decreased linearly with cycling. The sulfur utilization and the capacity fade as a function of cycle number are shown in Figures 7-2b and 7-2c, respectively. The sulfur utilization was based on the theoretical sulfur capacity 
of $1672 \mathrm{~mA} \mathrm{~h} \mathrm{~g}^{-1}$, while the capacity fade was based on the initial discharge capacity. The capacity was checked on the second cycle, and every 20 cycles after that. As can be seen from Figure 7-2b, increasing the quantity of electrolyte in the cell led to an increased initial discharge capacity, and thus enhanced initial sulfur utilization. At the 100th fully discharged cycles, sulfur utilization for the batteries with 5 and $8 \mathrm{ml} / \mathrm{g}$ of electrolytes demonstrated no big difference, and both of them were $\sim 50 \%$. The battery with $12 \mathrm{ml} / \mathrm{g}$ of electrolyte only had a sulfur utilization of 38\%. From Figure 7-2c, a large irreversible capacity loss between the first two cycles was observed for all of these three batteries, which was well agreed with the previous analysis for equation 10. After the second cycle, the capacity fade diverged greatly for these three batteries. The capacity of the battery with a sufficient amount of electrolyte $(12 \mathrm{ml} / \mathrm{g})$ decreased rapidly with increasing cycle numbers, and the capacity fade reached $60 \%$ over 100 cycles. However, the cells with an insufficient amount of electrolyte $(5 \mathrm{ml} / \mathrm{g})$ only lost $25 \%$ of its initial capacity after 100 cycles, and the capacity retained the same or a little bit larger with the cycle numbers after 80 cycles. Further, the rate of capacity fade between the second and the 100th cycles was the fastest for batteries with $12 \mathrm{ml} / \mathrm{g}$ of electrolyte among these three batteries. These results indicated that the quantity of electrolyte had a significant influence on the capacity and capacity fade of SMCNT electrodes.

The battery with $8 \mathrm{ml} / \mathrm{g}$ of electrolyte always had a Coulombic Efficiency (CE) approaching $100 \%$, and showed the best combination of specific capacity and capacity retention. The battery with $5 \mathrm{ml} / \mathrm{g}$ of electrolyte always had a CE larger than $100 \%$, resulting in a high cycling stability. Of note, the high CE (>100\%) means the discharge capacity was larger than charge capacity, indicating more Li-ion diffused into the cathode than that diffused out of the cathode during cycling. In the Li-S half-cell, $\mathrm{Li}$ source is infinite compared to that of sulfur. The insufficient amount of electrolyte resulted in a high concentration of polysulfide species in the cathode structure, and the high viscosity decreased the diffusion of $\mathrm{Li}$-ion and polysulfide species from the cathode to the electrolyte, thereby reduced polysulfide shuttle, and resulted in a high capacity retention. On the other hand, the high viscosity also hampered the electronic contact between polysulfide species with conductive CNTs, and thus generated a low discharge capacity. 
In this study, $\mathrm{LiNO}_{3}$ was added into the electrolyte, and thus the batteries with $12 \mathrm{ml} / \mathrm{g}$ of electrolyte also had a high CE of $\sim 95 \%$, indicating that the poly-shuttle effect was limited. However, a low capacity retention after 40 cycles and a rapid capacity fade trend along the whole cycling were observed. Therefore, poly-shuttle may not be the main reason for the rapid capacity fade in Li-S batteries.
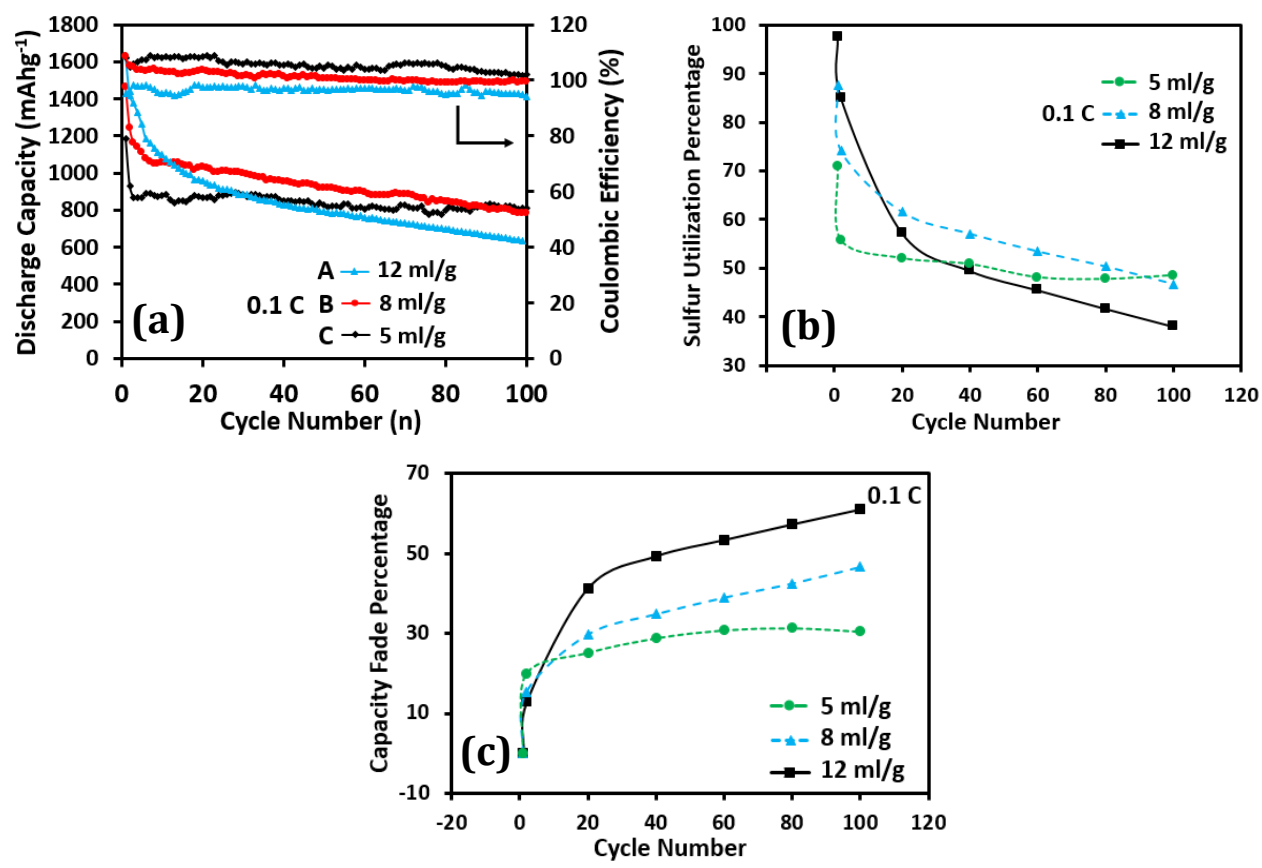

Figure 7-2 Cycling performance, sulfur utilization and capacity fade of Li-S batteries employing different quantities of electrolytes. (a) Cycling performance at 0.1 C. (b) Sulfur utilization vs. cycle numbers. (c) Capacity fade vs. cycle numbers.

\subsubsection{Sulfur Reaction Kinetics}

Next, sulfur reaction kinetics was analyzed. Figure 7-3a shows the output voltage as a function of depth of discharge (DOD), the cells with the three different amounts of electrolytes had been cycled up to 100 times. The output voltage of the half-cell under constant current can be simply represented as

$$
\mathrm{E}=\mathrm{E}_{0}-i \mathrm{R}_{\mathrm{i}}
$$

Where $\mathrm{E}_{0}$ is the standard cell potential and $\mathrm{R}_{\mathrm{i}}$ is the internal resistance of the cell, including electrolyte resistance, contact resistance, activation polarizations $\left(\eta_{\mathrm{ct}}\right.$, charge transfer over voltage) and concentration polarizations $\left(\eta_{c}\right)$ at cathode. [16] As can be seen, the output voltages of the cell with $12 \mathrm{ml} / \mathrm{g}$ of electrolyte at each DOD were always 
larger than that of the other two batteries, indicating that more electrolyte decreased the resistance of the battery, and thus enhanced the reaction kinetics. To further verify this conclusion, the first three cycles' voltage profiles of the Li-S cells were analyzed, as shown in Figures 7-3b-d. All of the three batteries showed an increase of both upper and lower discharge plateaus after their initial cycles. The lower voltage plateaus in the initial cycle indicated high polarizations of the sulfur cathode during the reaction time. After the initial cycle, most of the active sulfur materials dissolved into the liquid electrolyte and rearranged in the cathode, and thus showing an increase in the discharge plateaus. In addition, it was found that an increase in the quantity of electrolyte greatly enlarged the discharge/charge capacities and decreased the voltage difference between charge plateau and discharge plateau (from $0.298 \mathrm{~V}$ to $0.167 \mathrm{~V}$ ), indicating a fast reaction kinetics in the battery with more electrolytes. In the cells with a small amount of electrolytes $(5 \mathrm{ml} / \mathrm{g})$, a severe polarization was observed $(\Delta \mathrm{E}=0.298 \mathrm{~V})$, and both the discharge and charge curves in the first two cycles had a lot of bumps. Since the reaction of sulfur can only take place on the surfaces of CNTs, insufficient electrolytes slowed or inhibited the transportation of polysulfide species and Li-ions to the CNT surfaces, which caused an unevenly reactions in the cathode along with the reaction time, and thus resulted in a rough voltage profiles and high polarizations.

Based on these results, a sufficient amount of electrolyte dissolved more long-chain lithium polysulfide species and exposed the inner nonconductive sulfur/ $\mathrm{Li}_{2} \mathrm{~S}_{2} / \mathrm{Li}_{2} \mathrm{~S}$ to the conductive CNF framework, driving the reaction forward and thus produced a high capacity. On the other hand, more electrolytes made it easy for polysulfide species transferring from the cathode to the electrolyte, resulting in the active sulfur material loss into the dead corner of electrolyte, and thus leading to a rapid capacity fade in the first several cycles. [25] However, the electrolyte should be saturated with the dissolved longchain polysulfide species after the first several cycles, but the cell capacities always decreased no matter with $12 \mathrm{ml} / \mathrm{g}$ of electrolyte or $8 \mathrm{ml} / \mathrm{g}$ of electrolyte (Figure 7-2a). Therefore, in addition to the above reasons, other important reasons may be responsible for rapid capacity fade. 

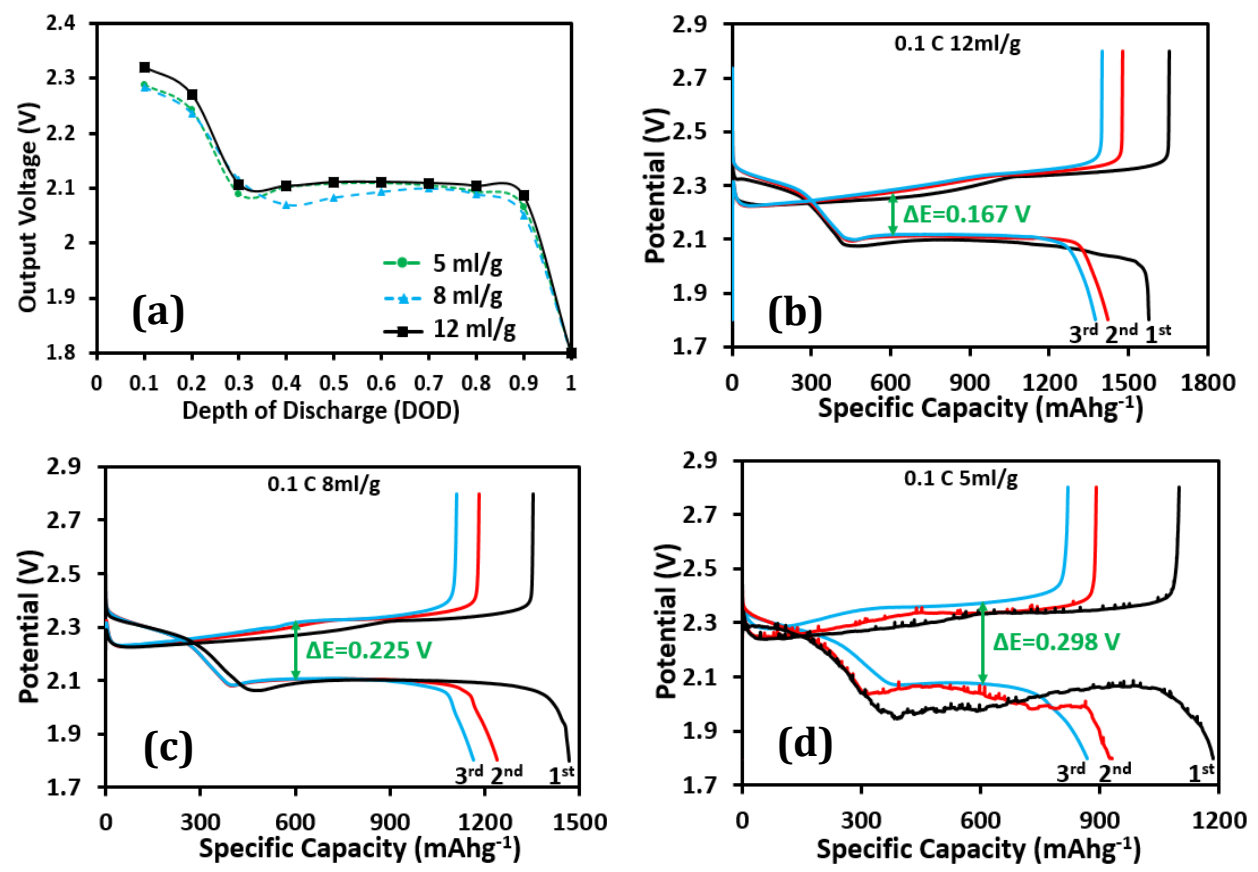

Figure 7-3 Output voltage and voltage profiles of Li-S cells with different quantities of electrolytes. (a) Output voltages over 100 cycles as a function of DOD. (b, c, d) The first three cycles' voltage profiles with the three different quantities of electrolytes.

\subsection{4 $\mathrm{Li}_{2} \mathrm{~S}_{2} / \mathrm{Li}_{2} \mathrm{~S}$ Precipitation Analysis}

To further investigate the parameters influencing the capacity fade of Li-S batteries, SEM was carried out to check the micro-structures of the sulfur electrodes cycled up to 100 times (Figure 7-4). Distinguishable differences between these batteries with different amounts of electrolytes were observed. After being fully discharged to 100 cycles, it can be seen that the cathode samples in the batteries with $5 \mathrm{ml} / \mathrm{g}$ of electrolytes (Figure 7-4a) were composed by numerous large $\mathrm{Li}_{2} \mathrm{~S}_{2} / \mathrm{Li}_{2} \mathrm{~S}$ particles, between which there were a lot of holes. However, a thick $\mathrm{Li}_{2} \mathrm{~S}_{2} / \mathrm{Li}_{2} \mathrm{~S}$ film with a lot of cracks was observed for the cathode samples of $8 \mathrm{ml} / \mathrm{g}$ of electrolytes (Figure 7-4b). For the cathode samples of 12 $\mathrm{ml} / \mathrm{g}$ of electrolytes (Figure 7-4c), a more dense thick $\mathrm{Li}_{2} \mathrm{~S}_{2} / \mathrm{Li}_{2} \mathrm{~S}$ film was observed. The deposition and accumulation of nonconductive and insoluble $\mathrm{Li}_{2} \mathrm{~S}_{2} / \mathrm{Li}_{2} \mathrm{~S}$ films in cathodes led to structural deterioration of cathode. On the other hand, after being fully charged to 100 cycles (Figures 7-4d-f), sulfur agglomerates were seen on the surface of the cathode samples with $8 \mathrm{ml} / \mathrm{g}$ and $12 \mathrm{ml} / \mathrm{g}$ of electrolytes, while no obvious sulfur accumulations were observed on the samples with $5 \mathrm{ml} / \mathrm{g}$ of electrolytes. In addition, increasing the 
quantity of electrolytes, an increased sulfur agglomerate size was observed. From Figure 7-4e, it can be seen that the average sulfur agglomerate size was around $5 \mu \mathrm{m}$. Since sulfur is nonconductive, and the electrochemical reaction can only occur on the surface of conductive CNTs, $5 \mu \mathrm{m}$ of nonconductive sulfur particles is too large for electron transport. Based on the SEM results, the formation of nonconductive $\mathrm{Li}_{2} \mathrm{~S}_{2} / \mathrm{Li}_{2} \mathrm{~S}$ films and large sulfur agglomerates on the sulfur electrodes was important reason for the rapid capacity fade in Li-S batteries.
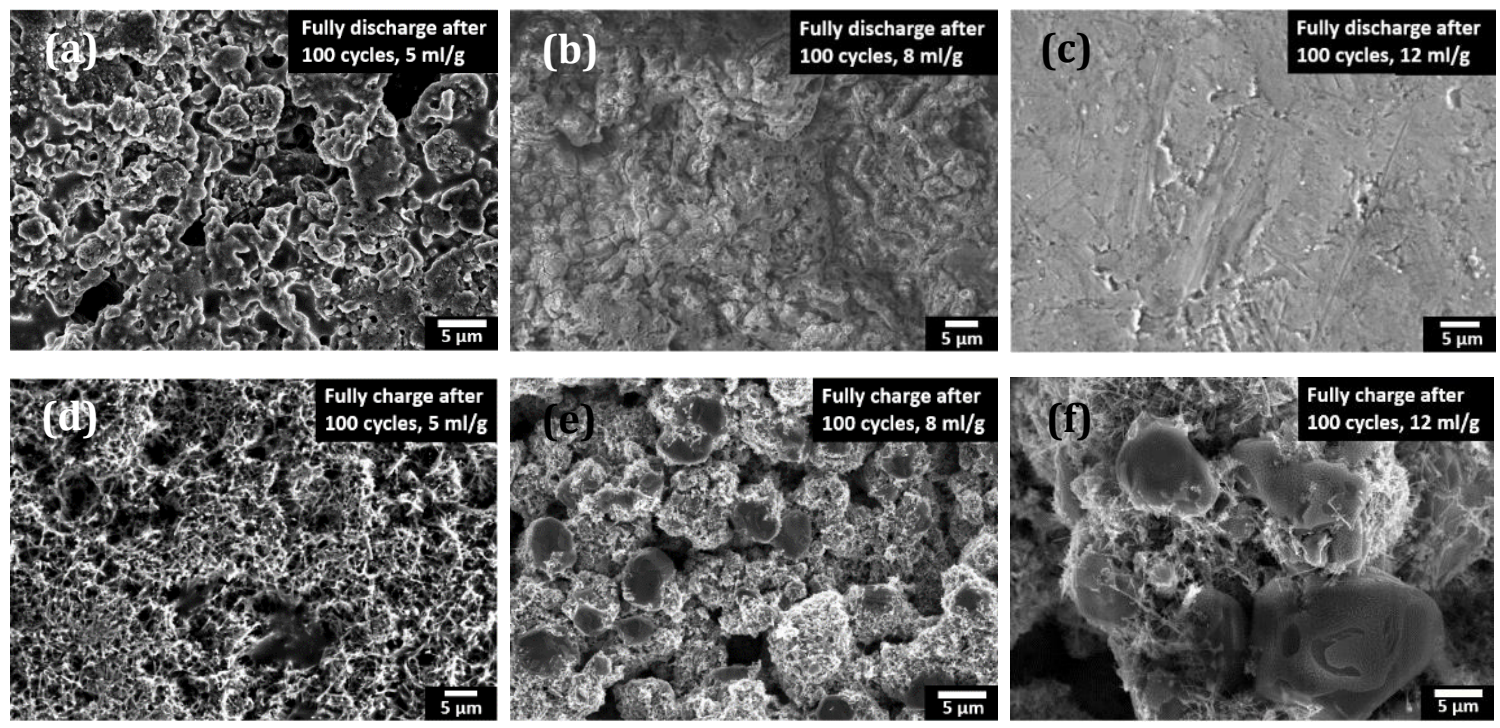

Figure 7-4 SEM images of the cathode in Li-S batteries cycled up to 100 times. Fully discharged batteries with electrolyte of (a) $5 \mathrm{ml} / \mathrm{g}$, (b) $8 \mathrm{ml} / \mathrm{g}$, and (c) $12 \mathrm{ml} / \mathrm{g}$. Fully charged batteries with electrolyte of (d) $5 \mathrm{ml} / \mathrm{g}$, (e) $8 \mathrm{ml} / \mathrm{g}$, and (f) $12 \mathrm{ml} / \mathrm{g}$.

\subsubsection{Electrochemical Impedance Spectroscopy (EIS) Study}

EIS is one of the most powerful tools for studying the electrochemical reactions in batteries. [33, 46, 54, 109, 158] To elucidate the control mechanism for the deposition and dissolution of the solid $\mathrm{Li}_{2} \mathrm{~S}_{2} / \mathrm{Li}_{2} \mathrm{~S}$ films, EIS measurements of $\mathrm{Li}-\mathrm{S}$ batteries cycled up to 100 times were carried out, as shown in Figure 7-5. In the fully discharged states (Figure 7-5a), all of the three impedance spectra exhibit two depressed semicircles in high and medium followed by an inclined line indicating solid-state diffusion at low frequency regions. For comparison, in the fully charged states (Figure 7-5b), all of the three impedance spectra are composed of one depressed semicircle in high and a short inclined line in low frequency regions. It was believed that the semicircle in the high- 
frequency region reflects the charge-transfer process at carbon interface and the semicircle in the middle-frequency region is related to the formation of solid $\mathrm{Li}_{2} \mathrm{~S}_{2} / \mathrm{Li}_{2} \mathrm{~S}$ films on the CNT surface in cathodes. [46, 54] As can be seen, in the fully discharged state, increasing the quantity of electrolytes increased the resistance of solid $\mathrm{Li}_{2} \mathrm{~S}_{2} / \mathrm{Li}_{2} \mathrm{~S}$ films. In both fully discharged and charged states, the charge-transfer impedance of the battery with a smaller amount of electrolytes was larger than that of the battery with a larger amount of electrolytes. This result was well agree with the previous conclusions: more electrolytes led to charge-transfer, but at the same time, produced thicker nonconductive films that increased the resistance of mass transport during the repeated cycles.
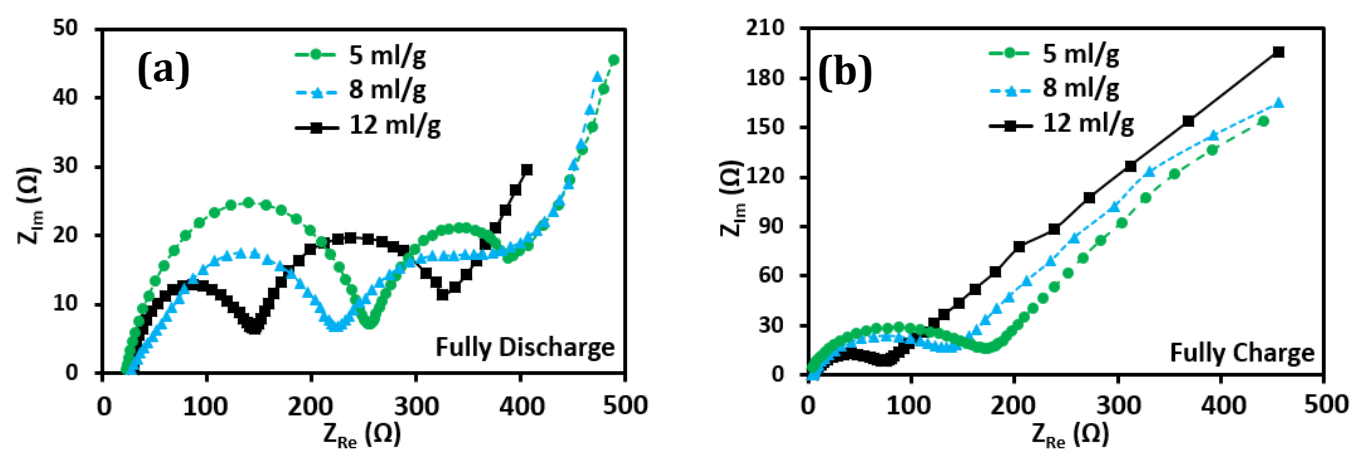

Figure 7-5 EIS plots of batteries cycled up to 100 cycles with different quantities of electrolytes at a discharge current rate of $0.1 \mathrm{C}$. The tested batteries had a $8 \mathrm{ml} / \mathrm{g}$ of electrolyte. (a) Fully discharge states (discharge to $1.8 \mathrm{~V}$ ). (b) Fully charge states (charge to $2.8 \mathrm{~V}$ ).

To examine the formation kinetics of the solid nonconductive $\mathrm{Li}_{2} \mathrm{~S}_{2} / \mathrm{Li}_{2} \mathrm{~S}$ films and large sulfur agglomerates during cycling, EIS studies at various points, as marked with points of A-G in Figure 7-6a were conducted. The chosen points A-G were selected according to discharge and charge time, in which the discharge/charge time in the first cycle had been used as the reference for the calculation of the state-of-charge or DOD. The EIS spectra were shown in Figure 7-6b. Of note, there is a fluctuation with the electrode resistances (characterized by the resistance of the very beginning points in each curve) for different states. As discharge proceeds, sulfur transformed to soluble polysulfide species, and thus the viscosity of electrolyte increased in the electrode, resulting in an increase in electrode resistance. It can be seen from the figures that the impedance spectra could be divided into two types according to the shape of the curves. 
At points $\mathrm{C}, \mathrm{D}, \mathrm{E}$, and $\mathrm{F}$, the EIS spectra comprised two depressed semi-circles and a strait sloping line; while the EIS spectra at points A, B and G only presented one depressed semi-circle and a strait sloping line. These results were well agreed with the above assumption that the depressed semi-circle in the medium frequency corresponded to the formation of $\mathrm{Li}_{2} \mathrm{~S}_{2} / \mathrm{Li}_{2} \mathrm{~S}$ films. From $\mathrm{A}$ to $\mathrm{B}$, the reduction reaction was dominated by charge transfer resistance, which decreased a lot due to the dissolution of polysulfide species into liquid electrolytes. From B to D, the charge transfer resistance increased gradually due to the slow kinetics from long-chain polysulfide species to nonconductive $\mathrm{Li}_{2} \mathrm{~S}_{2} / \mathrm{Li}_{2} \mathrm{~S}$. At the same time, the resistance from the solid $\mathrm{Li}_{2} \mathrm{~S}_{2} / \mathrm{Li}_{2} \mathrm{~S}$ film increased greatly due to the increasing thickness of $\mathrm{Li}_{2} \mathrm{~S}_{2} / \mathrm{Li}_{2} \mathrm{~S}$ films. This result indicated that from B to $\mathrm{D}$, the formation of $\mathrm{Li}_{2} \mathrm{~S}_{2} / \mathrm{Li}_{2} \mathrm{~S}$ films should be a main step controlling the reduction reaction. From $\mathrm{E}$ to $\mathrm{F}$, both resistances decreased due to the disappearance of solid $\mathrm{Li}_{2} \mathrm{~S}_{2} / \mathrm{Li}_{2} \mathrm{~S}$ films and the formation of soluble long-chain polysulfide species. At $\mathrm{G}$, only one depressed semi-circle that corresponded to the charge-transfer resistance was observed, indicating that the solid $\mathrm{Li}_{2} \mathrm{~S}_{2} / \mathrm{Li}_{2} \mathrm{~S}$ films were transformed into long-chain polysulfide species.
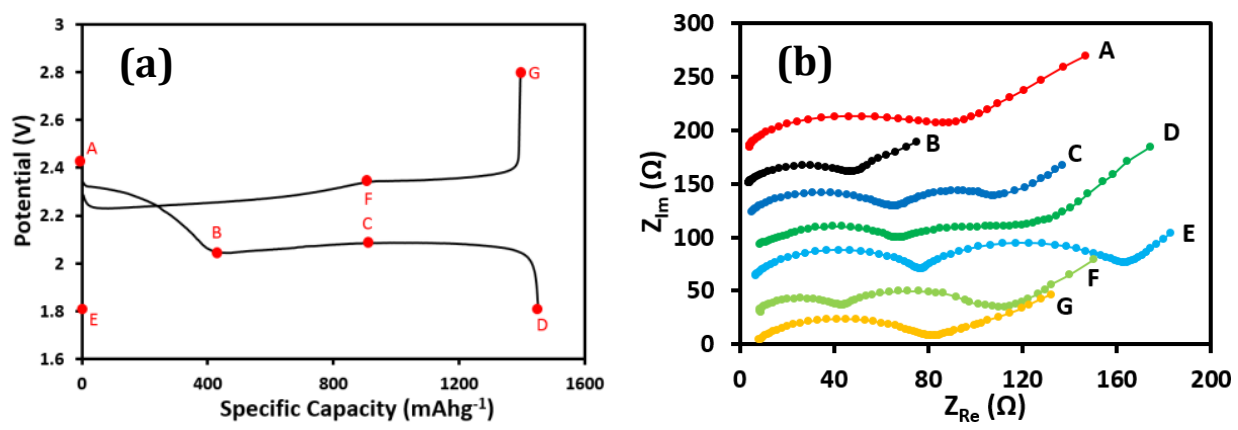

Figure 7-6 EIS characterization of cells with $12 \mathrm{ml} / \mathrm{g}$ of electrolyte at the first cycle. (a) The selected points for EIS tests in the voltage profiles. (b) EIS spectra at various points.

The morphologies and compositions of the sulfur electrodes at different discharge and charge states were investigated using SEM and energy-dispersive X-ray spectroscopy (EDX), respectively. Before taking SEM tests, the cycled electrodes at different states were washed with DOL solution in the glovebox. During this process, the soluble longchain polysulfide species were completely removed, and only solid insoluble species remained on the cathode. Then the washed electrodes were dried in the glovebox for 24 h. Prior to discharge, the original SMCNT electrodes had well distributed sulfur particles 
(Figure 7-1c), and the initial sulfur content was 71\%. After discharged to point B, as can be seen from Figure 7-7a, most sulfur particles disappeared, and only a little solid sulfur materials were observed. When it comes to the middle point $\mathrm{C}$ of the lower discharge plateau, there are disconnected solid films on the surfaces of CNTs without any aggregated sulfur particles (Figure 7-7b). Until the end of the discharge, the CNT surfaces were fully covered with a solid film (Figure 7-7c). At the middle charge state F, parts of the solid films were broken and sulfur particles were observed (Figure 7-7d). Until to the end of the charge, no obvious solid films and sulfur particles were seen on the CNT surfaces (Figure 7-7e). The sulfur content in the SMCNT electrodes at various discharge and charge states was summarized in Figure 7-7f. In the discharge process, sulfur content decreased sharply at the high plateau, and then increased at the low plateau. In the charge process, sulfur content decreased continuously. As discussed previously, at the high discharge plateau, most of elemental sulfur should be transferred into soluble long-chain polysulfide species. While at the low discharge plateau, nonconductive $\mathrm{Li}_{2} \mathrm{~S}_{2} / \mathrm{Li}_{2} \mathrm{~S}$ materials were generated. During the subsequently charge process, these nonconductive $\mathrm{Li}_{2} \mathrm{~S}_{2} / \mathrm{Li}_{2} \mathrm{~S}$ materials dissolved into the liquid electrolytes and transformed into long-chain polysulfide species. According to the previous study on $\mathrm{Li} / \mathrm{S}$ batteries, polysulfide species when recharging after the very first discharge do not transform back into elemental sulfur even at $100 \%$ depth of charge. [19, 24] Thus the $19 \%$ of sulfur at the end of charge should be ascribed to the remained $\mathrm{Li}_{2} \mathrm{~S}_{2} / \mathrm{Li}_{2} \mathrm{~S}$ materials, although the contact films were destroyed. Combining these results with the EIS spectra from Figure 7-6b, we conclude that the formation and accumulation of nonconductive $\mathrm{Li}_{2} \mathrm{~S}_{2} / \mathrm{Li}_{2} \mathrm{~S}$ films were the main reason for rapid capacity fade in the liquid-type Li-S batteries.
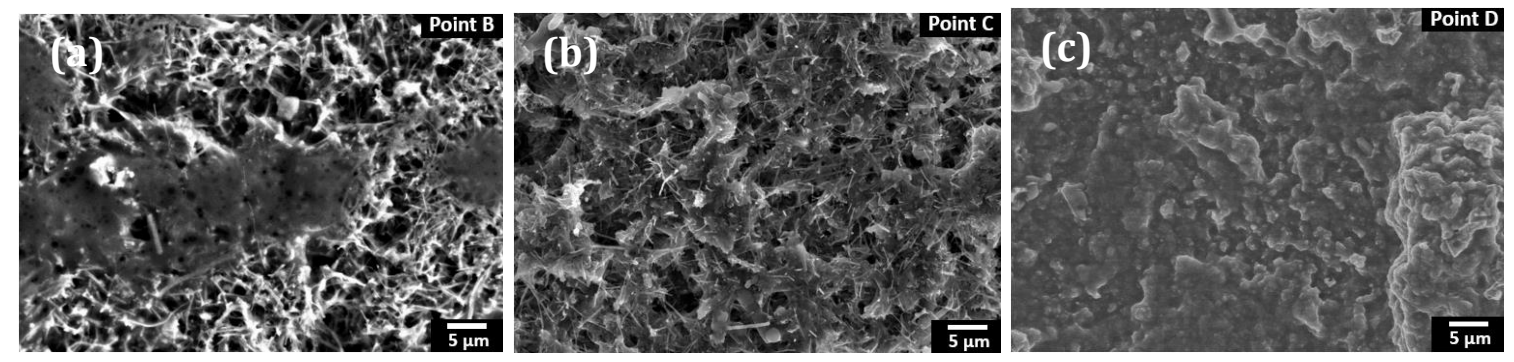

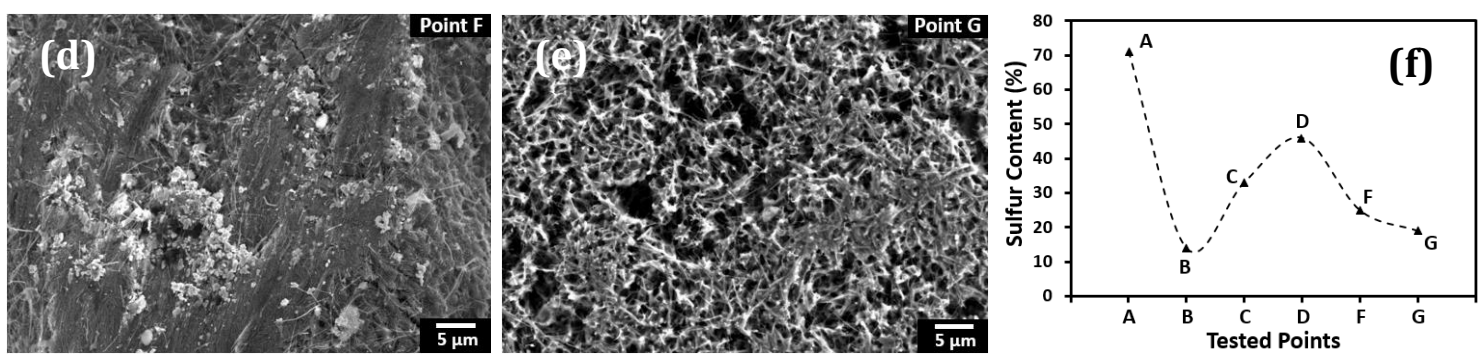

Figure 7-7 SEM characterizations and sulfur content of SMCNT electrodes at various discharge and charge states in the first cycle. The battery had a $8 \mathrm{ml} / \mathrm{g}$ of electrolyte. (a-e) At discharge points B, C and D, charge points $\mathrm{E}$ and F. (f) sulfur content at each tested states.

Based on the interpretation of the spectra of EIS, the equivalent circuit was constructed, as shown in Figure 7-8a. In the equivalent circuits, $R_{e}$ represents the impedance contributed by the resistance of the electrolyte, $R_{c t}$ and $C_{d I}$ are the charge transfer resistance at the conductive agent interface and its relative double-layer capacitance. $\mathrm{R}_{\text {film }}$ and $\mathrm{C}_{\text {film }}$ are the resistance in the $\mathrm{Li}_{2} \mathrm{~S} / \mathrm{Li}_{2} \mathrm{~S}_{2}$ film and its relative space charge capacitance. [109] $\mathrm{W}$ is the Warburg impedance due to the diffusion of the polysulfides within the cathode. To further verify the above conclusion, we compared the resistances of the nonconductive $\mathrm{Li}_{2} \mathrm{~S}_{2} / \mathrm{Li}_{2} \mathrm{~S}$ films at the first cycle and the 100th cycle, the data from points C, D and F were analyzed. From Figure 7-8b, the resistances in the first cycle were smaller than those in the 100th cycle for all of the tested points in the three different batteries. During the repeated cycles, the heat produced in the cells and the side reactions, as discussed in equation 13, would accelerate the evaporation and depletion of local electrolytes, and thus increased the resistance of the battery. As can be seen, for the battery with $12 \mathrm{ml} / \mathrm{g}$ of electrolyte, the rate of resistance increased at the two discharged states $\mathrm{C}$ and $\mathrm{D}$ was the fastest among the three different kinds of batteries. While at the charged state $\mathrm{F}$, the resistances were similar with the resistances at the middle discharged state $\mathrm{C}$. This result indicated that at the middle charged state $\mathrm{F}$, only some of the solid $\mathrm{Li}_{2} \mathrm{~S}_{2} / \mathrm{Li}_{2} \mathrm{~S}$ were transformed into soluble long-chain polysulfide species. The other $\mathrm{Li}_{2} \mathrm{~S}_{2} / \mathrm{Li}_{2} \mathrm{~S}$ films became passivation layers and inhibited further lithiation/delithiation processes, which greatly increased the resistance of the batteries, and thus resulted in a rapid capacity fade. 

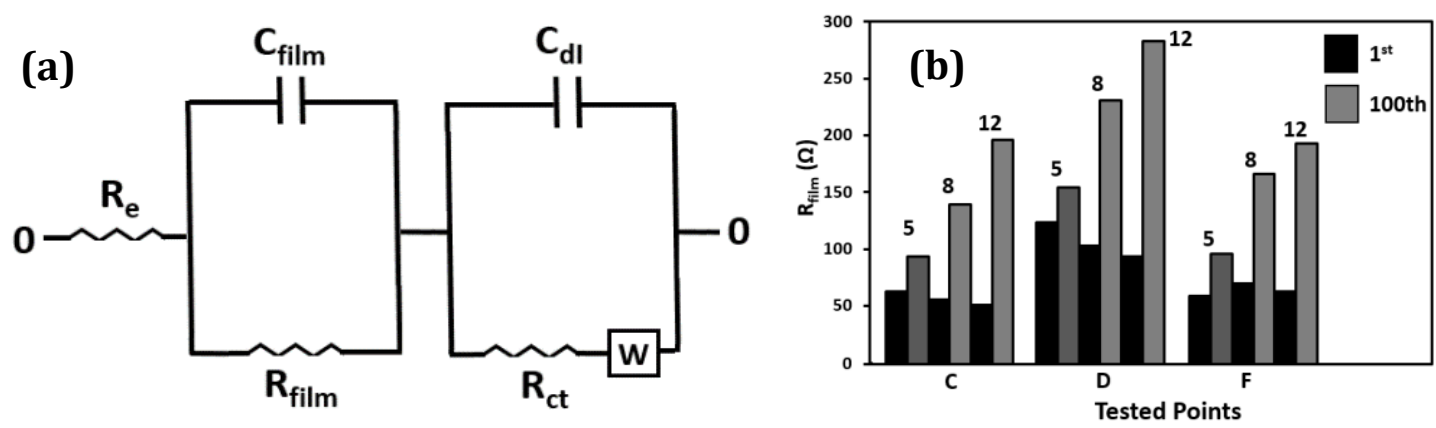

Figure 7-8 (a) Equivalent circuit of the EIS spectra. (b) $\mathrm{R}_{\text {film }}$ resistances of the solid $\mathrm{Li}_{2} \mathrm{~S}_{2} / \mathrm{Li}_{2} \mathrm{~S}$ films in the first cycle and 100th cycle with different quantity of electrolytes.

Based on the EIS analysis and the morphology of the sulfur electrodes at different discharged and charged states, we believed that the formation and accumulation of solid $\mathrm{Li}_{2} \mathrm{~S}_{2} / \mathrm{Li}_{2} \mathrm{~S}$ films had never stopped during the repeated cycles. In addition, more electrolytes led to more deposition of $\mathrm{Li}_{2} \mathrm{~S}_{2} / \mathrm{Li}_{2} \mathrm{~S}$ films due to the enhanced sulfur reaction kinetics. However, the dissolution and transformation of $\mathrm{Li}_{2} \mathrm{~S}_{2} / \mathrm{Li}_{2} \mathrm{~S}$ to long-chain polysulfide species were not complete, thus with cycling, the $\mathrm{Li}_{2} \mathrm{~S}_{2} / \mathrm{Li}_{2} \mathrm{~S}$ films became thicker and thicker, which greatly reduced the migration of Li-ion through the nonconductive films and hampered deeper discharge or charge in the cells, and thus resulted in a rapid capacity fade.

\subsection{Conclusions}

In summary, a systematic capacity fade study was carried out for Li-S batteries employing different amounts of electrolytes. Three major causes of capacity fade including the loss of active sulfur materials into the liquid electrolyte $\left(\mathrm{Q}_{1}\right)$, the precipitation of nonconductive $\mathrm{Li}_{2} \mathrm{~S}_{2} / \mathrm{Li}_{2} \mathrm{~S}$ films $\left(\mathrm{Q}_{2}\right)$ and the incomplete conversions $\left(\mathrm{Q}_{3}\right)$ were analyzed. In each case the precipitation of nonconductive $\mathrm{Li}_{2} \mathrm{~S}_{2} / \mathrm{Li}_{2} \mathrm{~S}$ films dominated the capacity fade of the whole battery. After the formation of thick $\mathrm{Li}_{2} \mathrm{~S}_{2} / \mathrm{Li}_{2} \mathrm{~S}$ films on the surfaces of sulfur electrodes, further lithiation was inhibited, which resulted in an incomplete reaction. While the loss of active sulfur materials into the liquid electrolytes directly influenced the discharge capacity from the second cycle. Large quantity of electrolytes enhanced sulfur reaction kinetics, while this was also favorable for the accumulation of thick $\mathrm{Li}_{2} \mathrm{~S}_{2} / \mathrm{Li}_{2} \mathrm{~S}$ films. EIS verified that the rapid capacity loss 
was correlated with the increase of the internal resistance, which was caused by the formation of thick $\mathrm{Li}_{2} \mathrm{~S}_{2} / \mathrm{Li}_{2} \mathrm{~S}$ films. SEM images further demonstrated that the deposition of such thick films during the repeated cycles on the surface of SMCNT electrodes. The formation kinetics of the solid nonconductive $\mathrm{Li}_{2} \mathrm{~S}_{2} / \mathrm{Li}_{2} \mathrm{~S}$ films and large sulfur agglomerates during cycling were also investigated: the semicircle in the middle frequency range was found to be caused by the solid $\mathrm{Li}_{2} \mathrm{~S}_{2} / \mathrm{Li}_{2} \mathrm{~S}$ film on the CNT surfaces in the electrode. 


\section{Chapter 8 Summary and Recommendations}

\section{Summary}

This dissertation summarized the principle and challenges of current liquid type Li-S batteries. To address these challenges, several original sulfurized materials and cathode structures were designed. For materials, SPANI and SCNT exhibited excellent rate capability, high capacity retention, and high Coulombic efficiency. For cathode structures, the binder-free multilayered sulfur cathode demonstrated not only high active sulfur mass utilizations, but also good active mass morphology control, representing a rational direction for further development. For large-scale applications of Li-S batteries, a rational combination of CNF paper and carbon black nanoparticles with a high sulfur-

loading $\left(6.7 \mathrm{mg} \mathrm{cm}^{-2}\right)$ was designed to construct sulfur cathode with high energy density. Based on these results, we tried to illustrate the mechanism and kinetics for capacity fading by designing a binder-free sulfur electrode with a freeze-drying method. The results indicated sulfur agglomeration and precipitation on electrode surface was the main reason for rapid capacity fade in Li-S batteries. In summary, four principles of developing a viable Li-S battery can be generalized as below:

(1) Appropriate dispersion of active sulfur into a well-conductive network. For one thing, short transport pathways for both electrons and $\mathrm{Li}$-ions are critical for achieving high capacity and high power capability. For another, a sufficient contact between the active sulfur and the conductive agents are necessary for the utilization of sulfur, although sulfur transforms into soluble polysulfides during cycling. As discussed in the section of multilayered sulfur cathode structure.

(2) A well designed conductive agents that have large surface areas. The deposition of insulating $\mathrm{Li}_{2} \mathrm{~S}_{2}$ and $\mathrm{Li}_{2} \mathrm{~S}$ destroy the morphology of the sulfur cathode, and lead to a detachment of the active sulfur mass from the conductive network, and thus lead to a fast capacity decay and inferior rate capability. Therefore, novel material synthesis 
method and new cathode fabrication technology should be developed, for example. As discussed in the sections of SPANI material and multilayered cathode structures.

(3) A stable electrolyte system. The current liquid electrolyte is not suitable for the commercialization of $\mathrm{Li}-\mathrm{S}$ batteries due to the side reactions between polysulfide species/electrolyte solvent/Li-anode. A more reliable electrolyte is preferred to avoid the consumption of electrolyte, which could reduce the capacity degradation of Li-S batteries.

(4) Large areal sulfur loading in cathode. The high sulfur-loading battery performance should be optimized by adjusting each parameter as shown in (1)-(3). The welldesigned carbon nanofiber paper seemed to be suitable for designing high sulfurloading battery. The paper cathode is expected to provide: (i) an interconnected network for rapid electron and ion transport, (ii) a large areal-sulfur loading. The developed approach is simple, low-cost, safe, and broadly applicable and (iii) a confined nanostructured matrix with tunable surface properties retards the shuttle of soluble polysulfides between the cathode and anode. This offers potential new avenues for the rational design and engineering of sulfur cathode materials with enhanced properties.

\section{Recommendations for Future Research}

The following two recommendations are offered for related research in the field of Li-S battery.

(1) High sulfur loading Li-S battery could be realized by employing CNF paper electrode. As shown in Figure 8-1, the reduction of sulfur can only take place on carbon surface (reaction (1), which obtains electrons and produces capacity.[52] Once sulfur is reduced to $\mathrm{Li}_{2} \mathrm{~S}$ and precipitated on carbon surface, these $\mathrm{Li}_{2} \mathrm{~S}$ species can quickly react with sulfur and form soluble long-chain lithium polysulfide species (reaction (2)). This step is a parasitic reaction, which does not 
transport electrons to external circuit and thus does not contribute to capacity.[25] However, it dissolves elemental sulfur $/ \mathrm{Li}_{2} \mathrm{~S}$, and drives the reaction forward. Under the electric filed in the cell, partial of these long-chain lithium polysulfide species diffuse to carbon surface, where they are reduced to $\mathrm{Li}_{2} \mathrm{~S}$ (3) and produces capacity. While the other partial diffuse into the dead corner of electrolyte and results in capacity fade. Therefore, since the reaction happens at the surface of carbon network, which has sufficient electrical conductivity, the insulating nature of sulfur and sulfide may not be a critical step toward the utilization of S-cathode in Li-S battery. In contrast, in a high sulfur-loading Li-S cathode system, a well-designed carbon network that affords an effective matrix for dispersing sulfur to prevent them from agglomerating is essential.

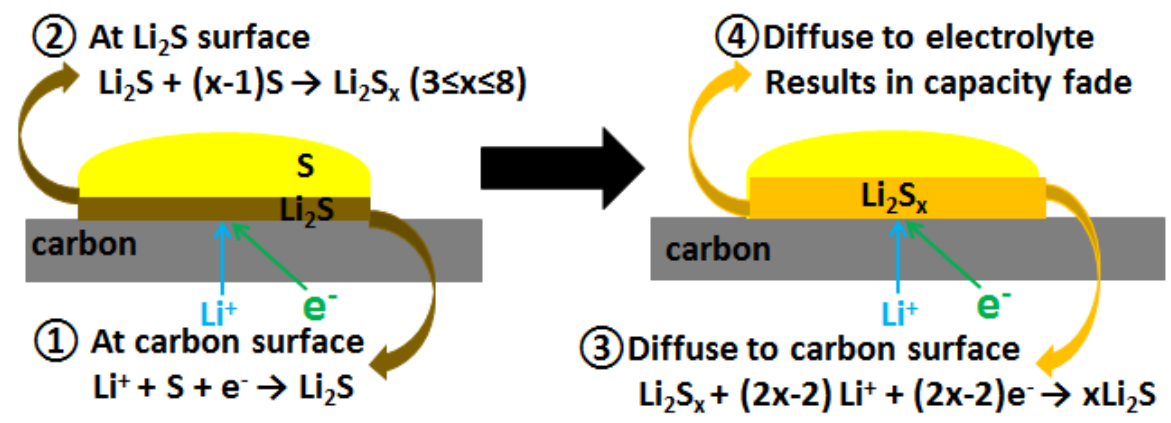

Figure 8-1 Schematic diagram of sulfur reactions at carbon surface and $\mathrm{Li}_{2} \mathrm{~S}$ surface.

(2) Protect the Li-anode with a mixed ionic and electronic conductor. As shown in Figure 8-2, after discharge, the Li surface is uneven because of the unevenness of Li-ion density that closed to Li-surface. Then in the following charge process, Liion deposition will be much more easier at the peak than that at the bottom, which causes Li-dendrite. In the conventional strategies, researchers used carbon or metal to protect the Li-anode. However, in these situations, lithium will deposit onto carbon/metal surfaces because of their excellent electric conductivities, and then will also damage the long-cycle stability of battery. However, if we change conducted carbon or metal to a mixed ionic and electronic conductor, which conducts Li-ions faster than conducts electrons, then $\mathrm{Li}$-ion deposition will take 
place between $\mathrm{Li}$-anode surface and the mixed ionic and electric conductor surface.

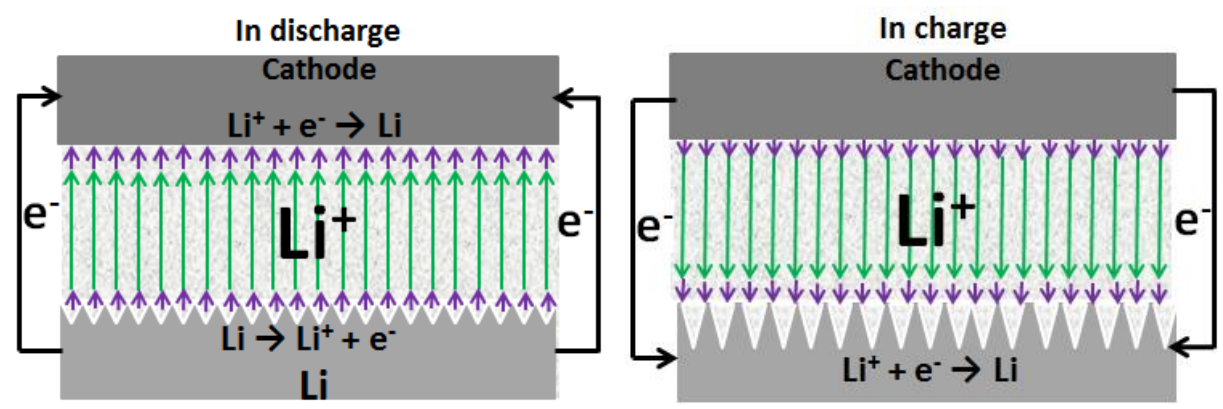

Figure 8-2 Schematic diagram of the formation of Li-dendrite. 


\section{Vita}

Jianhua Yan was born in 1987, in Henan, China. He received his B.S. degree in Electrics Engineering from Beijing Jiaotong University, in Beijing, China, in 2009; and then received his Master degree in Electronics Engineering from Institute of Microelectronics, Chinese Academy of Sciences, Beijing, China, in 2012. From January of 2013, he joined Dr. Xingbo Liu's battery and fuel cell group and Dr. Bingyun Li's biomaterial Group for his Ph.D study, in West Virginia University, USA. His research

focuses is on the development of nanostructured materials and renewable materials for energy applications. 


\section{Appendix}

\section{List of Oral Presentations in 2013 2015}

(1) J. Yan, B. Li, X. Liu. 225 ${ }^{\text {th }}$ ECS meeting in Orlando, FL, 05/10-05/15-2014

(2) J. Yan, B. Li, X. Liu. 227 ${ }^{\text {th }}$ ECS meeting in Chicago, IL, 05/24-05/28-2015

(3) J. Yan, B. Li, X. Liu. 228 ${ }^{\text {th }}$ ECS meeting in Phoenix, AZ, 10/11-10/15-2015

\section{List of Publications in 2013 2015}

(1) J. Yan, B. Li, X. Liu. A Cost-Effective and High Sulfur-Loading Li-S battery. Ready to submit

(2) J. Yan, B. Li, X. Liu. Ionic Liquid Electrolyte Stabilize Li-S battery. Ready to submit

(3) J. Yan, X. Liu, B. Li. Mechanism and Kinetics of Capacity Fade in Lithium Sulfur Batteries. Ready to submit

(4) J. Yan, B. Li, X. Liu. High Stability of Li-S Batteries by Using Ionic Liquid Electrolyte. Ready to submit.

(5) J. Yan, Q. Wang, P. Rutter, J. Noore, B. Li. Chemical Synthesis of Silver Nanoparticles on Carbon Nanotubes and Their Synergistic Effect for Antimicrobial Applications. Submitted, 2015

(6) J. Yan, Q. Wang, B. Li. Nanomedicine Promised Bone Fracture Repair. Accepted, Materials Today (IF: 14.11), 2015

(7) J. Yan, X. Liu, B. Li. Long-Life, High-Efficiency Lithium-Sulfur Battery from Nano-Assembled Cathode. Chemistry of Materials (IF: 8.36), 2015, 27, 5080-5087

(8) J. Yan, B. Li, X. Liu. Nano Polysulfide-Polyaniline Electrodes for Lithium Sulfur Batteries. In revision, Nano Energy (IF: 10.33), doi:10.1016/j.nanoen.2015.10.024

(9) J. Yan, X. Liu, Q. He, W. Li, Y. Zhou, M. Yao, B. Li. Cost-Effective Carbon Nanofiber-Porous Carbon Paper Electrodes with High Sulfur-Loading for High Rate, Long-Cycling Lithium-Sulfur Batteries. Chemistry of Materials (IF: 8.36), 2015, 27, 6394-6401

(10)J. Yan, X. Liu, B. Li. Nano-Assembled Na2FePO4F/Carbon Nanotube MultiLayered Cathodes for Na-Ion Batteries. Electrochemistry Communications (IF: 4.85), 2015, 56, 46-50 
(11)J. Yan, X. Liu, X. Wang, B. Li. Long-Life, High-Efficiency Lithium/Sulfur Batteries from Sulfurized Carbon Nanotube Cathodes, Journal of Material Chemistry A (IF: 7.44) $2015,3,10127-10133$

(12)J. Yan, X. Liu, B. Li. Recent progress in Li-rich layered oxides as cathode materials for Li-ion batteries, RSC advance (IF: 3.84) 2014, 108, 63268-63284

(13)J. Yan, X. Liu, B. Li. Multilayered Sulfur Electrode. US Patent No. 62/090,654 


\section{References}

1. Divya, K.C. and J. Østergaard, Battery energy storage technology for power systems-An overview. Electric Power Systems Research, 2009. 79(4): p. 511520.

2. Väyrynen, A. and J. Salminen, Lithium ion battery production. The Journal of Chemical Thermodynamics, 2012. 46: p. 80-85.

3. Hota, A.R., M. Juvvanapudi, and P. Bajpai, Issues and solution approaches in PHEV integration to smart grid. Renewable and Sustainable Energy Reviews, 2014. 30: p. 217-229.

4. Goodenough, J.B. and Y. Kim, Challenges for Rechargeable Li Batteries $\dagger$. Chemistry of Materials, 2010. 22(3): p. 587-603.

5. Scrosati, B., History of lithium batteries. Journal of Solid State Electrochemistry, 2011. 15(7-8): p. 1623-1630.

6. Kim, T.-H., et al., The Current Move of Lithium Ion Batteries Towards the Next Phase. Advanced Energy Materials, 2012. 2(7): p. 860-872.

7. Yan, J., X. Liu, and $\mathrm{B}$. Li, Recent progress in Li-rich layered oxides as cathode materials for Li-ion batteries. RSC Adv., 2014. 4(108): p. 63268-63284.

8. Dillon, S.J. and K. Sun, Microstructural design considerations for Li-ion battery systems. Current Opinion in Solid State and Materials Science, 2012. 16(4): p. 153-162.

9. Magasinski, A., et al., High-performance lithium-ion anodes using a hierarchical bottom-up approach. Nat Mater, 2010. 9(4): p. 353-8.

10. Wang, C., et al., Self-healing chemistry enables the stable operation of silicon microparticle anodes for high-energy lithium-ion batteries. Nat Chem, 2013. 5(12): p. 1042-8.

11. $\mathrm{Xu}, \mathrm{B} .$, et al., Recent progress in cathode materials research for advanced lithium ion batteries. Materials Science and Engineering: R: Reports, 2012. 73(5-6): p. 51-65.

12. Jiang, C., E. Hosono, and H. Zhou, Nanomaterials for lithium ion batteries. Nano Today, 2006. 1(4): p. 28-33. 
13. Kalhoff, J., et al., Enabling LiTFSI-based electrolytes for safer lithium-ion batteries by using linear fluorinated carbonates as (Co)solvent. ChemSusChem, 2014. 7(10): p. 2939-46.

14. Zhang, S.S., A review on the separators of liquid electrolyte Li-ion batteries. Journal of Power Sources, 2007. 164(1): p. 351-364.

15. Ozawa, K., Lithium-ion rechargeable batteries with LiCoO2 and carbon electrodes: the LiCoO2/C system. Solid State Ionics, 1994. 69: p. 10.

16. Park, M., et al., A review of conduction phenomena in Li-ion batteries. Journal of Power Sources, 2010. 195(24): p. 7904-7929.

17. Jiang, N., On the in situ study of Li ion transport in transmission electron microscope. Journal of Materials Research, 2014. 30(03): p. 424-428.

18. Akao, S., et al., Powder Characterization and Electrochemical Properties of LiNi0.5Mn1.5O4 Cathode Materials Produced by Large Spray Pyrolysis Using Flame Combustion. Advances in Materials Science and Engineering, 2011. 2011: p. 1-6.

19. A. K. Padhi, K.N., and J. B. Goodenough, Phospho-olivines as Positive-Electrode Materials for Rechargeable Lithium Batteries. J. Electrochem. Soc., 1997. 144(4): p. 7.

20. Whittingham, M., Lithium Batteries and Cathode Materials. Chem. Rev., 2004. 104: p. 31.

21. Wang, Q., et al., Thermal runaway caused fire and explosion of lithium ion battery. Journal of Power Sources, 2012. 208: p. 210-224.

22. $\quad$ Armand, J.-M.T.M., Issues and challenges facing rechargeable lithium batteries. Nature, 2001. 414: p. 9.

23. Cabana, J., et al., Beyond intercalation-based Li-ion batteries: the state of the art and challenges of electrode materials reacting through conversion reactions. Adv Mater, 2010. 22(35): p. E170-92.

24. Song, M.K., E.J. Cairns, and Y. Zhang, Lithium/sulfur batteries with high specific energy: old challenges and new opportunities. Nanoscale, 2013. 5(6): p. 2186204. 
25. Zhang, S.S., Liquid electrolyte lithium/sulfur battery: Fundamental chemistry, problems, and solutions. Journal of Power Sources, 2013. 231: p. 153-162.

26. Yin, Y.X., et al., Lithium-sulfur batteries: electrochemistry, materials, and prospects. Angew Chem Int Ed Engl, 2013. 52(50): p. 13186-200.

27. Ji, X. and L.F. Nazar, Advances in Li-S batteries. Journal of Materials Chemistry, 2010. 20(44): p. 9821.

28. Kumaresan, K., Y. Mikhaylik, and R.E. White, A Mathematical Model for a Lithium-Sulfur Cell. Journal of The Electrochemical Society, 2008. 155(8): p. A576.

29. Cañas, N.A., et al., In-situ X-ray diffraction studies of lithium-sulfur batteries. Journal of Power Sources, 2013. 226: p. 313-319.

30. Barchasz, C., et al., Lithium/sulfur cell discharge mechanism: an original approach for intermediate species identification. Anal Chem, 2012. 84(9): p. 3973-80.

31. Kawase, A., et al., Electrochemical reactions of lithium-sulfur batteries: an analytical study using the organic conversion technique. Phys Chem Chem Phys, 2014. 16(20): p. 9344-50.

32. Nelson, J., et al., In Operando X-ray diffraction and transmission X-ray microscopy of lithium sulfur batteries. J Am Chem Soc, 2012. 134(14): p. 633743.

33. Yuan, L., et al., New insight into the discharge process of sulfur cathode by electrochemical impedance spectroscopy. Journal of Power Sources, 2009. 189(1): p. 127-132.

34. Mikhaylik, Y.V. and J.R. Akridge, Polysulfide Shuttle Study in the Li/S Battery System. Journal of The Electrochemical Society, 2004. 151(11): p. A1969.

35. Zheng, J., et al., Controlled Nucleation and Growth Process of Li2S2/Li2S in Lithium-Sulfur Batteries. Journal of the Electrochemical Society, 2013. 160(11): p. A1992-A1996.

36. $\mathrm{Xu}, \mathrm{R}$., et al., Insight into sulfur reactions in Li-S batteries. ACS Appl Mater Interfaces, 2014. 6(24): p. 21938-45. 
37. Yan, J., et al., Long-life, high-efficiency lithium/sulfur batteries from sulfurized carbon nanotube cathodes. J. Mater. Chem. A, 2015. 3(18): p. 10127-10133.

38. $\mathrm{Zu}, \mathrm{C}$. and A. Manthiram, High-Performance Li/Dissolved Polysulfide Batteries with an Advanced Cathode Structure and High Sulfur Content. Advanced Energy Materials, 2014. 4(18): p. n/a-n/a.

39. Pope, M.A. and I.A. Aksay, Structural Design of Cathodes for Li-S Batteries. Advanced Energy Materials, 2015. 5(16): p. n/a-n/a.

40. Zhang, S.S., Sulfurized Carbon: A Class of Cathode Materials for High Performance Lithium/Sulfur Batteries. Frontiers in Energy Research, 2013. 1.

41. Yang, Y., G. Zheng, and Y. Cui, Nanostructured sulfur cathodes. Chem Soc Rev, 2013. 42(7): p. 3018-32.

42. Zheng, J., et al., How to Obtain Reproducible Results for Lithium Sulfur Batteries? Journal of the Electrochemical Society, 2013. 160(11): p. A2288A2292.

43. Shin, E.S., et al., Polysulfide dissolution control: the common ion effect. Chem Commun (Camb), 2013. 49(20): p. 2004-6.

44. Barchasz, C., et al., New insights into the limiting parameters of the Li/S rechargeable cell. Journal of Power Sources, 2012. 199: p. 322-330.

45. Cui, Y. and Y. Fu, Polysulfide transport through separators measured by a linear voltage sweep method. Journal of Power Sources, 2015. 286: p. 557-560.

46. Deng, Z., et al., Electrochemical Impedance Spectroscopy Study of a Lithium/Sulfur Battery: Modeling and Analysis of Capacity Fading. Journal of the Electrochemical Society, 2013. 160(4): p. A553-A558.

47. Diao, Y., et al., Analysis of Polysulfide Dissolved in Electrolyte in DischargeCharge Process of Li-S Battery. Journal of The Electrochemical Society, 2012. 159(4): p. A421.

48. Diao, Y., et al., Shuttle phenomenon - The irreversible oxidation mechanism of sulfur active material in Li-S battery. Journal of Power Sources, 2013. 235: p. 181-186.

49. Wolfgang Nehb, K.V., Sulfur. UIImann's Encyclopedia of Industrial Chemistry, 2006. 12. 
50. Yan, J., et al., Long-Life, High-Efficiency Lithium-Sulfur Battery from a Nanoassembled Cathode. Chemistry of Materials, 2015. 27(14): p. 5080-5087.

51. Zhang, S.S., Does the sulfur cathode require good mixing for a liquid electrolyte lithium/sulfur cell? Electrochemistry Communications, 2013. 31: p. 10-12.

52. Zhang, S.S., New insight into liquid electrolyte of rechargeable lithium/sulfur battery. Electrochimica Acta, 2013. 97: p. 226-230.

53. Choi, Y.-J., et al., Improvement of cycle property of sulfur electrode for lithium/sulfur battery. Journal of Alloys and Compounds, 2008. 449(1-2): p. 313316.

54. Kolosnitsyn, V.S., et al., A study of the electrochemical processes in lithiumsulphur cells by impedance spectroscopy. Journal of Power Sources, 2011. 196(3): p. 1478-1482.

55. Psaltis, S.T.P. and T.W. Farrell, Publisher's Note: Comparing Charge Transport Predictions for a Ternary Electrolyte Using the Maxwell-Stefan and NernstPlanck Equations [J. Electrochem. Soc., 158, A33 (2011)]. Journal of The Electrochemical Society, 2011. 158(3): p. S5.

56. Hart, C.J., et al., Rational design of sulphur host materials for Li-S batteries: correlating lithium polysulphide adsorptivity and self-discharge capacity loss. Chem Commun (Camb), 2015. 51(12): p. 2308-11.

57. Wood, K.N., R. O'Hayre, and S. Pylypenko, Recent progress on nitrogen/carbon structures designed for use in energy and sustainability applications. Energy \& Environmental Science, 2014. 7(4): p. 1212.

58. Wang, H., T. Maiyalagan, and X. Wang, Review on Recent Progress in NitrogenDoped Graphene: Synthesis, Characterization, and Its Potential Applications. ACS Catalysis, 2012. 2(5): p. 781-794.

59. Presser, V., et al., Flexible Nano-felts of Carbide-Derived Carbon with Ultra-high Power Handling Capability. Advanced Energy Materials, 2011. 1(3): p. 423-430.

60. SEN XIN, Y.-G.G., AND LI-JUN WAN, Nanocarbon Networks for Advanced Rechargeable Lithium Batteries. ACCOUNTS OF CHEMICAL RESEARCH, 2012. 45(10): p. 10. 
61. Choi, Y.-J., et al., Effects of carbon coating on the electrochemical properties of sulfur cathode for lithium/sulfur cell. Journal of Power Sources, 2008. 184(2): p. 548-552.

62. Merlet, C., et al., On the molecular origin of supercapacitance in nanoporous carbon electrodes. Nat Mater, 2012. 11(4): p. 306-10.

63. Moon, S., et al., Encapsulated monoclinic sulfur for stable cycling of li-s rechargeable batteries. Adv Mater, 2013. 25(45): p. 6547-53.

64. Ji, X., K.T. Lee, and L.F. Nazar, A highly ordered nanostructured carbon-sulphur cathode for lithium-sulphur batteries. Nat Mater, 2009. 8(6): p. 500-6.

65. Li, X., et al., Optimization of mesoporous carbon structures for lithium-sulfur battery applications. Journal of Materials Chemistry, 2011. 21(41): p. 16603.

66. Zhang, B., et al., Enhancement of long stability of sulfur cathode by encapsulating sulfur into micropores of carbon spheres. Energy \& Environmental Science, 2010. 3(10): p. 1531.

67. Demir-Cakan, R., et al., Cathode composites for Li-S batteries via the use of oxygenated porous architectures. J Am Chem Soc, 2011. 133(40): p. 16154-60.

68. Evers, S., T. Yim, and L.F. Nazar, Understanding the Nature of Absorption/Adsorption in Nanoporous Polysulfide Sorbents for the Li-S Battery. The Journal of Physical Chemistry C, 2012. 116(37): p. 19653-19658.

69. Han, J., et al., Porous nitrogen-doped hollow carbon spheres derived from polyaniline for high performance supercapacitors. J. Mater. Chem. A, 2014. 2(15): p. 5352-5357.

70. Zheng, G., et al., Interconnected hollow carbon nanospheres for stable lithium metal anodes. Nat Nanotechnol, 2014. 9(8): p. 618-23.

71. Wang, D.W., et al., A microporous-mesoporous carbon with graphitic structure for a high-rate stable sulfur cathode in carbonate solvent-based Li-S batteries. Phys Chem Chem Phys, 2012. 14(24): p. 8703-10.

72. Wang, J., et al., Sulfur-mesoporous carbon composites in conjunction with a novel ionic liquid electrolyte for lithium rechargeable batteries. Carbon, 2008. 46(2): p. 229-235. 
73. Sohn, H., et al., Porous spherical carbon/sulfur nanocomposites by aerosolassisted synthesis: the effect of pore structure and morphology on their electrochemical performance as lithium/sulfur battery cathodes. ACS Appl Mater Interfaces, 2014. 6(10): p. 7596-606.

74. Song, J., et al., Nitrogen-Doped Mesoporous Carbon Promoted Chemical Adsorption of Sulfur and Fabrication of High-Areal-Capacity Sulfur Cathode with Exceptional Cycling Stability for Lithium-Sulfur Batteries. Advanced Functional Materials, 2014. 24(9): p. 1243-1250.

75. E. PELED, A.G., M. SEGAL and Y. STERNBERG, RECHARGEABLE LITHIUM-SULFUR BATTERY Journal of Power Sources, 1989. 26: p. 3.

76. Xin, S., et al., Smaller sulfur molecules promise better lithium-sulfur batteries. J Am Chem Soc, 2012. 134(45): p. 18510-3.

77. Wang, K., et al., Super-Aligned Carbon Nanotube Films as Current Collectors for Lightweight and Flexible Lithium Ion Batteries. Advanced Functional Materials, 2013. 23(7): p. 846-853.

78. Cheng, X.-B., et al., Aligned carbon nanotube/sulfur composite cathodes with high sulfur content for lithium-sulfur batteries. Nano Energy, 2014. 4: p. 65-72.

79. Lee, S.W., et al., High-power lithium batteries from functionalized carbonnanotube electrodes. Nat Nanotechnol, 2010. 5(7): p. 531-7.

80. Weng, W., et al., Winding aligned carbon nanotube composite yarns into coaxial fiber full batteries with high performances. Nano Lett, 2014. 14(6): p. 3432-8.

81. $\mathrm{Pu}, \mathrm{X}$., G. Yang, and $\mathrm{C}$. Yu, Liquid-type cathode enabled by $3 D$ sponge-like carbon nanotubes for high energy density and long cycling life of Li-S batteries. Adv Mater, 2014. 26(44): p. 7456-61.

82. Haq, A.U., et al., Direct growth of polyaniline chains from $\mathrm{N}$-doped sites of carbon nanotubes. Small, 2013. 9(22): p. 3829-33.

83. Jia-jia, C., et al., The preparation of nano-sulfur/MWCNTs and its electrochemical performance. Electrochimica Acta, 2010. 55(27): p. 8062-8066.

84. Su, Y.S. and A. Manthiram, A new approach to improve cycle performance of rechargeable lithium-sulfur batteries by inserting a free-standing MWCNT interlayer. Chem Commun (Camb), 2012. 48(70): p. 8817-9. 
85. Fu, Y., Y.S. Su, and A. Manthiram, Highly reversible lithium/dissolved polysulfide batteries with carbon nanotube electrodes. Angew Chem Int Ed Engl, 2013. 52(27): p. 6930-5.

86. Tang, C., et al., Nitrogen-doped aligned carbon nanotube/graphene sandwiches: facile catalytic growth on bifunctional natural catalysts and their applications as scaffolds for high-rate lithium-sulfur batteries. Adv Mater, 2014. 26(35): p. 61005 .

87. Guo, J., Y. Xu, and C. Wang, Sulfur-impregnated disordered carbon nanotubes cathode for lithium-sulfur batteries. Nano Lett, 2011. 11(10): p. 4288-94.

88. Li, Y., et al., Sulfur-nitrogen doped multi walled carbon nanotubes composite as a cathode material for lithium sulfur batteries. International Journal of Hydrogen Energy, 2014. 39(28): p. 16073-16080.

89. Eigler, S., et al., Wet chemical synthesis of graphene. Adv Mater, 2013. 25(26): p. 3583-7.

90. Jang, B.Z., et al., Graphene surface-enabled lithium ion-exchanging cells: nextgeneration high-power energy storage devices. Nano Lett, 2011. 11(9): p. 378591.

91. Cao, Y., et al., Sandwich-type functionalized graphene sheet-sulfur nanocomposite for rechargeable lithium batteries. Phys Chem Chem Phys, 2011. 13(17): p. 7660-5.

92. Wang, H., et al., Graphene-wrapped sulfur particles as a rechargeable lithiumsulfur battery cathode material with high capacity and cycling stability. Nano Lett, 2011. 11(7): p. 2644-7.

93. Lu, J., et al., Layer-by-layer assembled sulfonated-graphene/polyaniline nanocomposite films: enhanced electrical and ionic conductivities, and electrochromic properties. RSC Advances, 2012. 2(28): p. 10537.

94. Ma, Z., et al., Sulfur-doped graphene derived from cycled lithium-sulfur batteries as a metal-free electrocatalyst for the oxygen reduction reaction. Angew Chem Int Ed Engl, 2015. 54(6): p. 1888-92. 
95. $\mathrm{Zu}, \mathrm{C}$. and $\mathrm{A}$. Manthiram, Hydroxylated Graphene-Sulfur Nanocomposites for High-Rate Lithium-Sulfur Batteries. Advanced Energy Materials, 2013. 3(8): p. 1008-1012.

96. Zhou, G., et al., Free-standing TiO2 nanowire-embedded graphene hybrid membrane for advanced Li/dissolved polysulfide batteries. Nano Energy, 2015. 12: p. 240-249.

97. Fanous, J., et al., High Energy Density Poly(acrylonitrile)-Sulfur CompositeBased Lithium-Sulfur Batteries. Journal of the Electrochemical Society, 2013. 160(8): p. A1169-A1170.

98. Zhang, W., et al., A Li+-conductive microporous carbon-sulfur composite for Li$S$ batteries. Electrochimica Acta, 2013. 87: p. 497-502.

99. Duan, B., et al., Carbyne polysulfide as a novel cathode material for lithium/sulfur batteries. Journal of Materials Chemistry A, 2013. 1(42): p. 13261.

100. Cheng, H. and S. Wang, Recent progress in polymer/sulphur composites as cathodes for rechargeable lithium-sulphur batteries. Journal of Materials Chemistry A, 2014. 2(34): p. 13783.

101. Wu, F., et al., Sulfur/Polythiophene with a Core/Shell Structure: Synthesis and Electrochemical Properties of the Cathode for Rechargeable Lithium Batteries. The Journal of Physical Chemistry C, 2011. 115(13): p. 6057-6063.

102. Zhang, K., et al., Improvement on electrochemical performance by electrodeposition of polyaniline nanowires at the top end of sulfur electrode. Applied Surface Science, 2013. 285: p. 900-906.

103. Zhang, S.-c., et al., A Novel cathode material based on polyaniline used for lithium/sulfur secondary battery. Synthetic Metals, 2010. 160(17-18): p. 20412044.

104. Xiao, L., et al., A soft approach to encapsulate sulfur: polyaniline nanotubes for lithium-sulfur batteries with long cycle life. Adv Mater, 2012. 24(9): p. 1176-81.

105. Zhao, X., et al., A ternary sulfur/polyaniline/carbon composite as cathode material for lithium sulfur batteries. Electrochimica Acta, 2013. 109: p. 145-152.

106. Zhou, W., et al., Yolk-shell structure of polyaniline-coated sulfur for lithiumsulfur batteries. J Am Chem Soc, 2013. 135(44): p. 16736-43. 
107. Yuan Yang, G.Y., Judy J. Cha, Hui Wu, Michael Vosgueritchian, Yan Yao, Zhenan Bao, and Yi Cui, Improving the Performance of Lithium Sulfur Batteries by Conductive Polymer Coating. ACS Nano, 2011. 5(11): p. 7.

108. Duan, L., et al., Fabrication of conductive polymer-coated sulfur composite cathode materials based on layer-by-layer assembly for rechargeable lithiumsulfur batteries. Colloids and Surfaces A: Physicochemical and Engineering Aspects, 2012. 414: p. 98-103.

109. Wang, L., et al., Kinetic investigation of sulfurized polyacrylonitrile cathode material by electrochemical impedance spectroscopy. Electrochimica Acta, 2011. 56(14): p. 5252-5256.

110. Zhang, S., Understanding of Sulfurized Polyacrylonitrile for Superior Performance Lithium/Sulfur Battery. Energies, 2014. 7(7): p. 4588-4600.

111. Xiao, L., et al., Molecular structures of polymer/sulfur composites for lithiumsulfur batteries with long cycle life. Journal of Materials Chemistry A, 2013. 1(33): p. 9517.

112. Doan, T.N.L., et al., Binding mechanism of sulfur and dehydrogenated polyacrylonitrile in sulfur/polymer composite cathode. Journal of Power Sources, 2013. 241: p. 61-69.

113. Yan, J., X. Liu, and B. Li, Nano-assembled Na2FePO4F/carbon nanotube multilayered cathodes for Na-ion batteries. Electrochemistry Communications, 2015. 56: p. 46-50.

114. Cheng, J.J., et al., Sulfur-Nickel Foam as Cathode Materials for Lithium-Sulfur Batteries. ECS Electrochemistry Letters, 2014. 4(2): p. A19-A21.

115. Wang, J.-H. and M. Liu, Computational study of sulfur-nickel interactions: A new S-Ni phase diagram. Electrochemistry Communications, 2007. 9(9): p. 22122217.

116. Wei Seh, Z., et al., Sulphur-TiO2 yolk-shell nanoarchitecture with internal void space for long-cycle lithium-sulphur batteries. Nat Commun, 2013. 4: p. 1331.

117. Liang, X., et al., A highly efficient polysulfide mediator for lithium-sulfur batteries. Nat Commun, 2015. 6: p. 5682. 
118. Ma, L., et al., Tethered Molecular Sorbents: Enabling Metal-Sulfur Battery Cathodes. Advanced Energy Materials, 2014. 4(17): p. n/a-n/a.

119. Pang, Q., et al., Surface-enhanced redox chemistry of polysulphides on a metallic and polar host for lithium-sulphur batteries. Nat Commun, 2014. 5: p. 4759.

120. Huang, C., et al., Manipulating surface reactions in lithium-sulphur batteries using hybrid anode structures. Nat Commun, 2014. 5: p. 3015.

121. Harry, K.J., et al., Detection of subsurface structures underneath dendrites formed on cycled lithium metal electrodes. Nat Mater, 2014. 13(1): p. 69-73.

122. Hassoun, J., et al., A contribution to the progress of high energy batteries: A metal-free, lithium-ion, silicon-sulfur battery. Journal of Power Sources, 2012. 202: p. 308-313.

123. Wu, F., et al., Harnessing Steric Separation of Freshly Nucleated Li2S Nanoparticles for Bottom-Up Assembly of High-Performance Cathodes for Lithium-Sulfur and Lithium-Ion Batteries. Advanced Energy Materials, 2014. 4(11): p. n/a-n/a.

124. Yan, J., et al., High-Performance Lithium-Sulfur Batteries with a Cost-Effective Carbon Paper Electrode and High Sulfur-Loading. Chemistry of Materials, 2015. 27(18): p. 6394-6401.

125. Jha, H., et al., Li-S Batteries with Li2S Cathodes and Si/C Anodes. Journal of the Electrochemical Society, 2015. 162(9): p. A1829-A1835.

126. Meini, S., et al., The Use of Redox Mediators for Enhancing Utilization of Li2S Cathodes for Advanced Li-S Battery Systems. J Phys Chem Lett, 2014. 5(5): p. 915-8.

127. Suo, L., et al., Carbon cage encapsulating nano-cluster Li2S by ionic liquid polymerization and pyrolysis for high performance Li-S batteries. Nano Energy, 2015. 13: p. 467-473.

128. Wang, C., et al., Slurryless Li2S/reduced graphene oxide cathode paper for highperformance lithium sulfur battery. Nano Lett, 2015. 15(3): p. 1796-802.

129. Zu, C., M. Klein, and A. Manthiram, Activated Li2S as a High-Performance Cathode for Rechargeable Lithium-Sulfur Batteries. J Phys Chem Lett, 2014. 5(22): p. 3986-91. 
130. $\mathrm{Xu}, \mathrm{K}$. , Electrolytes and interphases in Li-ion batteries and beyond. Chem Rev, 2014. 114(23): p. 11503-618.

131. Suo, L., et al., A new class of Solvent-in-Salt electrolyte for high-energy rechargeable metallic lithium batteries. Nat Commun, 2013. 4: p. 1481.

132. Li, G., et al., Developments of Electrolyte Systems for Lithiumâ€"Sulfur Batteries: A Review. Frontiers in Energy Research, 2015. 3.

133. Zhang, S.S., Role of LiNO3 in rechargeable lithium/sulfur battery. Electrochimica Acta, 2012. 70: p. 344-348.

134. Yuan, L.X., et al., Improved dischargeability and reversibility of sulfur cathode in a novel ionic liquid electrolyte. Electrochemistry Communications, 2006. 8(4): p. 610-614.

135. Zheng, J., et al., Ionic liquid-enhanced solid state electrolyte interface (SEI) for lithium-sulfur batteries. Journal of Materials Chemistry A, 2013. 1(29): p. 8464.

136. Lewandowski, A. and A. Świderska-Mocek, Ionic liquids as electrolytes for Liion batteries-An overview of electrochemical studies. Journal of Power Sources, 2009. 194(2): p. 601-609.

137. Lin, M.C., et al., An ultrafast rechargeable aluminium-ion battery. Nature, 2015. 520(7547): p. 325-8.

138. Agostini, M., et al., A lithium-sulfur battery using a solid, glass-type P2S5-Li2S electrolyte. Solid State Ionics, 2013. 244: p. 48-51.

139. Nagao, M., A. Hayashi, and M. Tatsumisago, Sulfur-carbon composite electrode for all-solid-state Li/S battery with Li2S-P2S5 solid electrolyte. Electrochimica Acta, 2011. 56(17): p. 6055-6059.

140. Trevey, J.E., Y.S. Jung, and S.-H. Lee, High lithium ion conducting Li2S-GeS2P2S5 glass-ceramic solid electrolyte with sulfur additive for all solid-state lithium secondary batteries. Electrochimica Acta, 2011. 56(11): p. 4243-4247.

141. Cao, R., et al., Anodes for Rechargeable Lithium-Sulfur Batteries. Advanced Energy Materials, 2015. 5(16).

142. Lee, Y.M., et al., Electrochemical performance of lithium/sulfur batteries with protected Li anodes. Journal of Power Sources, 2003. 119-121: p. 964-972. 
143. Zhang, X., et al., Improved cycle stability and high security of Li-B alloy anode for lithium-sulfur battery. Journal of Materials Chemistry A, 2014. 2(30): p. 11660.

144. Han, Y., et al., Effects of sulfur loading on the corrosion behaviors of metal lithium anode in lithium-sulfur batteries. Materials Research Bulletin, 2015. 68: p. $160-165$.

145. Vinayan, B.P., et al., Synthesis of graphene-multiwalled carbon nanotubes hybrid nanostructure by strengthened electrostatic interaction and its lithium ion battery application. Journal of Materials Chemistry, 2012. 22(19): p. 9949.

146. $\mathrm{Yu}, \mathrm{X} . \mathrm{-g}$., et al., Lithium storage in conductive sulfur-containing polymers. Journal of Electroanalytical Chemistry, 2004. 573(1): p. 121-128.

147. Park, M.S., et al., One-step synthesis of a sulfur-impregnated graphene cathode for lithium-sulfur batteries. Phys Chem Chem Phys, 2012.

148. Zhu, P., et al., Mechanism of Enhanced Carbon Cathode Performance by Nitrogen Doping in Lithium-Sulfur Battery: An X-ray Absorption Spectroscopic Study. The Journal of Physical Chemistry C, 2014. 118(15): p. 7765-7771.

149. Yuan, Z., et al., Hierarchical Free-Standing Carbon-Nanotube Paper Electrodes with Ultrahigh Sulfur-Loading for Lithium-Sulfur Batteries. Advanced Functional Materials, 2014. 24(39): p. 6105-6112.

150. Li, G., et al., Synthesis of Polyaniline Submicrometer-Sized Tubes with Controllable Morphology. Journal of Nanoparticle Research, 2006. 8(6): p. 10391044.

151. Lee, H.Y., W. Vogel, and P.P. Chu, Nanostructure and surface composition of Pt and $R u$ binary catalysts on polyaniline-functionalized carbon nanotubes. Langmuir, 2011. 27(23): p. 14654-61.

152. Byoung-Jin Kim, S.-G.O., Moon-Gyu Han, and Seung-Soon Im, Preparation of Polyaniline Nanoparticles in Micellar Solutions as Polymerization Medium. Langmuir, 2000. 16: p. 5.

153. Spellane, B.C.B.a.P., XPS Evidence of Redox Chemistry between Cold Rolled Steel and Polyaniline. Chem. Mater., 1997. 9: p. 5. 
154. Zheng, G., et al., Amphiphilic surface modification of hollow carbon nanofibers for improved cycle life of lithium sulfur batteries. Nano Lett, 2013. 13(3): p. 1265-70.

155. Wang, Z., et al., Enhancing lithium-sulphur battery performance by strongly binding the discharge products on amino-functionalized reduced graphene oxide. Nat Commun, 2014. 5: p. 5002.

156. Mao, Y., et al., Layer-by-layer assembled multilayer of graphene/Prussian blue toward simultaneous electrochemical and SPR detection of H2O2. Talanta, 2011. 85(4): p. 2106-12.

157. Zheng, H., et al., Layer-by-layer assembly and electrochemical properties of sandwiched film of manganese oxide nanosheet and carbon nanotube. Carbon, 2009. 47(6): p. 1534-1542.

158. Liu, S., et al., Layer-by-layer self-assembled conductor network composites in ionic polymer metal composite actuators with high strain response. Applied Physics Letters, 2009. 95(2): p. 023505.

159. Xiang, Y., S. Lu, and S.P. Jiang, Layer-by-layer self-assembly in the development of electrochemical energy conversion and storage devices from fuel cells to supercapacitors. Chem Soc Rev, 2012. 41(21): p. 7291-321.

160. Yang, M., et al., Layer-by-layer self-assembly of PDDA/PWA-Nafion composite membranes for direct methanol fuel cells. Chem Commun (Camb), 2010. 46(9): p. 1434-6.

161. Kim, J., et al., An Advanced Lithium-Sulfur Battery. Advanced Functional Materials, 2013. 23(8): p. 1076-1080.

162. Wang, C., et al., Preparation and performance of a core-shell carbon/sulfur material for lithium/sulfur battery. Electrochimica Acta, 2010. 55(23): p. 70107015.

163. Song, M.-K., et al., Nanostructured electrodes for lithium-ion and lithium-air batteries: the latest developments, challenges, and perspectives. Materials Science and Engineering: R: Reports, 2011. 72(11): p. 203-252. 
164. Du, W.C., et al., Wet Chemistry Synthesis of Multidimensional NanocarbonSulfur Hybrid Materials with Ultrahigh Sulfur Loading for Lithium-Sulfur Batteries. ACS Appl Mater Interfaces, 2015.

165. Zhao, M.Q., et al., Hierarchical vine-tree-like carbon nanotube architectures: Insitu CVD self-assembly and their use as robust scaffolds for lithium-sulfur batteries. Adv Mater, 2014. 26(41): p. 7051-8.

166. Zhang, S., Improved Cyclability of Liquid Electrolyte Lithium/Sulfur Batteries by Optimizing Electrolyte/Sulfur Ratio. Energies, 2012. 5(12): p. 5190-5197. 